\title{
Assessing the Role of Invasive Species in Successional Plant Communities using Hyperspectral Remote Sensing
}

\author{
Itiya Prajakta Aneece \\ Thane, Maharashtra, India
}

Bachelor of Science, Biology, College of Charleston, 2009

A Dissertation presented to the Graduate Faculty of the University of Virginia in Candidacy for the Degree of Doctor of Philosophy

Department of Environmental Sciences

University of Virginia

May 2016

Dr. Howard Epstein

Dr. Manuel Lerdau

Dr. Jennie Moody

Dr. Laura Galloway 


\section{Abstract}

Biodiversity has been correlated with ecosystem stability and function. Invasive species can decrease biodiversity and cause ecological and economical damage. These species are especially prevalent in abandoned agricultural fields, and can disrupt secondary successional dynamics. Although field surveys are used to assess the impacts of these species, remote sensing can be more efficient, especially at large spatial extents. I examined the ability to use ground-level hyperspectral remote sensing to study invasive species and their effects on community properties at the Blandy Experimental Farm (BEF) in north-central Virginia. Their effects on ecosystem properties could not be assessed using ground-level remote sensing in this system; thus, I used leaf and soil measurements to assess their effects on secondary succession.

I found that remote sensing can be used to differentiate among plant communities. The most influential species to community discriminability are considered invasive, suggesting that these species can strongly influence species compositions and other community properties. The most influential wavelengths for discrimination were distributed throughout the spectral profile and corresponded with plant physiological and structural elements.

Thus, spectral differences across species were large enough to be used in aggregate to differentiate plant communities. Additionally, these differences were large enough to differentiate individual species, but discriminability varied by species. The two thistle species that are similar phylogenetically and structurally were readily distinguished amongst each other. However, the shrubby buckthorn was difficult to distinguish from the oriental bittersweet vine despite phylogenetic distance and differences in structure. This was likely due to physical overlap in the field and thus the difficulty in obtaining pure signatures for discrimination. Discriminability also differed by the spectral region examined. Buckthorn and oriental bittersweet were least discriminable in the 550-599 $\mathrm{nm}$ and 650-699 $\mathrm{nm}$ regions, due 
to greater intraspecific variability of spectral data in these regions.

Additionally, remote sensing can be used to estimate higher order community properties like species diversity, and thus assess the effects of invasive species on plant diversity. However, correlations between species diversity and spectral diversity varied by the spectral transformation technique used and the spectral region examined. There was a strong positive correlation between the two in the visible region when band depth was used and in the near-infrared region when first derivatives were used. There were no strong correlations in the red edge, due to high intraspecific variability in chlorophyll content.

Lastly, I assessed the effects of these exotic invasive species on ecosystem properties, specifically secondary succession, using leaf and soil data. Differences in soil characteristics were larger across fields and stages than across species. However, there were species-level differences in leaf characteristics, suggesting that these species may influence succession over time. Satellite advances may help further explore the role of invasive species over large regions. This would help assess whether the relationships found at the ground-level are similar to ones found at the satellite level. Ecosystem studies such as effects over succession would also be possible with satellite imagery in a way not possible using ground-level remote sensing. 


\section{Table of Contents}

I Abstract 2

$\begin{array}{lr}\text { II Acknowledgments } & 13\end{array}$

1 Chapter 1: Introduction $\quad 14$

1.1 Research Background . . . . . . . . . . . . . . . . . . . 14

1.1.1 Invasive species and biodiversity . . . . . . . . . . . . . . 14

1.1.2 Remote sensing of vegetation . . . . . . . . . . . . . 17

1.1.3 Sources of variability in remote sensing . . . . . . . . . . . . . 20

1.1.4 Noise correction practices ................. 21

1.1.5 Dimension reduction practices . . . . . . . . . . . . . . 22

1.2 Research Objectives . . . . . . . . . . . . . . . . . . . 23

1.3 Research Approach . . . . . . . . . . . . . . . . . . . . . 24

1.4 Thesis Structure . . . . . . . . . . . . . . . . 26

2 Chapter 2: Distinguishing Early Successional Plant Communities Using $\begin{array}{ll}\text { Ground-Level Hyperspectral Data } & 27\end{array}$

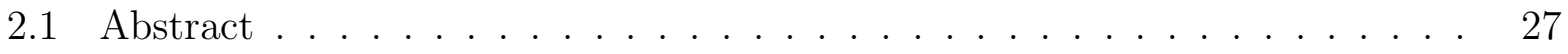

2.2 Introduction . . . . . . . . . . . . . . . . . . . . 28

2.3 Methods . . . . . . . . . . . . . . . . . . . 30

2.3.1 Study Site . . . . . . . . . . . . . . . . 30

2.3.2 Field Methods . . . . . . . . . . . . . . . . . . . . . 32

2.3.3 Statistical Methods . . . . . . . . . . . . . . 35

2.4 Results and Discussion . . . . . . . . . . . . . . . . . . 38

2.4.1 Species ordinations . . . . . . . . . . . . . . 38

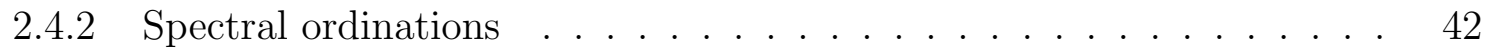


2.4 .3 Discriminant Analyses . . . . . . . . . . . . . . . . . . . . 46

2.4 .4 Other considerations . . . . . . . . . . . . . . . . 48

2.4 .5 Context of key findings . . . . . . . . . . . . . . . 50

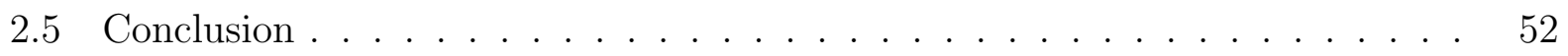

2.6 Appendix 1: Persistence of Invasive Plant Species _ . . . . . . . . . . 53

\section{Chapter 3: Identifying plant species using hyperspectral remote sensing} in successional systems of north central Virginia 54

3.1 Abstract . . . . . . . . . . . . . . . . . . . . 54

3.2 Introduction . . . . . . . . . . . . . . . . . 55

3.2 .1 Biodiversity and invasion . . . . . . . . . . . . . . 55

$3.2 .2 \quad$ Ecosystem and community properties . . . . . . . . . . 56

3.2 .3 Remote sensing of plant species . . . . . . . . . . . . . . 57

3.2 .4 Research Objectives . . . . . . . . . . . . . . . . . . 59

3.3 Methods . . . . . . . . . . . . . . . . . . . . . . . . . . 60

3.3 .1 Study Site . . . . . . . . . . . . . . . . . . . . . 60

3.3 .2 Field methods . . . . . . . . . . . . . . . . . . . . . 61

3.3 .3 Statistical analysis $\ldots \ldots \ldots \ldots 2 \ldots \ldots \ldots \ldots$

3.4 Results . . . . . . . . . . . . . . . . . . . . . . 64

3.5 Discussion . . . . . . . . . . . . . . . . . . . . . . . . 68

3.5 .1 Species discrimination $\ldots \ldots \ldots \ldots \ldots$

3.5.2 Wavelengths that improve discriminability . . . . . . . . 70

3.5.3 Wavelengths that hinder discriminability . . . . . . . . . . 72

3.5 .4 Species differences $\ldots \ldots \ldots \ldots \ldots \ldots$

3.6 Conclusion . . . . . . . . . . . . . . . . . . . . . . . . 74

3.7 Appendix 1: Species Phylogenies . . . . . . . . . . . 76

3.8 Appendix 2: Species Descriptions $\ldots \ldots \ldots \ldots \ldots \ldots \ldots \ldots$

$3.8 .1 \quad$ Rhamnus davurica . . . . . . . . . . . . . . . . 77 
3.8 .2 Ailanthus altissima . . . . . . . . . . . . . . . . 77

3.8 .3 Cirsium arvense . . . . . . . . . . . . . . . 78

3.8.4 Carduus acanthoides . . . . . . . . . . . . . . . . . . . 79

3.8 .5 Galium verum . . . . . . . . . . . . . . . . . . . . . . . . 79

3.8 .6 Celastrus orbiculatus . . . . . . . . . . . . . . . . . 80

3.9 Appendix 3: Persistence of Invasive Plant Species _ . . . . . . . . . . . . 81

\section{Chapter 4: Correlating species and spectral diversities using hyperspectral} remote sensing in early successional fields $\quad 82$

4.1 Abstract . . . . . . . . . . . . . . . . . . . . . 82

4.2 Introduction . . . . . . . . . . . . . . . . . . . . . . . . 83

4.2.1 Biodiversity and Ecosystem Processes . . . . . . . . . . . . . 83

4.2 .2 Remote Sensing of Diversity . . . . . . . . . . . . . . . . . . . 84

4.2 .3 Variability in Pigment Content . . . . . . . . . . . . . 85

4.2 .4 Remote Sensing of Pigments . . . . . . . . . . . . . . . . 86

4.2 .5 Research Objectives . . . . . . . . . . . . . . . . . 88

4.3 Methods . . . . . . . . . . . . . . . . . . . . . . . . . . . . . 89

4.3 .1 Study Site . . . . . . . . . . . . . . . . . . . . . . . . 89

4.3 .2 Field methods . . . . . . . . . . . . . . . . . . . . . . . 90

4.3 .3 Species descriptions . . . . . . . . . . . . . . . . . . . . . . . . . . 92

4.3 .4 Statistical analysis $\ldots \ldots \ldots \ldots$. . . . . . . . . . . . 93

4.4 Results and Discussion . . . . . . . . . . . . . . . . . . . . . 96

4.5 Visible Region . . . . . . . . . . . . . . . . . . . . . . . . . . . . . . . . . . 99

4.6 Near-Infrared Region . . . . . . . . . . . . . . . . . . . . . . . . 100

4.7 Red Trough and Red Edge Regions . . . . . . . . . . . . . . . . . . 100

4.8 Species Pigment Comparisons . . . . . . . . . . . . . . . . . . . . . . . 101

4.9 Conclusion . . . . . . . . . . . . . . . . . . . . . . 105 
5 Chapter 5: Species effects on ecosystem properties and processes through$\begin{array}{ll}\text { out succession } & 107\end{array}$

5.1 Abstract . . . . . . . . . . . . . . . . . . . . 107

5.2 Introduction . . . . . . . . . . . . . . . . . . . . . . 108

5.3 Methods . . . . . . . . . . . . . . . . . . . . . . . . . . . . . . . . . 112

5.3 .1 Study Site . . . . . . . . . . . . . . . . . . . . . . . . . 112

5.3 .2 Field methods . . . . . . . . . . . . . . . . . . . . . . . . . . . 114

5.3 .3 Statistical analysis . . . . . . . . . . . . . . . . . 116

5.4 Results . . . . . . . . . . . . . . . . . . . . . . . . . . . 117

5.4 .1 Soil Temperature . . . . . . . . . . . . . . . . . . . . 117

5.4 .2 Soil Moisture . . . . . . . . . . . . . . . . . . . . . . 117

$5.4 .3 \quad$ Soil $\mathrm{pH} \quad \ldots \ldots \ldots \ldots \ldots \ldots \ldots$

5.4.4 Soil Carbon and Nitrogen _. . . . . . . . . . . . . . . . 120

5.4 .5 Leaf Carbon and Nitrogen . . . . . . . . . . . . . . . . . . . 123

5.5 Discussion . . . . . . . . . . . . . . . . . . 126

5.5.1 Soil temperature, moisture, and $\mathrm{pH} \ldots \ldots \ldots \ldots$

5.5 .2 Soil $\mathrm{C}$ and $\mathrm{N}$, Leaf $\mathrm{C}$ and $\mathrm{N} \ldots \ldots . \ldots . . \ldots 127$

6 Chapter 6: Conclusion 137

6.1 Biodiversity and invasion . . . . . . . . . . . . . . . . . 137

6.2 Distinguishing among plant communities . . . . . . . . . . . . 137

6.3 Distinguishing among plant species . . . . . . . . . . . . . . . . . . 138

6.4 Correlating species diversity and spectral diversity . . . . . . . . . . . . 138

6.5 Assessing species effects in successional communities . . . . . . . . . . . 139

6.6 Limitations . . . . . . . . . . . . . . . . . . . . . . . . . . . . . . 139

6.6 .1 Vegetation discrimination $\ldots \ldots \ldots \ldots$

6.6.2 Estimating community and ecosystem properties . . . . . . . . . . 141

6.7 Future directions . . . . . . . . . . . . . . . . . . . . . . . . . 143 


\section{List of Figures}

1 Blandy Experimental Farm, Boyce VA with study site labels including two secondary successional fields. . . . . . . . . . . . . . . . . . . . . 31

2 Examples of early-stage community plots from a) Lake Arnold, b) the northeast boundary, c) the Northeast chronosequence, and d) the Southwest chronose-

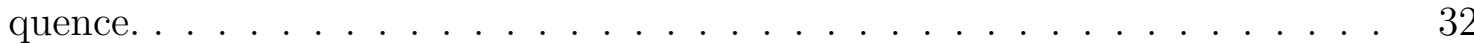

3 Layout of $5 \mathrm{~m} * 5 \mathrm{~m}$ community-plots. Circles represent spectral footprints taken from outside the plots so as not to trample vegetation. Vegetation surveys were conducted at each $0.5 \mathrm{~m}$ interval within a plot for a total of 121 points at the ground, understory, and canopy level. . . . . . . . . . .

4 Calculating band depth (normalized absorption) from original reflectance using continuum removal. . . . . . . . . . . . . . . . . . . . 36

5 Species composition from vegetation surveys of community plots (CP) at Blandy Experimental Farm in north-central Virginia at Lake Arnold (LA), the boundary near the northwest successional field (NEB), the northeast early successional seres (NEE), and the southwest early successional seres (SWE), where the y-axis represents the number of intersects (out of the total 121 intersects surveyed in each plot) at which certain species were found. . . .

$6 \quad$ Non-metric multidimensional scaling (NMS) ordination results using species composition from Lake Arnold (LA), northeast boundary (NEB), northeast early (NEE), and southwest early (SWE) fields at the Blandy Experimental Farm in north-central Virginia for a) axes 1 and 2, b) axes 1 and 3, and c) axes 2 and $3 . \ldots \ldots \ldots \ldots$. . . . . . . . . . . . . . 40 
7 Non-metric multidimensional scaling (NMS) ordination results using band depth values from Lake Arnold (LA), northeast boundary (NEB), northeast early (NEE), and southwest early (SWE) fields at the Blandy Experimental Farm in north-central Virginia for a) axes 1 and 2, b) axes 1 and 3, and c) axes 2 and $3 . \ldots \ldots \ldots \ldots \ldots \ldots \ldots$

8 Blandy Experimental Farm, Boyce VA with study site labels including two secondary successional field chronosequences . . . . . . . . . . . . . . . . . . 61

9 Calculating band depth (normalized absorption) from original reflectance using continuum removal. . . . . . . . . . . . . . . . . . .

10 Blandy Experimental Farm with study sites Southwest Early (SWE), Northeast Early (NEE), Northeast boundary (NEB), and Lake Arnold (LA). . . . 90

11 Layout of $5 \mathrm{~m} * 5 \mathrm{~m}$ community plots. Circles represent spectral footprints taken from outside the plots so as not to trample vegetation. Vegetation surveys were conducted at each $0.5 \mathrm{~m}$ interval within a plot for a total of 121 points at the ground, understory, and canopy level. . . . . . . . . . . .

12 An illustration, using an average spectral profile from Dahurian buckthorn spectra, of calculating band depth (normalized absorption) from original reflectance using continuum removal. . . . . . . . . . . . . . . . . . . . . . 94

13 To quantify spectral diversity, band depth was divided into regions and areas under the curve calculated, and then standard deviations of the areas under the curve for respective plots were calculated. . . . . . . . . . . .

14 Correlations between species diversity and spectral diversity for six spectral regions using the area under the band depth profile. . . . . . . . . . . . . . 98

15 Correlations between species diversity and spectral diversity for six spectral regions using the area under the first derivative profile. . . . . . . . . . 
16 Estimates of a) anthocyanins, b) carotenoids, and c) chlorophylls for Achillea millefolium (acmi), Dactylis glomerata (dagl), Festuca rubra (feru), Solidago altissima (soal), and Symphoricarpos orbiculatus (syor) using ground-level hyperspectral data. . . . . . . . . . . . . . . . . . . 102

17 Blandy Experimental Farm, Boyce VA with study site labels including two secondary successional fields . . . . . . . . . . . . . . . . . . . . 113

18 Average soil temperatures $\left({ }^{\circ} \mathrm{C}\right)$ at the depth of $5 \mathrm{~cm}$ for the summer of 2012 by stage (early (E), middle (M), and late (S)) for the northeast (NE) and southwest (SW), and for the fields Lake Arnold (LA) and the northeast boundary (NEB) at the Blandy Experimental Farm in north-central Virginia. Asterisks represent significant differences at $\mathrm{p}<0.05 . \ldots \ldots \ldots$. . . . . . . . 118

19 Average soil moisture (\% by volume) at 0 to $12 \mathrm{~cm}$ for the summer of 2012 by stage (early (E), middle (M), and late $(\mathrm{S})$ ) for the northeast (NE) and southwest (SW), and for the fields Lake Arnold (LA) and the northeast boundary (NEB) at the Blandy Experimental Farm in north-central Virginia. Asterisks

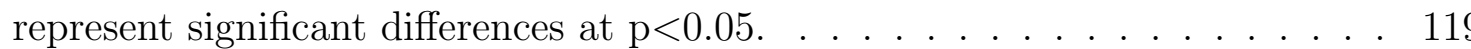

20 Average soil carbon (\% by mass) for the summer of 2012 by species (Ailanthus altissima (AIAL), Carduus acanthoides (CAAC), Celastrus orbiculatus (CEOR), Cirsium arvense (CIAR), Galium verum (GAVE), and Rhamnus davurica (RHDA)) for the fields a) Lake Arnold (LA), b) the northeast boundary $(\mathrm{NEB}), \mathrm{c})$ the northeast field chronosequence (NE), and d) the southwest field chronosequence at the Blandy Experimental Farm in north-central Virginia. Asterisks represent significant differences at $\mathrm{p}<0.05 . \quad$. . . . . . . . . 121 
21 Average soil nitrogen (\% by mass) for the summer of 2012 by species (Ailanthus altissima (AIAL), Carduus acanthoides (CAAC), Celastrus orbiculatus (CEOR), Cirsium arvense (CIAR), Galium verum (GAVE), and Rhamnus davurica (RHDA)) for the fields a) Lake Arnold (LA), b) the northeast boundary (NEB), c) the northeast field chronosequence (NE), and d) the southwest field chronosequence at the Blandy Experimental Farm in north-central Virginia. No comparisons led to significant differences at $\mathrm{p}<0.05 \ldots \ldots \ldots$

22 Average leaf carbon (\% by mass) for the summer of 2012 by species (Ailanthus altissima (AIAL), Carduus acanthoides (CAAC), Celastrus orbiculatus (CEOR), Cirsium arvense (CIAR), Galium verum (GAVE), and Rhamnus davurica (RHDA)) for the fields a) Lake Arnold (LA), b) the northeast boundary (NEB), c) the northeast field chronosequence (NE), and d) the southwest field chronosequence at the Blandy Experimental Farm in north-central Virginia. Asterisks represent significant differences at $\mathrm{p}<0.05 . \ldots \ldots \ldots$

23 Average leaf nitrogen (\% by mass) for the summer of 2012 by species (Ailanthus altissima (AIAL), Carduus acanthoides (CAAC), Celastrus orbiculatus (CEOR), Cirsium arvense (CIAR), Galium verum (GAVE), and Rhamnus davurica (RHDA)) for the fields a) Lake Arnold (LA), b) the northeast boundary (NEB), c) the northeast field chronosequence (NE), and d) the southwest field chronosequence at the Blandy Experimental Farm in north-central Virginia. Asterisks represent significant differences at $\mathrm{p}<0.05 \ldots \ldots \ldots$ 


\section{List of Tables}

1 Number and date of community spectra collected; no species-level spectra were used for this study. Signatures were collected in a two-day period during peak growing season to minimize seasonal variability and soil signature while providing a fair comparison across plant communities. . . . . . . . . .

2 Stepwise regression results on which species most influence non-metric multidimensional scaling (NMS) ordination axes. Enough species were retained to have a cumulative $\mathrm{R}^{2}$ of 0.80 . All species indicated here are significant to

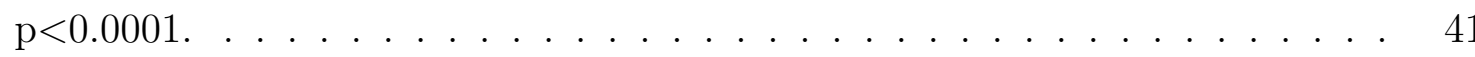

3 Multiple regression coefficients, assessing which wavelengths most influence non-metric multidimensional scaling (NMS) ordination axes. . . . . . . . . 44

4 Confusion matrix for summer 2014 discriminant analysis to test discriminabilty of plots using 7 simulated WorldView2 bands: 400-449, 450-509, 510$580,585-625,630-690,705-745$, and 770-895 nm. . . . . . . . . 46

5 Confusion matrix for summer 2014 discriminant analysis to test discriminabilty of plots using wavelengths selected using principal components analysis: $435,525,575,635,680,710,750,835,970 \mathrm{~nm} \ldots \ldots \ldots \ldots$

6 A comparison of discrimination accuracies and reliability using simulated WorldView2 broad bands, and narrow bands from hyperspectral field-measurements. 48

7 Summer 2012 Support Vector Machine Analysis using the entire spectral profile transformed into band depth for all target exotic invasive species; spectra collected from population plots. . . . . . . . . . . . .

8 Matthew's Correlation coefficients from support vector machine outputs with certain $50 \mathrm{~nm}$ regions omitted for sensitivity analysis. . . . . . . . . 66

9 ANOVA results comparing among and within variance of reflectance values by region. No $\mathrm{p}<0.001 \ldots \ldots \ldots \ldots \ldots$ 
10 ANOVA results comparing among and within variance of band depth values by region. ${ }^{*}$ represents $\mathrm{p}<0.001 \ldots \ldots$. . . . . . . . . . . . . 68

11 ANOVA results comparing among and within variance in pigment estimates by species. . . . . . . . . . . . . . . . . . . . . 102

12 Differences in soil temperature across fields, stages, and species . . . . . . . 130

13 Differences in soil moisture across fields, stages, and species . . . . . . . . . 131

14 Differences in soil pH across fields, stages, and species . . . . . . . . . . . . 132

15 Differences in soil carbon (C) across fields, stages, and species . . . . . . . 133

16 Differences in soil nitrogen (N) across fields, stages, and species . . . . . . 134

17 Differences in leaf carbon (C) across fields, stages, and species . . . . . . . 135

18 Differences in leaf nitrogen $(\mathrm{N})$ across fields, stages, and species . . . . . . 136

\section{Acknowledgments}

I thank my committee members, Howie Epstein, Manuel Lerdau, Jennie Moody, and Laura Galloway for their advice on writing and experimental design. I also thank Dave Carr and Clay Ford for statistical advice. Additionally, I thank all of the graduate and undergraduate students who helped in data collection. I also thank Chelsea Goforth for her help with LaTex. 


\section{Chapter 1: Introduction}

\subsection{Research Background}

\subsubsection{Invasive species and biodiversity}

Biodiversity influences ecosystem productivity (Cardinale et al., 2007; Gustafsson and Bostrom, 2011; Symstad and Jonas, 2011; Wilsey and Potvin, 2000) and community stability (Gustafsson and Bostrom, 2011; Symstad and Jonas, 2011; Yachi and Loreau, 1999). It can also deter invasion by non-native plants by affecting resource-use and competition (Cardinale et al., 2007; Gustafsson and Bostrom, 2011; Hooper and Vitousek, 1998; Scherber et al., 2010). Once established, however, exotic invasive plant species can decrease biodiversity (Bradley and Mustard, 2006), and thus monitoring their spread and studying their effects should aid conservation efforts. Exotic invasive species can affect community properties such as native species diversity and composition, and community structure and ecosystem properties such as productivity, nutrient cycling, disturbance regimes, and other functions (Bradley and Mustard, 2006; Kuhman et al., 2011; Mascaro and Schnitzer, 2007; Vitousek, 1990; Yoshida and Oka, 2004; Yurkonis et al., 2005). Plants have been purposefully introduced as ornamentals, windbreaks, and for erosion control, and unintentionally introduced alongside seed grains, in packaging material or bilge/ ballast water, and transported on vehicles and shoes (Bickmore, 2003). Although not all exotic species become invasive, those that do can drastically affect the local environment. Additionally, climate change may further facilitate invasion (Boyd et al., 2013), since canopy cover, temperature, and precipitation regimes influence invasibility (Butler et al., 2014). The increase in globalization may also facilitate invasion with the increase in trade and travel (Boyd et al., 2013). Thus, monitoring the spread and effects of exotic invasive species may be increasingly important in conservation efforts to preserve community and ecosystem properties. 


\subsubsection{Community properties}

Exotic species can suppress establishment of other plant species thus altering plant communities (DeMeester and deB. Richter, 2010; Yurkonis et al., 2005), and reducing native species richness and cover (Yoshida and Oka, 2004). At small spatial and large temporal extents, invasive species can reduce biodiversity (Gaertner et al., 2009) by decreasing species richness as well as evenness (Gaertner et al., 2009; Hejda et al., 2009; Yurkonis et al., 2005). It is necessary to consider longer time periods, because local extinction of species may take long periods of time, and even if local extinction does not result, there can be a drastic decline in genetic diversity with the reduction of population size (Gaertner et al., 2009). Positive correlations between non-native invasive species diversity and native species diversity over large areas may be due to a lack of accounting for local processes (Gaertner et al., 2009).

\subsubsection{Ecosystem properties}

Alterations in plant community composition by invasive species in turn can affect nutrient cycling, because species differ in nutrient uptake efficiencies, and can also alter soil fauna and herbivore community composition (DeMeester and deB. Richter, 2010). They can also affect disturbance frequency and community interactions (Chapin III et al., 1997; Kuhman et al., 2011). An increase in resource availability through faster nutrient cycling may also lead to an increase in the density and diversity of introduced species, leading to a potential positive feedback loop (Ehrenfeld et al., 2001; Kuhman et al., 2011).

Exotic invasive species themselves can alter a variety of ecosystem properties and processes, especially when they are dominant or when they differ from native species in terms of resource acquisition and resource use efficiency. For example, Ailanthus altissima (tree of heaven) can affect ecosystem properties and processes even at low densities by increasing nutrient cycling rates, increasing local nutrient pools, and changing the community species 
composition to favor species that thrive in high-nutrient environments like itself (GomezAparicio and Canham, 2008). Celastrus orbiculatus (oriental bittersweet) can decrease the growth of native species by girdling trees and increasing their susceptibility to ice damage, and by shading out their saplings (Leicht-Young et al., 2007). Rhamnus frangula (glossy buckthorn) cover is negatively correlated with woody seedling density, herbaceous species cover, and species richness (Frappier et al., 2003). Rhamnus cathartica (common buckthorn) alters forest structure by increasing woody stem density, shade, decomposition, and nitrogen turnover (Mascaro and Schnitzer, 2007). Additionally, native species restoration may be difficult even with the removal of exotic invasive species because of lingering ecosystem effects (Heneghan et al., 2006; MacDougall and Turkington, 2005; Sullivan et al., 2007).

Disturbances, such as in agricultural fields, urban areas, roads, and fragmented habitats, can facilitate invasion by promoting the growth of invasive species (Aragon and Morales, 2003; Butler et al., 2014; Gaertner et al., 2009; Kota et al., 2007; Kuhman et al., 2011; Mosher et al., 2009; Yoshida and Oka, 2004). Additionally, invasion can affect succession after disturbance (Kuhman et al., 2011; Yoshida and Oka, 2004), potentially altering the trajectory, rate, species composition, species richness, future disturbance regimes, and nutrient cycling during succession (Grau et al., 1997; Leicht-Young et al., 2009; Simberloff, 2010; Sullivan et al., 2007; Yoshida and Oka, 2004). As an example, the growth of Celastrus orbiculatus (oriental bittersweet) can impede succession by inhibiting the re-establishment of secondary forest species (Fike and Niering, 1999; Ladwig and Meiners, 2010; Pavlovic and Leicht-Young, 2011; Riedel and Epstein, 2005).

Introduced invasive species can cause substantive economic and ecological damage (Bickmore, 2003); considering the combination of productivity loss, eradication efforts, and restoration efforts in the U.S., plant and animal invasive species can cost $\$ 100-\$ 137$ billion, and 700,000 hectares of native vegetation annually (Miao et al., 2006; Wilfong et al., 2009). In the U.S. alone, 5000 exotic species have been established (Wilfong et al., 2009). Carduus 
acanthoides (spiny plumeless thistle) and Carduus nutans (nodding thistle) are two of the most notorious weeds in the continental U.S. and southern Canada (Allen and Shea, 2006; Tiley, 2010). For example, Cirsium arvense (Canada thistle) drastically reduces crop yield (Grekul and Bork, 2004); a population with the density of 20 plants per square meter can reduce the yield of barley by $34 \%$, corn by $57 \%$, canola by $26 \%$, wheat by $51 \%$, and soybean by $91 \%$ (Armel et al., 2005; Grekul and Bork, 2004). Even at low densities, Cirsium arvense can reduce yield; a density of 6 Cirsium arvense shoots $/ \mathrm{m}^{2}$ led to a reduction of wheat yield by $18 \%$ (Hunter, 1996).

\subsubsection{Remote sensing of vegetation}

Due to limited resources, conservation strategies must focus on the invasive species that have the most detrimental impacts on ecosystems; however, the impacts of exotic species depend on the species, and the community that is being invaded (Frappier et al., 2003). Ground-based methods of monitoring invasive species and their effects are costly and can limit research and management; remote sensing can supplement field data to monitor spatial and temporal distribution of invasive species more efficiently (Bradley and Mustard, 2006; Schmidt and Skidmore, 2001; Wilfong et al., 2009; Zhang et al., 2006).

\subsubsection{Estimating vegetation characteristics}

Remote sensing has been used to assess vegetation distribution, characteristics, and diversity. Different regions of the spectral profile can be used to estimate various ecological properties and processes. Visible (VIS) reflectance at the leaf level is mostly a function of pigment content, near-infrared (NIR) reflectance is influenced by leaf structure and surface characteristics, and short-wave infrared (SWIR) reflectance is influenced by water content, structural compound content, and atmospheric water absorption bands (Mahlein, 2011; Xiao, Y. et al., 2014). More specifically, Thenkabail et al. (2014) find that the ultraviolet region 
(375 nm) can be used to estimate leaf water and fPAR; the blue region (405 and $490 \mathrm{~nm}$ ) can be used to estimate nitrogen and carotenoid content, senescence, light-use efficiency, and vegetation stress; the green region $(515,531,550,570 \mathrm{~nm})$ can be used to estimate nitrogen and pigment content, plant vigor, light-use efficiency, vegetation stress, and disease/ pests; the red region $(682 \mathrm{~nm})$ can be used to estimate LAI, biomass, height, and yield; the red edge region (705, 720, 700-740 nm) can be used to estimate plant stress, senescence, and chlorophyll content; the near-infrared region (855, 910, $970 \mathrm{~nm}$ ) can be used to estimate LAI, biomass, yield, moisture, protein content, and chlorophyll content; the far near-infrared region $(1075,1180,1245 \mathrm{~nm})$ can be used to estimate LAI, biomass, height, yield, pigment content, and leaf water; the low short-wave infrared region $(1450,1518,1650,1725 \mathrm{~nm})$ can be used to estimate biomass, moisture, heavy metal stress, lignin and starch content, and to classify vegetation; and the far short-wave infrared region $(1950,2025,2133,2205,2260$, 2295, $2359 \mathrm{~nm}$ ) can be used to estimate water absorption, content of lignin, cellulose, sugar, starch content, protein, nitrogen and leaf moisture, heavy metal stress, and biomass.

Multispectral and hyperspectral data have been used to observe these vegetation characteristics; however, hyperspectral data may lead to more accurate estimates of properties, because they include reflectance measurements at more numerous and narrower wavebands. As one example, Smith and Blackshaw (2003) compared discriminability of 2 crop and 5 weed species with hyperspectral (90\% accuracy) and multispectral (89\% accuracy) data. Although accuracy rates were similar, hyperspectral misclassification was less severe (grass as another grass and broadleaf as another broadleaf) than multispectral (grass as broadleaf and broadleaf as grass). There are major challenges, however, in using hyperspectral remote sensing, and remote sensing in general, including the large amounts of data, spectral mixing, sensor noise, and atmospheric effects (Bioucas-Dias et al., 2013). 


\subsubsection{Discriminating species spectrally}

If interspecific differences in spectral characteristics are greater than intraspecific and intra-individual differences, spectral data can be used to discriminate species (Zhang

et al., 2006). Species differences have been detected remotely (Burkholder, 2010; Daughtry and Walthall, 1998; Narumalani et al., 2009; Pinard and Bannari, 2003; Rud et al., 2006; Schmidt and Skidmore, 2001; Yingying et al., 2011) by looking at vegetation characteristics such as total chlorophyll (chl), chl a, and chl b, carotenoids, soluble C, lignin, foliar $\mathrm{N}$ and phosphorus $(\mathrm{P})$, leaf water content, compactness of the mesophyll layer, specific leaf area (SLA), and leaf mass per area (LMA), which can differ by species and have been estimated using remote sensing (Asner and Martin, 2011, 2009; Carlson et al., 2007; CastroEsau et al., 2004). Species discrimination has been successfully accomplished using several different methods (Everitt et al., 2008; Narumalani et al., 2009; Somers and Asner, 2012; van Aardt and Wynne, 2001) and various wavelengths (Gao and Zhang, 2006; Jiao et al., 2014; Lewis, 2002; Pinard and Bannari, 2003; Ribeiro da Luz and Crowley, 2010; Sanchez-Azofeifa et al., 2009; Schmidt and Skidmore, 2003, 2001; Smith and Blackshaw, 2003; Somers and Asner, 2012).

\subsubsection{Estimating ecosystem characteristics spectrally}

Remote sensing can also be used to estimate vegetation cover, photosynthetic activity, biomass / yield, phenological stages, pigment content, changes in pigment ratios, and leaf area index with various methods including specific bands, vegetation indices, spectral features such as the green peak and the red edge, spectral angle mapper, and radiative transfer models (Bottcher et al., 2014; Cho and Skidmore, 2009; Delegido et al., 2010; Gamon and Berry, 2012; Gitelson et al., 2003; Laidler et al., 2008; Lemaire et al., 2008; RahimzadehBajgiran et al., 2012; Sims and Gamon, 2002; Walker et al., 2003; Xiao, Y. et al., 2014; Yang et al., 2008, 2010). 


\subsubsection{Sources of variability in remote sensing}

\subsubsection{Variability in ecological characteristics}

When extracting ecological information from spectral data, there are many sources of spectral variability, due to variability in ecological characteristics, including leaf properties such as surface characteristics, internal structure, water content, nutrient content, stress, disease, and phenology/ senescence (Cochrane, 2000; Mahlein, 2011; Merzlyak et al., 2003) as well as crown properties such as foliar reflectance, foliar transmittance, crown architecture, leaf area index, stand age, and forest health (Castro-Esau et al., 2006; Papes et al., 2010; Roberts et al., 2004; Zhang et al., 2006). Leaf chlorophyll a: chlorophyll b ratios, thickness, and pigment concentrations can also differ with levels of illumination (Buschmann et al., 1990; Gamon and Berry, 2012). Additionally, absorption bands can be affected by more than one chemical constituent, and one chemical constituent can influence a broad spectral region (Kokaly and Clark, 1999).

Species biochemical and structural similarities in some traits, and differences in illumination within canopies, make species discrimination challenging (Ribeiro da Luz and Crowley, 2010; Rud et al., 2006). However, Asner (1998) suggests that vegetation types should be distinguishable remotely due to differences in biochemical and structural properties. Additionally, Asner et al. (2007) suggest that hyperspectral data can be used to estimate canopy water content, pigment and nitrogen concentrations, and structural elements such as cellulose and lignin, and thus discriminate among tree species. Differences in pigments, water, structural elements, cell size, intercellular space, and cell wall thickness assist in differentiating species at the leaf level (Roberts et al., 2004). 


\subsubsection{Spectral noise}

The signal variability must also be teased apart from variability due to noise. Variation in leaf-level vegetation spectra may be due to variation in leaf orientation, diurnal changes in leaf angle, and canopy position (Castro-Esau et al., 2004; Cochrane, 2000; Mutanga et al., 2004; Xiao, Y. et al., 2014; Zhang et al., 2006). At the canopy level, differences in atmospheric conditions, illumination, viewing geometry, leaf angle distribution, crown shape, shading and signatures from wood, soil, epiphytes, and lianas can be sources of noise (Asner, 1998; Castro-Esau et al., 2006; Mutanga et al., 2004; Roberts et al., 1998, 2004; Zhang et al., 2006). Differences in LAI and leaf angle distribution can also affect the relationship between leaf and canopy spectra (Asner, 1998). At regional extents, spectral mixing within pixels can be a large source of noise (Xiao, Y. et al., 2014). Topography, micro-climate, and soil composition and characteristics can also be sources of variation among sites (Cochrane, 2000; Laidler et al., 2008; Zhang et al., 2006).

Variability may also depend on the spectral region examined. The VIS and NIR portions of the spectral profile have fewer atmospheric absorption features and a higher signal: noise ratio than some other regions (Sanches et al., 2014). Furthermore within this VNIR (VIS + NIR) region, Zhao et al. (2007) limited their analysis to 400-1000 nm due to variation caused by differences in leaf water content at wavelengths greater than $1000 \mathrm{~nm}$ (Broge and Leblanc, 2001). Additionally, the NIR region has greater variability in reflectance than does the VIS region, maybe due to the variability in leaf water content and leaf thickness that influences NIR reflectance (Asner et al., 2009; Schmidt and Skidmore, 2001).

\subsubsection{Noise correction practices}

Atmospheric and soil noise must be corrected to better study vegetation spectrally. Continuum removal (CR), continuum-removed derivative reflectance (CRDR), band depth 
(BD), band depth ratio (BDR), and normalized band depth index (NBDI) can be used to reduce noise from leaf water, soil background, the sensor, bandwidth, and the atmosphere (Mitchell et al., 2012; Mutanga et al., 2004; Sanches et al., 2014).

Continuum removal uses a continuum that is a convex hull made up of straight-line segments that connect local maxima (Schmidt and Skidmore, 2003). As it is most commonly used, continuum removal increases discriminability in the VIS region, but decreases it in the NIR and SWIR regions (Schmidt and Skidmore, 2003). Schmidt and Skidmore (2001) found more statistically significant differences between species using continuum removal compared to other techniques. Additionally, Sanches et al. (2014) found that the Plant Stress Detection Index using continuum removal was more accurate in estimating plant stress than were chlorophyll feature depth, width, and area, and the narrow-band normalized difference vegetation index. Band depth, which is calculated using continuum removed spectral profiles, minimizes noise from leaf water content, soil signature, and atmosphere better than first and second derivatives; band depth is less successful at minimizing soil moisture effects than other noise factors (Kokaly and Clark, 1999).

Derivatives of original spectral profiles can minimize noise from differences in illumination due to cloud cover and topography (Zhang et al., 2006). Second derivatives are also not sensitive to background reflectance (Broge and Leblanc, 2001). In contrast, derivatives are sensitive to the noise in the original spectra, which can only partially be removed with smoothing; noise from environmental variation is enhanced by derivative analysis, increasing intraspecific variability and impeding discrimination of species (Bajwa et al., 2004; Zhang et al., 2006).

\subsubsection{Dimension reduction practices}

After noise corrections have been done, there are still choices to be made on extracting information from remote sensing data, including the use of broadband versus narrowband 
indices and the use of hyperspectral data versus multispectral data. Multispectral broadband remote sensing has a limited capacity to detect biochemical and structural properties of vegetation (Asner et al., 2007; Cho et al., 2012). Discriminability can be improved by the higher spectral resolution of hyperspectral imagery (Jafari and Lewis, 2012). As an example, Thenkabail et al. (2013) found that when discriminating eight crops, the use of 6 non-thermal Landsat ETM+ broadbands led to an accuracy of $67 \%$, the use of 9 EO-1 ALI broadbands to an accuracy of $71 \%$, and the use of 20 hyperspectral narrowbands to an accuracy of $95 \%$.

Consolidating data across the spectral profile may give more accurate predictions than using only a few bands in the form of vegetation indices (Mirik et al., 2006). Data along the profile can also be consolidated using maximum likelihood classification, discriminant analysis, principal components analysis, regression analysis, wavelet analysis, various decision tree analyses, support vector machine analysis, and artificial neural network analyses (Agarwal et al., 2013; Bai et al., 2012; Bajwa et al., 2004; Banskota et al., 2011; Cheng et al., 2014; Cho et al., 2012; Eddy et al., 2014; Farrell and Mersereau, 2005; Goel et al., 2003; Koger et al., 2003; Lewis, 2002; Mirik et al., 2006; Naidoo et al., 2012; Nooni et al., 2014; Ranganathan and Borges, 2010; Shafri et al., 2007; Sun et al., 2014; Villa et al., 2011; $\mathrm{Xu}$ and Gong, 2007; Yu et al., 2014; Zhang et al., 2006).

\subsection{Research Objectives}

Given that invasive species can alter community and ecosystem characteristics and that successional fields are often dominated by invasive species, in this dissertation, I assess the ability to use remote sensing to study the role of invasive species in successional plant communities, thus more efficiently informing conservation efforts.

Specifically, I address the following objectives:

1. Can plant communities be distinguished in successional fields inhabited by invasive 
plant species using hyperspectral remote sensing?

2. Can particular invasive plant species be distinguished using hyperspectral remote sensing?

3. Is plant species diversity correlated with spectral diversity in successional fields inhabited by invasive plant species?

4. What species effects exist on ecosystem properties and processes throughout succession?

\subsection{Research Approach}

Although the distribution and effects of invasive species have been observed using field measurements, these methods may be limited in scope due to limitations in resources such as time and funding. Additionally, some field measurements may require destructive sampling of vegetation. Remote sensing can allow for faster and non-destructive means of vegetation sampling; additionally, remote sensing from airborne or satellite borne platforms may allow for the study of larger spatial extents than possible with field measurements. However, to be observed from airborne and satellite borne platforms, these characteristics much be spectrally detectable. In this study, I examined the ability to discriminate among plant communities and plant species using ground-level hyperspectral remote sensing, the ability to estimate species diversity with spectral diversity using remote sensing, and the ability to detect species effects on ecosystem properties and processes throughout secondary succession using field measurements.

To address these objectives, I collected field measurements and ground-level spectral data from the Blandy Experimental Farm (BEF) in the Shenandoah Valley in Clarke County VA $\left(39^{\circ} 09 \mathrm{~N}, 7^{\circ} 06 \mathrm{~W}\right)$ (Bowers, 1997; Wang et al., 2007). The BEF is a 300 ha biological

field station bequeathed to UVa in 1926; it includes the 60 ha Virginia State Arboretum, 
80 ha successional fields, 120 ha pastures and croplands, and 40 ha woodlots and forests (Bowers, 1997). The BEF elevation is $190 \mathrm{~m}$, average annual temperature and precipitation are $12{ }^{\circ} \mathrm{C}$ and $94 \mathrm{~cm}$ respectively, and average growing season is 157 days. Average annual primary productivity in the successional fields is $1.0 \mathrm{~kg} / \mathrm{m}^{2}$ (Bowers, 1997). The soils are deep colluvial and alluvial sediment from karst limestone, shale, and siltstone; they are well-drained silt loams with slopes of less than 10\% (Bowers, 1997). Measurements were collected along the successional field chronosequences and two additional sites that contained an invasive species not found within the chronosequences: Lake Arnold and a strip of land at the border of the northeast chronosequence, here referred to as the Northeast Boundary.

To assess discriminability of plant communities, I established community-level plots consisting of multiple species in the early successional stages of the chronosequences, along with Lake Arnold and the Northeast Boundary. Vegetation surveys were conducted and community-level spectra collected at these plots. To assess species discriminability, I established population-level plots consisting of only one invasive species at each of the early stages, and Lake Arnold and the Northeast Boundary. Population-level and leaf-level spectra were collected from these plots. Also for species identification, plant-level and leaf-level spectra were also collected from transects that I established across the chronosequences and within Lake Arnold and the Northeast Boundary. Community plots were also used to assess the correlation between species diversity and spectral diversity. Along with spectra data, I collected field measurements of soil and leaf characteristics along the transects and within the community- and population-level plots. I used these field measurements to assess differences in soil and leaf characteristics across time, field, successional stage, and species to determine species-level effects on ecosystem properties throughout succession. 


\subsection{Thesis Structure}

The thesis is structured into four research chapters along with an introduction and conclusion chapter:

1. Differentiation among plant communities using field-level remote sensing

2. Differentiation among target exotic invasive species using field-level remote sensing

3. Estimation of species diversity using spectral diversity using field-level remote sensing

4. Assessment of species effects on ecosystem processes using field measurements 


\section{Chapter 2: Distinguishing Early Successional Plant Communities Using Ground-Level Hyperspectral Data}

\subsection{Abstract}

Abandoned agricultural fields have recently become more abundant in the U.S. and remain susceptible to species invasions after cultivation disturbance. As invasive species become more widespread with increases in anthropogenic activities, we need more effective ways to use limited resources for conservation of native ecosystems. Remote sensing can help us monitor the spread and effects of invasive species, and thus determine the species and locations to target for conservation. To examine this potential, I studied plant communities dominated by exotic invasive plant species in secondary successional fields in north-central Virginia using ground-level hyperspectral data. Within these communities, ordination analyses of vegetation surveys revealed differences in species compositions among plots and fields. These differences among communities were also observed in the spectral data. Stepwise multiple linear regression analyses to determine which species influenced the ordination axes revealed that many of the influential species are considered invasive, again underscoring the influence of invasive species on community properties. Stepwise regression analyses also revealed that the most influential wavelengths for discrimination were distributed along the spectral profile from the visible to the near-infrared regions. A discriminant analysis using wavelengths selected with a principal components analysis demonstrated that different plant communities were separable using spectral data. These spectrally observable differences suggest that I can use hyperspectral data to distinguish among invasive-dominated successional plant communities in this region. 


\subsection{Introduction}

Abandoned agricultural fields are becoming more prevalent in the U.S., especially in the northeast and midwest (Wang et al., 2010), and are easily occupied by exotic invasive plant species (Mosher et al., 2009). These invasive species can alter community composition and ecosystem properties, such as resource availability and use, disturbance frequency, plant community interactions, and the community compositions of herbivores, soil microbes, and birds (Chapin III et al., 1997; DeMeester and deB. Richter, 2010; Kuhman et al., 2011; Sullivan et al., 2007). These species can also alter community and ecosystem dynamics during secondary succession (Kuhman et al., 2011; Yoshida and Oka, 2004). The invasive species may take advantage of open niches during early succession (Feldpausch et al., 2004), thus affecting the degree, duration, and direction of ecosystem change. They can have no

effect (Kassi N'Dja and Decocq, 2008), or their effects can be limited to earlier stages of succession with eventual reclamation by natives (Cunard and Lee, 2009; Otto et al., 2006). Alternatively, they can completely change the trajectory, rate, species composition, species richness, disturbance regimes, and nutrient cycling during succession (Grau et al., 1997; Leicht-Young et al., 2009; Simberloff, 2010; Sullivan et al., 2007; Yoshida and Oka, 2004). In order to monitor invasive species, we need to develop better methodologies for mapping them at fine space-time resolutions.

The control of these invasive species is resource intensive and due to the limited availability of such resources as time and funding, conservation strategies must be targeted. To do this, we must determine which species are most detrimental to the environment and can most easily be controlled. Ground-based methods for monitoring invasive species are costly and thus can limit research and management; alternatively, remote sensing can supplement field data to monitor spatial and temporal distributions of invasive species (Bradley and Mustard, 2006; Schmidt and Skidmore, 2001; Wilfong et al., 2009; Zhang et al., 2006).

Multispectral data have been used to observe vegetation characteristics and discrim- 
inate among species; as an example, Smith and Blackshaw (2003) were able to discriminate among two crop species and five weed species with $89 \%$ accuracy using multispectral data with some misclassification of grasses as broad-leaf plants and vice versa. However, hyperspectral data may provide better estimates of such vegetation characteristics and more accurately discriminate species due to more numerous and narrower wavebands (Jafari and Lewis, 2012; Smith and Blackshaw, 2003). In addition to their multispectral analysis, Smith and Blackshaw (2003) observed 90\% accuracy in discriminating the crop and weed species using hyperspectral data; however, the misclassifications were now within grasses and broadleaf plants rather than across. Hyperspectral data have recently been used more frequently to distinguish among individual plant species (Burkholder, 2010; Narumalani et al., 2009; Pinard and Bannari, 2003; Rud et al., 2006; Schmidt and Skidmore, 2001; Yingying et al., 2011), and we may be able to examine community properties and processes spectrally where certain individual species dominate.

When examining plant species and communities with remote sensing, we need to consider several sources of variation in spectral data. Variation of visible (VIS) reflectance is mostly due to leaf pigment and nutrient content, while variation in the near-infrared (NIR) region is due to leaf structure and surface characteristics; variation in the shortwave infrared (SWIR) region is due to plant water content (Mahlein, 2011; Xiao, Y. et al., 2014). At the leaf level, reflectance is further influenced by biochemical processes, stress, and phenological processes (e.g. senescence) (Mahlein, 2011; Merzlyak et al., 2003). Spectral signatures also differ between sun and shade leaves, as sun leaves have lower reflectance values along the entire spectral profile than do shade leaves due to greater leaf thickness and pigment concentrations (Buschmann et al., 1990). At the canopy level, vegetation spectra are influenced by foliar reflectance, foliar transmittance, and crown architecture (Papes et al., 2010). Certain biological traits that influence spectra also vary in response to changes in the environment; for example, chlorophyll a: chlorophyll b ratios change with illumination (Gamon and Berry, 2012). Additionally, absorption bands can be affected by more than one chemical constituent 
of a leaf, and one chemical constituent can influence a broad spectral region (Kokaly and Clark, 1999).

Such spectral variability in these characteristics may weaken direct correlations between biological properties or processes and spectral data. However, these data can be used to discriminate species and communities if interspecific differences in such characteristics are greater than intraspecific and intra-individual differences (Zhang et al., 2006). Spectral differences due to diversity in pigment content, water content, structural elements, cell size, intercellular space, and cell wall thickness can assist in differentiating among plant species and communities (Roberts et al., 2004). In this paper, I ask: 1) Can plant communities in successional fields in a ridge-and-valley system in north-central Virginia be distinguished using ground-level hyperspectral remote sensing? 2) Which species are most influential in affecting discriminability? 3) Which spectral variables explain the greatest variance in community composition?

\subsection{Methods}

\subsubsection{Study Site}

The Blandy Experimental Farm (BEF) (Figure 17), located in the Shenandoah Valley in Clarke County Virginia at $39^{\circ} 09^{\prime} \mathrm{N}, 7^{\circ} 06^{\prime} \mathrm{W}$ (Wang et al., 2007), is a 300 ha biological field station owned by the University of Virginia since 1926 and operated by the Department of Environmental Sciences since 1983 (Bowers, 1997). The BEF contains 120 ha of pasture and cropland, 40 ha of woodland, the 60 ha Virginia State Arboretum, and 80 ha of old fields in early, middle, and late succession (Bowers, 1997). Each of two successional series (southwest and northeast) contains an early, mid, and late successional field. The successional fields are former agricultural fields, abandoned in 2001 (Early 1), 2003 (Early 2), 1986 (Mid 1), 1987 (Mid 2), before 1910 (Late 1) and before 1920 (Late 2) (Wang et al., 2010). Two additional 
field sites were considered alongside the successional field chronosequences: near Lake Arnold and a site at a field boundary near the northeast successional series. Soils are deep colluvial and alluvial sediment from karst limestone, shale, and siltstone; study sites have well-drained silt loam soil, of the soil Order Ultisol, with slopes less than 10\% (Bowers, 1997). With an elevation of $190 \mathrm{~m}$, the BEF has a mean annual temperature and precipitation of $11.8^{\circ} \mathrm{C}$ and $940 \mathrm{~mm}$ respectively, an average growing season of 157 days, and average annual primary productivity of $1.0 \mathrm{~kg} \mathrm{~m}^{-2}$ in the successional fields (Bowers, 1997; Wang et al., 2010). The exotic invasive species that occupy these fields at BEF have several traits that assist their establishment and spread, and thus affect community composition (see Appendix 1).

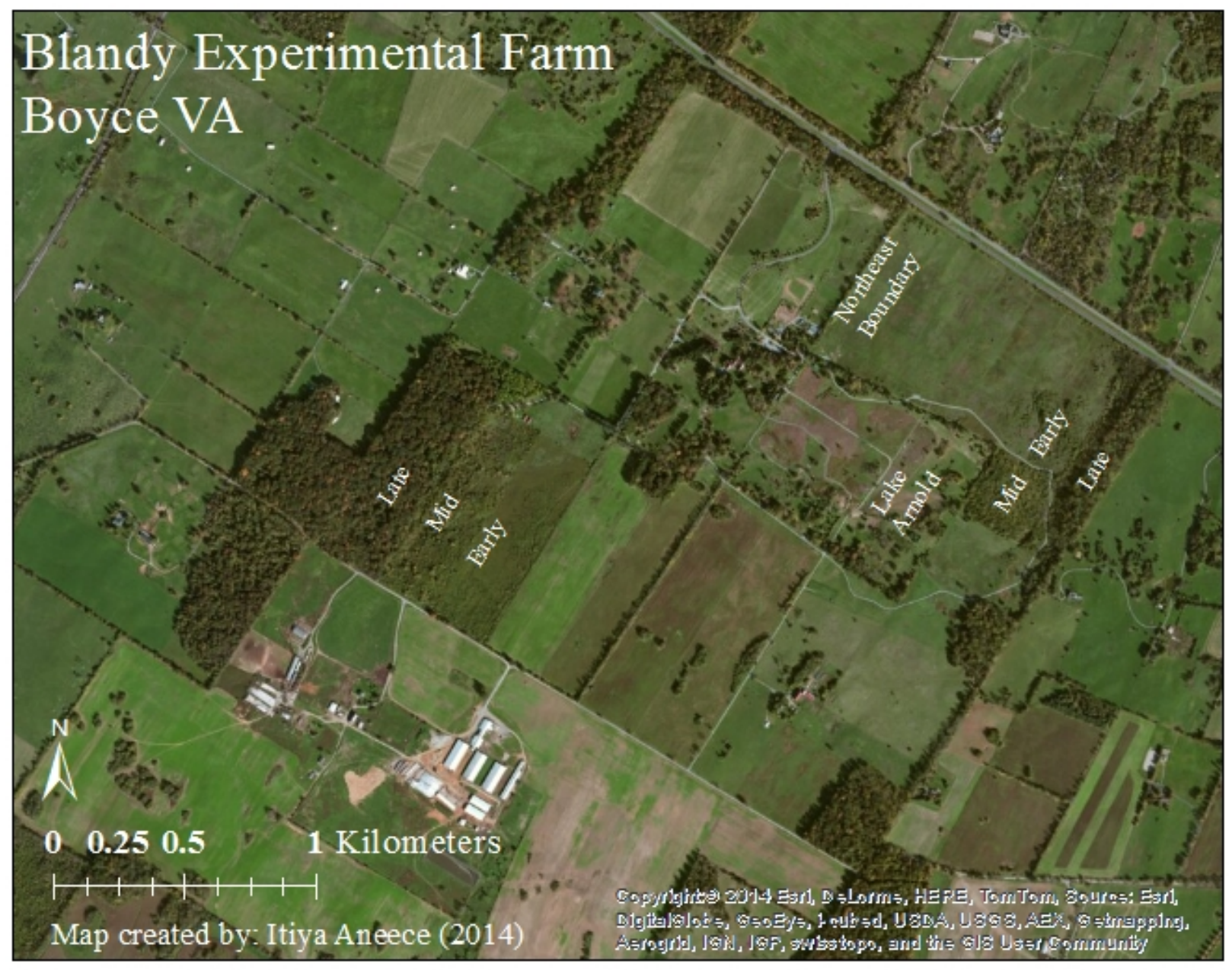

Figure 1: Blandy Experimental Farm, Boyce VA with study site labels including two secondary successional fields. 

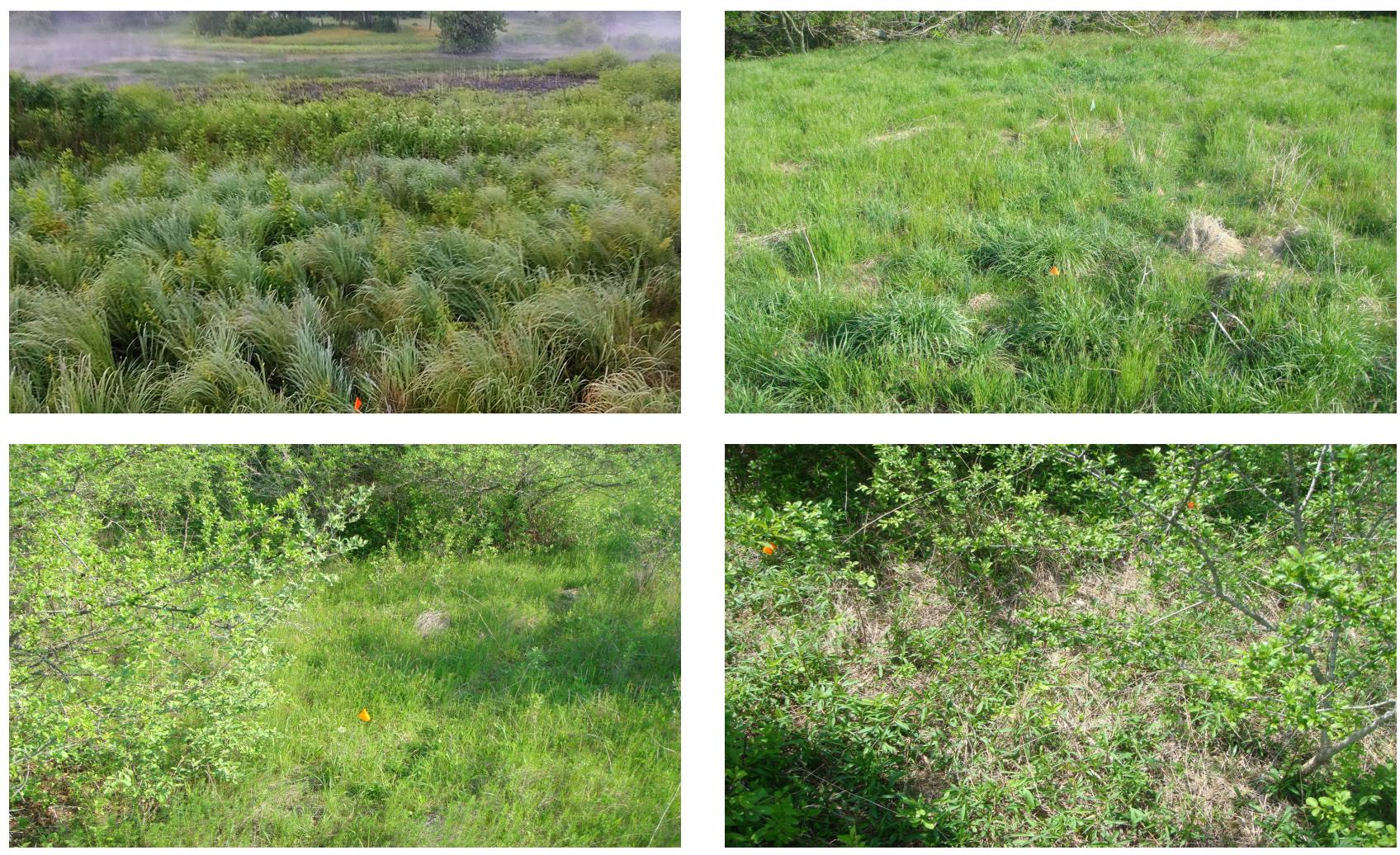

Figure 2: Examples of early-stage community plots from a) Lake Arnold, b) the northeast boundary, c) the Northeast chronosequence, and d) the Southwest chronosequence.

\subsubsection{Field Methods}

To discriminate plant communities using hyperspectral remote sensing, three $5 \mathrm{~m} * 5$ m community-level plots were established in the summer of 2014 in each of four sites at the BEF: Lake Arnold (LA), the northeast boundary (NEB), and the early successional stage in both the northeast (NEE) and southwest (SWE) successional chronosequences for a total of 24 plots. Only early stages from the successional series were used for ground-level spectral analyses (Figure 2) because of vegetation height in later successional stages. From these plots, using a PANalytical Analytical Spectral Devices (ASD) Inc. FieldSpec ${ }^{\circledR} 3$ with a $25^{\circ}$ field of view (FOV), I collected community-level spectra in the summer of 2014. Hyperspectral reflectance measurements from $350 \mathrm{~nm}$ to $1025 \mathrm{~nm}$ were collected from approximately $2.5 \mathrm{~m}$ in height for a measurement footprint of approximately $1.15 \mathrm{~m}$ in diameter. I accomplished 
this by standing on a stool and using a custom-made PVC-pipe extension holding the pistol grip to avoid any spectral signature from the stool or observer. I collected spectra in a way that maximized coverage without trampling vegetation, taking measurements in each corner of the plot, in the center, and the middle of each edge for a total of 12 spectral footprints per plot with each footprint capturing a subsample of the community (Figure 11). Approximately three spectral samples were collected for each spectral footprint for a total of around 36 spectra per plot (Table 1), and spectral measurements were averaged by footprint. I measured the location of the center of each footprint using a plumb-line for several plots and calculated the average location for each footprint in the grid. Spectra were taken during cloud-free days between 10 AM and 2 PM during peak growing season (July) to minimize diurnal and seasonal variability and minimize soil signatures; the spectroradiometer was calibrated at approximately 10 minute intervals using a Spectralon white reference panel and dark current measurements. I also conducted vegetation surveys on the $5 \mathrm{~m} * 5 \mathrm{~m}$ grids at $0.5 \mathrm{~m}$ intervals, recording species at the ground level, sub-canopy, and canopy to assess species composition of the spectral footprints. Grids were established using PVC pipes to mark the periphery of the $5 * 5$ m plots. Pipes had holes drilled at $0.5 \mathrm{~m}$ intervals; a string with hooks on either end was then moved along the pipes, using holes as anchors. The string had knots at $0.5 \mathrm{~m}$ intervals, and plants were surveyed at the knots. Therefore, I was able to map the gridpoints that fell within each footprint, using the footprint centers measured with the plumb-line, and know which species were encompassed within each footprint. 


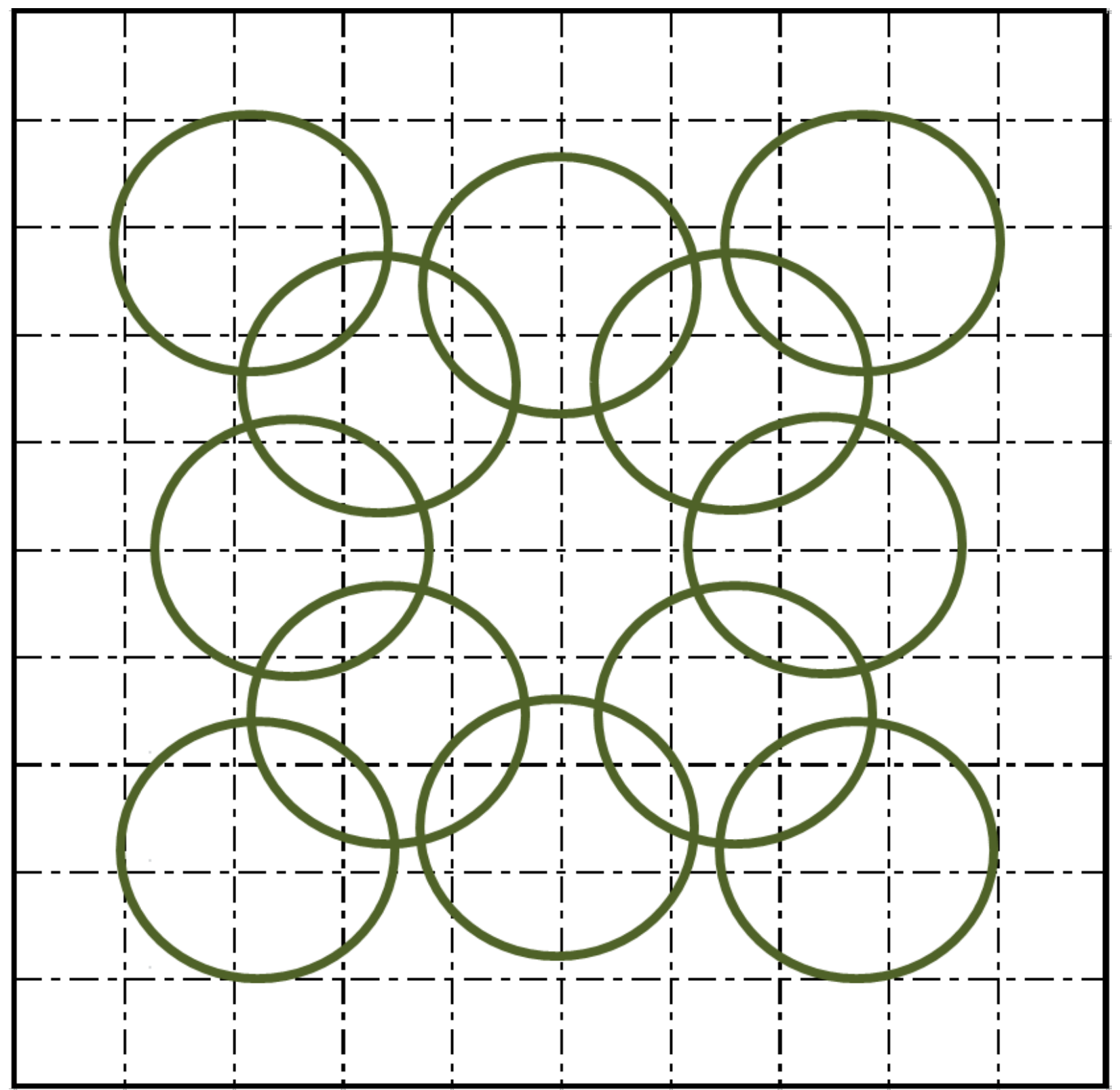

Figure 3: Layout of $5 \mathrm{~m} * 5 \mathrm{~m}$ community-plots. Circles represent spectral footprints taken from outside the plots so as not to trample vegetation. Vegetation surveys were conducted at each $0.5 \mathrm{~m}$ interval within a plot for a total of 121 points at the ground, understory, and canopy level. 
Table 1: Number and date of community spectra collected; no species-level spectra were used for this study. Signatures were collected in a two-day period during peak growing season to minimize seasonal variability and soil signature while providing a fair comparison across plant communities.

\begin{tabular}{lcc}
\hline Plot & Number of Spectra & Date of Collection \\
\hline \hline lacp1 & 37 & $7 / 5 / 2014$ \\
lacp2 & 36 & $7 / 5 / 2014$ \\
lacp3 & 36 & $7 / 5 / 2014$ \\
nebcp1 & 36 & $7 / 4 / 2014$ \\
nebcp2 & 36 & $7 / 4 / 2014$ \\
nebcp3 & 36 & $7 / 4 / 2014$ \\
neecp1 & 37 & $7 / 4 / 2014$ \\
neecp2 & 37 & $7 / 4 / 2014$ \\
neecp3 & 36 & $7 / 4 / 2014$ \\
swecp1 & 35 & $7 / 5 / 2014$ \\
swecp2 & 36 & $7 / 5 / 2014$ \\
swecp3 & 38 & $7 / 5 / 2014$ \\
\hline
\end{tabular}

\subsubsection{Statistical Methods}

To minimize any atmospheric and soil noise in the spectral data, I calculated band depth from original reflectance profiles, and this band depth profile was used for subsequent analysis. To obtain band depth, a continuum hull was matched to the original spectral profile, and this continuum was removed from the original spectral profile to get normalized reflectance; I then subtracted these continuum-removed reflectance values from one to get the band depth profile. An example of this calculation is illustrated using an average buckthorn spectral profile (Figure 12). The continuum hull is comprised of several lines connecting local maxima and has been used by many researchers to minimize noise, increase 
discriminability, and increase accuracy in estimating physiological characteristics (Mitchell et al., 2012; Sanches et al., 2014; Schmidt and Skidmore, 2001). For more information on continuum removal, refer to Schmidt and Skidmore (2003) and Clark and Roush (1984).
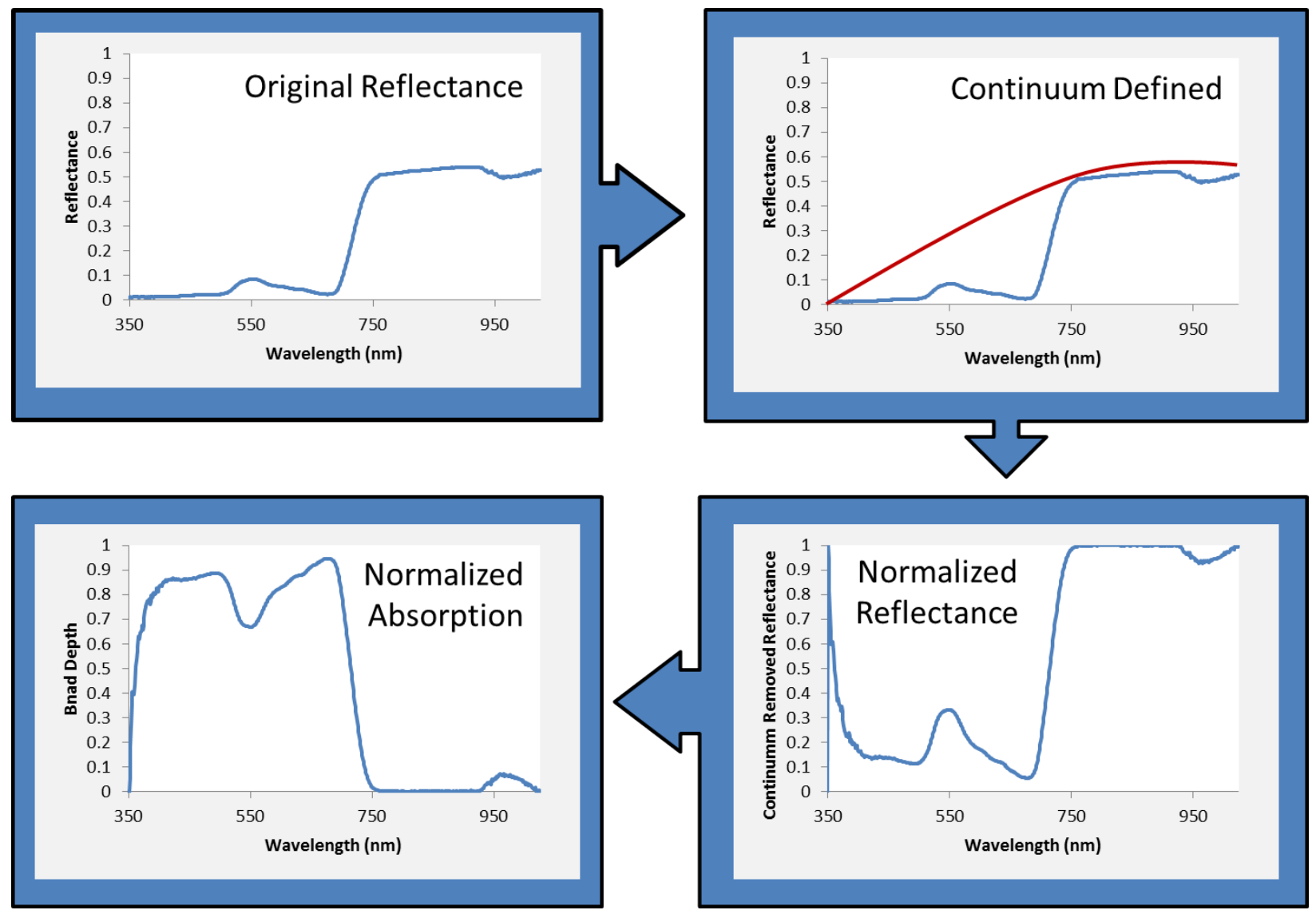

Figure 4: Calculating band depth (normalized absorption) from original reflectance using continuum removal.

Vegetation survey data were matched to footprints used for spectral data collection using the grid points that fell within the footprints. To determine discriminability among communities using community-plot spectra and vegetation surveys, I used PC-ORD (Version 6, MjM Software, Gleneden Beach, Oregan) to conduct multivariate non-metric multidimensional scaling (NMS) ordination analyses. This analysis orients samples in an ordination space based on the similarities between samples (Schmidtlein et al., 2007). I used this technique, along with Bray-Curtis distance, to determine clustering of footprints within plots, by species compositions. Subsequently, I ran a stepwise regression in SAS (Statistical Analysis 
Software, Version 9.4, SAS Institute Inc., Cary, North Carolina) to examine which species most influenced the ordination axes and thus plot footprint clustering, considering species with a significance level of $\mathrm{p}<0.0001$.

I ran a similar ordination analysis using footprint-level spectral data to assess spectral clustering of plot footprints, followed by a multiple regression to examine which wavelengths most influenced clustering. To reduce correlation among wavelengths prior to running the regression analysis, I performed a principal components analysis (PCA) in SAS to select uncorrelated wavelengths that explained most of the variability in the dataset; this was done by selecting wavelengths with the greatest absolute value of factor loadings. The regression then used these wavelengths to assess which most influenced the ordination axes. I also assessed the relationships between species ordination axis loadings and band depth axis loadings to determine whether certain species may be associated with certain spectral characteristics.

To determine whether I could use spectral data to differentiate among plots and whether the use of multiple narrow bands would increase discriminability, I ran two discriminant analyses (DA). One used seven simulated broad bands corresponding with those of WorldView2, and another used wavelengths selected from the PCA. The WorldView2 bands were simulated using the reflectance spectra, averaging 400-449 nm, 450-509 nm, 510-580 $\mathrm{nm}, 585-625 \mathrm{~nm}, 630-690 \mathrm{~nm}, 705-745 \mathrm{~nm}$, and 770-895 nm. The eighth WorldView2 band of 860-1040 nm extends past the wavelengths measured using the FieldSpec3, and thus was not simulated. User's, producer's, and overall accuracies were calculated, along with the Matthew's Correlation Coefficient (MCC, Equation 1, where TP=True Positive, TN=True Negative, $\mathrm{FP}=$ False Positive, and $\mathrm{FN}=$ False Negative) to test for reliability. MCC values range from 1 to -1 , where 1 represents perfect predictability, 0 represents predictability as good as random, and -1 represents predictability exactly opposite of expected. 


$$
M C C=\frac{(T P * T N)-(F P * F N)}{\sqrt{(T P+F P) *(T P+F N) *(T N+F P) *(T N+F N)}}
$$

\subsection{Results and Discussion}

In this study, I asked whether plant communities could be distinguished spectrally, and which species and spectral attributes were most useful for discrimination. Species composition differed by field, as found through vegetation surveys and species ordination results, and these differences were observed spectrally using ordinations of band depth data. Using the bands selected by the PCA in a discriminant analysis, plots within fields were not as readily distinguished as plots across fields, because of greater similarities in species compositions within fields than between fields. Nevertheless, plots were able to be separated more successfully using narrow bands derived from hyperspectral data than by using simulated WorldView2 broad bands.

\subsubsection{Species ordinations}

Species compositions differed by fields and by plots within fields (Figure 5). Lake Arnold (LA) plots predominantly consisted of Galium verum (yellow bedstraw), Poa trivialis (rough bluegrass), and Bromus japonicus (Japanese brome). In the northeast boundary (NEB), plots were dominated by grass species including Poa trivialis, Festuca rubra (red

fescue), and Festuca octoflora (sixweek fescue). The northeast early (NEE) successional plots consisted mostly of Galium verum, Poa trivialis, and Rhamnus davurica (Dahurian buckthorn). The southwest early (SWE) plots mostly contained Rhamnus davurica, Solidago altissima (tall goldenrod), and Celastrus orbiculatus (oriental bittersweet) (Figure 5). 


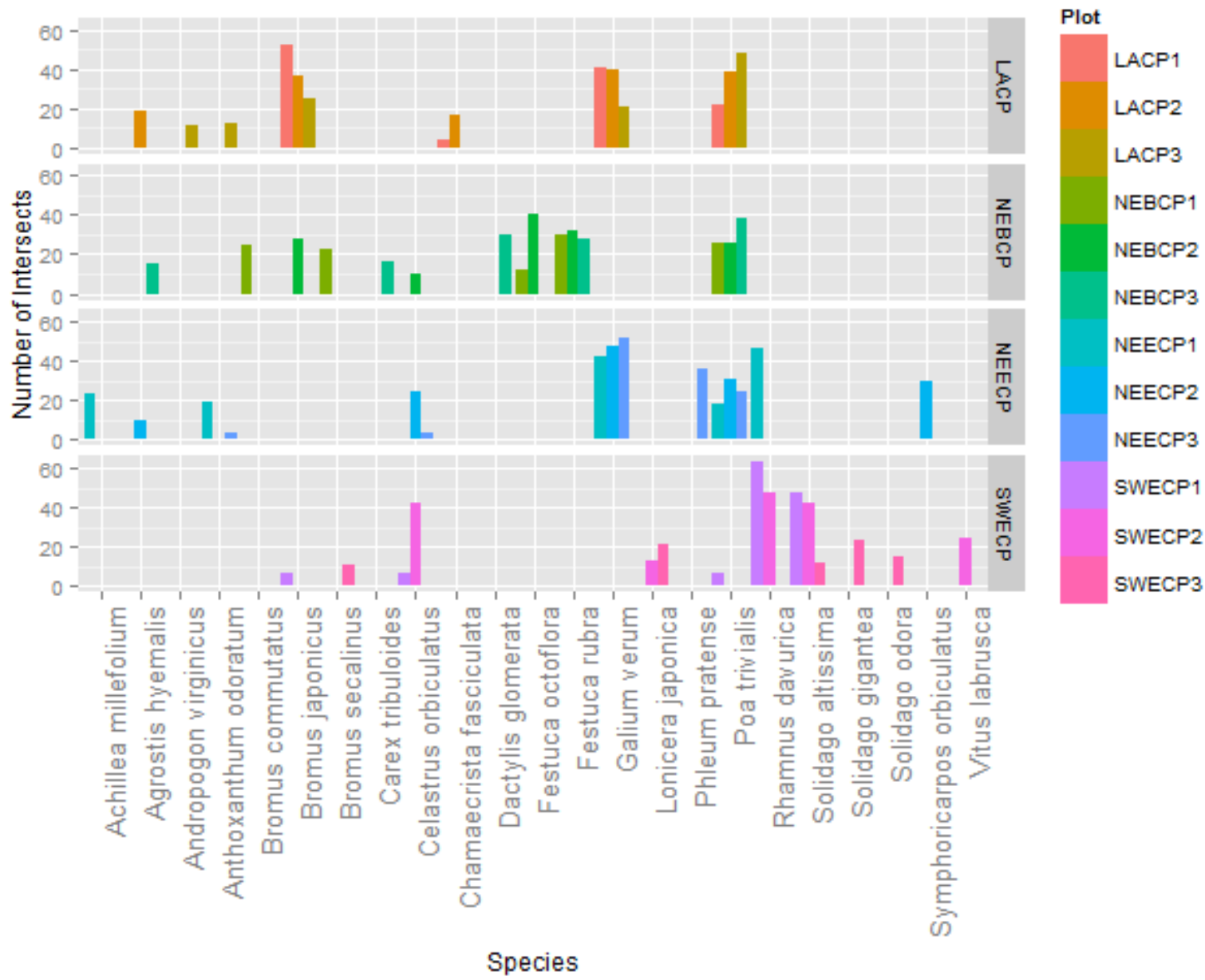

Figure 5: Species composition from vegetation surveys of community plots (CP) at Blandy Experimental Farm in north-central Virginia at Lake Arnold (LA), the boundary near the northwest successional field (NEB), the northeast early successional seres (NEE), and the southwest early successional seres (SWE), where the y-axis represents the number of intersects (out of the total 121 intersects surveyed in each plot) at which certain species were found.

These differences in species compositions were demonstrated in the ordination results as footprints clustered by plot and by field in ordination space (Figure 6). Hence, species compositions were similar within plots and within fields. The species that most influenced axis 1 of the composition ordination were Solidago altissima (tall goldenrod) and Bromus japonicus (Japanese brome), while axis 2 was most influenced by Festuca rubra (red fescue), Galium verum (yellow bedstraw), Muhlenbergia schreberi (nimblewill), Achillea millefolium 
(yarrow), and Bromus commutatus (meadow brome). Axis 3 was most influenced by Galium verum (yellow bedstraw), Solidago gigantea (giant goldenrod), Dactylis glomerata (orchard grass), Bromus japonicus (Japanese brome), Ambrosia artemisiifolia (common ragweed), and Lonicera japonica (Japanese honeysuckle) (Table 2).

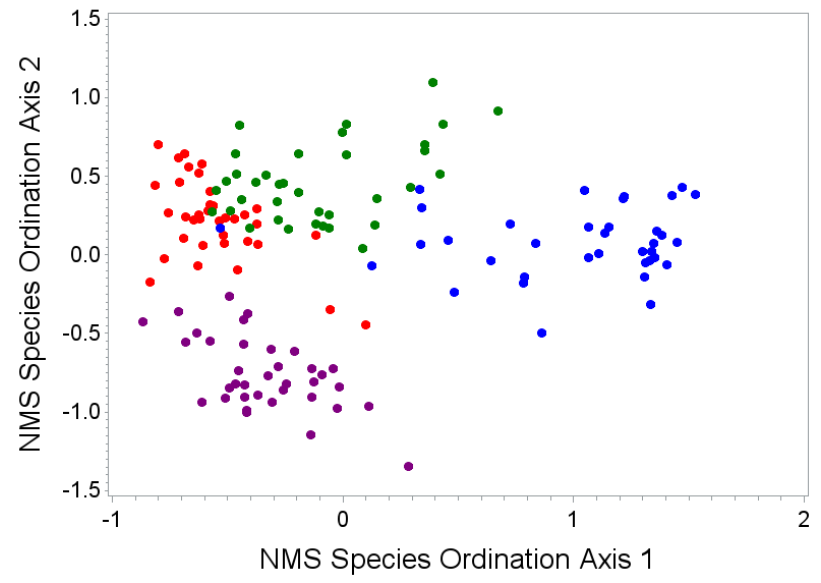

(a) $\mathrm{A}$

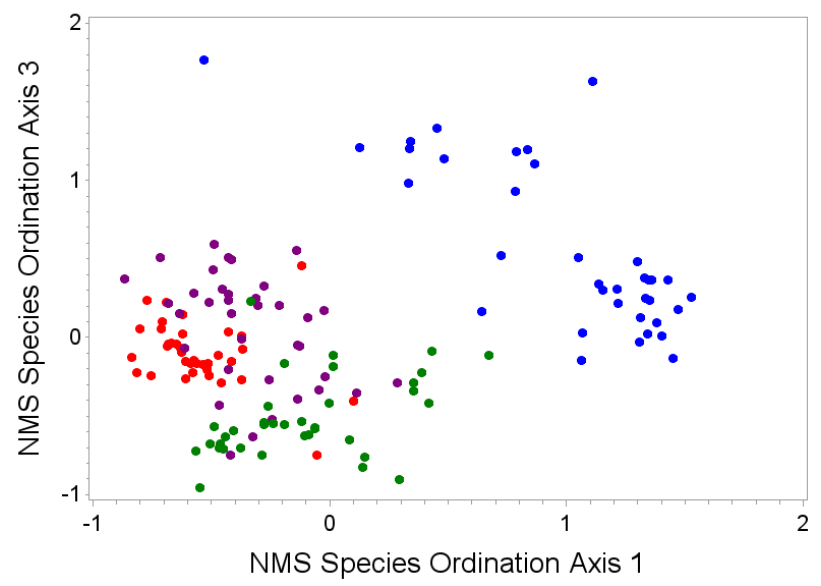

(b) B

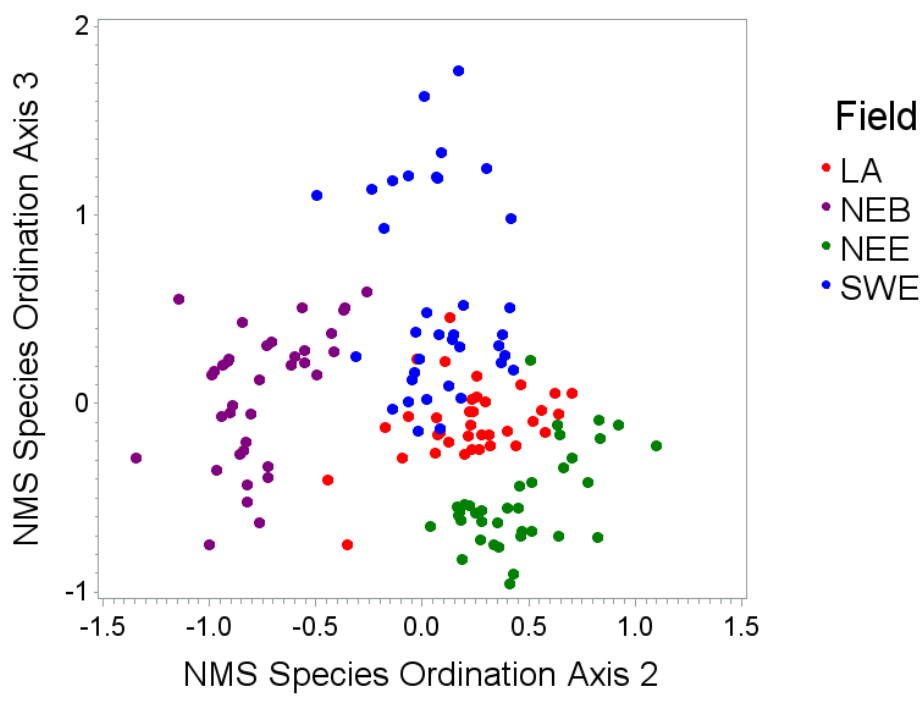

(c) $\mathrm{C}$

Figure 6: Non-metric multidimensional scaling (NMS) ordination results using species composition from Lake Arnold (LA), northeast boundary (NEB), northeast early (NEE), and southwest early (SWE) fields at the Blandy Experimental Farm in north-central Virginia for a) axes 1 and 2, b) axes 1 and 3, and c) axes 2 and 3 . 
Table 2: Stepwise regression results on which species most influence non-metric multidimensional scaling (NMS) ordination axes. Enough species were retained to have a cumulative $\mathrm{R}^{2}$ of 0.80 . All species indicated here are significant to $\mathrm{p}<0.0001$.

\begin{tabular}{ccc}
\hline Axis & Species & Partial R-square \\
\hline \hline Axis 1 & Solidago altissima & 0.6962 \\
Axis 1 & Bromus japonicus & 0.1117 \\
\hline Axis 2 & Festuca rubra & 0.5538 \\
Axis 2 & Galium verum & 0.1251 \\
Axis 2 & Muhlenbergia schreberi & 0.0737 \\
Axis 2 & Achillea millefolium & 0.0433 \\
Axis 2 & Bromus commutatus & 0.0363 \\
\hline Axis 3 & Galium verum & 0.3817 \\
Axis 3 & Solidago gigantea & 0.2266 \\
Axis 3 & Dactylis glomerata & 0.0813 \\
Axis 3 & Bromus japonicus & 0.0573 \\
Axis 3 & Ambrosia artemisiifolia & 0.0476 \\
Axis 3 & Lonicera japonica & 0.0336 \\
\hline
\end{tabular}

Many of the species that most influenced the ordination axes were also dominant in the community plots, especially in a particular field, making them important for discriminating across fields. As examples, S. altissima was dominant in the SWE plots, F. rubra was dominant in the NEB plots, and G. verum was dominant in the LA and NEE plots. These three species were influential to axes 1, 2, and 3 respectively in the species ordinations.

As I had surmised, many of the most influential species are also considered invasive, including Festuca rubra, Galium verum, Muhlenbergia schreberi, Achillea millefolium, Dactylis glomerata, Ambrosia artemisiifolia, and Lonicera japonica (EDDMapS, 2014; USDA Plants Database, 2015). This supports the idea that these invasive species affect commu- 
nity composition, and likely community properties as well. Additionally, subordinate species may be important determinants of ecosystem function because they can influence which species become dominant and may themselves become dominant if current dominants are suppressed (Grime, 1998). Thus, invasive species might have effects on ecosystem function and community composition even at low densities.

\subsubsection{Spectral ordinations}

Footprint similarities were also assessed using spectral data; I again found clustering of footprints by plot and by field (Figure 7). Before running a regression analysis to determine which bands most influenced NMS ordination axis values, a segmented principal components analysis (PCA) was conducted; the wavelengths selected, based on the greatest absolute value of factor loadings, were $435 \mathrm{~nm}, 525 \mathrm{~nm}, 575 \mathrm{~nm}, 635 \mathrm{~nm}, 680 \mathrm{~nm}, 710 \mathrm{~nm}, 750 \mathrm{~nm}, 835$ $\mathrm{nm}$, and $970 \mathrm{~nm}$. Band depths at these wavelengths were entered into a regression analysis to determine which wavelengths most explained the ordination axes; these wavelengths were $435 \mathrm{~nm}, 635 \mathrm{~nm}, 680 \mathrm{~nm}, 710 \mathrm{~nm}, 750 \mathrm{~nm}$, and $970 \mathrm{~nm}$ for axis 1; $435 \mathrm{~nm}, 525 \mathrm{~nm}, 575 \mathrm{~nm}$, $635 \mathrm{~nm}, 750 \mathrm{~nm}, 970 \mathrm{~nm}$ for axis 2; and $525 \mathrm{~nm}, 575 \mathrm{~nm}, 635 \mathrm{~nm}, 710 \mathrm{~nm}, 750 \mathrm{~nm}$, and 835 nm for axis 3 (Table 3 ). 


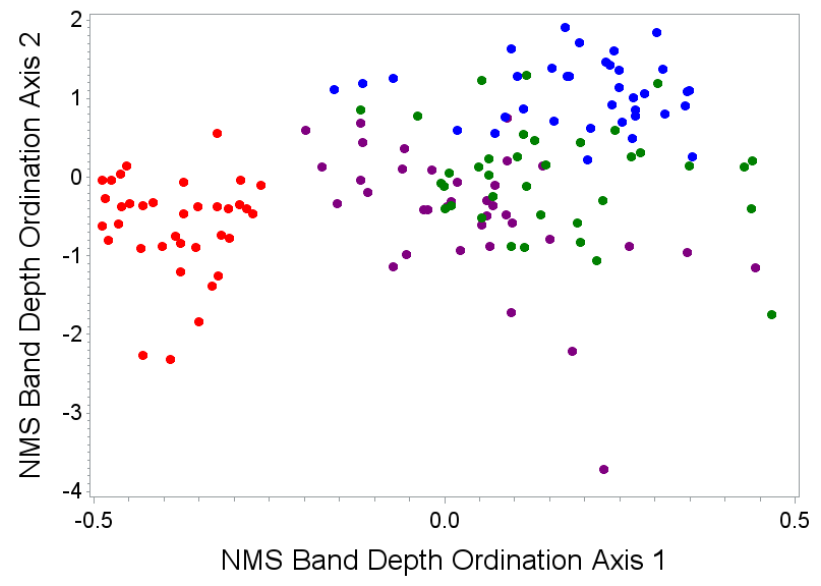

(a) $\mathrm{A}$

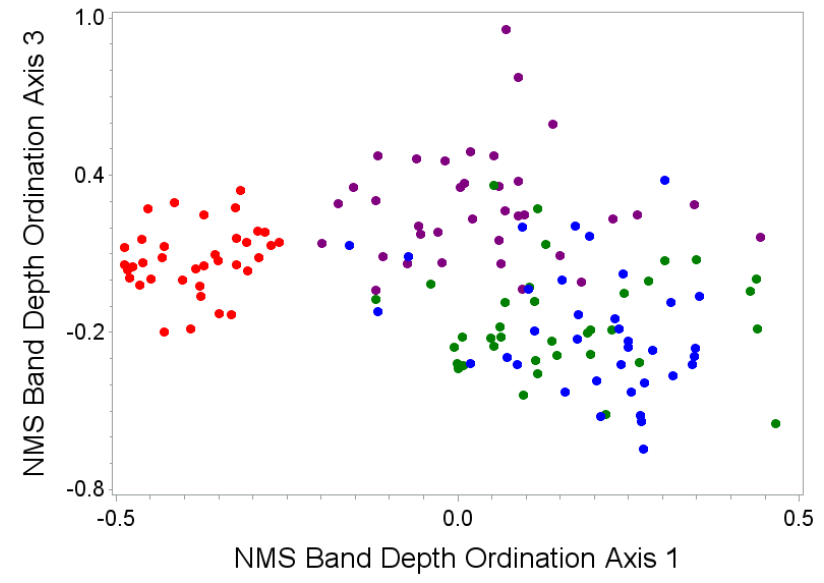

(b) B

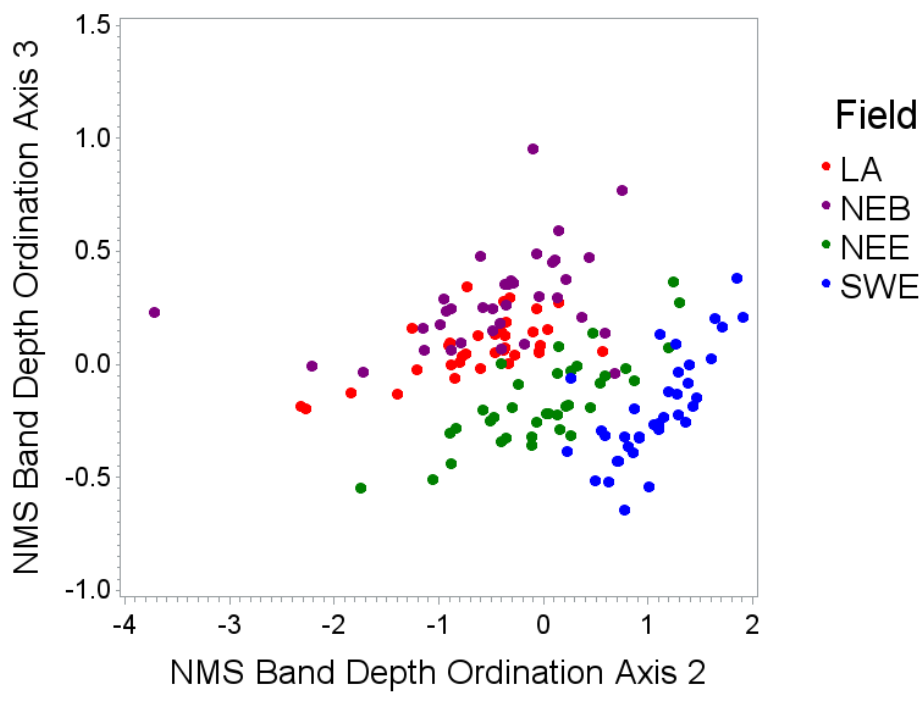

(c) $\mathrm{C}$

Figure 7: Non-metric multidimensional scaling (NMS) ordination results using band depth values from Lake Arnold (LA), northeast boundary (NEB), northeast early (NEE), and southwest early (SWE) fields at the Blandy Experimental Farm in north-central Virginia for a) axes 1 and 2, b) axes 1 and 3 , and c) axes 2 and 3 . 
Table 3: Multiple regression coefficients, assessing which wavelengths most influence nonmetric multidimensional scaling (NMS) ordination axes.

\begin{tabular}{c|ccccccccc}
\hline Axis & 435 & 525 & 575 & 635 & 680 & 710 & 750 & 835 & 970 \\
\hline \hline Axis 1 & 3.60 &. &. & 7.40 & -7.66 & -4.78 & 1.78 &. & 8.48 \\
Axis 2 & 6.31 & -1.65 & 3.44 & 7.28 &. &. & 2.86 &. & 2.22 \\
Axis 3 &. & -4.11 & 6.96 & -6.41 &. & 3.79 & 5.31 & 5.59 &. \\
\hline
\end{tabular}

The wavelengths selected through the principal components analysis (PCA) as most encompassing variability across plots were 435, 525, 575, 635, 680, 710, 750, 835, and $970 \mathrm{~nm}$. The entire spectral profile was represented, because I used a segmented PCA rather than using the entire spectral profile. This is important because of the differences in magnitudes of reflectance values along the spectral profile; the greater the reflectance value at a particular wavelength, the more likely that wavelength may be to influence a principal component. Using the segmented PCA allows for the representation of biologically meaningful features across the entire spectral profile. As examples, the reflectance values at $435 \mathrm{~nm}$ and 575 $\mathrm{nm}$ are influenced by carotenoids and chlorophyll more so than by anthocyanins (Blackburn, 2006; Koning, 1994). At $525 \mathrm{~nm}$, there is more influence by anthocyanins than carotenoids and chlorophylls (Blackburn, 2006; Koning, 1994). Chlorophylls a and b have peaks near 680 and $635 \mathrm{~nm}$ respectively (Blackburn, 2006; Koning, 1994). Wavelengths in the red edge such as $710 \mathrm{~nm}$ and $750 \mathrm{~nm}$ can be used to estimate chlorophyll content because they are less affected by leaf structure and canopy structure (Sims and Gamon, 2002). The nearinfrared bands, such as $835 \mathrm{~nm}$, have been used to assess leaf structure (Gamon et al., 1993). The water absorption feature near $970 \mathrm{~nm}$ is often used to estimate leaf water content (Wang et al., 2009). Using these wavelengths, a discriminant analysis was successfully used to distinguish among communities. The DA revealed that there was high discriminability across fields, but less discriminability within fields; this is consistent with greater species composition similarity across than within fields. 
Within the band depth ordination results, axis 1 was positively influenced by band depth at 435, 635, 750, and $970 \mathrm{~nm}$ and negatively influenced by band depth at 680 and $710 \mathrm{~nm}$. Spectra with high axis 1 values are characterized by 1) having high absorption associated with carotenoids and chlorophyll (chl), especially chl b over chl a, 2) having a less steep red edge, and 3) having a large water absorption feature at $970 \mathrm{~nm}$. Axis 2 was positively influenced by 435, 575, 635, 750, and $970 \mathrm{~nm}$ and negatively influenced by $525 \mathrm{~nm}$. Thus spectra with high axis 2 values are characterized by high absorption associated with carotenoids and chlorophylls, especially chl b, and not by anthocyanins; they also have high absorption at the red-edge shoulder and a large water absorption feature at $970 \mathrm{~nm}$. Axis 3 was positively associated with 575, 710, 750, and $835 \mathrm{~nm}$ and negatively associated with 525 and $635 \mathrm{~nm}$. Spectra with high axis 3 values are characterized by high absorption associated with carotenoids and chl a, but not by chl b or anthocyanins; they have high absorptions in the near-infrared plateau.

To determine whether these spectral characteristics may be correlated with certain species, the species ordination axis loadings were assessed for correlations with band depth loadings. There were positive correlations between species axis 1 and band depth axis 1 $(\mathrm{r}=0.513, \mathrm{pi} 0.0001)$ and between species axis 1 and band depth axis $2\left(\mathrm{r}=0.718, \mathrm{p}_{\mathrm{i}} 0.0001\right)$. There was a negative correlation between species axis 2 and band depth axis 3 ( $\mathrm{r}=-0.450$, pi0.0001). The species that were most strongly correlated with axis 1 in the species ordinations were $S$. altissima and B. japonicus. These species may be characterized by higher absorption by carotenoids and chl b than by anthocyanins and chl a; they also may have high absorption in the red-edge shoulder region and the water absorption feature at 970 nm. The species associated with axis 2 may be characterized by greater absorption due to anthocyanins and chl b, and higher reflectance in the red edge and near-infrared regions. However, caution must be used in analyzing these composite spectra, since features from multiple species are being expressed within one spectral profile. 


\subsubsection{Discriminant Analyses}

There was high separability among fields, but low separability among plots using simulated WorldView2 broad bands (Table 4). As an example, 32 out of 36 NEB spectra were correctly identified as NEB, but only 16 out of those 32 were identified as the correct plot within NEB. Similarly, 32 out of 36 SWE spectra were correctly identified as SWE, but only 22 out of those 32 were identified as the correct SWE plot.

Table 4: Confusion matrix for summer 2014 discriminant analysis to test discriminabilty of plots using 7 simulated WorldView2 bands: 400-449, 450-509, 510-580, 585-625, 630-690, 705-745, and 770-895 $\mathrm{nm}$.

\begin{tabular}{|c|c|c|c|c|c|c|c|c|c|c|c|c|c|c|}
\hline & \multicolumn{14}{|c|}{ Number of Observations Classified into Plot } \\
\hline & lacp1 & lacp2 & lacp3 & nebcp1 & nebcp2 & nebcp3 & neecp1 & neecp2 & neecp3 & swecp1 & swecp2 & swecp3 & Total & $\begin{array}{l}\text { Accu- } \\
\text { racy }\end{array}$ \\
\hline lacp1 & 12 & 0 & 0 & 0 & 0 & 0 & 0 & 0 & 0 & 0 & 0 & 0 & 12 & $85.7 \%$ \\
\hline lacp2 & 0 & 12 & 0 & 0 & 0 & 0 & 0 & 0 & 0 & 0 & 0 & 0 & 12 & $100 \%$ \\
\hline lacp3 & 2 & 0 & 8 & 0 & 0 & 1 & 0 & 0 & 0 & 1 & 0 & 0 & 12 & $88.9 \%$ \\
\hline nebcp1 & 0 & 0 & 0 & 4 & 5 & 2 & 0 & 1 & 0 & 0 & 0 & 0 & 12 & $44.4 \%$ \\
\hline nebcp2 & 0 & 0 & 0 & 4 & 6 & 2 & 0 & 0 & 0 & 0 & 0 & 0 & 12 & $46.2 \%$ \\
\hline nebcp3 & 0 & 0 & 0 & 1 & 2 & 6 & 0 & 0 & 2 & 1 & 0 & 0 & 12 & $54.5 \%$ \\
\hline neecp1 & 0 & 0 & 0 & 0 & 0 & 0 & 4 & 3 & 2 & 2 & 1 & 0 & 12 & $44.4 \%$ \\
\hline neecp2 & 0 & 0 & 1 & 0 & 0 & 0 & 3 & 6 & 1 & 0 & 0 & 1 & 12 & $40.0 \%$ \\
\hline neecp3 & 0 & 0 & 0 & 0 & 0 & 0 & 2 & 3 & 7 & 0 & 0 & 0 & 12 & $50.0 \%$ \\
\hline swecp1 & 0 & 0 & 0 & 0 & 0 & 0 & 0 & 1 & 1 & 5 & 1 & 4 & 12 & $45.5 \%$ \\
\hline swecp2 & 0 & 0 & 0 & 0 & 0 & 0 & 0 & 0 & 0 & 2 & 8 & 2 & 12 & $72.7 \%$ \\
\hline swecp3 & 0 & 0 & 0 & 0 & 0 & 0 & 0 & 1 & 1 & 0 & 1 & 9 & 12 & $56.3 \%$ \\
\hline Total & 14 & 12 & 9 & 9 & 13 & 11 & 9 & 15 & 14 & 11 & 11 & 16 & 144 & \\
\hline $\begin{array}{l}\text { User's } \\
\text { Accu- } \\
\text { racy }\end{array}$ & $100 \%$ & $100 \%$ & $66.7 \%$ & $33.3 \%$ & $50.0 \%$ & $50.0 \%$ & $33.3 \%$ & $50.0 \%$ & $58.3 \%$ & $41.7 \%$ & $66.7 \%$ & $75.0 \%$ & & \\
\hline $\begin{array}{l}\text { Overall } \\
\text { Accu- } \\
\text { racy }\end{array}$ & & & & & & & & & & & & & & $60.4 \%$ \\
\hline
\end{tabular}


Table 5: Confusion matrix for summer 2014 discriminant analysis to test discriminabilty of plots using wavelengths selected using principal components analysis: 435, 525, 575, 635, 680, 710, 750, 835, $970 \mathrm{~nm}$.

\begin{tabular}{|c|c|c|c|c|c|c|c|c|c|c|c|c|c|c|}
\hline & \multicolumn{14}{|c|}{ Number of Observations Classified into Plot } \\
\hline & lacp1 & lacp2 & lacp3 & nebcp1 & nebcp2 & nebcp3 & neecp1 & neecp2 & neecp3 & swecp1 & swecp2 & swecp3 & Total & Accu- \\
\hline & & & & & & & & & & & & & & \\
\hline lacp1 & 11 & 1 & 0 & 0 & 0 & 0 & 0 & 0 & 0 & 0 & 0 & 0 & 12 & 78.6 \\
\hline lacp2 & 1 & 10 & 1 & 0 & 0 & 0 & 0 & 0 & 0 & 0 & 0 & 0 & 12 & 83.3 \\
\hline lacp3 & 2 & 1 & 7 & 0 & 0 & 2 & 0 & 0 & 0 & 0 & 0 & 0 & 12 & 77.8 \\
\hline nebcp1 & 0 & 0 & 0 & 8 & 3 & 0 & 0 & 0 & 1 & 0 & 0 & 0 & 12 & 88.9 \\
\hline nebcp2 & 0 & 0 & 0 & 1 & 10 & 1 & 0 & 0 & 0 & 0 & 0 & 0 & 12 & 71.4 \\
\hline nebcp3 & 0 & 0 & 1 & 0 & 1 & 9 & 0 & 0 & 1 & 0 & 0 & 0 & 12 & 75.0 \\
\hline neecp1 & 0 & 0 & 0 & 0 & 0 & 0 & 8 & 0 & 1 & 2 & 0 & 1 & 12 & 80.0 \\
\hline neecp2 & 0 & 0 & 0 & 0 & 0 & 0 & 1 & 7 & 0 & 0 & 0 & 4 & 12 & 77.8 \\
\hline neecp3 & 0 & 0 & 0 & 0 & 0 & 0 & 1 & 1 & 10 & 0 & 0 & 0 & 12 & 77.0 \\
\hline swecp1 & 0 & 0 & 0 & 0 & 0 & 0 & 0 & 0 & 0 & 11 & 1 & 0 & 12 & 73.3 \\
\hline swecp2 & 0 & 0 & 0 & 0 & 0 & 0 & 0 & 0 & 0 & 2 & 9 & 1 & 12 & 90.0 \\
\hline swecp3 & 0 & 0 & 0 & 0 & 0 & 0 & 0 & 1 & 0 & 0 & 0 & 11 & 12 & 64.7 \\
\hline Total & 14 & 12 & 9 & 9 & 14 & 12 & 10 & 9 & 13 & 15 & 10 & 17 & 144 & \\
\hline $\begin{array}{l}\text { User's } \\
\text { Accu- } \\
\text { racy }\end{array}$ & $91.7 \%$ & $83.3 \%$ & $58.3 \%$ & $66.7 \%$ & $83.3 \%$ & $75 \%$ & $66.7 \%$ & $58.3 \%$ & $83.3 \%$ & $91.7 \%$ & $75.0 \%$ & $91.7 \%$ & & \\
\hline $\begin{array}{l}\text { Overall } \\
\text { Accu- } \\
\text { racy }\end{array}$ & & & & & & & & & & & & & & 77.1 \\
\hline
\end{tabular}

In contrast, using multiple narrowband wavelengths selected by the PCA in a discriminant analysis, I found greater spectral separability of plots (Table 5). As an example, 33 out of 36 NEB spectra were correctly identified as NEB, and 27 out of those 33 were identified as the correct NEB plot. Similarly, 35 out of 36 SWE spectra were correctly identified as SWE, and 31 out of those 35 were identified as the correct SWE plot. User's, producer's, and overall accuracies and the MCC values were greater using narrow bands than using simulated broad bands (Table 6). 
Table 6: A comparison of discrimination accuracies and reliability using simulated WorldView2 broad bands, and narrow bands from hyperspectral field-measurements.

\begin{tabular}{r|cc}
\hline & Simulated Broad Bands & Narrow Bands \\
\hline \hline Matthew's Correlation Coefficient & 0.548 & 0.745 \\
Overall Accuracy & $60.4 \%$ & $77.1 \%$ \\
Average Producer's Accuracy & $60.7 \%$ & $78.1 \%$ \\
Average User's Accuracy & $60.4 \%$ & $77.1 \%$ \\
\hline
\end{tabular}

Therefore, plant communities may be more successfully discriminated spectrally using narrow bands than broad bands. Additionally, the narrow band values entered into the discriminant analysis were band depth rather than reflectance values, which may also have contributed to the increase in discriminability.

\subsubsection{Other considerations}

The spectral differences between fields may also have been due to differences in soil characteristics among fields. If soil signatures were a large part of the spectral footprints (i.e. for small-leaved species), these differences in soil signatures in the plots and fields may contribute to the spectral differences in plots and fields. Depending on vegetation cover, differences in soil moisture and soil texture can influence spectral data (Cochrane, 2000; Laidler et al., 2008; Zhang et al., 2006). Differences in soil characteristics such as soil nutrients, soil biota, and soil pH could also directly and indirectly influence differences observed among communities (Baron et al., 2014). Land use can influence soil characteristics (Castro et al., 2010) and species composition (Aragon and Morales, 2003; Grau et al., 1997; Riedel and Epstein, 2005). The four fields studied at the Blandy Experimental Farm differ in land use history (Wang et al., 2010) and in soil characteristics. Therefore, it is important to take land use history into account when studying invaded systems (Rooney and Rogers, 2011; Seabloom et al., 2013) and secondary successional systems (Arroyo-Mora et al., 2005; Riedel 
and Epstein, 2005). Additionally, species composition can influence soil characteristics by mechanically changing the soil, affecting nutrient cycling, altering soil biota, and by changing herbivore community compositions (DeMeester and deB. Richter, 2010; Weidenhamer and Callaway, 2010).

As another consideration, band depth may not always be the best way to normalize data and correct for noise although it is quite commonly used (Crowley et al., 1989; Kokaly and Clark, 1999; Rice et al., 2013; Wang et al., 2009). Additional techniques for extracting spectral information include the use of first and second derivatives (Carlson et al., 2007; Castro-Esau et al., 2004), and band ratios (Broge and Leblanc, 2001; Clevers and Kooistra, 2012). Band depth, however, is widely used to estimate vegetation water, nitrogen, lignin, and cellulose content (Kokaly and Clark, 1999; Wang et al., 2009) and to discriminate among minerals (Crowley et al., 1989; Rice et al., 2013), because it reduces the effects of sensor noise, atmospheric effects, background soil signatures, and variations in topography and albedo (Crowley et al., 1989; Kokaly and Clark, 1999). However, the output of this procedure varies depending on the range over which the continuum is established. Band depth might also not be the most useful technique for all parts of the spectral profile. Therefore, another noise minimization technique may be better able to preserve information from the original reflectance spectral profile, for example in the near-infrared region where differences are often dampened by band depth calculations.

Additionally, only early-stage spectral signatures were analyzed in this study due to the height of the vegetation. Therefore, the separability of plant communities in the early stages could not be compared with separability of plant communities at mid and late stages. Future research with satellite or airborne imagery could help rectify this shortcoming; however, the differences in remote-sensing platforms, such as spatial and spectral resolutions, would need to be taken into account. Further research could also be done to assess discriminability across plant communities early and late in the growing season, but 
at these times the soil signature may inhibit discrimination; senescence during late stages of the growing season could also inhibit discriminability.

\subsubsection{Context of key findings}

Overall, I were able to visualize and analyze differences in communities by species composition using ordination analyses. Schmidtlein et al. (2007) used NMS ordinations to study undefined vegetation assemblages and used partial least squares regression analysis to assess which bands were most influential to the assemblages. Similarly, I used regressions to determine the most influential species to clustering: Solidago altissima (tall goldenrod), Bromus japonicus (Japanese brome), Festuca rubra (red fescue), Galium verum (yellow bedstraw), Muhlenbergia schreberi (nimblewill), Achillea millefolium (yarrow), Bromus commutatus (meadow brome), Solidago gigantea (giant goldenrod), Dactylis glomerata (orchard grass), Ambrosia artemisiifolia (common ragweed), and Lonicera japonica (Japanese honeysuckle). Several of these species are considered invasive in Virginia (F. rubra, G. verum, M. schreberi, A. millefolium, D. glomerata, A. artemisiifolia, and L. japonica), illustrating how invasive species can influence community composition (EDDMapS, 2014).

I was also able to spectrally separate communities using ordinations. Gao and Zhang (2006) also examined such differences in vegetation, using ground-level spectral data to discriminate salt marsh communities. These spectral differences by communities may be due to differences in species-level characteristics since the reflectance in the visible region is influenced by pigment concentration and reflectance in the near-infrared region is influenced by leaf structure (Xiao, Y. et al., 2014), and these characteristics can differ by species. This idea was supported when I used regressions to determine the most influential wavelengths for clustering of communities: 435, 525, 575, 635, 680, 710, 750, 835, and $970 \mathrm{~nm}$. These wavelengths are representative of absorption by pigments, leaf structure, and leaf water content; such features differ by species and by communities that differ in species composition. 
Similar spectral features have been used to discriminate among species (Burkholder, 2010; Narumalani et al., 2009; Pinard and Bannari, 2003; Rud et al., 2006; Schmidt and Skidmore, 2001; Yingying et al., 2011). If such features are able to be detected at the satellite level, discriminability may also be possible using satellite imagery. Since the most readily available satellite data are multispectral with medium or coarse spatial resolution, this may be challenging considering the lower discriminability I observed using simulated broad bands. However, discriminability may become easier with the advances in hyperspectral satellite technology such as the existing Hyperion and future EnMAP and HyspIRI satellites. The German EnMAP (Environmental Mapping and Analysis Program) satellite mission aims to use a pushbroom sensor to collect visible, near infrared, and shortwave infrared (420 nm -2450 $\mathrm{nm}$ ) reflectances with 244 bands, high radiometric resolution of 14 bits, a spatial resolution of $30 \mathrm{~m}$, and a $30^{\circ}$ off-nadir pointing feature and sun-synchronous orbit that will allow a 4-day temporal resolution; it is scheduled to launch around 2018 (EnMAP, 2015). Additionally, the HyspIRI (Hyperspectral Infrared Imager) mission, scheduled to launch by 2022, will have two instruments on a satellite in Low Earth Orbit that will collect reflectance measurements from $380 \mathrm{~nm}$ to $2500 \mathrm{~nm}$ and $3 \mu \mathrm{m}$ to $12 \mu \mathrm{m}$ with a spatial resolution of $60 \mathrm{~m}$ and revisit times of 19 days for visible to shortwave regions and 5 days for thermal infrared (Hook, 2015). Advances in high spatial resolution satellites, such as the WorldView2 and WorldView3 satellites with resolutions of $1.84 \mathrm{~m}$ and $1.24 \mathrm{~m}$ respectively for multispectral bands, would also increase species discriminability with the reduction of spectral mixing; WorldView3 also has decent spectral resolution, with 16 bands from the visible to shortwave-infrared regions. Using hyperspectral and high-spatial resolution data to monitor plant communities and how they may be affected by invasion at large spatial extents can aid conservation efforts and help us preserve the biodiversity that is associated with ecosystem function. 


\subsection{Conclusion}

I was able to distinguish among plant communities that differed in species compositions using ground-level hyperspectral remote sensing data. Seven of the eleven most influential species in defining these plant communities are considered invasive in Virginia, demonstrating the impact of invasive species on community composition. Plant communities were more accurately discriminated amongst using narrow bands than by using simulated broad bands, with a $77 \%$ overall accuracy versus $60 \%$ percent. Thus, narrow bands provide improved accuracies relative to broad bands in the study of plant communities, because narrow bands provide useful details that may be averaged out by broad bands. In this study, I demonstrated that I could discriminate among early successional plant communities using remote sensing data collected at the ground-level. Further work could be done using airborne or satellite imagery in mid and late successional stages to observe plant community discriminability at larger spatial extents. However, challenges to this include spatial and spectral resolutions most commonly available in airborne and satellite imagery. Such research will become more feasible with advances in satellite technology, such as the upcoming hyperspectral EnMAP and the available hyperspatial WorldView3 satellites. 


\subsection{Appendix 1: Persistence of Invasive Plant Species}

The non-native invasive plant species in this paper have several traits that allow them to persist in and take over a region. As examples, Carduus acanthoides (spiny plumeless thistle) has numerous, though not persistent, seeds (Feldman, 1997), is tolerant to repeated disturbances (Zhang et al., 2011), and is opportunistic in colonizing gaps (Allen and Shea, 2006). Rhamnus cathartica (Common buckthorn) has high shade tolerance, high growth and photosynthesis rates, wide range of tolerance of moisture and drought, unique leaf phenology, high fecundity, bird-dispersal of fruit, high germination rate, high seedling success in disturbed sites, and secondary metabolites, especially emodin, which may protect the plant from herbivores, pathogens, and high light levels; emodin may have allelopathic effects on natives nearby, and affect soil microbes and unripe fruit consumption/ digestion by birds (Knight et al., 2007). Celastrus orbiculatus (Oriental bittersweet) sprawls over or twines around and into the canopy of surrounding vegetation and has low palatability (Fryer, 2011). It does not have a host preference (Ladwig and Meiners, 2010). It can also persist at low photosynthetic rates in the shade and respond quickly to increases in light penetration to outgrow competition even in mature forests (Fryer, 2011), able to spread substantially within the canopy and decrease tree growth after gap-formation (Pavlovic and Leicht-Young, 2011). Oriental bittersweet can outcompete American bittersweet due to greater tolerance to various environmental conditions (e.g. shade), faster growth and reproduction rates, ability to increase photosynthetic rates with increases in light, the ability to perceive and grow toward nearby vegetation that it could then climb (Fryer, 2011), a shorter juvenile period, and greater seed viability (Pooler et al., 2002). In addition to changing species composition of plants, these invasive species can also be host to other types of organisms that could in turn affect other plants; buckthorn is the primary overwintering host for soybean aphids, Aphis gossypii and A. glycines (Heimpel et al., 2010; Kim et al., 2010), and oriental bittersweet is host for the bacterim Xylella fastidiosa, which in turn infects crop plants (Fryer, 2011). 


\section{Chapter 3: Identifying plant species using hyper- spectral remote sensing in successional systems of north central Virginia}

\subsection{Abstract}

Since biodiversity can affect several aspects of ecosystems including productivity and stability, it is important to study factors that may threaten biodiversity, such as invasive plant species. Remote sensing can be more efficient in the study of the prevalence and effects of invasive species over large regions than are field surveys alone. I collected ground-level hyperspectral data of six exotic invasive plant species in abandoned agricultural fields at the Blandy Experimental Farm in north-central Virginia to determine discriminability of these species using visible and near-infrared wavelengths. The entire spectral profile from 350 $\mathrm{nm}$ to $1025 \mathrm{~nm}$ was used in Support Vector Machine analysis to determine separability of species. I used sensitivity analyses to determine which spectral regions were most influential to discriminability by removing $50 \mathrm{~nm}$ regions and comparing discriminability to that using the entire spectral profile. Ailanthus altissima, Carduus acanthoides, and Cirsium arvense had high discriminability $(75 \%, 87.5 \%$, and $75 \%$ respectively). Galium verum had low discriminability (44.4\%), due to high spectral contamination from soil. Celastrus orbiculatus and Rhamnus davurica had low discriminability (27.3\% and 30.8\% respectively), however they were often misclassified as each other; this may be due to their physical overlap in the field. The sensitivity analysis revealed that the 350-399, 500-549, 700-749, and 900-949 nm regions were most useful for species discrimination, while 550-599 and 650-699 nm regions were detrimental to discrimination, due to greater intraspecific variability than interspecific variability in these regions. These most influential regions for discrimination were similar to those found in other studies. 


\subsection{Introduction}

\subsubsection{Biodiversity and invasion}

Biodiversity can affect ecosystem productivity (Cardinale et al., 2007; Gustafsson and Bostrom, 2011; Symstad and Jonas, 2011; Wilsey and Potvin, 2000), resource-use and resource-use efficiency (Cardinale et al., 2007; Gustafsson and Bostrom, 2011; Hooper and Vitousek, 1998), community stability (Gustafsson and Bostrom, 2011; Symstad and Jonas, 2011; Yachi and Loreau, 1999), infection resistance (Haas et al., 2011), and structural and functional diversity at higher trophic levels (Gustafsson and Bostrom, 2011). To conserve biodiversity and its resultant ecosystem properties, we need to study factors that influence diversity, such as the prevalence of exotic invasive species. These species can affect community properties, such as plant and microbial community composition and structure, and ecosystem properties, such as productivity, nutrient cycling, water cycling, soil pH, disturbance regimes, and successional trajectory (Bongard et al., 2013; Bradley and Mustard, 2006; DeMeester and deB. Richter, 2010; Denslow and Hughes, 2004; Gomez-Aparicio and Canham, 2008; Kuhman et al., 2011; Mascaro and Schnitzer, 2007; Vicente et al., 2013; Vitousek, 1990; Yoshida and Oka, 2004; Yurkonis et al., 2005).

Additionally, these invasive species have caused losses of $\$ 100-\$ 137$ billion and 700,000 hectares of native vegetation in the U.S. annually (Miao et al., 2006; Wilfong et al., 2009). As examples, Carduus acanthoides (spiny plumeless thistle) and Carduus nutans (nodding thistle) are two of the most notorious weeds in the continental U.S. and southern Canada due to their damaging effects on crop yield; higher cost of handling and processing product; lower seed, grain, and crop residue quality; and lower grazing quality (Allen and Shea, 2006; Tiley, 2010). Cirsium arvense (Canada thistle) drastically reduces crop yield; a population

with the density of 20 plants $/ \mathrm{m}^{2}$ has been shown to reduce the yield of canola by $26 \%$, barley by $34 \%$, wheat by $51 \%$, corn by $57 \%$, and soybean by $91 \%$ (Armel et al., 2005; Grekul and 
Bork, 2004). Even at low densities, C. arvense can reduce yield; a density of 6 C. arvense shoots $/ \mathrm{m}^{2}$ led to a reduction of wheat yield by $18 \%$ (Hunter, 1996). Such species have been found to alter community and ecosystem properties to promote their own growth over that of other species (Rooney and Rogers, 2011).

\subsubsection{Ecosystem and community properties}

Numerous invasive plant species occupy large fractions of the ridge-and-valley system of the mid-Atlantic and affect the properties of these ecosystems. As examples, Ailanthus altissima (tree of heaven) and Rhamnus cathartica (common buckthorn) increase nutrient cycling rates (Gomez-Aparicio and Canham, 2008; Mascaro and Schnitzer, 2007). R. cathartica and Celastrus orbiculatus (oriental bittersweet) are associated with greater litter decomposition rates (Heneghan et al., 2006; Knight et al., 2007; Leicht-Young et al., 2007; Mascaro and Schnitzer, 2007). R. cathartica, A. altissima, and C. orbiculatus can increase soil carbon as well as nutrients such as nitrogen, calcium, potassium, and magnesium (Gomez-Aparicio and Canham, 2008; Heneghan et al., 2006; Knight et al., 2007; Leicht-Young et al., 2007), and affect soil pH (Gomez-Aparicio and Canham, 2008; Heneghan et al., 2006; Knight et al., 2007; Leicht-Young et al., 2007). R. cathartica is also associated with greater soil moisture (Heneghan et al., 2006).

As they change their environment, these species can also alter species composition. A. altissima can promote the establishment of species that thrive in high-nutrient environments, such as itself, by increasing soil nutrient pools and cycling rates (Gomez-Aparicio and Canham, 2008). C. orbiculatus has been correlated with an increase in liana richness (Leicht-Young et al., 2007). Cirsium arvense (Canada thistle), Rhamnus davurica (Dahurian buckthorn), C. orbiculatus and A. altissima have allelopathic compounds that chemically deter the growth of other species (Burda and Oleszek, 2004; Grekul and Bork, 2004; Knight et al., 2007; Landenberger et al., 2007; Mastelic and Jerkovic, 2002; Pisula and Meiners, 
2010; Tsahar et al., 2002).

These species can also physically inhibit the growth of others. C. orbiculatus can decrease the growth of native tree species by girdling them and increasing their susceptibility to ice damage, and by shading out their saplings (Leicht-Young et al., 2007). It can also arrest the reestablishment of forests after a disturbance by suppressing shrub growth and reducing tree reproduction, (Fike and Niering, 1999; Ladwig and Meiners, 2010; Pavlovic and LeichtYoung, 2011; Riedel and Epstein, 2005). Various Rhamnus species can alter forest structure by affecting woody seedling or stem density, herbaceous species cover, and canopy openness by inhibiting germination and growth of native saplings (Frappier et al., 2003; Mascaro and Schnitzer, 2007). Rhamnus species can also have effects outside of the plant community by affecting earthworms, insects, and soil microbes through changing litter decomposition rates and soil properties, and by affecting birds due to changes in the availability and nutritional quality of their food (Heimpel et al., 2010; Heneghan et al., 2006; Knight et al., 2007).

\subsubsection{Remote sensing of plant species}

Thus, invasive species can affect biodiversity and the conservation of ecosystems by promoting changes in ecosystem and community properties. As funding for conservation efforts becomes limited with more landscapes needing protection or restoration, it becomes increasingly important to incorporate remote sensing data alongside field data to more efficiently determine the geographical regions and the exotic invasive species on which to focus. Remote sensing can be used to supplement field data and monitor spatial and temporal distribution of invasive species more efficiently than field work alone (Bradley and Mustard, 2006; Schmidt and Skidmore, 2001; Wilfong et al., 2009; Zhang et al., 2006).

If interspecific differences in vegetation characteristics are greater than intraspecific and intra-individual differences, remote sensing data can be used to discriminate species (Zhang et al., 2006). Differences in pigments, water content, cell size, intercellular space, 
cell wall thickness, and other structural elements assist in differentiating species at the leaf level (Roberts et al., 2004). Visible reflectance (VIS) at the leaf level is mostly a function of pigment content, near-infrared reflectance (NIR) is influenced by leaf structure, and shortwave infrared reflectance (SWIR) is influenced by water content and structural compound content (Mahlein, 2011; Xiao, Y. et al., 2014). Variation in dry matter content and leaf nitrogen $(\mathrm{N})$ can also account for substantive variability across the VIS, NIR, and SWIR regions (Xiao, Y. et al., 2014). In terms of leaf structure, leaf hairs increase reflectance in the VIS region and have variable effects in the NIR region; leaf surface wax increases VIS and NIR reflectance (Sims and Gamon, 2002).

Although such biophysical differences occur at the species level, certain elements also contribute to intraspecific variability. Spectral variability within species can differ by wavelength (Asner and Martin, 2011) and by spectrum level (leaf vs. branch vs. canopy) (Roberts et al., 2004; Ustin and Gamon, 2010). Certain biological traits also change with changes in the environment; for example, chlorophyll a: chlorophyll b ratios change with illumination (Gamon and Berry, 2012). Sun leaves also have lower reflectance values along the entire spectral profile than do shade leaves because of greater thickness and pigment concentrations (Buschmann et al., 1990). Reflectance can also be a function of stress, as well as phenology (e.g. senescence) (Mahlein, 2011; Merzlyak et al., 2003). Additionally, absorption bands can be affected by more than one chemical constituent and one chemical constituent can influence a broad spectral region (Kokaly and Clark, 1999).

Despite high intraspecific variability due to environmental factors and sometimes low interspecific variability across species for some traits (Ribeiro da Luz and Crowley, 2010; Rud et al., 2006), Asner (1998) suggests that plant species should be distinguishable remotely due to differences in biochemical and structural properties. Species differences have been detected remotely (Burkholder, 2010; Narumalani et al., 2009; Pinard and Bannari, 2003; Rud et al., 2006; Schmidt and Skidmore, 2001; Yingying et al., 2011) by examining such 
vegetation characteristics as total chlorophyll (chl), chl a, and chl b, carotenoids, soluble carbon (C), lignin, foliar $\mathrm{N}$ and phosphorus (P), leaf water content, compactness of the mesophyll layer, specific leaf area (SLA), and leaf mass per area (LMA) (Asner and Martin, 2011, 2009; Carlson et al., 2007; Castro-Esau et al., 2004). Hyperspectral data can be used to estimate these properties to discriminate among species (Asner et al., 2007).

\subsubsection{Research Objectives}

To discriminate species, they must be spectrally distinct from each other and these species-level differences must be able to be detected by instrumentation at either the ground level or, for studies at broader spatial extents, at the satellite level. I asked whether spectral characteristics of Ailanthus altissima (tree of heaven), Carduus acanthoides (spiny plumeless thistle), Celastrus orbiculatus (oriental bittersweet), Cirsium arvense (Canada thistle), Galium verum (yellow bedstraw), and Rhamnus davurica (Dahurian buckthorn) can be used to differentiate these species at the ground level at the Blandy Experimental Farm (BEF) in north-central Virginia. Galium verum has been discriminated successfully using first derivatives and Normalized Difference Vegetation Index (NDVI) band ratios from spectral data at the time of inflorescence (Yingying et al., 2011). Ailanthus altissima was discriminated using laboratory spectra during July using data from the red edge, near-infrared region, and especially the shortwave-infrared region (SWIR) (Burkholder, 2010). I hypothesized that Carduus acanthoides and Cirsium arvense may be difficult to differentiate because of their

phylogenetic closeness (see Appendix 1). Similarly, I hypothesized that Rhamnus davurica and Celastrus orbiculatus may be difficult to differentiate, because Celastrus orbiculatus grows on top of Rhamnus davurica in several fields at the BEF. Phenological information can also be used to discriminate species. For example, Rhamnus davurica may be able to be discriminated late in the growing season, because Rhamnus species have a longer leaf retention time than surrounding species (Knight et al., 2007). However, in this study, I wanted to see whether these species could be differentiated during peak growing season, as high spatial 
resolution satellite imagery can be expensive and species may need to be differentiated using one image.

\subsection{Methods}

\subsubsection{Study Site}

Measurements were taken from two series of successional fields and two additional field sites at the BEF located in the Shenandoah River Valley, Virginia (Figure 17). This 300 ha biological field station has been owned by the University of Virginia (UVA) since 1926 and operated by the Department of Environmental Sciences since 1983 (Bowers, 1997). The site is also a satellite monitoring location for the National Ecological Observatory Network (NEON, 2015). The BEF includes 120 ha of pasture and cropland, 40 ha of woodland, the 60 ha Virginia State Arboretum, and 80 ha of successional fields in early, middle, and late succession (Bowers, 1997). Each of two successional series contains an early, mid, and late successional field. The successional fields are former agricultural fields, abandoned in 2001 (Early 1), 2003 (Early 2), 1986 (Mid 1), 1987 (Mid 2), before 1910 (Late 1) and before 1920 (Late 2) (Wang et al., 2010). All sites have silt loam soil, of the soil type Ultisol, with slopes less than 10\%. Mean annual temperature and precipitation for the BEF are 11.8 ${ }^{\circ} \mathrm{C}$ and $940 \mathrm{~mm}$ respectively (Wang et al., 2010). I studied six exotic invasive species that are prevalent at the BEF: Ailanthus altissima (tree of heaven), Carduus acanthoides (spiny plumeless thistle), Celastrus orbiculatus (oriental bittersweet), Cirsium arvense (Canada thistle), Galium verum (yellow bedstraw), and Rhamnus davurica (Dahurian buckthorn) (see Appendix 2 for species details). These species have several characteristics that have assisted their establishment and spread at the BEF (see Appendix 3). 


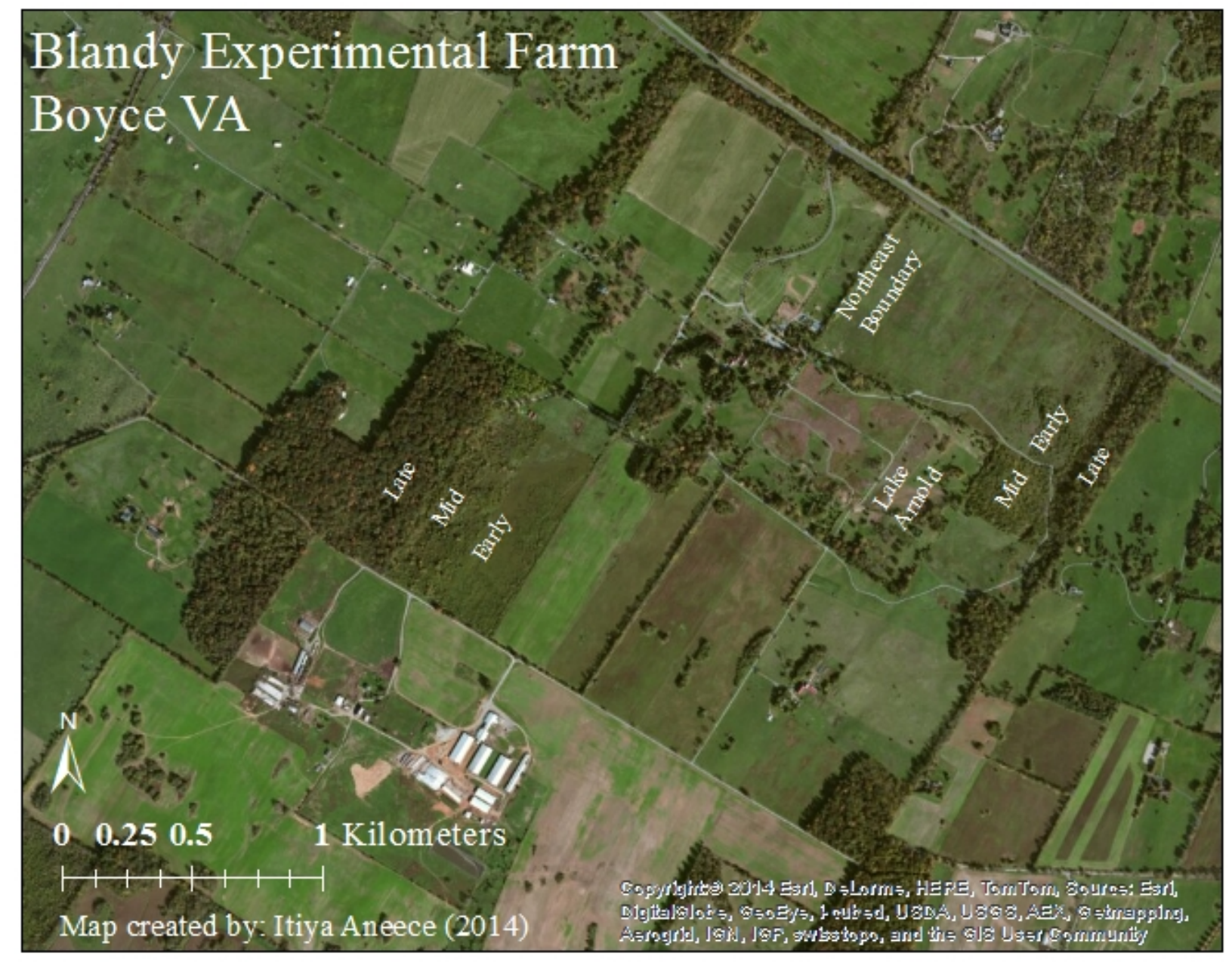

Figure 8: Blandy Experimental Farm, Boyce VA with study site labels including two secondary successional field chronosequences

\subsubsection{Field methods}

During the summer of 2012, I established two $1 \mathrm{~m} * 1 \mathrm{~m}$ population-level plots per target non-native invasive species where present in the early stages of each of the successional series and at Lake Arnold and the northeast boundary field sites. A total of four Ailanthus altissima plots, eight Carduus acanthoides plots, four Celastrus orbiculatus plots, four Cirsium arvense plots, four Galium verum plots, and four Rhamnus davurica plots were established. Spectra were collected multiple times for each plot from June to August using a PANalytic Analytical Spectral Devices (ASD) Inc. Field Spec ${ }^{\circledR} 3$ between 10:00 AM 
and 2:00 PM on days with clear skies and in the absence of windy conditions. I collected population-level spectra with a $25^{\circ}$ field of view (FOV) from a height of approximately 2.5 $\mathrm{m}$ for a footprint of $1.15 \mathrm{~m}$ in diameter. I also collected leaf-level spectra with a $1^{\circ} \mathrm{FOV}$ from detached leaves that were wrapped in wet paper-towels, put into zippered plastic bags, and stored on ice until measurements were taken within 20 minutes of detachment.

\subsubsection{Statistical analysis}

I used band depth instead of original reflectance profiles to minimize any atmospheric and soil noise in the spectral data. To obtain band depth, a continuum hull was matched to the original spectral profile, and this continuum was removed from the original spectral profile to get normalized reflectance; these continuum-removed reflectance values were then subtracted from one to get the band depth profile (Figure 12). 

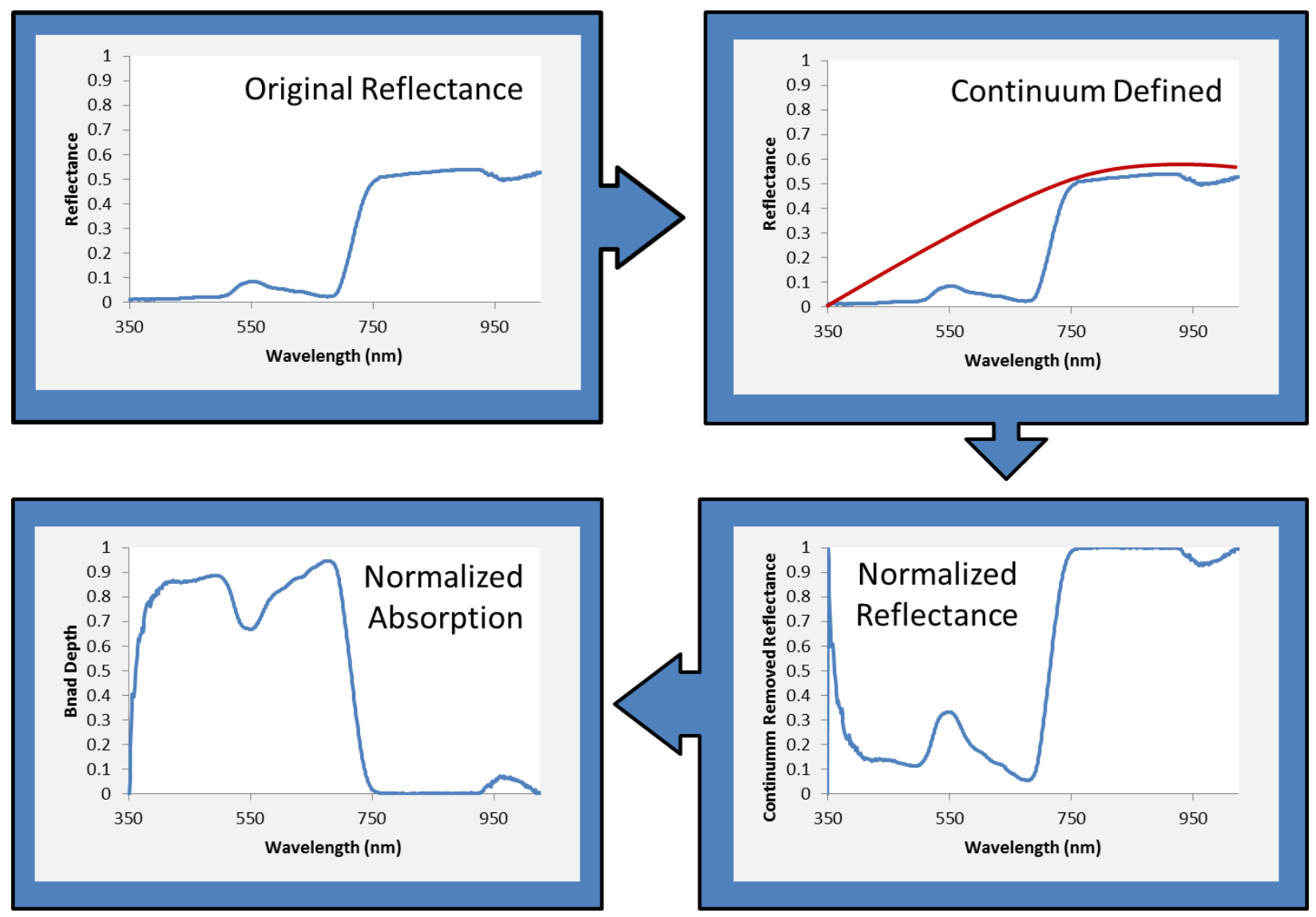

Figure 9: Calculating band depth (normalized absorption) from original reflectance using continuum removal.

Subsequently, I ran these band depth profiles for both leaf-level and population-level data, through a support vector machine (SVM) analysis in R (Version 2, Free Software Foundation Inc., Boston, Massachusetts) using the e1071 package. This machine learning analysis allowed us to use the entire spectral profile for differentiating species. Since there were six species classes and SVM is a binary classifier, I used a one-against-all technique (Nooni et al., 2014). I chose a linear kernal because the number of independent variables is greater than the number of samples. Six samples of each target species were randomly selected from the dataset for training, and the rest of the samples were used to test the model. The model was tuned with different estimations of cost (penalty for misidentification) to assess which level of cost best helped predictability and the ability to extrapolate results. Cost was set at 1000, based on the tuning of the model. 
I assessed the accuracy of the model using the confusion matrix and by calculating the Matthew's correlation coefficient (MCC) for each species. The classification accuracies were then averaged across species to represent the model accuracy. The MCC varies between +1 and -1 , with +1 representing a perfect match between prediction and observation, -1 representing a perfect mismatch between prediction and observation, and 0 representing a match that is no better than random.

Following support vector machine analysis using the entire spectral profile, I conducted a sensitivity analysis by removing $50 \mathrm{~nm}$ regions one at a time from the spectral profile; I ran this new profile through the SVM and compared the output with that from the entire spectral profile using the Matthew's correlation coefficient (Equation 1, where $\mathrm{TP}=$ True Positive, $\mathrm{TN}=$ True Negative, $\mathrm{FP}=$ False Positive, and $\mathrm{FN}=$ False Negative). To assess whether the importance of regions for discrimination may be influenced by amounts of interspecific and intraspecific variability, averages of reflectance and band depths by region were calculated and evaluated with an ANOVA to compare among and within mean squares in SAS (Statistical analysis software, Version 9.4, SAS Institute Inc., Cary, North Carolina).

\subsection{Results}

Using the support vector machine analysis with the training set, I was able to create a model that was predictive for the test set (Table 7) with 33 support vectors. Ailanthus altissima (tree of heaven), Carduus acanthoides (spiny plumeless thistle), and Cirsium arvense (Canada thistle) were able to be distinguished much of the time from the other target exotic invasive species $(75 \%, 87.5 \%$, and $75 \%$ respectively). Rhamnus davurica (Dahurian buckthorn) and Celastrus orbiculatus (oriental bittersweet) were often misidentified as each other (accuracies of $30.8 \%$ and $27.3 \%$ respectively). Galium verum (yellow bedstraw) (accuracy of $44.4 \%$ ) was often misidentified as Carduus acanthoides, Cirsium arvense, or Celastrus orbiculatus. 
Table 7: Summer 2012 Support Vector Machine Analysis using the entire spectral profile transformed into band depth for all target exotic invasive species; spectra collected from population plots.

\begin{tabular}{l|ccccccc}
\hline & \multicolumn{7}{|c}{ Predicted } \\
\hline True & AIAL & CAAC & CEOR & CIAR & GAVE & RHDA & Total \\
\hline \hline AIAL & 6 & 1 & 0 & 1 & 0 & 0 & 8 \\
CAAC & 0 & 7 & 0 & 1 & 0 & 0 & 8 \\
CEOR & 2 & 1 & 3 & 0 & 1 & 4 & 11 \\
CIAR & 0 & 0 & 0 & 6 & 2 & 0 & 8 \\
GAVE & 0 & 3 & 2 & 4 & 8 & 1 & 18 \\
RHDA & 1 & 0 & 8 & 0 & 0 & 4 & 13 \\
Total & 9 & 12 & 13 & 12 & 11 & 9 & 66 \\
\hline
\end{tabular}

The Matthew's correlation coefficients using the entire spectral profile reveal a high predictability for Ailanthus altissima, Carduus acanthoides, and Cirsium arvense with MCCs of $0.63,0.63$, and 0.50 respectively (Table 7 ). There was moderate predictability for Galium verum with an MCC of 0.39. Celastrus orbiculatus and Rhamnus davurica had low predictability with MCCs of 0.03 and 0.19 , because they were frequently misclassified as each other. Using the entire spectral profile, three out of 11 spectra were correctly classified as Celastrus orbiculatus, and four out of 11 were misclassified as Rhamnus davurica. Additionally, four out of 13 spectra were correctly classified as Rhamnus davurica, and eight out of 13 spectra were misclassified as Celastrus orbiculatus. 
Table 8: Matthew's Correlation coefficients from support vector machine outputs with certain $50 \mathrm{~nm}$ regions omitted for sensitivity analysis.

\begin{tabular}{lccccccc}
\hline Species & AIAL & CAAC & CEOR & CIAR & GAVE & RHDA & Average \\
\hline \hline none & 0.63 & 0.63 & 0.03 & 0.50 & 0.39 & 0.19 & 0.39 \\
$350-399$ & 0.68 & 0.55 & 0.04 & 0.17 & 0.38 & 0.32 & 0.36 \\
$400-449$ & 0.62 & 0.59 & 0.10 & 0.43 & 0.29 & 0.27 & 0.38 \\
$450-499$ & 0.68 & 0.59 & 0.12 & 0.49 & 0.29 & 0.19 & 0.39 \\
$500-549$ & 0.48 & 0.62 & -0.08 & 0.49 & 0.39 & 0.29 & 0.37 \\
$550-599$ & 0.63 & 0.63 & 0.11 & 0.50 & 0.40 & 0.23 & 0.42 \\
$600-649$ & 0.58 & 0.63 & 0.03 & 0.47 & 0.39 & 0.27 & 0.39 \\
$650-699$ & 0.58 & 0.63 & 0.11 & 0.47 & 0.40 & 0.33 & 0.42 \\
$700-749$ & 0.53 & 0.53 & 0.06 & 0.46 & 0.29 & 0.29 & 0.36 \\
$750-799$ & 0.63 & 0.63 & 0.03 & 0.47 & 0.39 & 0.23 & 0.39 \\
$800-849$ & 0.63 & 0.63 & 0.03 & 0.50 & 0.39 & 0.19 & 0.39 \\
$850-899$ & 0.63 & 0.63 & 0.03 & 0.50 & 0.39 & 0.19 & 0.39 \\
$900-949$ & 0.57 & 0.67 & 0.02 & 0.43 & 0.39 & 0.14 & 0.37 \\
$950-999$ & 0.57 & 0.77 & 0.00 & 0.41 & 0.39 & 0.14 & 0.38 \\
$1000-1025$ & 0.63 & 0.63 & 0.03 & 0.50 & 0.39 & 0.19 & 0.39 \\
\hline
\end{tabular}

When $350 \mathrm{~nm}$ to $399 \mathrm{~nm}$ wavelengths were omitted, the average MCC across species was 0.36 as opposed to 0.39 with the use of the entire spectral profile; thus, this region may be useful for species discrimination (Table 8). Similarly, the omission of 500-549 nm, 700-749 nm, and 900-949 nm led to lower average MCCs of 0.37, 0.36, and 0.37 respectively. The omission of 550-599 nm and 650-699 nm wavelengths led to greater average MCCs of 0.42 for both wavelength ranges.

When comparing interspecific and intraspecific variability within spectral regions, results differed between reflectance and band depth. For reflectance, many regions had 
greater within mean squares than among mean squares (Table 9). In contrast, all regions from the band depth values had greater among mean squares (Table 10). Comparing band depth variability by region, there was no relationship between the $\mathrm{F}$ value and the usefulness of particular regions for species discrimination; regions that were helpful and detrimental for discrimination had both low and high F values (Table 10). However, comparing reflectance variability by region, the two regions detrimental to discrimination were among the top three highest $\mathrm{F}$ values scores, meaning the regions with the greatest interspecific variability (Table $9)$.

Table 9: ANOVA results comparing among and within variance of reflectance values by region. No $\mathrm{p}<0.001$

\begin{tabular}{lccc}
\hline Reflectance Region & Among Mean Square & Within Mean Square & F value \\
\hline \hline $350-399$ & $1.38 \mathrm{E}-04$ & $1.94 \mathrm{E}-04$ & 0.7098 \\
$400-449$ & $4.30 \mathrm{E}-05$ & $2.09 \mathrm{E}-04$ & 0.2079 \\
$450-499$ & $2.40 \mathrm{E}-05$ & $2.41 \mathrm{E}-04$ & 0.0987 \\
$500-549$ & $2.97 \mathrm{E}-04$ & $5.62 \mathrm{E}-04$ & 0.5290 \\
$550-599$ & $7.83 \mathrm{E}-04$ & $8.02 \mathrm{E}-04$ & 0.9766 \\
$600-649$ & $4.65 \mathrm{E}-04$ & $3.94 \mathrm{E}-04$ & 1.1813 \\
$650-699$ & $2.57 \mathrm{E}-04$ & $3.09 \mathrm{E}-04$ & 0.8335 \\
$700-749$ & 0.0015 & 0.0059 & 0.2481 \\
$750-799$ & 0.0076 & 0.0131 & 0.5821 \\
$800-849$ & 0.0071 & 0.0132 & 0.5379 \\
$850-899$ & 0.0065 & 0.0130 & 0.4974 \\
$900-949$ & 0.0055 & 0.0127 & 0.4372 \\
$950-999$ & 0.0050 & 0.0117 & 0.4257 \\
$1000-1025$ & 0.0047 & 0.0118 & 0.4015 \\
\hline
\end{tabular}


Table 10: ANOVA results comparing among and within variance of band depth values by region. * represents $\mathrm{p}<0.001$

\begin{tabular}{lccc}
\hline Band Depth Region & Among Mean Square & Within Mean Square & F value \\
\hline \hline $350-399$ & 0.0263 & 0.009097 & 2.8866 \\
$400-449$ & 0.0232 & 0.005643 & 4.1034 \\
$450-499$ & 0.0201 & 0.003612 & $5.5747^{*}$ \\
$500-549$ & 0.0213 & 0.004782 & 4.4600 \\
$550-599$ & 0.0300 & 0.00554 & $5.4185^{*}$ \\
$600-649$ & 0.0134 & 0.00333 & 4.0216 \\
$650-699$ & 0.0081 & 0.00232 & 3.4747 \\
$700-749$ & 0.0165 & 0.003145 & $5.2591^{*}$ \\
$750-799$ & $5.47 \mathrm{E}-05$ & $5.39 \mathrm{E}-06$ & $10.155^{*}$ \\
$800-849$ & $4.89 \mathrm{E}-06$ & $4.17 \mathrm{E}-06$ & 1.1734 \\
$850-899$ & $1.22 \mathrm{E}-05$ & $4.35 \mathrm{E}-06$ & 2.8076 \\
$900-949$ & $8.24 \mathrm{E}-05$ & $5.48 \mathrm{E}-05$ & 1.5031 \\
$950-999$ & 0.0017 & $3.81 \mathrm{E}-04$ & $4.5902^{*}$ \\
$1000-1025$ & $1.68 \mathrm{E}-04$ & $7.10 \mathrm{E}-05$ & 2.3689 \\
\hline
\end{tabular}

\subsection{Discussion}

\subsubsection{Species discrimination}

I was able to discriminate among six exotic invasive species using ground-level remote sensing data and support vector machine analysis. I chose to use SVMs for several reasons including their computational efficiency over similarly accurate classification and regression tree analyses (Agarwal et al., 2013), their non-parametric nature, so parametric assumptions did not need to be met (Cho et al., 2012; Feret and Asner, 2013), and their capacity to 
work with complex, noisy, and/ or small datasets (Bai et al., 2012; Villa et al., 2011). SVMs have also been used by other researchers to distinguish species (Colgan et al., 2012; Nooni et al., 2014). This technique enables the use of the entire spectral profile, which is important because spectral variability within and across species depends on wavelength (Asner and Martin, 2011). Using the entire spectral profile rather than selected narrow bands has also been better for detecting chemical components (Asner et al., 2012) and photosynthetic apparatuses (Rascher et al., 2007).

In this study, discriminability varied by species (Table 7). This is expected because spectral discriminability depends on spectral differences within individuals, within species, and across species (Zhang et al., 2006). Classification errors also increase with the inclusion of more species (Asner and Martin, 2011). Additionally, closely related species are often difficult to distinguish from each other because they may have similar spectral features (Feret and Asner, 2011). Species with similar canopy structures can also be easily misclassified (Jiao et al., 2014). Despite their phylogenetic closeness (see Appendix 1) and structural similarity, Carduus acanthoides and Cirsium arvense were able to be separated spectrally using SVMs; none of the $C$. arvense spectra were misidentified as $C$. acanthoides, and only one of eight C. acanthoides spectra was misclassified as C. arvense.

In contrast, Celastrus orbiculatus and Rhamnus davurica were often misclassified as each other. This might be because $C$. orbiculatus commonly grows on top of $R$. davurica in these field sites. Therefore, the $C$. orbiculatus signatures collected may have been contaminated by spectral information from $R$. davurica, making the model difficult to train regarding the classification of these two species. Celastrus orbiculatus is shade-tolerant and can survive in the understory until a disturbance allows it to climb into the canopy (Pavlovic and Leicht-Young, 2011). Changes in canopy composition through disturbance, such as with the invasion of Rhamnus davurica, can facilitate the spread of exotic invasive shade-tolerant species such as Celastrus orbiculatus over shade-tolerant natives that were established be- 
fore the disturbance (Kuhman et al., 2011). Additionally, C. orbiculatus does not undergo self-thinning when growing at high densities (Leicht-Young et al., 2011). These lianas then compete with trees for aboveground and belowground resources (Ladwig and Meiners, 2010). Castro-Esau et al. (2004) also stated that it may be difficult to differentiate lianas from the trees they grow on if there is little spectral difference between the two. Lianas generally have different chlorophyll content, higher visible reflectance, and lower near-infrared reflectance than trees (Castro-Esau et al., 2004); however, sufficient differences for separation were not detected in this study.

Galium verum was also frequently misclassified as the other forbs or the liana. This might be due to the growth structure of $G$. verum, which has very small and narrow leaves (approximately $2 \mathrm{~mm}$ by $10 \mathrm{~mm}$ ) arranged in whorls around a stem. Spectral signatures from these plants often have large amounts of noise from the soil background. This may have created substantial variability in the signal, thus decreasing discriminability. Jiao et al. (2014) had similar difficulty differentiating wheat from oat due to similarities in canopy structure and large amounts of soil noise.

Overall, support vector machines were able to classify species. However, there are some disadvantages of using SVMs including computational demand, especially with large training datasets (Villa et al., 2011), and lack of interpretability. It is difficult to determine the importance of specific independent variables to classification within this "black-box" technique.

\subsubsection{Wavelengths that improve discriminability}

To interpret this "black-box" technique, I conducted a sensitivity analysis to assess which wavelength regions might be most important for classification (Table 8). The spectral regions 350-399 nm, 500-549 nm, 700-749 nm, and 900-949 nm seem important for classification due to the decrease in predictability with the omission of these regions. The importance 
of 350-399 nm for classification supports the findings of Schmidt and Skidmore (2003) who found the blue absorption maximum at $404 \mathrm{~nm}$ to be useful for species discrimination in coastal saltmarshes in the Netherlands. The $375 \mathrm{~nm}$ region is used to estimate the fraction of photosynthetically active radiation (fPAR) and leaf water content (Thenkabail et al., 2014).

The importance of 500-549 $\mathrm{nm}$ supports Sanchez-Azofeifa et al. (2009), who found that the $500 \mathrm{~nm}$ region was useful for discriminating species in tropical dry forest species in Panama. Schmidt and Skidmore (2003) also found that $501 \mathrm{~nm}$, at the blue edge, was useful for discriminating coastal saltmarsh species. The $515 \mathrm{~nm}$ region is also useful for estimating pigment concentrations (Thenkabail et al., 2014). The $531 \mathrm{~nm}$ region can be used to estimate light use efficiency, xanthophyll cycle, and vegetation stress (Thenkabail et al., 2014).

Similarly, the importance of 700-749 nm in this study supports several other studies. Lewis (2002) found that bands above $720 \mathrm{~nm}$ were useful for discriminating southeast Australian arid region species. Schmidt and Skidmore (2001) state that the red edge slope may be used to discriminate species, because reflectance in this region is influenced by nitrogen, phosphorous, and potassium concentrations (Mutanga et al., 2004). Smith and Blackshaw (2003) also found that 720-730 nm were useful for discrimination. Sanchez-Azofeifa et al. (2009) found the $720 \mathrm{~nm}$ region useful for discriminating lianas from trees in dry forests. The $705 \mathrm{~nm}$ region and $720 \mathrm{~nm}$ region can be used to estimate stress and chlorophyll concentrations (Thenkabail et al., 2014). More broadly, the 700-740 nm region can be used to estimate chlorophyll concentrations and observe the effects of senescence and stresses, such as drought (Thenkabail et al., 2014).

Finally, I found the 900-949 nm region useful for discriminating species in this temperate abandoned agricultural system. The $910 \mathrm{~nm}$ region is useful for estimating moisture, biomass, and protein content (Thenkabail et al., 2014). However, Schmidt and Skidmore (2003) found the $986 \mathrm{~nm}$ region more useful for discrimination, because in their study sys- 
tem of tropical dry forest, moisture content differs drastically by species, and the $970 \mathrm{~nm}$ region is a good indicator of plant moisture (Thenkabail et al., 2013).

Additional wavelengths in the visible and near-infrared regions were also found to be important in other studies, including the chlorophyll b absorption feature at $466 \mathrm{~nm}$ (Naidoo et al., 2012), the red absorption maximum region at $628 \mathrm{~nm}$ (Schmidt and Skidmore, 2003), and the red edge shoulder region at $770 \mathrm{~nm}$ (Schmidt and Skidmore, 2003). Although these regions have been shown to influence discriminability, they were not the most influential regions in our study. Whereas this study focused on visible and near-infrared spectral regions from $350 \mathrm{~nm}$ to $1025 \mathrm{~nm}$, others have also found regions beyond $1025 \mathrm{~nm}$ to be useful for discriminating species, as shortwave infrared regions (Pinard and Bannari, 2003) and thermal infrared regions (Ribeiro da Luz and Crowley, 2010) can have greater interspecific variability than the visible region.

\subsubsection{Wavelengths that hinder discriminability}

On the other hand, omissions of 550-599 nm and 650-699 $\mathrm{nm}$ seem to increase prediction capacity of the model. Upon closer examination of the MCCs for each species with these wavelength region omissions, I observed that only the discriminabilities of $C$. orbiculatus and R. davurica are increased (Table 8). This may be due to greater intraspecific variability in these regions (Table 9) and thus greater difficulty with classification; minimizing the intraspecific variability in reflectance using band depth, as was observed in comparing among and within mean squares for reflectance versus band depth, illustrates how well band depth methods eliminate noise from spectral data. However, despite this correction, the greater intraspecific variability compared with interspecific variability in the reflectance values at 550-599 $\mathrm{nm}$ and 650-699 $\mathrm{nm}$ hindered species discrimination.

In this study, the 550-599 $\mathrm{nm}$ region was found detrimental to discriminability of

C. orbiculatus and R. davurica. In contrast, Schmidt and Skidmore (2003) found that the 
$579 \mathrm{~nm}$ region, the green absorption minimum, was useful for species discrimination in a tropical dry forest. The $550 \mathrm{~nm}$ and $570 \mathrm{~nm}$ regions are useful for estimating chlorophyll, anthocyanin, and nitrogen concentrations (Thenkabail et al., 2014).

I also found that 650-699 nm wavelengths were detrimental to discrimination of $C$. orbiculatus and R. davurica. In contrast, Sanchez-Azofeifa et al. (2009) found the $675 \mathrm{~nm}$ region useful for discriminating tropical dry forest species, and Lewis (2002) found the 680 $\mathrm{nm}$ region useful for discriminating southeast Australian arid region species. The $680 \mathrm{~nm}$ region is associated with the photosystem II reaction center (Sanches et al., 2014). The double-peak features of chlorophyll fluorescence emissions are located at the 690 to $710 \mathrm{~nm}$ wavelength region. The $682 \mathrm{~nm}$ region has also been used to estimate biophysical quantities and yields (Thenkabail et al., 2014).

\subsubsection{Species differences}

The differences in important regions among studies may be due to differences in ecosystems and thus species compositions. For example, MCCs by species examined in this study indicate that regions of hindrance and assistance to discrimination differ greatly by

species (Table 8). For A. altissima, the omission of spectral regions 500-549 nm and 700-749 $\mathrm{nm}$ were most detrimental to discrimination and omissions of 350-399 $\mathrm{nm}$ and 450-499 $\mathrm{nm}$ slightly improved discriminability. For C. acanthoides, the omission of 700-749 nm was most detrimental, and the omission of 950-999 nm was quite beneficial to discriminability. For $C$. orbiculatus, the omission of 500-549 nm was most detrimental, while the omissions of 400-449 nm, 450-499 nm, 550-599 nm, and 650-699 nm were slightly beneficial. For C. arvense, the omission of 350-399 nm was most detrimental, while no omissions were beneficial. For $G$. verum, the omissions of 400-449 nm, 450-499 nm, and 700-749 nm were most detrimental, while no omissions were beneficial to discriminability. Lastly, for $R$. davurica, omissions of 900-949 $\mathrm{nm}$ and 950-999 $\mathrm{nm}$ were most detrimental, while omissions of 350-399 $\mathrm{nm}$ and 
650-699 $\mathrm{nm}$ were most beneficial to discrimination.

These differences by species may be due to differences in species' spectral features and variability in such features as pigment absorptions, structural elements, and leaf water content. As an example, C. acanthoides may have high intraspecific variability in leaf water content, which makes the 950-999 nm region detrimental to discriminability. Omissions of 550-599 $\mathrm{nm}$ and 650-699 nm were beneficial to discriminability of $C$. orbiculatus and $R$. davurica, the two species that were most often misidentified as each other. Perhaps these two regions are where the two species are most alike, due to similarities in pigment content.

Regions that are most important for discriminability do somewhat overlap across studies, but differences may be due to differences in ecosystems and species compositions, especially in arid vs non-arid systems. This supports findings by Sanchez-Azofeifa et al. (2009), who found that results of discriminability of lianas from trees differed between tropical dry forests and tropical rain forests. Further studies using similar spectral analyses across various ecosystems and species compositions would help answer such a question. Other studies have also examined the importance of the near-infrared beyond $1025 \mathrm{~nm}$ and the shortwave-infrared region, which are useful for estimation of structural elements and thus discrimination.

\subsection{Conclusion}

I was able to discriminate exotic invasive species using ground-level hyperspectral remote sensing data in the visible and near-infrared regions, although Galium verum was not easily discriminable due to large amounts of soil noise, a function of the species' canopy structure. Additionally, Celastrus orbiculatus and Rhamnus davurica were often misclassified as each other due to their physical overlap in the field. Although I attempted to collect spectra with minimal influence from other species, such contamination by the other species

hindered discriminability between these two species. Across species, the regions most influ- 
ential to discrimination were 350-399, 500-549, 700-749, and 900-949 nm; those detrimental to discrimination were 550-599 and 650-699 $\mathrm{nm}$, due to greater intraspecific than interspecific variability of reflectance values in these regions. However, the regions that helped and hindered discriminability differed by species. Some of the regions most important to discriminating the species in this study were different from those found to be most important in other studies; this may be due to differences in ecosystems and thus species compositions. Further study of multiple ecosystems and species compositions using the same spectral analyses could help determine whether this is so. 


\subsection{Appendix 1: Species Phylogenies}

Species differences among many of these features depend on phylogenetic differences. To study the phylogenetic relationships among these species, I refer to phylogenies constructed by the Tree of Life Web Project (2002), which has compiled results from multiple phylogenetic analyses conducted by 540 scientists into the most plausible tree. The exotic invasive species in this study are all Core Eudicots, and separate into Rosids and Asterids. Rosids in turn split into Fabidae and Malvidae. Within Fabidae, Rhamnus davurica is categorized in the Rosales and Celastrus orbiculatus is in the Celastrales. Ailanthus altissima is in the Sapindales within Malvidae. Galium verum, Carduus acanthoides, and Cirsium arvense are in the Euasterids within the Asterids, which in turn are separated into Euasterids I (lamiids) and Euasterids II (campanulids). Galium verum is in the Gentianales within Euasterids I. The rest are in Euasterids II, and Carduus acanthoides and Cirsium arvense in the Asterales. Carduus acanthoides and Cirsium arvense are very closely related, branching together within the Asterales all the way out to Carduinae, where they finally separate out to Carduus and Cirsium. Their relationship to each other within the Carduinae is not wholly understood. 


\subsection{Appendix 2: Species Descriptions}

\subsubsection{Rhamnus davurica}

Rhamnus davurica (Dahurian buckthorn) is an open dioecious shrub-tree with an average height of $2.5 \mathrm{~m}$, but able to grow up to $9 \mathrm{~m}$; leaves are 7 to $10 \mathrm{~cm}$ long and $2-3 \mathrm{~cm}$ wide (Zouhar, 2011). Rhamnus flowers are unisexual and are 6 to $10 \mathrm{~mm}$ long and 5 to 10 $\mathrm{mm}$ in diameter. They grow in axillary clusters and grow on short pedicels (Zouhar, 2011). Fruits are drupes, 5 to $8 \mathrm{~mm}$ in diameter; seeds are 5 to $6 \mathrm{~mm}$ long and 3.6 to $3.7 \mathrm{~mm}$ wide (Zouhar, 2011). Seeds are dispersed by birds aided by the laxative effect of the fruits (Zouhar, 2011). In the Northern Great Plains, they flower in June and fruit in September (Zouhar, 2011), which correspond to dates in the Blandy Experimental Farm (BEF) from personal observation. The plant also has the ability to sprout from cut or damaged stems (Zouhar, 2011).

\subsubsection{Ailanthus altissima}

In China, Ailanthus altissima (tree of heaven) is positively correlated with agricultural use, and in the U.S. is associated with medium forest cover and precipitation (Albright et al., 2010). Its ecological niche in the U.S. may be expanding due to reduced competition and increased strength of allelopathic compounds and new genotypes (Albright et al., 2010). This species reproduces via root sprouts or numerous wind-dispersed seeds. A. altissima grows in the mountains, piedmont, and coastal regions, in full and partial sun, and in mesic soil (DCR, 2014). 


\subsubsection{Cirsium arvense}

The niche of Cirsium arvense (Canada thistle) is restricted by low winter and high summer temperatures and the necessity for a long flowering day of 14 to 16 hours (Tiley, 2010). It is an herbaceous perennial (Tiley, 2010) that invades new areas via seeds established on bare or disturbed ground (Tiley, 2010) and has an extensive, widely-dispersing, and deep root system (Tiley, 2010). It invades areas where forest over-story is removed and soil is disturbed, including clear-cut areas, forest openings, and wet and wet-mesic grasslands (Zouhar, 2001). Adventitious buds develop into roots along the horizontal roots, the development triggered by damage or decay of shoots above (Tiley, 2010). The root system is deep, down to 2 to $6.75 \mathrm{~m}$, and widespread, with a slim taproot (Zouhar, 2001). New plants are able to grow from root fragments as small as $6 \mathrm{~mm}$ (Zouhar, 2001). The species is imperfectly dioecious, in that male plants are self-fertile hermaphrodites or subhermaphrodites (Zouhar, 2001). The combination of sexual and vegetative reproduction contributes to its success by maintaining genetic diversity (Tiley, 2010). Much energy is allocated to vegetative reproduction, with which it forms dense patches (Zouhar, 2001). Shoots are slim and can be 0.3 to $2 \mathrm{~m}$ tall (Zouhar, 2001). Leaves are 3 to $18 \mathrm{~cm}$ long, and 0.5 to $6 \mathrm{~cm}$ wide (Zouhar, 2001). Flowers are 1 to $2 \mathrm{~cm}$ in diameter and grow in clusters. Seeds are 2.4 to $5 \mathrm{~mm}$ long and $1 \mathrm{~mm}$ wide, water- or wind-dispersed over long distances with the aid of the pappus (Zouhar, 2001). C. arvense begins to grow in spring (Tiley, 2010). Emergence in late March

to early April is followed by rosette expansion, which is followed in May and June by rapid shoot growth with the increase in day length (Tiley, 2010; Zouhar, 2001). This shoot growth rate is optimized during the last two weeks of June. Inflorescences are seen in June and July, with pappus emergence in late July to August. Senescence and withering of the stem begins in late September (Tiley, 2010). C. arvense is insect pollinated, mostly by honeybees (Zouhar, 2001), but seed production and germination are highly variable (Zouhar, 2001). Seed-release follows 2 to 3 weeks after pollination, and germination can take place days after 
flower-opening, or more commonly the following spring (Zouhar, 2001). Germination is best at warm soil temperatures, although there is a wide range of tolerance for soil moisture (Zouhar, 2001). C. arvense is found in mountain, piedmont, and coastal regions, in full sun and mesic soil (DCR, 2014). It thrives in environments with temperature between 0 and 32 ${ }^{\circ} \mathrm{C}, 15$ hour days, 400 to $750 \mathrm{~mm}$ of annual precipitation, and a shallow slope of 9 to $30 \%$ (Zouhar, 2001).

\subsubsection{Carduus acanthoides}

Carduus acanthoides (spiny plumeless thistle) is a winter annual or biennial (Kok, 2001) that is most commonly found in pastures and disturbed sites (Skarpaas and Shea, 2007). It reproduces once, and colonizes by seed (Skarpaas and Shea, 2007). Achene development takes place from late spring to the end of summer (Feldman, 1997), and most of this wind-dispersal takes place July to August with approximately 2 meter average dispersal (Skarpaas and Shea, 2007). The seeds remain dormant in the seed bank until high summer soil temperatures are followed by low winter temperatures, and then germination begins (Kruk and Benech-Arnold, 2000). The majority of seedlings emerge within one year of sowing, so that the population must be maintained by continuously producing propagules (Feldman, 1997).

\subsubsection{Galium verum}

Galium verum (yellow bedstraw) is a dominating, densely growing $\mathrm{C}_{3}$ forb originating in Europe, but now naturalized in the U.S. and Canada (Heckman, 2005). It grows in dry or well-drained places such as grasslands or dunes, but seed germination is limited in dry soil (Evans and Etherington, 1990). It is known to tolerate low $\mathrm{pH}$ and high calcium levels in limestone soils (Steele, 1955) and low nitrogen conditions (Heckman, 2005). It was observed at the BEF in the 1920s, and is now found throughout the Shenandoah Valley (Heckman, 
2005). When exposed to nitrogen loading, G. verum decreased in biomass because of light competition with other graminoids, suggesting that it is a poor competitor for light (van den Berg et al., 2005).

\subsubsection{Celastrus orbiculatus}

Celastrus orbiculatus (oriental bittersweet) can easily hybridize Celastrus scandens (American bittersweet) in the lab and in the field, and hybrids are very difficult to identify as such (Fryer, 2011). It can grow in mesic, mixed-hardwood or coniferous forests, woodlands and shrublands, old fields, and coastal systems (Fryer, 2011). In the southeast, it has been found in old-field successional sites such as the edges of late-successional stages of oak-hickory forests, and mixed-hardwood forests (Fryer, 2011). At the Boston Harbor Islands National Park in Massachusetts, $C$. orbiculatus was abundant on the nonnative shrub thickets consisting of Berberis thunbergii (Japanese barberry), Rosa multiflora (multiflora rose), Lonicera morrowii (Morrows honeysuckle), and Frangula alnus (glossy buckthorn) (Fryer, 2011); similar nonnative shrubs exist at the BEF also covered by C. orbiculatus. Certain tree species like yellow poplar may be preferred over oak because germination is best with moist soil and thin litter depth (Fryer, 2011). C. orbiculatus can have stems 2.4 to $10.5 \mathrm{~mm}$ in diameter and deep spreading roots up to $2 \mathrm{~cm}$ in diameter (Fryer, 2011). It spreads by sprawling in open areas and climbing by twining around trees and lianas in closed areas (Fryer, 2011). In the southeast U.S., plants flower mostly in May and go through September, and seeds are dispersed in November through January. One plant can produce 370 fruits/year with each capsule having 3 valves, each with one or two seeds dispersed by small mammals and birds; vegetative reproduction is also possible via sprouting from roots (Fryer, 2011). Seeds can survive in various light intensities; they can also tolerate various soil textures but preferring loamy, sandy, or silty soils (Fryer, 2011). C. orbiculatus is most commonly found on soils with high levels of calcium, potassium, and magnesium (Fryer, 2011). 


\subsection{Appendix 3: Persistence of Invasive Plant Species}

The exotic invasive plant species in this paper have several traits that allow them to persist in and take over a region. As examples, Carduus acanthoides (spiny plumeless thistle) has numerous, though not persistent, seeds (Feldman, 1997), is tolerant to repeated disturbances (Zhang et al., 2011), and is opportunistic in colonizing gaps (Allen and Shea, 2006). Rhamnus cathartica (Common buckthorn) has high shade tolerance, high growth and photosynthesis rates, wide range of tolerance of moisture and drought, unique leaf phenology, high fecundity, bird-dispersal of fruit, high germination rate, high seedling success in disturbed sites, and secondary metabolites, especially emodin, which may protect the plant from herbivores, pathogens, and high light levels; emodin may have allelopathic effects on natives nearby, and affect soil microbes and unripe fruit consumption/ digestion by birds (Knight et al., 2007). Celastrus orbiculatus (Oriental bittersweet) sprawls over or twines around and into the canopy of surrounding vegetation and has low palatability (Fryer, 2011). It does not have a host preference (Ladwig and Meiners, 2010). It can also persist at low photosynthetic rates in the shade and respond quickly to increases in light penetration to outgrow competition even in mature forests (Fryer, 2011), able to spread substantially within the canopy and decrease tree growth after gap-formation (Pavlovic and Leicht-Young, 2011). C. orbiculatus can outcompete $C$. scandens due to greater tolerance to various environmental conditions (e.g. shade), faster growth and reproduction rates, ability to increase photosynthetic rates with increases in light, the ability to perceive and grow toward nearby vegetation that it could then climb (Fryer, 2011), a shorter juvenile period, and greater seed viability (Pooler et al., 2002). In addition to changing species composition of plants, these invasive species can also be host to other types of organisms that could in turn affect other plants; Rhamnus is the primary overwintering host for soybean aphids, Aphis gossypii and A. glycines (Heimpel et al., 2010; Kim et al., 2010), and C. orbiculatus is host for the bacterim Xylella fastidiosa, which in turn infects crop plants (Fryer, 2011). 


\section{Chapter 4: Correlating species and spectral diversi- ties using hyperspectral remote sensing in early suc- cessional fields}

\subsection{Abstract}

Conserving biodiversity can help preserve ecosystem properties and functions, and advances in remote sensing technology can help estimate biodiversity at large spatial extents. To assess whether I could use remote sensing to estimate species diversity, I examined the correlations between species diversity and spectral diversity in early successional fields in Virginia, and evaluated whether these correlations differed among spectral regions throughout the visible and near-infrared wavelength regions and across spectral noise correction techniques. I established plant community plots in secondary successional fields at the Blandy Experimental Farm in north-central Virginia and collected vegetation surveys and groundlevel hyperspectral data from 350 to $1025 \mathrm{~nm}$ wavelengths. I found positive correlations in the visible region using band depth, positive correlations in the near-infrared region using first derivatives, and weak to no correlations in the red edge region using either noise correction technique. To investigate the role of pigment variability in these correlations, I estimated chlorophyll, carotenoid, and anthocyanin concentrations of five dominant species in the plots using vegetation indices. Although interspecific variability in pigment levels exceeded intraspecific variability, chlorophyll was more varied within species than carotenoids and anthocyanins, contributing to the lack of correlation between species diversity and spectral diversity in the red edge region. Interspecific differences in pigment levels, however, make it possible to differentiate these species remotely, contributing to the species-spectral diversity correlations. Thus, remote sensing can be used to estimate species diversity, but the correlation depends on the spectral region examined and the noise correction technique 
used.

\subsection{Introduction}

\subsubsection{Biodiversity and Ecosystem Processes}

Biodiversity can have numerous positive effects on the function of ecosystems. For example, it can affect ecosystem productivity by influencing resource-use and promoting resource-use efficiency (Cardinale et al., 2007; Gustafsson and Bostrom, 2011; Hooper and Vitousek, 1998; Symstad and Jonas, 2011; Wilsey and Potvin, 2000). It can also positively influence community stability by reducing fluctuations in production via compensatory effects (Gustafsson and Bostrom, 2011; Isbell et al., 2009; Symstad and Jonas, 2011; Yachi and Loreau, 1999). In addition, biodiversity can affect infection resistance through increases in heterogeneity and thus dilution of hosts (Haas et al., 2011), and invasion resistance by again affecting resource-use as well as by competitive effects (Cardinale et al., 2007; Gustafsson and Bostrom, 2011; Hooper and Vitousek, 1998; Scherber et al., 2010). Thus, it is potentially important to conserve biodiversity as a means for conserving ecosystem function.

We can use field methods to estimate biodiversity in great detail at small spatial extents (Lengyel et al., 2008). However, these methods can be costly and time-intensive, and difficult to scale up to larger spatial extents. Remote sensing can be used to collect information at vastly larger spatial extents more quickly and more cheaply per unit area than field samples (Lengyel et al., 2008). Remote sensing can also be combined with field

data to more efficiently assess spatial and temporal distributions of biodiversity (Bradley and Mustard, 2006; Lengyel et al., 2008; Schmidt and Skidmore, 2001; Wilfong et al., 2009; Zhang et al., 2006) and to incorporate information at different spatial scales (Lengyel et al., 2008). Remote sensing has already been used to measure various surrogates to estimate species diversity, such as the normalized difference vegetation index, biomass, land cover, 
and heterogeneity in biomass and land cover (Foody and Cutler, 2003; Turner et al., 2003). Moreover, the direct measurement of species diversity through species-level characteristics is becoming possible with advances in satellite technology, specifically the increases in spatial and spectral resolutions (Turner et al., 2003). Assessing biodiversity using remote sensing affords us the opportunity to potentially estimate biodiversity at coarser spatial scales and larger spatial extents.

\subsubsection{Remote Sensing of Diversity}

Spectral reflectance of vegetation canopies in the visible range is predominantly influenced by pigment content, reflectance in the near-infrared region is mostly influenced by leaf structure and leaf surface characteristics, and that in the shortwave-infrared region is mainly influenced by structural compounds and water content (Mahlein, 2011; Xiao, Y. et al., 2014). Since these characteristics differ by species, we may likely be able to distinguish species spectrally; Asner (1998) suggests that species should be distinguishable remotely due to differences in biochemical and structural properties, and species differences have in fact been detected remotely (Burkholder, 2010; Narumalani et al., 2009; Pinard and Bannari, 2003; Rud et al., 2006; Schmidt and Skidmore, 2001; Yingying et al., 2011).

It is also possible that species diversity can be estimated using remotely sensed data, by using the ranges, standard deviations, or coefficients of variation of reflectance values, spectrum derivative values, or band ratios, along with regression models (Asner and Martin, 2008; Rocchini et al., 2010). Several researchers have been able to estimate species diversity and chemical diversity using remotely sensed data (Asner and Martin, 2011, 2008; Asner et al., 2012; Rocchini et al., 2010). Carlson et al. (2007) found a correlation between biochemical diversity and spectral diversity at 530, 720, 1201, and $1523 \mathrm{~nm}$ wavelengths in lowland tropical forest ecosystems in Hawaii. Asner et al. (2009) found a positive relationship between chemical diversity (estimated spectrally) and taxonomic diversity in Australian 
tropical forest ecosystems. Feret and Asner (2014) estimated species alpha and beta diversity using spectral diversity in lowland tropical forest ecosystems in the Amazon. Rocchini et al. (2010) suggest that taking into account landscape heterogeneity while measuring spectral heterogeneity leads to more accurate remotely sensed estimations of species diversity. In tropical forests, species diversity was also correlated with canopy nutrient content variability (estimated spectrally) and thus potentially diversity in ecosystem function (Asner and Martin, 2009).

\subsubsection{Variability in Pigment Content}

Differences in hyperspectral reflectances in the visible region are influenced by species differences in pigment content. There are three main groups of pigments: chlorophylls (eg. chl a and chl b), carotenoids (carotenes: a and b, xanthophylls: lutein, zeazanthin, violoxanthin, antherazanthin, and neoxanthin), and phycobilins (Delvin and Barker, 1971; Gitelson et al., 2002), and these pigments have different structures and characteristics as well as functions (Pavia et al., 1999). Even though chlorophylls a and b are similar in structure, they have different physical and chemical properties related to photosynthesis (Delvin and Barker, 1971). Carotenoids funnel light energy to the chlorophyll a reaction center and guard against photoinhibition (Delvin and Barker, 1971; Liu et al., 2009; Rosevear et al., 2001), and are structurally important in pigment-binding proteins and membranes (Rosevear et al., 2001). Anthocyanins, a subgroup within a fourth category of pigments called flavonoids, are also photoprotective (Sims and Gamon, 2002), and additionally can alleviate stress from freezing, drought, leaf damage, and fungal pathogens (Blackburn, 2006; Sims and Gamon, 2002). Flavonoids and luteins also help with energy dissipation (Merzlyak et al., 2003; Rascher et al., 2007). In this study, I estimated the concentrations of carotenoids, anthocyanins, and chlorophylls, because they encompass the major groups of pigments in terrestrial plants, and the equations for estimating these three pigments are relatively well-

defined in the remote sensing literature (Gitelson et al., 2006; Merzlyak et al., 2003; Yu et al., 
Plant age affects pigment concentrations. Anthocyanin concentrations are greatest in very young and very old leaves (Sims and Gamon, 2002). Chlorophyll concentrations are greatest in middle-aged leaves (Liu et al., 2009). These changes in pigment absorptions with age can be observed spectrally, with a disappearance of the green peak, a decrease in absorption in the red trough, and a decrease in reflectance in the near-infrared plateau, as plants get older (Philpot, 2011). Environmental conditions and stresses can also influence pigment concentrations. Plant growth conditions, such as light regimes, can greatly affect pigment levels (Rosevear et al., 2001); for example, changes in illumination can affect chl a: b ratios (Gamon and Berry, 2012). Higher light conditions are associated with greater chlorophyll, carotenoid, and xanthophyll content (Rosevear et al., 2001). Drought stress can lead to greater xanthophyll activity, increases in carotenoid concentrations, and decreases in chlorophyll concentrations (Genc et al., 2013; Naumann et al., 2010; Rascher et al., 2007; Yang et al., 2010). Pigment concentrations may also differ by successional stage; Alvarez-Anorve et al. (2012) suggest that early stages of succession have lower photochemical reflectance index (PRI) values, because early successional plants invest more in photoprotective xanthophylls and carotenes than in chlorophyll.

\subsubsection{Remote Sensing of Pigments}

Although pigment concentrations have traditionally been estimated using wet lab techniques, these procedures are labor- and time-intensive, cannot be used for temporal analyses due to their destructive nature, and need large numbers of samples for accurate representation of spatial variability (Blackburn, 2006). In addition, these techniques are susceptible to inaccurate measurements due to incomplete extractions, light-absorbing impurities, and the instability of the pigments (Merzlyak et al., 2003). In contrast, remote sensing, especially hyperspectral remote sensing, can be used to detect pigments quickly and 
non-destructively (Asner et al., 2007; Blackburn, 2006; Gamon and Berry, 2012; Gitelson et al., 2006; Merzlyak et al., 2003). When using spectral reflectances to estimate pigment levels, we need to use multiple wavelengths (Blackburn, 2006), because absorption bands can be affected by more than one chemical constituent, and one chemical constituent can influence a broad spectral region (Kokaly and Clark, 1999). Many vegetation indices using multiple bands are available to estimate pigment levels (see Yu et al. (2014) for examples). It is important to understand which absorption features are being examined in certain bands when choosing an appropriate index.

When estimating chlorophyll content, bands near $550 \mathrm{~nm}$ or $705 \mathrm{~nm}$ can be used, as both have strong chlorophyll absorptions and are sensitive to chlorophyll levels. However, if leaves have anthocyanins, the region near $705 \mathrm{~nm}$ is better. Subtracting the inverse of the reflectance at $705 \mathrm{~nm}$ from that at $770 \mathrm{~nm}$ makes the index directly proportional to chlorophyll content. Reflectance at $770 \mathrm{~nm}$ is also used to calibrate the chlorophyll index, since it is not a function of chlorophyll absorption. Therefore, these three regions were used to calculate chlorophyll content.

For carotenoid content, it is important to select wavelengths that do not have interference from chlorophyll absorptions, anthocyanin absorptions, and carotenoid saturation. The region around $515 \mathrm{~nm}$ is most sensitive to carotenoid absorption, but is also affected by chlorophyll absorption. To remove the effects of chlorophyll absorption, the region around $565 \mathrm{~nm}$ can be used. Reflectance around $770 \mathrm{~nm}$ helps calibrate with a region that does not have absorption from carotenoids or chlorophylls.

The band region around $550 \mathrm{~nm}$ has strong anthocyanin absorption features. However, there are also chlorophyll absorption features; the effects of chlorophyll can be removed using reflectance around $700 \mathrm{~nm}$. Again, reflectance around $770 \mathrm{~nm}$ can be used for calibration, since it is not affected by anthocyanin or chlorophyll absorption. 


\subsubsection{Research Objectives}

To better inform biodiversity conservation efforts, ecological processes need to be studied at large spatial extents as well as small spatial extents. Remote sensing has the potential to monitor such processes at larger spatial extents more efficiently than field surveys alone. Certain spectral features might be more instrumental in estimating biodiversity than others. The study of interspecific and intraspecific variability in these features may help elucidate the spectral regions most correlated with biodiversity. Although the need for using satellite imagery to directly monitor diversity is realized, there are few in-depth studies on factors that influence the ability to use remote sensing to estimate biodiversity. Moreover, few such studies have been conducted in early successional communities, where biodiversity and species composition may be important for determining successional trajectory.

I wish to study correlations between species diversity and spectral diversity in a temperate ridge and valley ecosystem in north-central Virginia. The Blandy Experimental Farm, our study site in Boyce, Virginia, is inhabited by several invasive species that affect ecosystem diversity. These species can alter their surroundings, inhibiting the growth of other species and promoting the growth of their own both mechanically and chemically. In this study, I asked 1) whether species diversity was correlated with spectral diversity in secondary successional ecosystems in this region, 2) how these correlations differ by spectral region, and 3) whether intraspecific and interspecific variabilities in pigments influence these correlations. 


\subsection{Methods}

\subsubsection{Study Site}

I collected data at the Blandy Experimental Farm (BEF) (Figure 10), which is located in the Shenandoah Valley in Clarke County Virginia at $39^{\circ} 09^{\prime} \mathrm{N}, 78^{\circ} 06^{\prime} \mathrm{W}$ (Wang et al., 2007). This 300 ha biological field station has been owned by the University of Virginia (UVA) since 1926 and operated by the Department of Environmental Sciences at UVA since 1983 (Bowers, 1997). The field station includes 120 ha of pasture and cropland, 40 ha of woodland, the 60 ha Virginia State Arboretum, and 80 ha of old fields in early, middle, and late succession (Bowers, 1997). Each of two successional series (southwest and northeast) is a set of former agricultural fields and contains an early, mid, and late successional field, abandoned in 2001 (Early 1), 2003 (Early 2), 1986 (Mid 1), 1987 (Mid 2), before 1910 (Late 1) and before 1920 (Late 2) (Wang et al., 2010). Spectral and species compositional data were collected from the two early successional fields and two additional field sites: Lake Arnold and a site at a field boundary near the northeast succesional series referred to hereafter as the northeast boundary. Soils are deep colluvial and alluvial sediment from karst limestone, shale, and siltstone; study sites have well-drained silt loam soil, of the soil Order Ultisol (Bowers, 1997). The average elevation of the BEF is $190 \mathrm{~m}$, and slopes are less than $10 \%$ (Bowers, 1997). Mean annual temperature and precipitation are $11.8{ }^{\circ} \mathrm{C}$ and $940 \mathrm{~mm}$ respectively; the average growing season is 157 days with average annual primary productivity of $1.0 \mathrm{~kg}$ $\mathrm{m}^{-2}$ in the successional fields including all stages (Bowers, 1997; Wang et al., 2010). 


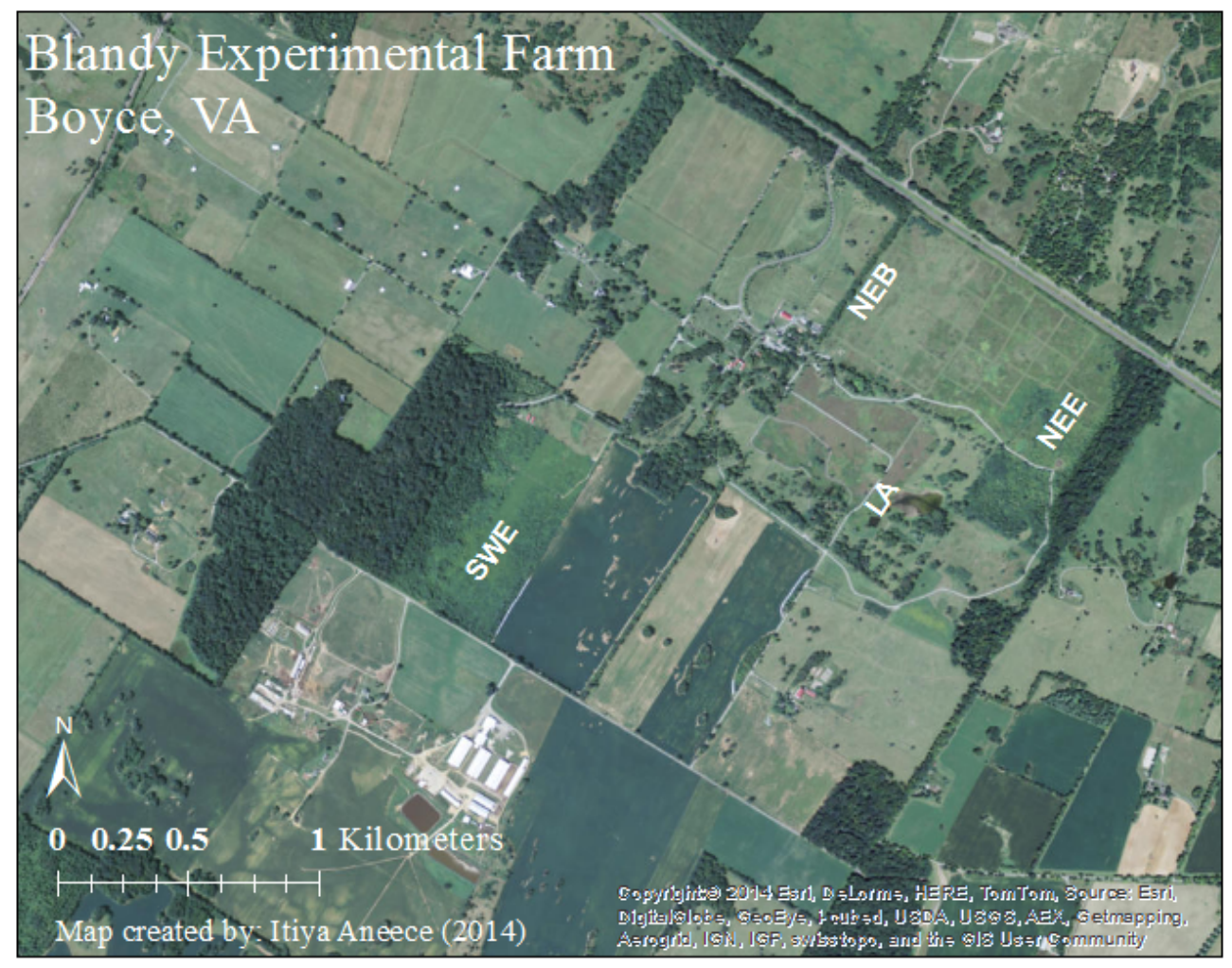

Figure 10: Blandy Experimental Farm with study sites Southwest Early (SWE), Northeast Early (NEE), Northeast boundary (NEB), and Lake Arnold (LA).

\subsubsection{Field methods}

In the summer of 2014, I established three randomly placed $5 \mathrm{~m} * 5 \mathrm{~m}$ communitylevel plots at each early successional site, Lake Arnold, and the northeast boundary (Figure 10). From early June to late July, I collected community-level spectral data from 350 to 1025 nm using a PANalytical ASD Inc. FieldSpec ${ }^{\circledR} 3$ with a $25^{\circ}$ field of view. Spectra were collected from approximately $2.5 \mathrm{~m}$ height so that the footprint was approximately $1.15 \mathrm{~m}$ in diameter. I collected spectra on cloud-free days between $10 \mathrm{am}$ and $2 \mathrm{pm}$ in a systematic manner to maximize coverage without trampling vegetation, and capture vegetation in each corner of the plot, in the center, and the middle of each edge for a total of 12 spectral footprints per plot (Figure 11). Approximately three spectral measurements were collected at each footprint (with each measurement being the average calculated by the spectroradiome- 
ter of ten spectra) and averaged for smoothing of the spectral profile. Thus, I collected approximately 36 spectral measurements $\left(12^{*} 3\right)$ per plot. Additionally, I conducted vegetation surveys on the $5 \mathrm{~m} * 5 \mathrm{~m}$ grid at $0.5 \mathrm{~m}$ intervals, recording species at the ground level, sub-canopy, and canopy to assess the species diversity and species composition of the spectral footprints.

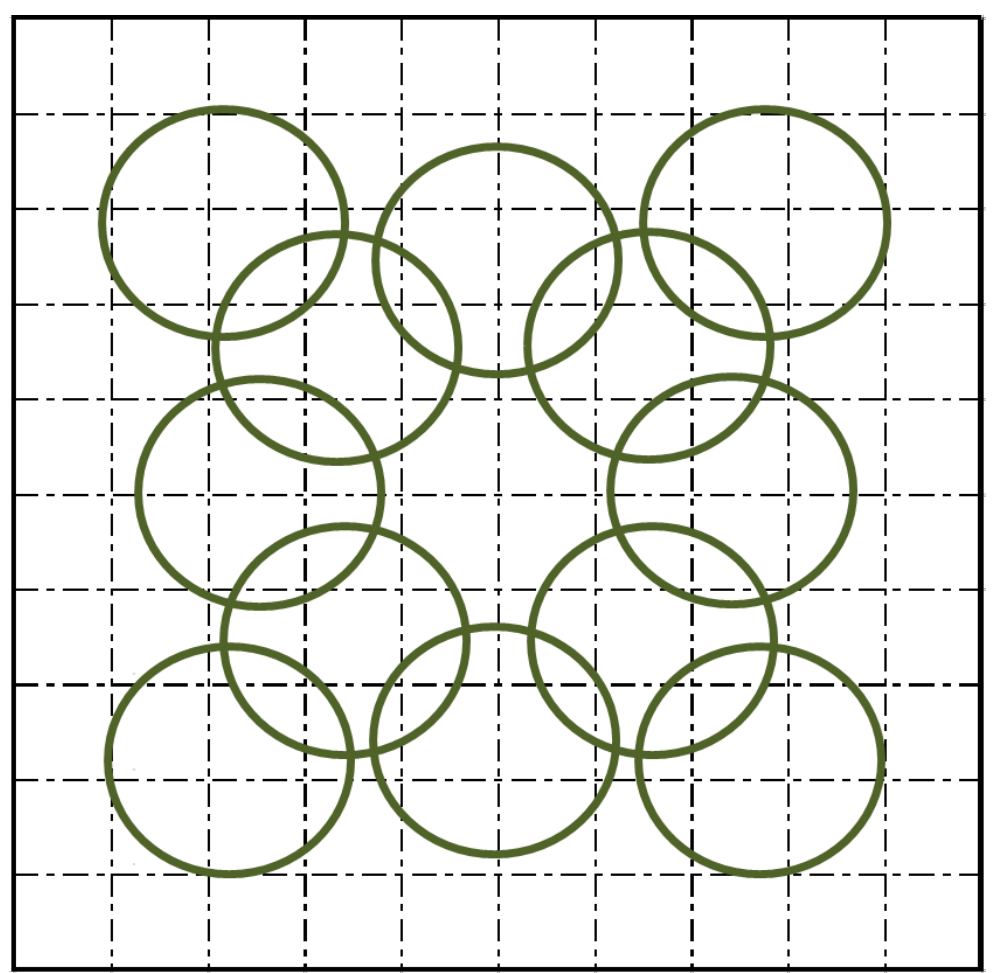

Figure 11: Layout of $5 \mathrm{~m} * 5 \mathrm{~m}$ community plots. Circles represent spectral footprints taken from outside the plots so as not to trample vegetation. Vegetation surveys were conducted at each $0.5 \mathrm{~m}$ interval within a plot for a total of 121 points at the ground, understory, and canopy level.

In the summer of 2015, I collected leaf-level spectra for pigment analysis from five of the dominant species in the community plots: Achillea millefolium (common yarrow), Dactylis glomerata (orchard grass), Festuca rubra (red fescue), Solidago altissima (tall goldenrod), and Symphoricarpos orbiculatus (coralberry). All of these species have the potential to become invasive, especially in disturbed areas. Ten individual plants of each species were examined, except for F. rubra, of which five individual plants were sampled due to time 
and weather constraints. Three leaf samples were collected from each individual. I obtained leaf-level spectra from detached leaves, which I wrapped in wet paper towels, put into zippered plastic bags, and stored on ice until measurements were taken within 20 minutes of detachment.

\subsubsection{Species descriptions}

Achillea millefolium is a perennial herb with one to ten stems $20-100 \mathrm{~cm}$ tall, coming from a fibrous rhizome (Cummins, 2014; Hurteau, 2001). Its leaves are lanceolate, bipinnately dissected, 0.5-3 cm wide, 3-15 cm long, and can be pubescent (Hurteau, 2001). The inflorescence is a corymb with 10-20 whitish to yellowish-white ray flowers (Hurteau, 2001). It can grow in disturbed, well-drained soils in grasslands and open forests, and is drought tolerent; it persists from May to June (Hurteau, 2001). A. millefolium is not tolerant of dense shade, and has a palatability of fair to poor (Aleksoff, 1999).

Dactylis glomerata is a cool season perennial $\mathrm{C}_{3}$ bunchgrass, and is one of the earliest grasses to emerge in spring; it can grow 50-120 cm tall (Barbehenn and Bernays, 1992; Bush et al., 2012). Its leaves are 2-8 $\mathrm{mm}$ wide and 20-30 $\mathrm{cm}$ long, and its panicles are 5-20 $\mathrm{cm}$ long with laterally compressed spikelets of 2-5 flowers in dense one-sided clusters (Bush et al., 2012). D. glomerata does not reproduce vegetatively, but still has the potential to become invasive (Bush et al., 2012). It grows well in moderate to well-drained slightly basic to acidic soils ( $\mathrm{pH}$ 5.8-7.5), that can vary in texture from clay to gravelly loam, and in depth from shallow to deep; however, it cannot tolerate salinity or high soil moisture (Bush et al., 2012). D. glomerata can tolerate cold winters when snow is present for insulation, high summer temperatures and humidity, as well as shade. It has a high palatability (Sullivan, 1992).

Festuca rubra is a $\mathrm{C}_{3}$ perennial cool season grass that also starts growing early in the spring with a high growth rate in late summer (Barbehenn and Bernays, 1992; St. John et al., 2012). Its leaves are mostly basal, 5-15 cm long and 1-2 mm wide; the inflorescence is 
a narrow panicle 3-20 cm long with 3-10-flowered spikelets (St. John et al., 2012). F. rubra grows rhizomatously, and can become invasive especially in disturbed areas (St. John et al., 2012). It is shade and salt tolerant, and grows in soils of varying texture from sandy to gravelly, from moist meadows to disturbed areas; it can grow in soils that have low fertility and varying $\mathrm{pH}$, from acidic to slightly alkaline (pH 4.5-7.5) (St. John et al., 2012). F. rubra has fair palatability (St. John et al., 2012).

Solidago altissima is a perennial forb, 1-2 m tall (United, 2010). Its leaves are $15 \mathrm{~cm}$ long, $2 \mathrm{~cm}$ wide, linear-lanceolate in shape, pubescent on the underside, and scabrous on the upper surface of the leaf; its inflorescence is a terminal pyramidal panicle, $15 \mathrm{~cm}$ broad and $20 \mathrm{~cm}$ tall with yellow flowers, blooming from August to November (Tenaglia, 2007). S. altissima inhabits dry open spaces, fallow fields, prairies, rocky outcrops, open woods, thickets, wastelands, roadsides, and railroad corridors (Tenaglia, 2007; United, 2010). Within the fields at the BEF, this species forms extensive monocultural stands.

Symphoricarpos orbiculatus is a branching shrub, 0.66 to $1.33 \mathrm{~m}$ tall (Hilty, 2015). Its leaves are $5 \mathrm{~cm}$ long, $3 \mathrm{~cm}$ wide, oval-ovate in shape with an upper surface that is glabrous to slightly pubescent (Hilty, 2015). Flowers are greenish yellow and approximately $0.64 \mathrm{~cm}$ long; berries are reddish purple and approximately $0.64 \mathrm{~cm}$ long (Hilty, 2015). $S$. orbiculatus grows in partial sun, moist to dry soil, loamy to rocky in texture; it inhabits thin rocky woodlands, woodland openings and borders, disturbed areas, thickets, and limestone glades (Hilty, 2015). It is very palatable to deer (Hilty, 2015).

\subsubsection{Statistical analysis}

I used band depth instead of original reflectance values to reduce noise from the sensor, atmosphere, soil background, topographic variation, and differences in albedo (Crowley et al., 1989; Kokaly and Clark, 1999). To obtain band depth, a continuum hull was matched to the original spectral profile, and this continuum was removed to get normalized reflectance 
using ENVI (Versions 5.0 and Classic, Exelis Visual Information Solutions, Boulder, Colorado). I anchored the continuum hull to the near-infrared shoulder because preliminary data had suggested that much of the variability in that region was due to changes in atmospheric conditions and incoming radiation than to differences in vegetation characteristics. Therefore, anchoring the continuum hull at the shoulder minimized this variability and emphasized variability due to differences in vegetation characteristics. I then subtracted these continuum-removed reflectance values from one to get the band depth profile (Figure 12). I also assessed spectral diversity using first derivatives of the original reflectance profile to examine whether the correlation between species and spectral diversities depends on the noise correction technique used.

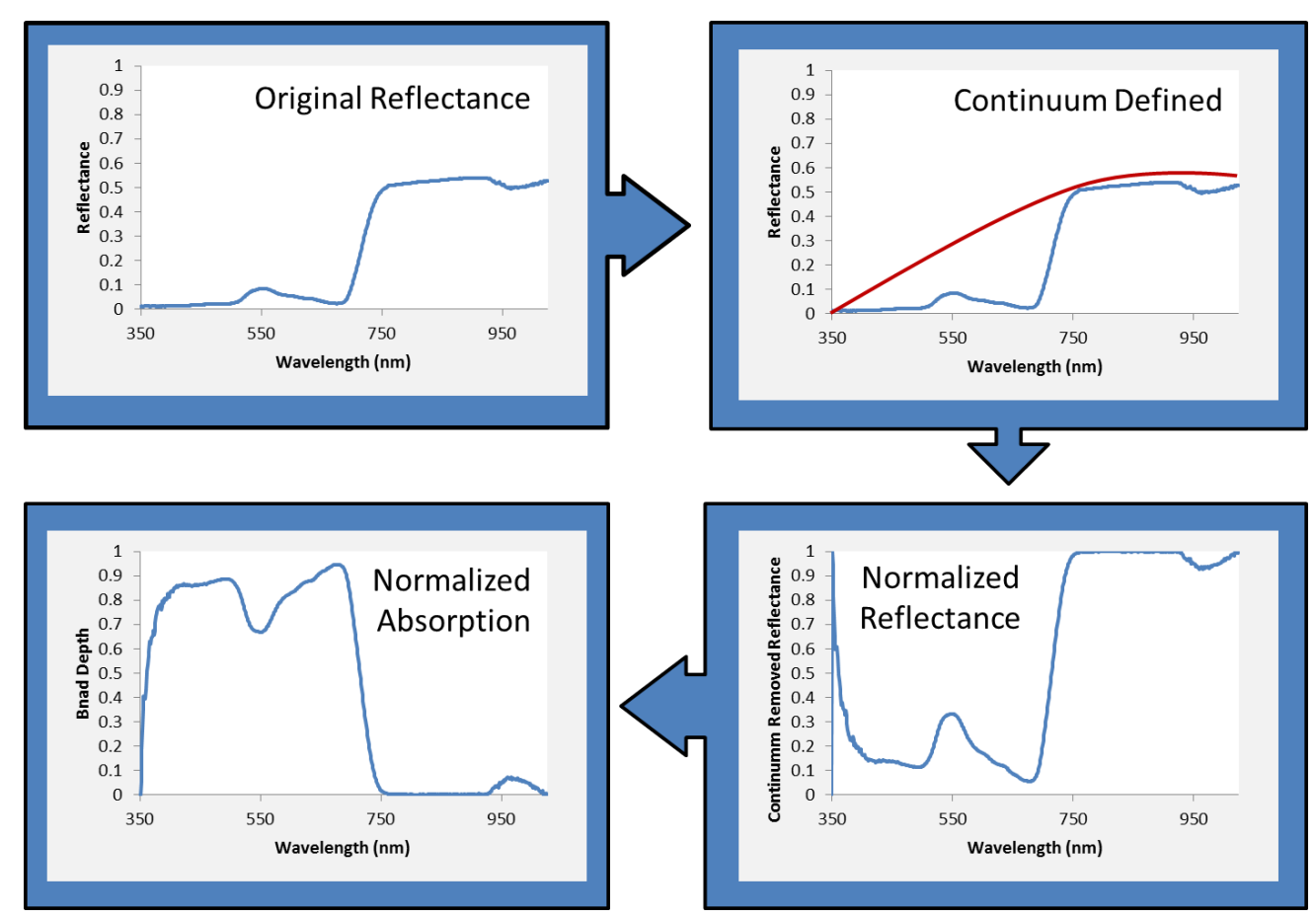

Figure 12: An illustration, using an average spectral profile from Dahurian buckthorn spectra, of calculating band depth (normalized absorption) from original reflectance using continuum removal. 


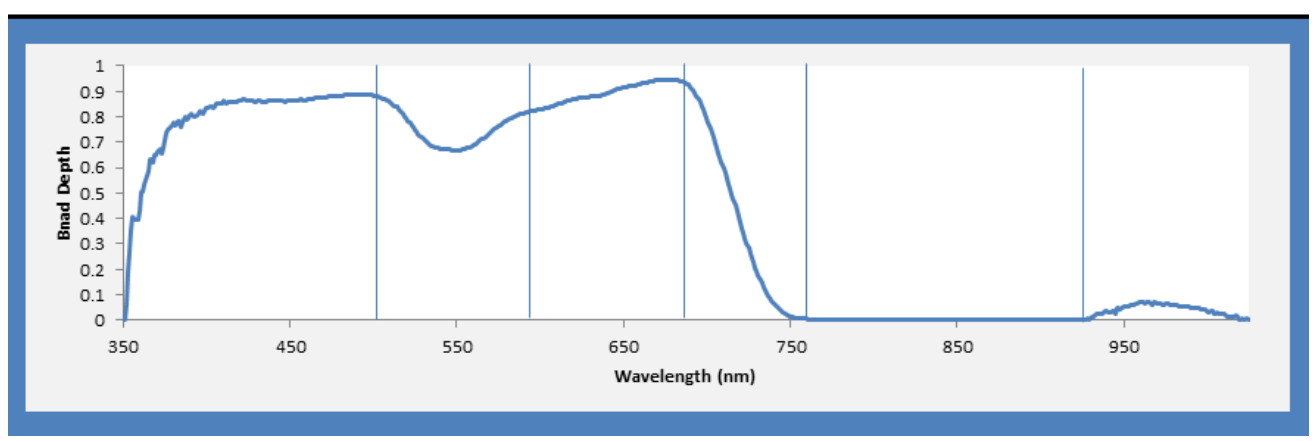

Figure 13: To quantify spectral diversity, band depth was divided into regions and areas under the curve calculated, and then standard deviations of the areas under the curve for respective plots were calculated.

To quantify spectral diversity, I used standard deviations of areas under the band depth profile curve and the first derivative profile curve for the following regions corresponding with key spectral features: 350-499 nm, 500-589 nm, 590-674 nm, 675-754 nm, 755-924 nm, and 925-1025 nm (Figure 13). I calculated species diversity using the Shannon Diversity Index (Equation 2). To make a more direct comparison with spectral diversity, only the sampling points that were within the spectral footprints were included in calculating species diversity. I conducted Pearson correlation analyses in SAS (Statistical analysis software, Version 9.4, SAS Institute Inc., Cary, North Carolina) to assess the relationship between species and spectral diversity using spectra and vegetation surveys from the summer of 2014 for the early successional fields, Lake Arnold, and the northeast boundary.

$$
H^{\prime}=\sum_{i=1}^{n} p_{i} * \ln \left(p_{i}\right)
$$

To assess whether the relationships between spectral diversity and species diversity may be influenced by the interspecific and intraspecific diversity of certain vegetation characteristics, I used the leaf-level spectra of five dominant species in the community plots to estimate pigment concentrations and assess interspecific and intraspecific diversity of chlorophyll (Equation 3), carotenoid (Equation 4), and anthocyanin (Equation 5) levels using 
equations by Gitelson et al. (2003), Gitelson et al. (2006), and Gitelson et al. (2001) respectively. Chlorophyll, carotenoid, and anthocyanin levels were assessed using an analysis of variance (ANOVA) in SAS to compare intraspecific and interspecific pigment variability among Achillea millefolium, Dactylis glomerata, Festuca rubra, Solidago altissima, and Symphoricarpos orbiculatus, using among and within mean square and the F value. Since parametric assumptions were not met, I used the non-parametric pairwise comparison Dwass, Steel, Critchlow-Fligner (DSCF) method to assess whether species were significantly different in terms of pigment estimates (SAS support, 2012).

$$
\begin{aligned}
& \text { Chlorophyll }=R_{770}\left(\left(R_{705}\right)^{-1}-\left(R_{770}\right)^{-1}\right) \\
& \text { Carotenoids }=R_{770}\left(\left(R_{515}\right)^{-1}-\left(R_{565}\right)^{-1}\right) \\
& \text { Anthocyanin }=R_{770}\left(\left(R_{550}\right)^{-1}-\left(R_{700}\right)^{-1}\right)
\end{aligned}
$$

\subsection{Results and Discussion}

In this paper, I wished to examine the ability to use remote sensing to estimate species diversity; specifically, I asked whether species diversity and spectral diversity were correlated in secondary successional fields in north-central Virginia in a ridge-and-valley ecosystem. There was a strong positive relationship between species diversity and spectral diversity using band depth in the summer of 2014 for the $350 \mathrm{~nm}$ to $499 \mathrm{~nm}$ wavelength region $\left(R^{2}=0.41, p=0.03\right)$, the $500 \mathrm{~nm}$ to $589 \mathrm{~nm}$ wavelength region $\left(\mathrm{R}^{2}=0.35, \mathrm{p}=0.04\right)$, and the $590 \mathrm{~nm}$ to $674 \mathrm{~nm}$ wavelength region $\left(\mathrm{R}^{2}=0.44, \mathrm{p}=0.02\right)$, and a marginally positive relationship in the $675 \mathrm{~nm}$ to $754 \mathrm{~nm}$ wavelength region $\left(\mathrm{R}^{2}=0.26, \mathrm{p}=0.09\right)$ (Figure 14). 
However, relationships between species diversity and spectral diversity were not strongly positive in the $755 \mathrm{~nm}$ to $924 \mathrm{~nm}$ wavelength region $\left(\mathrm{R}^{2}=0.01, \mathrm{p}=0.74\right)$ or in the $925 \mathrm{~nm}$ to $1025 \mathrm{~nm}$ wavelength region $\left(\mathrm{R}^{2}=0.17, \mathrm{p}=0.19\right)$. Using first derivatives instead of band depth, there was a strong positive correlation between spectral diversity and species diversity in the $350 \mathrm{~nm}$ to $499 \mathrm{~nm}$ wavelength region $\left(\mathrm{R}^{2}=0.41, \mathrm{p}=0.02\right)$ (Figure 15). There were no correlations in the $500 \mathrm{~nm}$ to $589 \mathrm{~nm}$ wavelength region $\left(\mathrm{R}^{2}=0.04, \mathrm{p}=0.54\right)$, the $590 \mathrm{~nm}$ to $674 \mathrm{~nm}$ wavelength region $\left(\mathrm{R}^{2}=0.0009, \mathrm{p}=0.92\right)$, and the $675 \mathrm{~nm}$ to $754 \mathrm{~nm}$ wavelength region $\left(\mathrm{R}^{2}=0.15, \mathrm{p}=0.21\right)$. There was a weak positive correlation in the $755 \mathrm{~nm}$ to $924 \mathrm{~nm}$ wavelength region $\left(\mathrm{R}^{2}=0.30, \mathrm{p}=0.06\right)$ and a strong positive correlation in the $925 \mathrm{~nm}$ to $1025 \mathrm{~nm}$ wavelength region $\left(\mathrm{R}^{2}=0.44, \mathrm{p}=0.02\right)$. Therefore, the method of noise correction and the spectral regions considered will influence the ability to estimate species diversity using spectral diversity. 


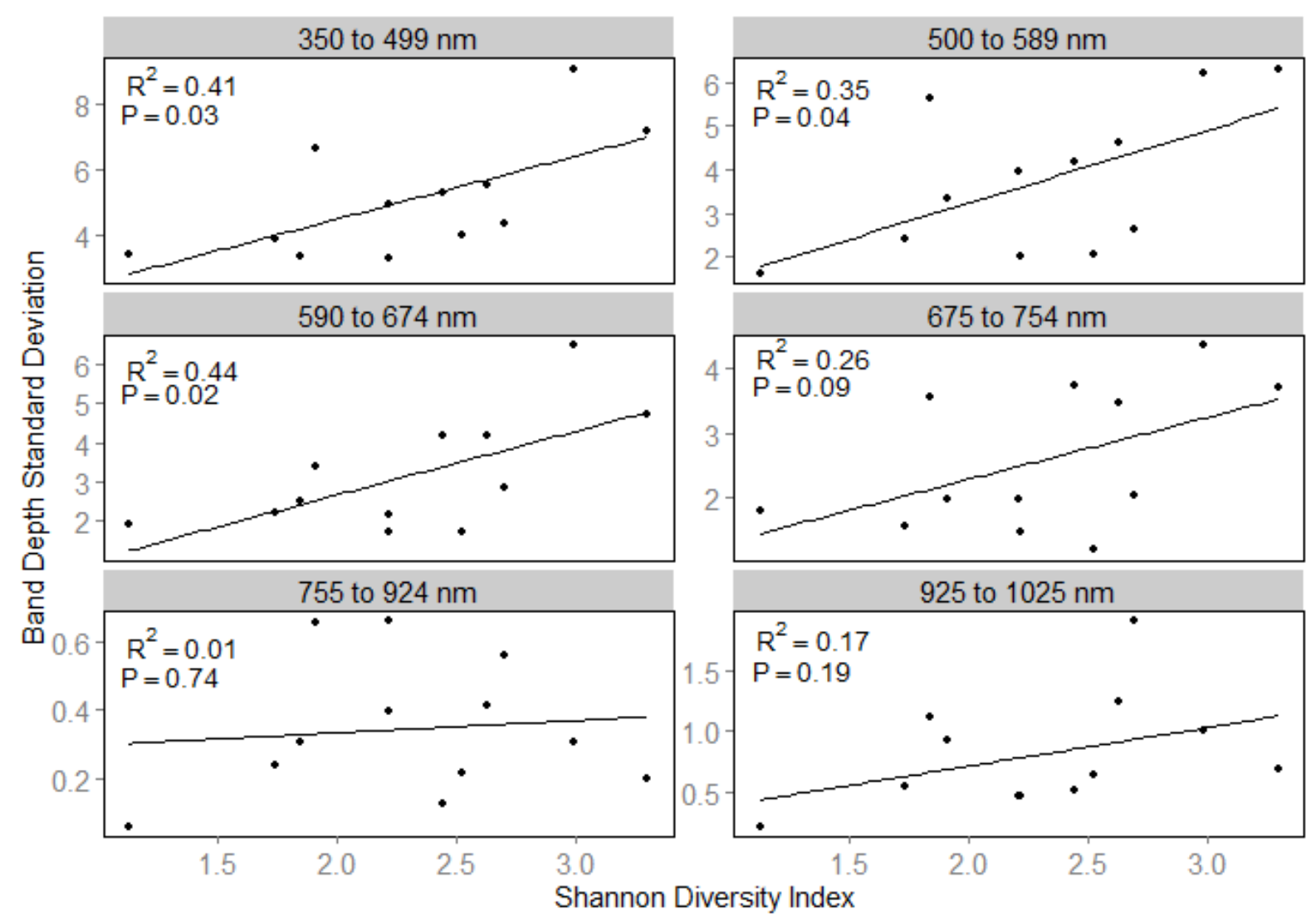

Figure 14: Correlations between species diversity and spectral diversity for six spectral regions using the area under the band depth profile. 


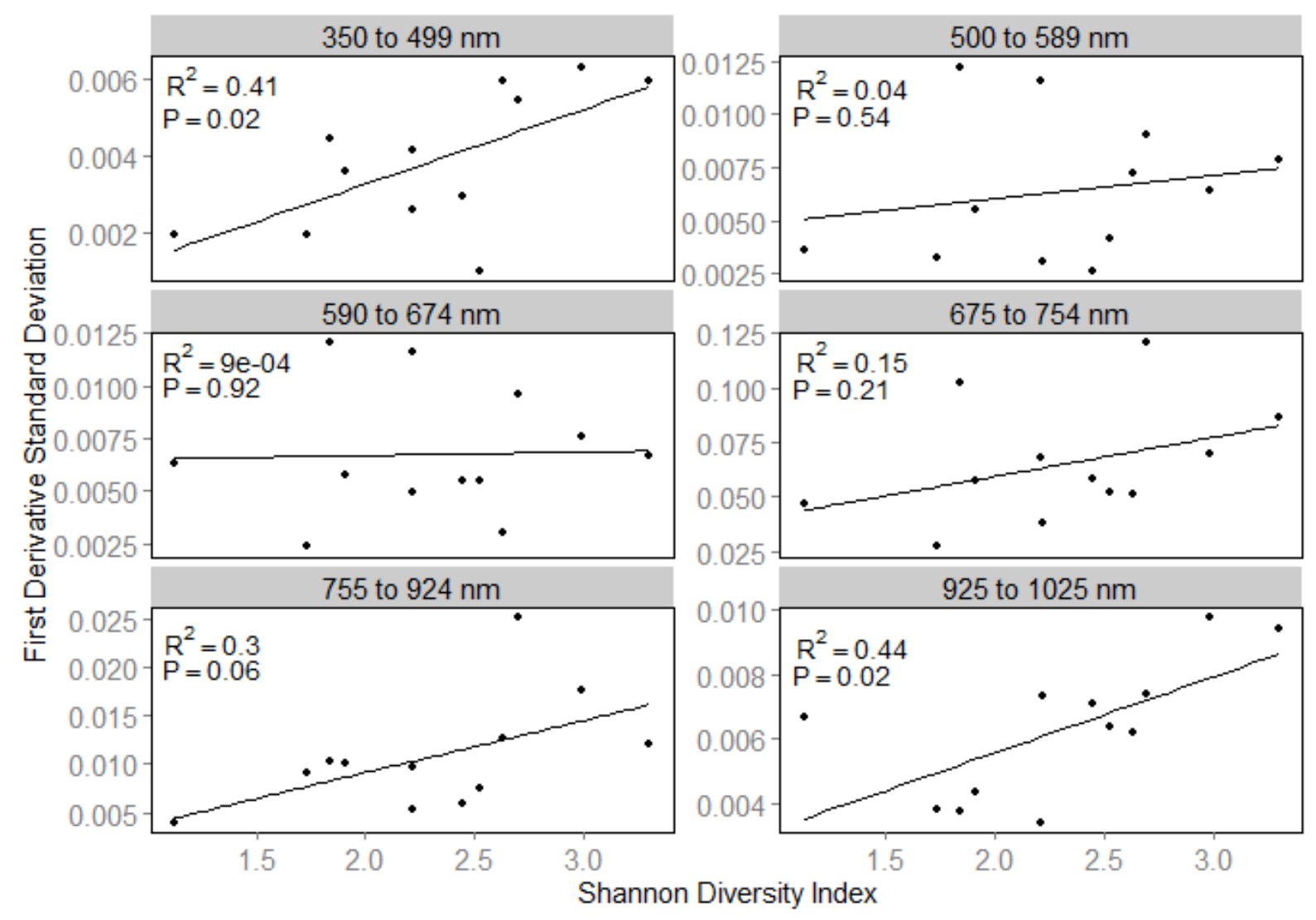

Figure 15: Correlations between species diversity and spectral diversity for six spectral regions using the area under the first derivative profile.

\subsection{Visible Region}

The $350 \mathrm{~nm}$ to $499 \mathrm{~nm}$ region had a strong positive correlation using band depth and first derivatives, suggesting that this region has large interspecific variability. Using band depth, there were also strong positive correlations in the rest of the visible region. However, there was no correlation when using first derivatives. This may be because first derivatives have been found to exaggerate noise due to environmental variation and increase intraspecific spectral variability (Zhang et al., 2006). 


\subsection{Near-Infrared Region}

The lack of correlation in the near-infrared region when using band depth may be due to the fact that band depth drastically reduces variability in the near-infrared plateau to reduce noise in these data; however, this reduction may mask variability in the near-infrared plateau that may be caused by interspecific differences. Therefore, it may be better to use derivatives to compare the correlations between species diversity and spectral diversity in this region. Indeed, when using first derivatives, there was a strong positive correlation between spectral diversity and species diversity in the $755-924 \mathrm{~nm}$ wavelength region $\left(\mathrm{R}^{2}=\right.$ $0.30, \mathrm{p}=0.06)$ and the $925-1025 \mathrm{~nm}$ wavelength region $\left(\mathrm{R}^{2}=0.44, \mathrm{p}=0.02\right)$ (Figure 15).

\subsection{Red Trough and Red Edge Regions}

The most interesting result is a weak correlation using band depth and the lack of correlation in the red edge region using first derivatives, likely due to greater intraspecific variability versus interspecific variability in this region. Variability in the red edge region may be due to differences in the red trough or differences in the near-infrared plateau; however, since differences in the near-infrared plateau are minimized while using band depth, the differences are likely in the red trough. To determine how there might be greater interspecific variability in most of the visible region yet greater intraspecific variability in the red edge region, especially the red trough, the absorption peaks of different pigments were considered. Chlorophyll a and b peaks are in the visible and red trough regions, and anthocyanin and carotenoid peaks occur in the visible region (For more detailed absorption peak locations, see Jensen (2007)). The intraspecific variability in the red edge region (675 nm to $754 \mathrm{~nm}$ ) may be due to intraspecific variability in chlorophyll content, which may be more plastic and more sensitive to environmental factors than other pigments. In contrast, carotenoid and anthocyanin content may have greater interspecific variability than intraspecific variability. 
This may be because anthocyanin content and carotenoid content are highly influenced by genetics (Ficco et al., 2014; Fournier-Level et al., 2009; Guzman et al., 2010; Nicolle et al., 2004) while chlorophyll content is influenced by both genetics and environmental conditions and stressors (Cao, 2000; Malyshev et al., 2016).

\subsection{Species Pigment Comparisons}

To assess intraspecific and interspecific differences in pigment estimations, I used spectra of five dominant species in the community plots to calculate indices estimating the amounts of chlorophyll (Equation 3), carotenoids (Equation 4), and anthocyanins (Equation $5)$ in the leaves. The analysis of variance for pigment estimates revealed that there was greater interspecific variability than intraspecific variability in terms of all three pigment types; however, within-species variability was proportionally greater in chlorophyll than in carotenoid and anthocyanin estimates (Table 11). This is concluded based on the F value, which is the ratio of variance among species (among mean square) to variance within species (within mean square); the smaller the $\mathrm{F}$ value, the greater the within-species variance proportional to total variance. This greater intraspecific variability may account for some of the lack of correlation between spectral diversity and species diversity in the red trough region. Although there is greater intraspecific variability in chlorophyll than the other pigments, interspecific variability is still greater, leading to significant differences by species for all three pigments (Figure 16). In terms of anthocyanins and carotenoids, all species were significantly different $(\mathrm{p}<0.0001)$ except for $A$. millefolium vs. S. orbiculatus and $D$. glomerata vs. F. rubra. In terms of chlorophyll, all species were significantly different except for D. glomerata vs. F. rubra and S. altissima vs. S. orbiculatus. Thus, species were still significantly different in terms of all spectral pigment estimates (Figure 16). 
Table 11: ANOVA results comparing among and within variance in pigment estimates by species.

\begin{tabular}{cccc}
\hline Pigment & Among Mean Square & Within Mean Square & F value \\
\hline \hline Anthocyanins & 5.8774 & 0.0467 & 125.87 \\
Carotenoids & 260.21 & 0.8093 & 321.52 \\
Chlorophylls & 12.454 & 0.1059 & 117.59 \\
\hline
\end{tabular}

Anthocyanin Estimates by Species

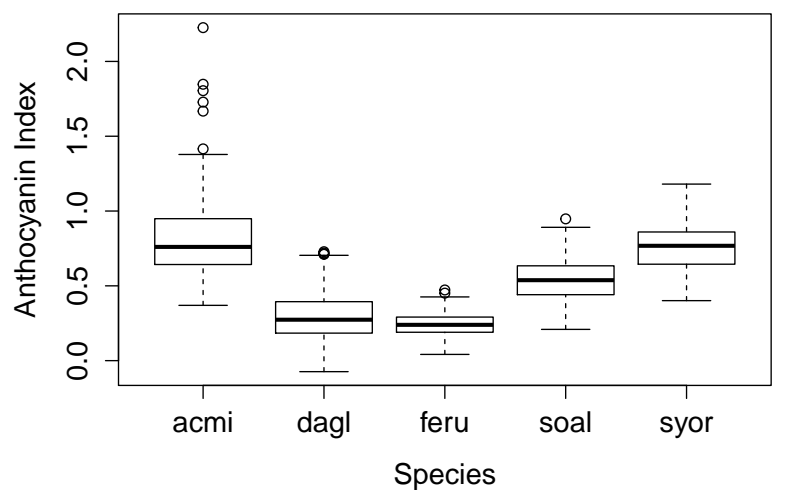

(a)
Carotenoid Estimates by Species

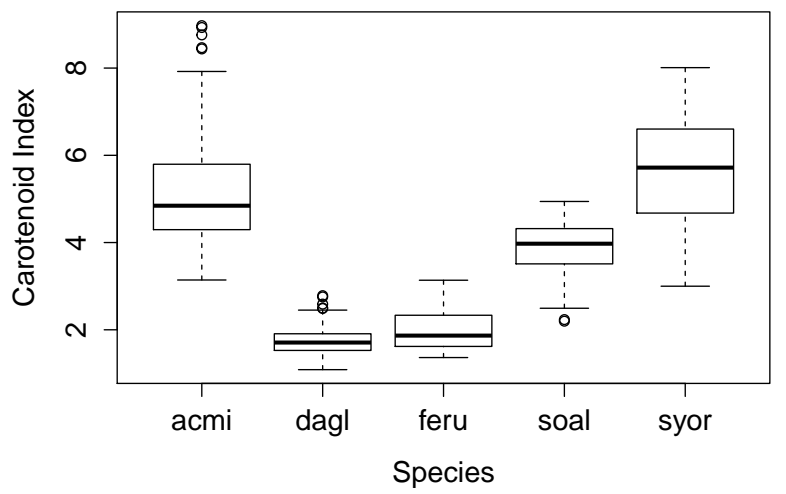

(b)

\section{Chlorophyll Estimates by Species}

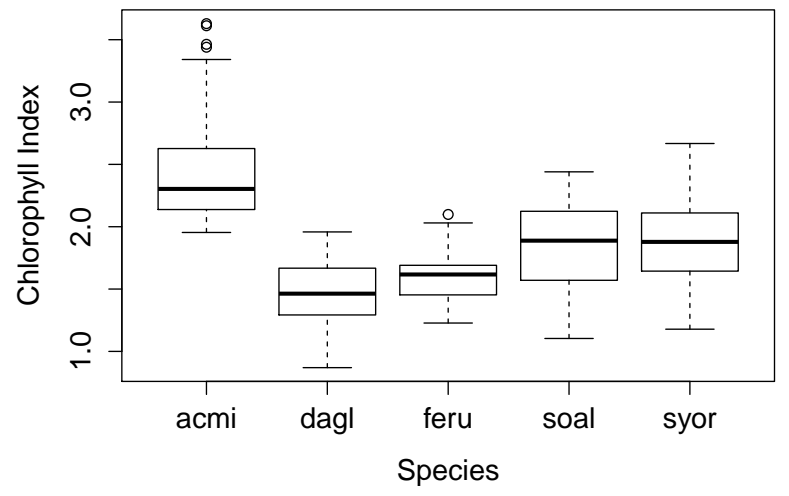

(c)

Figure 16: Estimates of a) anthocyanins, b) carotenoids, and c) chlorophylls for Achillea millefolium (acmi), Dactylis glomerata (dagl), Festuca rubra (feru), Solidago altissima (soal), and Symphoricarpos orbiculatus (syor) using ground-level hyperspectral data. 
A. millefolium had greater chlorophyll content than did S. orbiculatus and S. altissima, which had greater chlorophyll content than did D. glomerata and F. rubra. A. millefolium and S. orbiculatus had greater anthocyanin content than S. altissima, which had greater anthocyanin content than D. glomerata and F. rubra. In contrast, Veres et al. (2006) found that Festuca pseudovina had higher xanthophyll content than A. millefolium. In this study, A. millefolium and S. orbiculatus had greater carotenoid content than $S$. altissima, which had greater carotenoid content than D. glomerata and F. rubra. Similarly, Veres et al. (2006) found that out of the monocots they tested, Festuca pseudovina had the lowest carotenoid content, and of the dicots tested, A. millefolium had the greatest carotenoid content. Carotenoid content and composition can vary by environment and have high interspecific variation (Veres et al., 2006).

There may be several reasons why Festuca rubra and Dactylis glomerata had low levels of photoprotective pigments. Grass leaves have high Si content, which might help them reflect UV-B radiation and thus not need as much photoprotection from pigments (Deckmyn and Impens, 1999). Out of Festuca arundinacea, Festuca rubra, Lolium perenne, and Poa pratensis, Zhang and Ervin (2009) found that F. rubra had the greatest tolerance to UV-B. This higher tolerance may be due to narrower leaves and thick waxy cuticles (Zhang and Ervin, 2009). Narrow leaves can lead to a reduction in boundary layer growth, thus reducing leaf temperature in high light conditions (Letts et al., 2009). When treating $F$. rubra and D. glomerata with increasing levels of UV-B, Deckmyn and Impens (1999) found that there was an increase in protective pigments in D. glomerata, but not in F. rubra. This implies that F. rubra may have a different way of dissipating excess energy such as antioxidant activity and activation of hormones that cue defense mechanisms (Zhang and Ervin, 2009).

Another reason these species were significantly different from each other in terms of pigment levels may be that they are from different plant functional types (two grasses, 
two forbs, and one shrub). Forbs have lower foliar support costs than shrubs, which need to invest more in woody biomass growth; therefore, forbs may have greater leaf dry mass per unit area than do woody species (Niinemets, 2010). This greater ability to invest in leaves may explain the high chlorophyll levels of A. millefolium compared with those of $S$. orbiculatus, although those of $S$. altissima were just as low.

These plants also differ in shade tolerance: S. altissima is less shade tolerant than S. orbiculatus and A. millefolium, which are less shade tolerant than D. glomerata and $F$. rubra. Shade-tolerant species usually have lower leaf dry mass per unit area and greater specific leaf area to intercept more light in the shade (Niinemets, 2010). These leaves with high specific leaf area have greater longevity but lower net photosynthesis levels and lower photosynthetic nitrogen-use efficiency, because of greater allocation to non-photosynthesizing cell wall material and large vein networks over photosynthetic machinery (Johnson and Tieszen, 1976; Niinemets, 2010). In this study, the two most shade tolerant species also had the lowest concentrations of pigments.

For these pigment analyses, leaf-level spectra were used to examine only photosynthetic tissue and thus get a more accurate representation of photosynthetic machinery. However, diversity correlations were made using spectra that included both photosynthetic and structural elements. Structural signatures are more prevalent in the shortwave-infrared region than the visible and near-infrared regions (Mahlein, 2011), but a component of structure is leaf angle distribution, which in turn affect signatures in the visible and near-infrared regions. Thus, some of the variability in the correlation analyses may be due to the structural component of species diversity.

Overall, band depths of visible range values within the $350 \mathrm{~nm}$ to $674 \mathrm{~nm}$ region can be used to estimate species diversity. This finding of a correlation between spectral diversity and species diversity supports prior research (Asner and Martin, 2011; Asner et al., 2009, 2007, 2012; Carlson et al., 2007; Feret and Asner, 2014; Rocchini et al., 2010). However, 
other methods of noise minimization must be implemented to use the near-infrared region for estimating species diversity. Additionally, variability in the red edge region may be due to intraspecific variability in chlorophyll a and b content rather than differences in species composition. Species plasticity in pigment levels also needs to be considered when analyzing species discriminability; however, this difference in pigment levels across species supports the possibility of discriminating species spectrally. Thus, remote sensing can be used to estimate diversity and aid conservation efforts at large spatial extents; additionally, if invasive species decrease diversity, spectral diversity may be used to assess the invadedness of an area. However, methods used to estimate species diversity must be chosen and interpreted carefully. Continuum removal is more appropriate for correcting for sources of noise in the near-infrared region and emphasizing features in the visible region while minimizing the effects of noise. First derivatives are more appropriate for emphasizing spectral features in the visible region only when there is little noise in that region. They are more useful for preserving variability in the near-infrared region while minimizing effects of noise in that region.

\subsection{Conclusion}

The correlation between species diversity and spectral diversity depends on the spectral region examined and the spectral noise correction technique used. Using band depth, Pearson correlation analyses revealed positive correlations between spectral diversity and species diversity in the visible ranges of 350-499 $\mathrm{nm}\left(\mathrm{R}^{2}=0.41, \mathrm{p}=0.03\right), 500-589 \mathrm{~nm}\left(\mathrm{R}^{2}=\right.$ 0.35, $\mathrm{p}=0.04)$, and 590-674 $\mathrm{nm}\left(\mathrm{R}^{2}=0.44, \mathrm{p}=0.02\right)$, slight positive correlation in the red edge range of $675-754 \mathrm{~nm}\left(\mathrm{R}^{2}=0.26, \mathrm{p}=0.09\right)$, and no correlation in the near-infrared ranges of 755-924 nm $\left(\mathrm{R}^{2}=0.01, \mathrm{p}=0.74\right)$ and $925-1025 \mathrm{~nm}\left(\mathrm{R}^{2}=0.17, \mathrm{p}=0.19\right)$. Using first derivatives, I found a strong positive correlation in the visible range of 350 to $499 \mathrm{~nm}\left(\mathrm{R}^{2}=0.41\right.$, $\mathrm{p}=0.02)$, but no correlations in the visible ranges of 500 to $589 \mathrm{~nm}\left(\mathrm{R}^{2}=0.04, \mathrm{p}=0.54\right)$ and 
590 to $674 \mathrm{~nm}\left(\mathrm{R}^{2}=0.0009, \mathrm{p}=0.92\right) ; \mathrm{I}$ found no correlation in the red edge region $\left(\mathrm{R}^{2}=\right.$ $0.15, \mathrm{p}=0.21)$ and positive correlations in the near-infrared ranges of 755 to $924 \mathrm{~nm}\left(\mathrm{R}^{2}=\right.$ $0.30, \mathrm{p}=0.06)$ and 925 to $1025 \mathrm{~nm}\left(\mathrm{R}^{2}=0.44, \mathrm{p}=0.02\right)$. The lack of correlation in the visible region using first derivatives may be because first derivatives exaggerate spectral noise in the visible region. The lack of correlation in the near-infrared region using band depth may be because band depth minimizes variability in the near-infrared region, thus dampening interspecific differences. The lack of correlation in the red edge may be partially due to the greater intraspecific variability of chlorophyll content over content of other pigments. This variability can be expressed in the red trough region, at the base of the red edge, dampening interspecific differences and thus lessening the correlation between species diversity and spectral diversity. Thus, remote sensing can be used to estimate species diversity, but methods to do so must be chosen carefully. 


\section{Chapter 5: Species effects on ecosystem properties and processes throughout succession}

\subsection{Abstract}

As abandoned agricultural fields become more prevalent and remain susceptible to invasive plant species, we must examine the effects of these invasive species on community and ecosystem properties. I examined leaf and soil properties in successional fields in

north-central Virginia containing six key exotic invasive species, to assess changes in soil characteristics throughout the summer and differences in leaf and soil characteristics across fields, successional stages, and species. Specifically, I examined soil temperature, soil moisture, soil pH, soil $\mathrm{C}$ and $\mathrm{N}$, and leaf $\mathrm{C}$ and N. Soil temperature increased and soil moisture decreased as the summer progressed. Fields differed in all characteristics, as did successional stages within fields. Temperature and moisture differences across stages often followed predictions based on secondary succession, with earlier stages being warmer and less moist, and soil pH was inversely correlated with soil moisture as expected. Soil C and N increased with succession. However, leaf C and N were similar across successional stages. Species were often similar in terms of soil characteristics, suggesting that either they did not affect successional ecosystem dynamics or that different species affected them in similar ways. However, there were species differences in terms of leaf characteristics, suggesting that species effects may translate to soil effects over time. 


\subsection{Introduction}

\section{Secondary succession}

Abandoned agricultural fields have become more prevalent in the U.S., especially in the Northeast and Midwest (Wang et al., 2010), and are easily invaded by exotic invasive plant species as they undergo secondary succession (Mosher et al., 2009). As these species can alter their surrounding environment, it is important to study their effects on successional dynamics.

Secondary succession following disturbance exhibits certain patterns of temporal change, which may be explained by several hypotheses. The colonization-nutrient competition hypothesis, which states that there is a trade-off between allocation to seeds and allocation to roots and thus between colonization and resource acquisition ability, may best

explain very early succession; the nutrient: light ratio hypothesis, which states that there is a trade-off between allocation to roots for nutrient acquisition and allocation to leaves for light acquisition, may best explain later stages of succession to woody species (Tilman, 1990). During succession, facilitation (organisms benefiting from each others' presence), inhibition (organisms restraining the growth of others), and tolerance (organisms being able to endure the potentially detrimental presence of others) can occur simultaneously; times at which one of these processes is dominant over others may be influenced by species density, successional stage, type of succession, resource availability, and disturbance regime (Walker and Chapin, 1987).

Disturbances, such as in agricultural fields, urban areas, roads, and fragmented habitats, can facilitate species invasion during succession by promoting the growth of invasive propagules, increasing light availability, increasing exposure to invasive species populations, removing litter, disturbing soil surfaces, and changing canopy species composition (Aragon and Morales, 2003; Butler et al., 2014; Gaertner et al., 2009; Kota et al., 2007; Kuhman 
et al., 2011; Mosher et al., 2009; Yoshida and Oka, 2004). Newly abandoned fields and early successional stages have low vegetation biomass, low photochemical reflectance index values, because of greater investment in photo-protection (Alvarez-Anorve et al., 2012), and generally more annuals than perennials (Battaglia et al., 1995).

With succession, there is a decrease in N acquisition efficiency (Paschke et al., 2000), nitrification rates (Gorham et al., 1979), net photosynthetic capacity (Ellsworth and Reich, 1996), and photosynthetic rates (Ellsworth and Reich, 1996). With lower litter quality (Castro et al., 2010), decomposition rates decrease (Castro et al., 2010), and there is an increase in soil carbon and nitrogen with the accumulation of soil organic matter. There is likely an increase in soil moisture with the increase in canopy shading (Wang et al., 2010) and a decrease in soil pH (Dolle and Schmidt, 2009). Unlike the changes in soil carbon and nitrogen throughout succession, the changes in leaf carbon throughout succession are very small. Depending on the species, leaf nitrogen may also not greatly differ or may decrease throughout succession (Ellsworth and Reich, 1996). Whole-plant nitrogen decreases throughout succession due to increases in woody and other structural tissue.

\section{Invasive species and ecosystem properties}

Species can differ in resource acquisition and resource use efficiency, transpiration, LAI, photosynthetic biomass, root depth, phenology, growth rate, quantity and quality of litter production, microbial community associations, and spatial distributions (DeMeester and deB. Richter, 2010; Vicente et al., 2013; Vitousek, 1990). Changes in plant species composition, such as those associated with invasive species, can lead to changes in soil fauna through changes in nutrient inputs and soil characteristics (Maharning et al., 2009), and changes in herbivore community compositions (DeMeester and deB. Richter, 2010). With these changes in community composition, exotic invasive species can alter ecosystem properties and processes such as productivity, nutrient cycling, water cycling, soil microbial 
activity, and disturbance regimes, especially when they are dominant (Denslow and Hughes, 2004). Invasive species can affect soil properties and processes via root exudation, altering carbon and nutrient cycles and pools, and affecting soil pH (Gomez-Aparicio and Canham, 2008; Weidenhamer and Callaway, 2010). If they have greater specific leaf area, growth rates, foliar nutrient concentrations, and/ or nitrogen-fixing symbioses, invasive species can increase decomposition and nutrient cycling rates (Weidenhamer and Callaway, 2010).

An increase in resource availability with faster decomposition and nutrient cycling may also lead to an increase in the density and diversity of introduced species, into a potential positive feedback loop (Ehrenfeld et al., 2001; Kuhman et al., 2011). Even invasions with low invasive cover can alter microbial communities and thus ecosystem processes such as decomposition (Mayer et al., 2005). For example, Ailanthus altissima can affect ecosystem properties and processes even at low densities by increasing nutrient cycling rates, increasing local nutrient pools, and changing the community species composition to favor species that thrive in high-nutrient environments (Gomez-Aparicio and Canham, 2008). Celastrus orbiculatus can decrease the growth of native species by girdling trees and increasing their susceptibility to ice damage, and by shading out their saplings (Leicht-Young et al., 2007). Rhamnus frangula cover is negatively correlated with woody seedling density, herbaceous species cover, and species richness (Frappier et al., 2003). Rhamnus cathartica alters forest structure by increasing woody stem density but not total basal area, increasing shade and thus excluding other woody and herbaceous species, increasing decomposition, and increasing nitrogen turnover (Mascaro and Schnitzer, 2007). Invasive species can also affect ecosystems by affecting community members other than plants, including birds (Rodewald et al., 2010; Schmidt and Whelan, 1999; Sullivan et al., 2007), earthworms (Heimpel et al., 2010), and insects (Heimpel et al., 2010). Additionally, native species restoration may be difficult even with the removal of exotic invasive species because of lingering ecosystem effects (Heneghan et al., 2006; MacDougall and Turkington, 2005; Milchunas and Lauenroth, 1995; Sullivan et al., 2007). 


\section{Invasion and secondary succession}

Invasion can also affect the trajectory of succession (Kuhman et al., 2011; Yoshida and Oka, 2004), although the degree of influence might depend on environmental factors such as moisture regimes (Otto et al., 2006). Allelopathic species can affect succession by affecting the rate and direction of species composition change and altering biochemical processes such as nitrogen fixation. Tilman (1985) describes succession as a change from high light, low soil nutrient conditions to low light, high nutrient conditions. The open niches during early succession may make the area susceptible to invasion by species that require fewer nutrients (Feldpausch et al., 2004), and this invasion can then affect the degree, duration, and direction of ecosystem change during succession. Invasive species may have no effect (Kassi N'Dja and Decocq, 2008), or their effects may be limited to earlier stages of succession with eventual reclamation by natives (Cunard and Lee, 2009; Otto et al., 2006).

Alternatively, they can completely change the trajectory, rate, species composition, species richness, disturbance regimes, and nutrient cycling during succession (Grau et al., 1997; Leicht-Young et al., 2009; Simberloff, 2010; Sullivan et al., 2007; Yoshida and Oka, 2004). For example, the growth of Celastrus orbiculatus can impede succession by inhibiting the re-establishment of secondary forest species (Fike and Niering, 1999; Ladwig and Meiners, 2010; Pavlovic and Leicht-Young, 2011; Riedel and Epstein, 2005) and the invasion by koa haole may alter secondary succession by establishing dense thickets and reducing the growth of native species (Yoshida and Oka, 2004).

\section{Research Objectives}

I examined the effects of specific non-native invasive species on secondary succession at the Blandy Experimental Farm (BEF) in north-central Virginia. The Blandy Experimental Farm has two successional field chronosequences of abandoned agricultural fields that contain 
several non-native invasive plant species including Rhamnus davurica (Dahurian buckthorn), Celastrus orbiculatus (oriental bittersweet), Galium verum (yellow bedstraw), Ailanthus altissima (tree of heaven), Cirsium arvense (Canada thistle), and Carduus acanthoides (spiny plumeless thistle). These species may affect ecosystem properties and processes by altering resource availability and species composition both of native plant species and of organisms that utilize this vegetation. I examined changes in leaf and soil characteristics throughout secondary succession and evaluated species-level differences in these changes.

\subsection{Methods}

\subsubsection{Study Site}

Measurements were taken from two series of successional fields and two additional field sites at the Blandy Experimental Farm (BEF) located in the Shenandoah River Valley in Clarke County Virginia at $39^{\circ} 09 \mathrm{~N}, 78^{\circ} 06 \mathrm{~W}$ (Wang et al., 2007) (Figure 17). This 300 ha biological field station has been owned by the University of Virginia (UVA) since 1926 and operated by the Department of Environmental Sciences since 1983 (Bowers, 1997). It is also a satellite monitoring location for the National Ecological Observatory Network (NEON) (NEON, 2015). The BEF includes 120 ha of pasture and cropland, 40 ha of woodland, the 60 ha Virginia State Arboretum, and 80 ha of old fields in early, middle, and late succession (Bowers, 1997). Each of two successional series contains an early, mid, and late successional field (southwest, SW, and northeast, NE). The successional fields are former agricultural fields, abandoned in 2001 (Early 1), 2003 (Early 2), 1986 (Mid 1), 1987 (Mid 2), before 1910 (Late 1) and before 1920 (Late 2) (Wang et al., 2010). To observe Cirsium

arvense (Canada thistle) which is not present in the successional series, a site at Lake Arnold (LA) and a site at a field boundary near the northeast successional series (northeast boundary, NEB) was also studied. All sites have silt loam soil, of the soil type Ultisol, with slopes less than 10\%. At an elevation of $190 \mathrm{~m}$, mean annual temperature and precipitation 
for the Blandy Experimental Farm are $11.8^{\circ} \mathrm{C}$ and $940 \mathrm{~mm}$ respectively (Bowers, 1997; Wang et al., 2010). The BEF also has an average growing season of 157 days, and average annual primary productivity of $1.0 \mathrm{~kg} / \mathrm{m}^{2}$ in the successional fields (Bowers, 1997; Wang et al., 2010). The BEF has several exotic invasive species present in the field sites observed in this study including Ailanthus altissima (tree of heaven), Carduus acanthoides (spiny plumeless thistle), Celastrus orbiculatus (oriental bittersweet), Cirsium arvense (Canada thistle), Galium verum (yellow bedstraw), and Rhamnus davurica (Dahurian buckthorn).

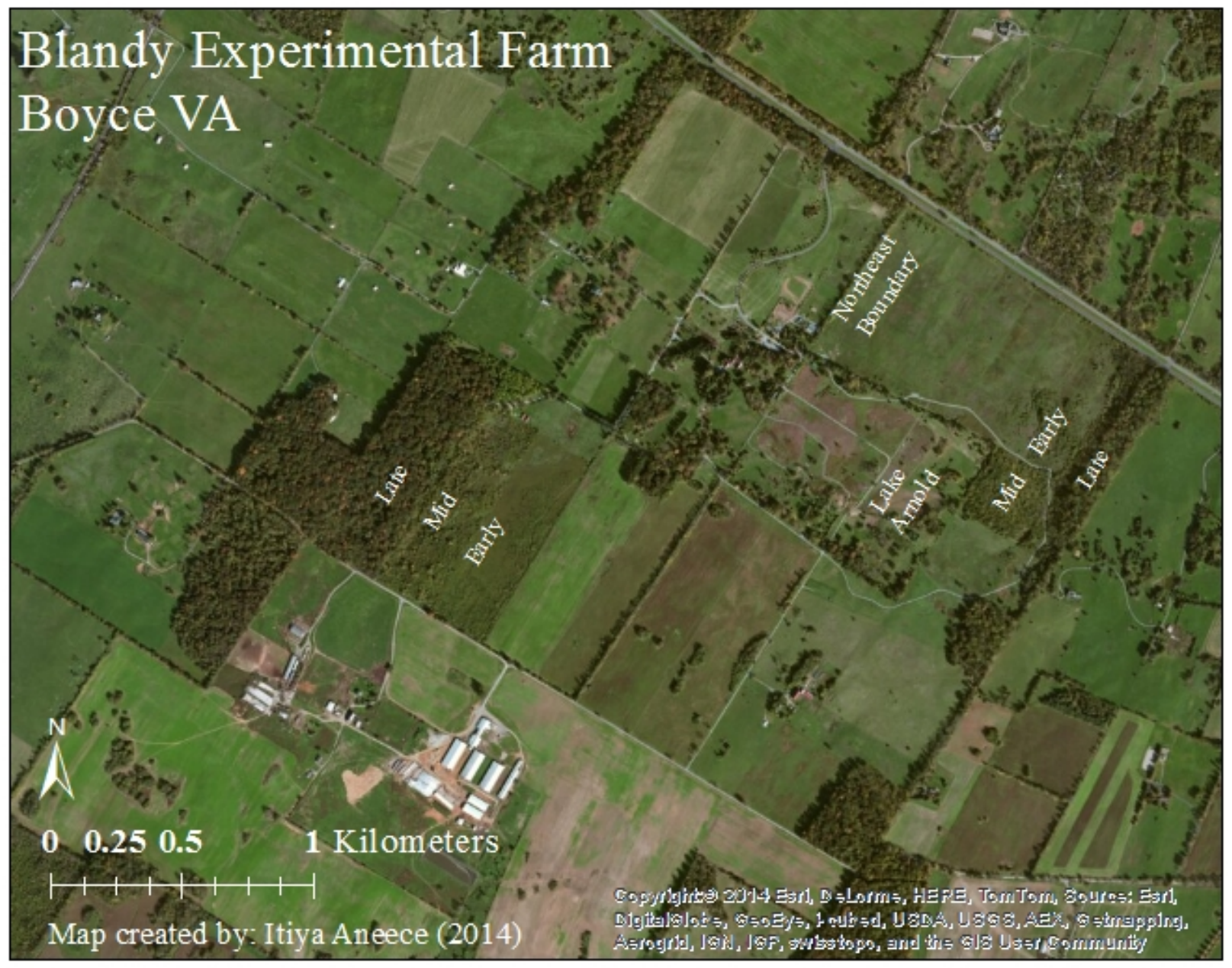

Figure 17: Blandy Experimental Farm, Boyce VA with study site labels including two secondary successional fields 


\subsubsection{Field methods}

In the summer of 2011, I established transects through both successional series, as well as through Lake Arnold and the northeast boundary field sites, to locate non-native invasive species in different successional stages; individuals of Rhamnus davurica, Ailanthus altissima, Carduus acanthoides, Celastrus orbiculatus, Cirsium arvense, and Galium verum were tagged. In this study, Lake Arnold and the northeast boundary sites are considered early stages due to recency of disturbance. Within each successional series, the transects extended through early, mid, and late successional stages: $300 \mathrm{~m}$ long in the northeast successional fields and $550 \mathrm{~m}$ long in the southwest successional fields. The transect in the northeast boundary was approximately $200 \mathrm{~m}$, and the one at Lake Arnold was 20 m. Where present, at least five individuals of each species at each successional stage were tagged for a total of ten $C$. arvense individuals (Lake Arnold and northeast boundary), ten G. verum individuals (northeast successional field early and mid- successional stages), $17 C$. acanthoides individuals (early and mid- successional stages of both successional series), 15 A. altissima individuals (mid successional stage of both successional series and late stage of northeast successional series), and 36 R. davurica individuals (all successional stages of both successional series).

Soils data were also collected from the transects in the summer of 2011. Soil temperature at $5 \mathrm{~cm}$ and soil moisture at 0 to $12 \mathrm{~cm}$ were collected along the transects directly under each tagged individual weekly from June to August using a Horizen Hydroponics digital soil thermometer and a HydroSense soil water measurement system respectively. Soil moisture readings are integrated over the length of the $12 \mathrm{~cm}$ rods and the volume surrounding the rods to a radius of $3 \mathrm{~cm}$ for a total volume of $650 \mathrm{~cm}^{3}$ (Campbell Scientific, 2010). Two soil cores per individual were also collected in August to $20 \mathrm{~cm}$ depth with $2.54 \mathrm{~cm}$ diameter. These soil samples were used to determine soil pH and soil $\mathrm{C}$ and $\mathrm{N}$ content. Soils were kept refrigerated until soil $\mathrm{pH}$ could be estimated, at most three days after collection. Soil 
pH was obtained after making a soil slurry of $20 \mathrm{~g}$ soil and $20 \mathrm{~mL}$ distilled water. This mixture was stirred by hand for 30 seconds and allowed to equilibrate for approximately five minutes. The FieldScout SoilStik was used to obtain two measurements per slurry, in the aqueous layer. Samples were dried at $105{ }^{\circ} \mathrm{C}$ for 24 hours, and dry weight was obtained for bulk density. Soil ground using a pica soil mill was used for measuring carbon and nitrogen with a Carlo Erba elemental analyzer, model NA2500.

Also during the summer of 2011, leaf C and N were analyzed to examine differences in species foliar properties. Leaf $\mathrm{N}$ can also potentially be estimated from chlorophyll indices based on spectral data. To determine these leaf characteristics, at least five middle-aged, non-senescing leaves were obtained from all targeted individuals in early July 2011. For tree of heaven, leaflets of a single middle-aged leaf were collected. For yellow bedstraw, multiple whorls of leaves were collected due to their small size. Leaves were dried at $60{ }^{\circ} \mathrm{C}$ for 60 hours. Dried and ground leaves were used to obtain carbon and nitrogen with the elemental analyzer.

In the summer of 2012, two one meter by one meter population-level plots per target exotic invasive species were established in the early stages of each of the successional series and at Lake Arnold and the northeast boundary field sites. Three randomly placed $5 \mathrm{~m} * 5 \mathrm{~m}$ community-level plots consisting of several species were established at each successional seres site, Lake Arnold, and the northeast boundary. Soil temperature was measured every hour from June to September using Thermachron iButtons placed in the center of each half of each community plot and the center of each population plot. I collected leaf and soil samples from these plots for $\mathrm{C}$ and $\mathrm{N}$ analysis. Soil samples were taken using a soil core sampler of $5.08 \mathrm{~cm}$ diameter and $15.24 \mathrm{~cm}$ depth in each half of each community-plot and each population-plot, keeping away from the iButtons. Soil samples were used to obtain $\mathrm{pH}$, bulk density, soil organic matter, gravimetric soil moisture content, and soil $\mathrm{C}$ and $\mathrm{N}$ content with the same methods as above except for $\mathrm{pH}$. Soil slurries were made using a different procedure than the 
previous summer, resulting in more consistent $\mathrm{pH}$ measurements. This new method called for 1:2 slurry of soil to water with five 30 second stir/ 3 minute wait cycles.

\subsubsection{Statistical analysis}

Ecosystem property differences in soil and vegetation characteristics among species, fields, and successional stages were assessed using analysis of variance (ANOVA) except for soil temperature measurements in the summers of 2011 and 2012 and soil moisture measurements in the summer of 2011, which were analyzed with repeated-measures ANOVA using SAS (Statistical Analysis Software, Version 9.4, SAS Institute Inc., Cary, North Carolina). Summer 2012 temperature measurements were averaged by day before using repeatedmeasures ANOVA. If parametric assumptions were met, Tukey pairwise comparisons were made at the confidence level of 0.05. Otherwise, I used the Dwass, Steel, Critchlow-Fligner method for non-parametric comparisons of more than two groups (SAS support, 2012).

Due to the unbalanced design of species distributions by field and stage, when assessing differences across fields, LA was compared with NEB, and NE was compared with SW. For the summer 2011 data, I removed G. verum from the NE to SW comparison, since it was

not found in the SW fields. Since LA and NEB only consisted of one successional stage, only NE and SW were used to assess stage effects. For these stage comparisons using the summer 2011 data, the NEE and NEM were compared including species data of C. acanthoides, G. verum, and $R$. davurica, since these three species were found in both NEE and NEM. NEM and NEL were compared including $R$. davurica and A. altissima. SWE and SWM were compared including $C$. acanthoides and R. davurica. Furthermore, stages were compared within the NE and SW separately using only $R$. davurica data, since $R$. davurica was found in all three stages in both fields. Species effects were assessed across fields for LA and NEB and across fields and stages for NE and SW. For the summer 2012 data, population plot and community plot data were combined since the two were not found to be significantly 
different from each other. The combination was used to assess field differences of LA vs. NEB and SW vs. NE, stage effects in NE and SW, and species effects in LA, NEB, SWE and NEE, since population plots were only located in the early stages. Summer 2011 and 2012 data could not be combined, because they were found to be significantly different.

\section{$5.4 \quad$ Results}

\subsubsection{Soil Temperature}

Soil temperatures differed across fields for both 2011 and 2012, but differences varied by year. Although successional stages within SW and NE were mostly similar to each other in terms of soil temperature in 2011 and 2012, SWE was greater than SWM in 2011 and NEE was greater than NEM in 2012 (Figure 18). When stages were compared only using $R$. davurica samples from 2011, SWE was greater than SWM. Temperatures were mostly similar across species, but $C$. acanthoides had greater soil temperatures than A. altissima and $R$. davurica in 2011 within SWM. Similarly, C. acanthoides also had greater soil temperatures than A. altissima in 2011 within NEB. G. verum had greater soil temperatures than $C$. orbiculatus and R. davurica in 2012 within NEE.

\subsubsection{Soil Moisture}

Soil moisture differed by field, with differences varying by year. LA had greater soil moisture than NEB for both years, and NE had greater moisture than SW for 2012. Although stages within NE and SW were often similar, NEM had greater soil moisture than NEE, and SWM had greater soil moisture than SWE in 2011. NEL had greater moisture than NEE and SWM had greater moisture than SWE in 2012 (Figure 19). When considering only $R$. davurica samples in 2011, NEM and NEL had greater moisture than NEE. Although species were almost always similar in terms of soil moisture, A. altissima had greater levels than $R$. 


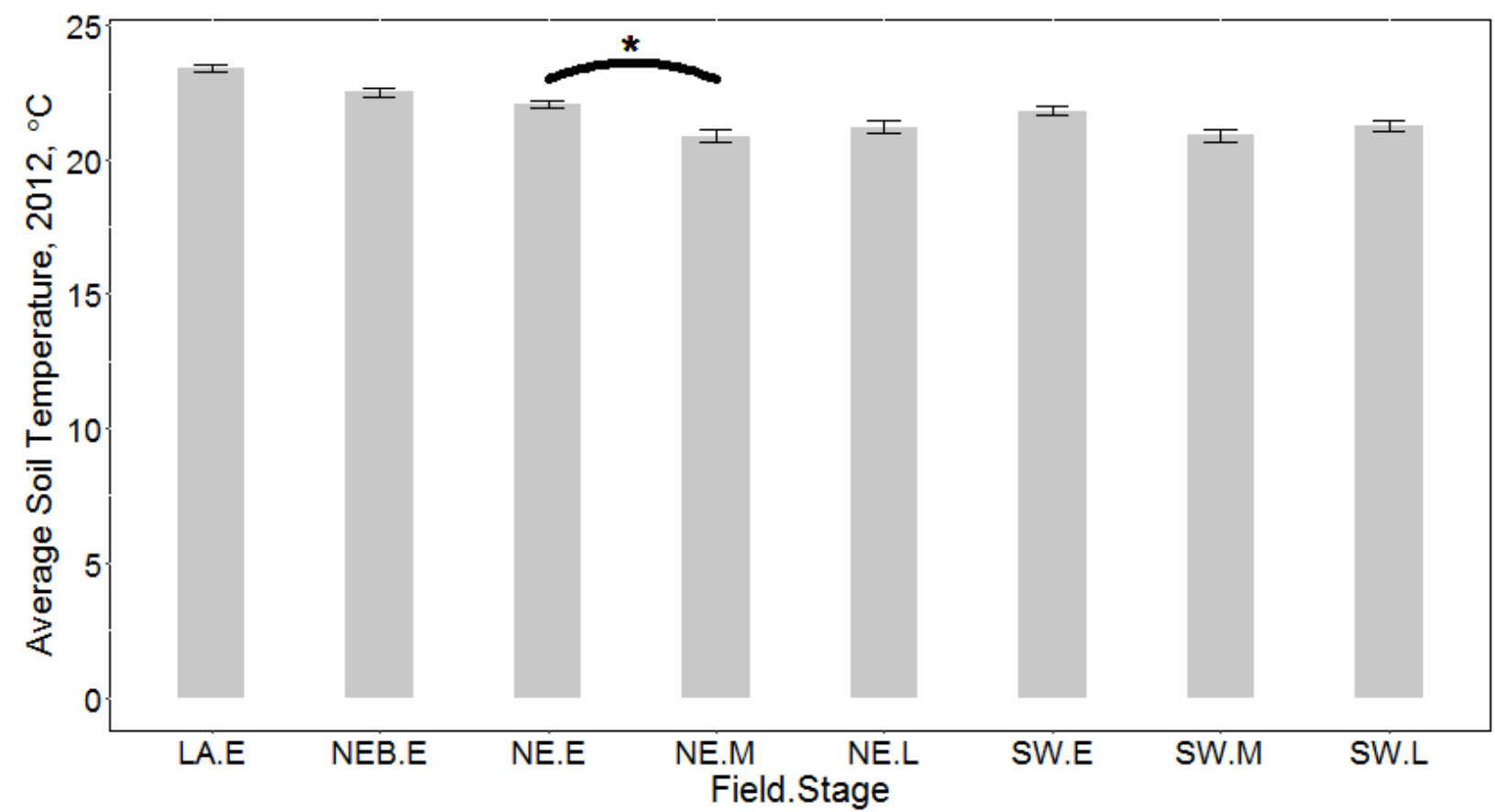

Figure 18: Average soil temperatures $\left({ }^{\circ} \mathrm{C}\right)$ at the depth of $5 \mathrm{~cm}$ for the summer of 2012 by stage (early (E), middle (M), and late (S)) for the northeast (NE) and southwest (SW), and for the fields Lake Arnold (LA) and the northeast boundary (NEB) at the Blandy Experimental Farm in north-central Virginia. Asterisks represent significant differences at $\mathrm{p}<0.05$. 


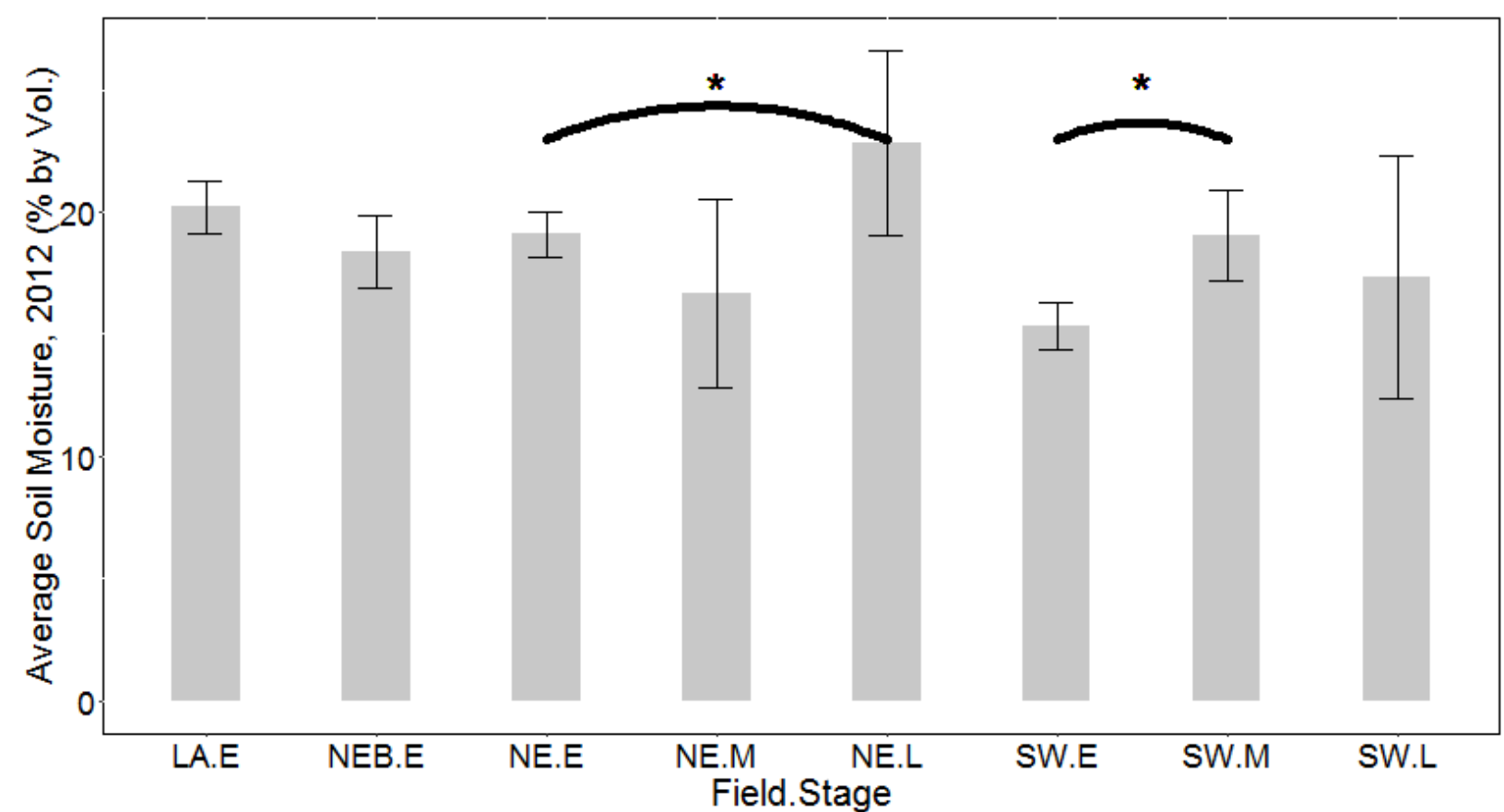

Figure 19: Average soil moisture (\% by volume) at 0 to $12 \mathrm{~cm}$ for the summer of 2012 by stage (early (E), middle (M), and late $(\mathrm{S})$ ) for the northeast (NE) and southwest (SW), and for the fields Lake Arnold (LA) and the northeast boundary (NEB) at the Blandy Experimental Farm in north-central Virginia. Asterisks represent significant differences at $\mathrm{p}<0.05$.

davurica in 2011.

\subsubsection{Soil $\mathrm{pH}$}

LA had greater soil pH than NEB in both years, and SW was similar to NE in both years. Even though the two fields were similar, stages within SW and NE differed. NEM had greater pH than NEL, and SWE had greater pH than SWM in 2011, while NEE had greater $\mathrm{pH}$ than NEL in 2012. When comparing only $R$. davurica in 2011, NEE had greater pH than NEL, and SWE had greater pH than SWM. However, SWL had greater pH than SWE and SWM, due to species effects. Soil pH levels were mostly similar across species, but C. acanthoides had greater $\mathrm{pH}$ than G. verum, and A. altissima had greater $\mathrm{pH}$ than R. davurica in 2011. Species differed by pH in LA during 2012, with G. verum having lower $\mathrm{pH}$ than C. acanthoides, which had greater $\mathrm{pH}$ than C. arvense. 


\subsubsection{Soil Carbon and Nitrogen}

Soil C and N were similar between LA and NEB for both 2011 and 2012, but NE had greater soil C and N than SW in both years. In 2011, NEE and NEL had greater soil C and N than NEM. In 2012, NEL had greater soil C and N than NEE and NEM. SWL had greater soil C than SWE, but similar soil N. Within R. davurica in 2011, NEL had greater soil C and N than NEM, and SWL had greater soil C and N than SWM. Species were mostly similar in terms of soil $\mathrm{C}$ and $\mathrm{N}$ (Figures 20 and 21), but $R$. davurica had greater soil $\mathrm{C}$ and N than C. acanthoides in 2011, and in 2012, G. verum had greater soil C than C. arvense, but similar soil $\mathrm{N}$. 


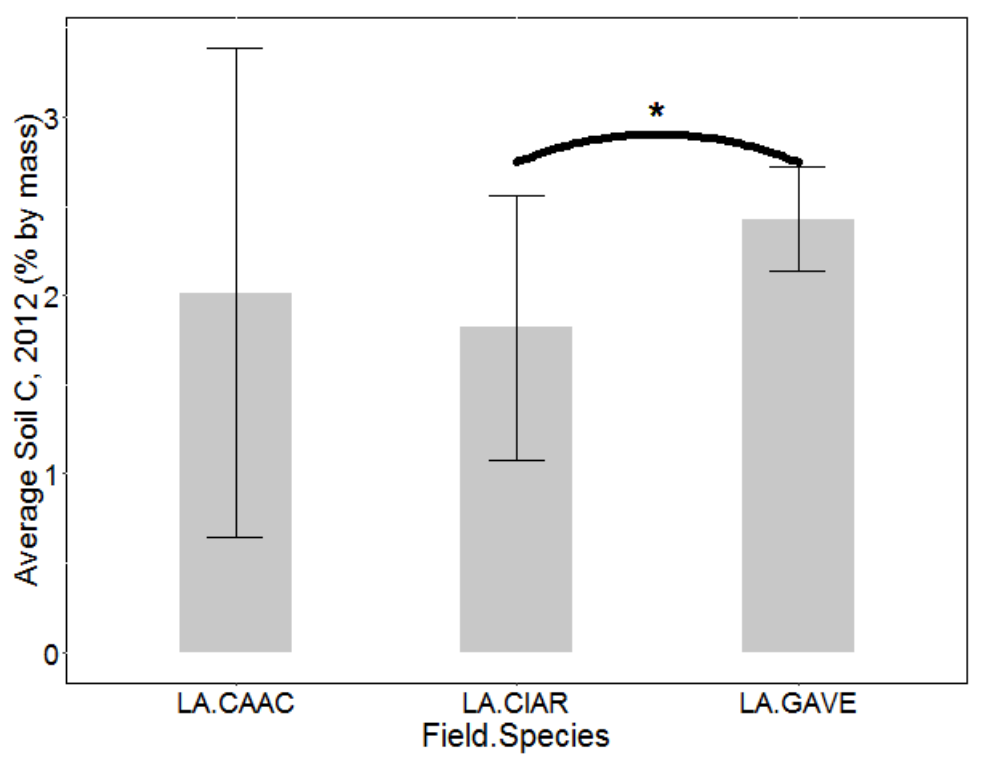

(a)

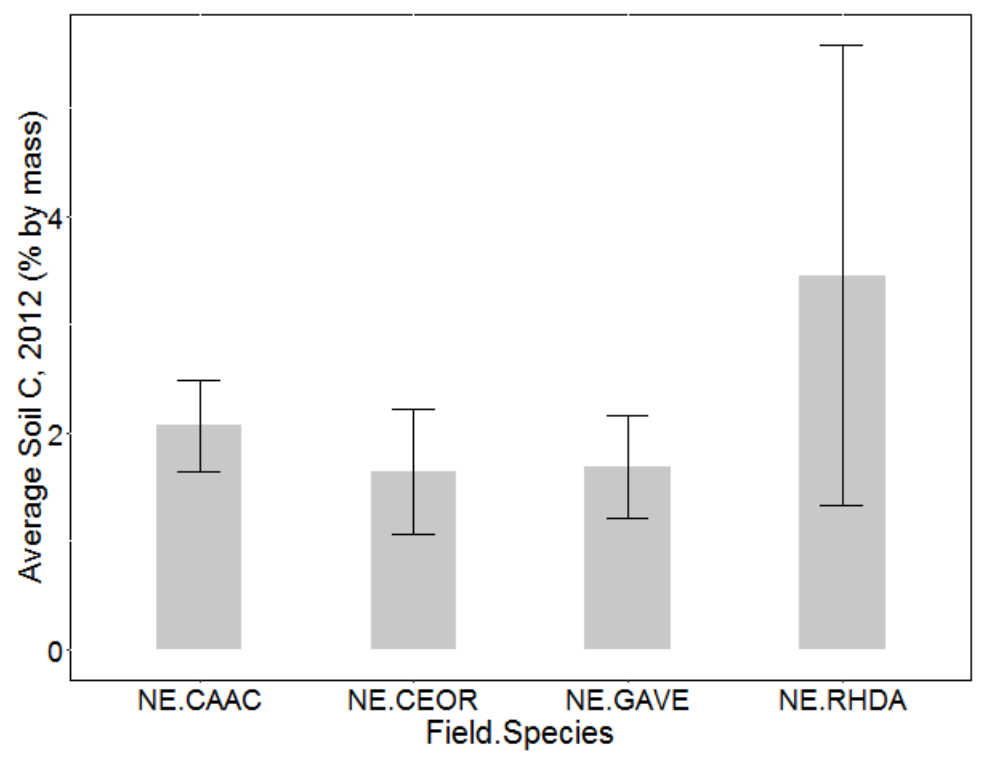

(c)

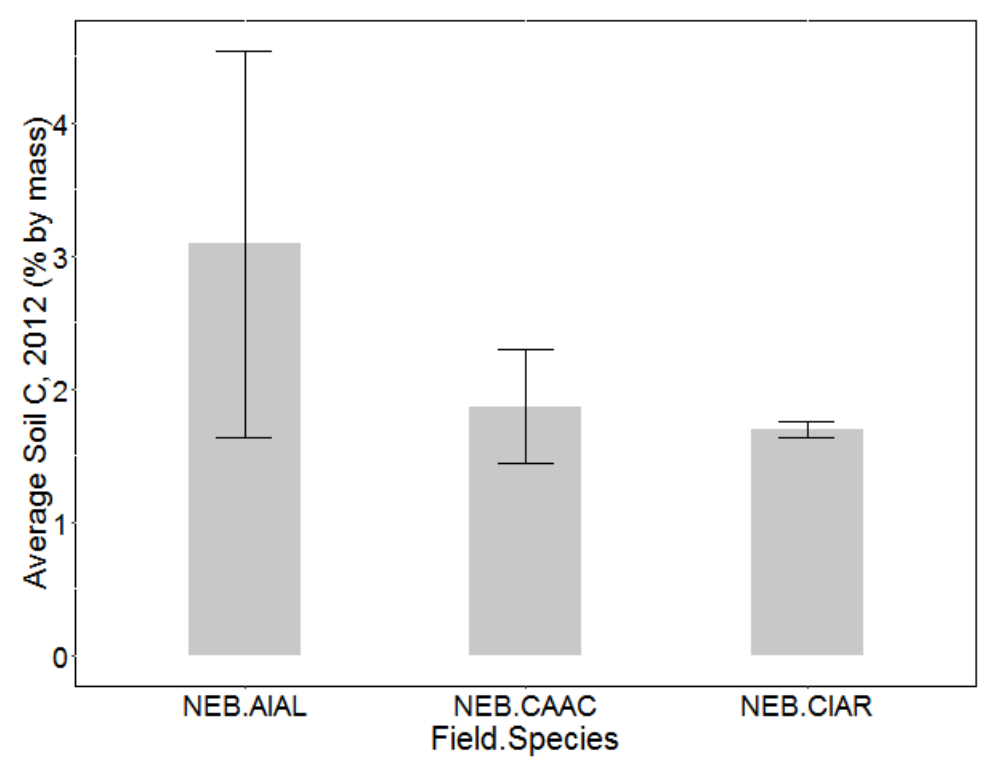

(b)

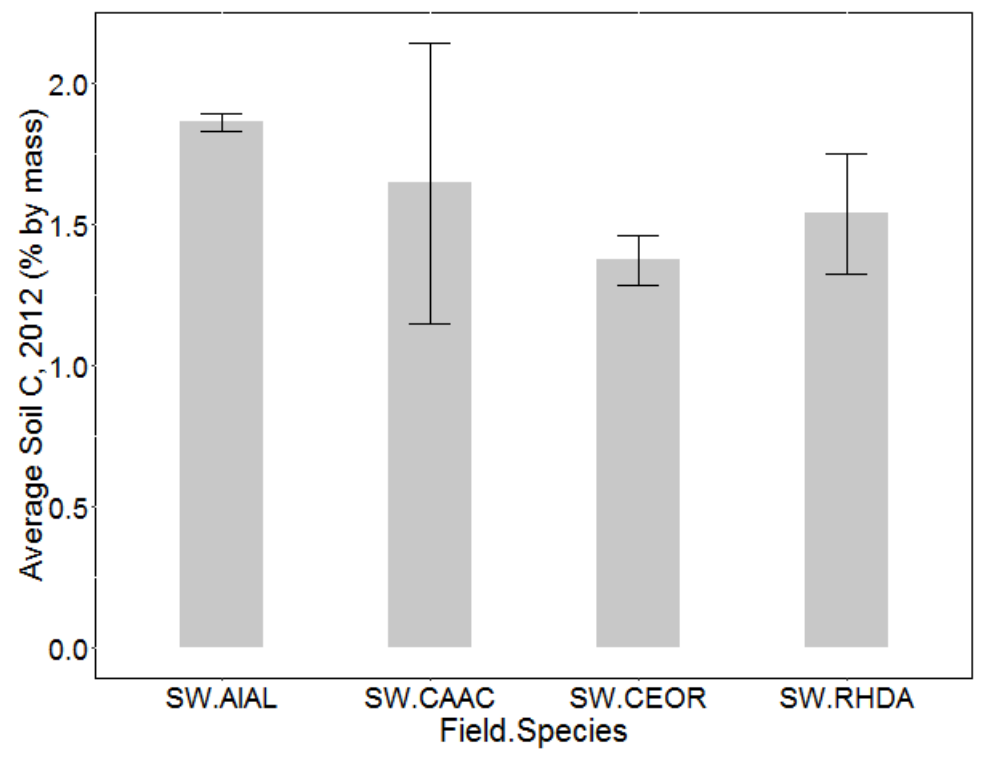

(d)

Figure 20: Average soil carbon (\% by mass) for the summer of 2012 by species (Ailanthus altissima (AIAL), Carduus acanthoides (CAAC), Celastrus orbiculatus (CEOR), Cirsium arvense (CIAR), Galium verum (GAVE), and Rhamnus davurica (RHDA)) for the fields a) Lake Arnold (LA), b) the northeast boundary (NEB), c) the northeast field chronosequence $(\mathrm{NE})$, and d) the southwest field chronosequence at the Blandy Experimental Farm in northcentral Virginia. Asterisks represent significant differences at $\mathrm{p}<0.05$. 


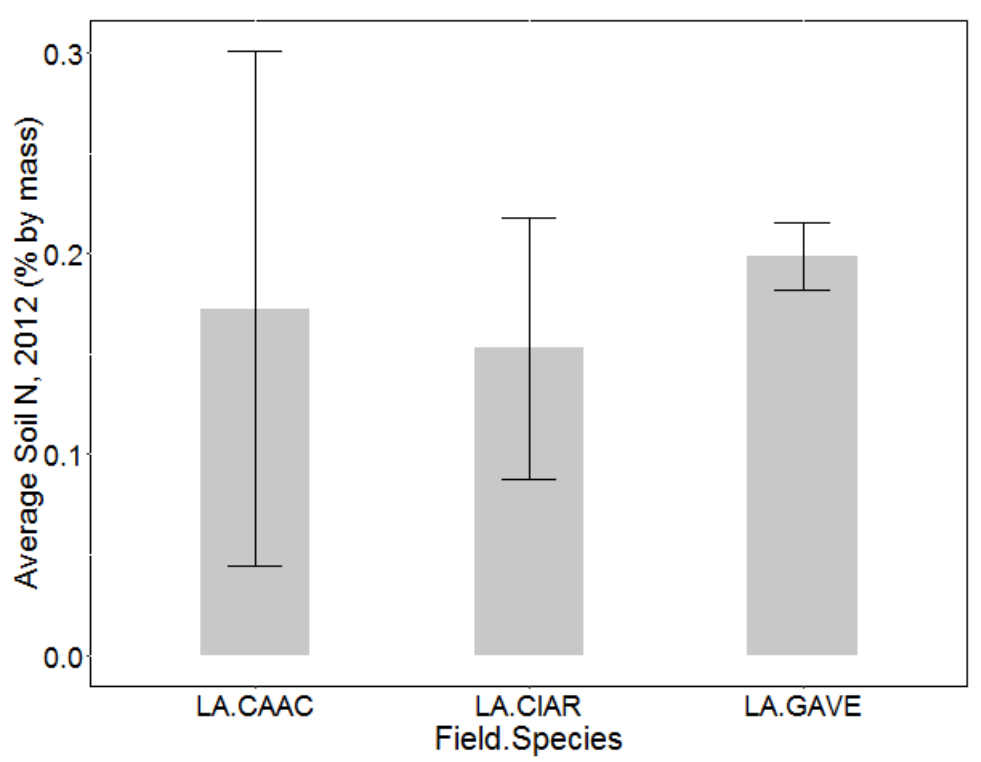

(a)

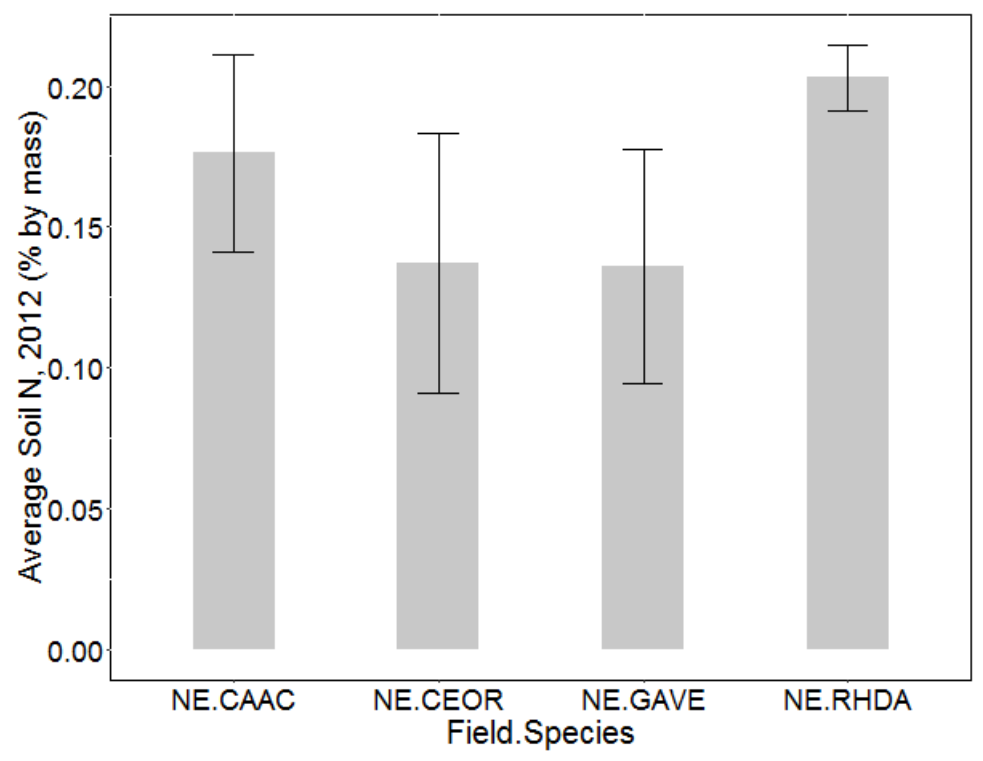

(c)

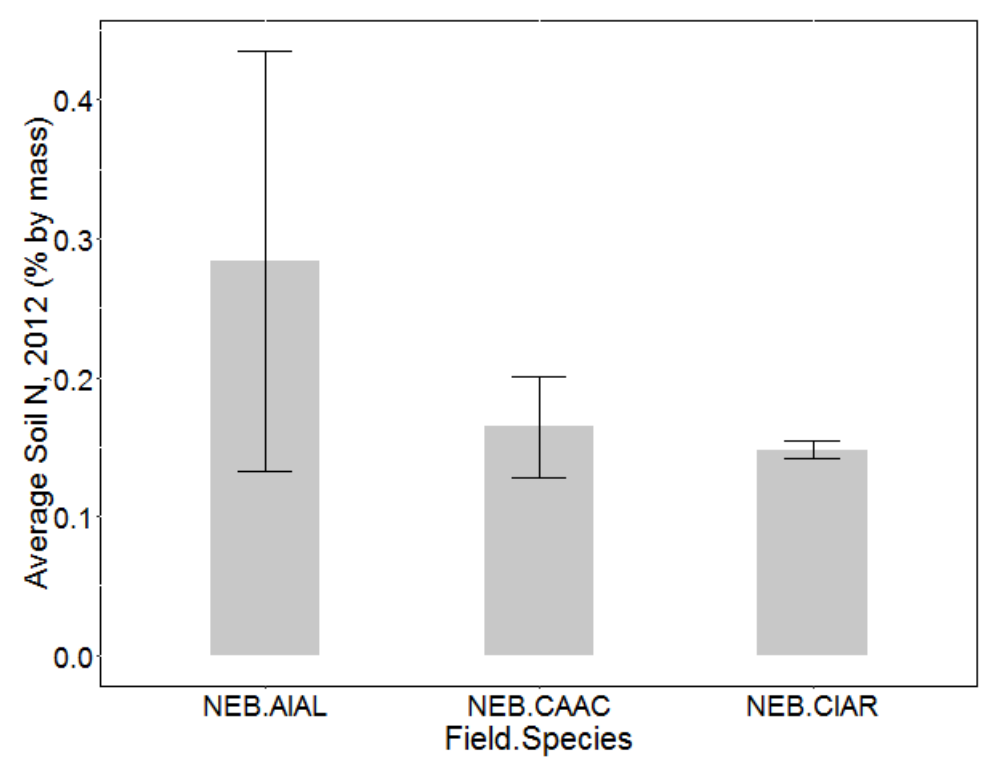

(b)

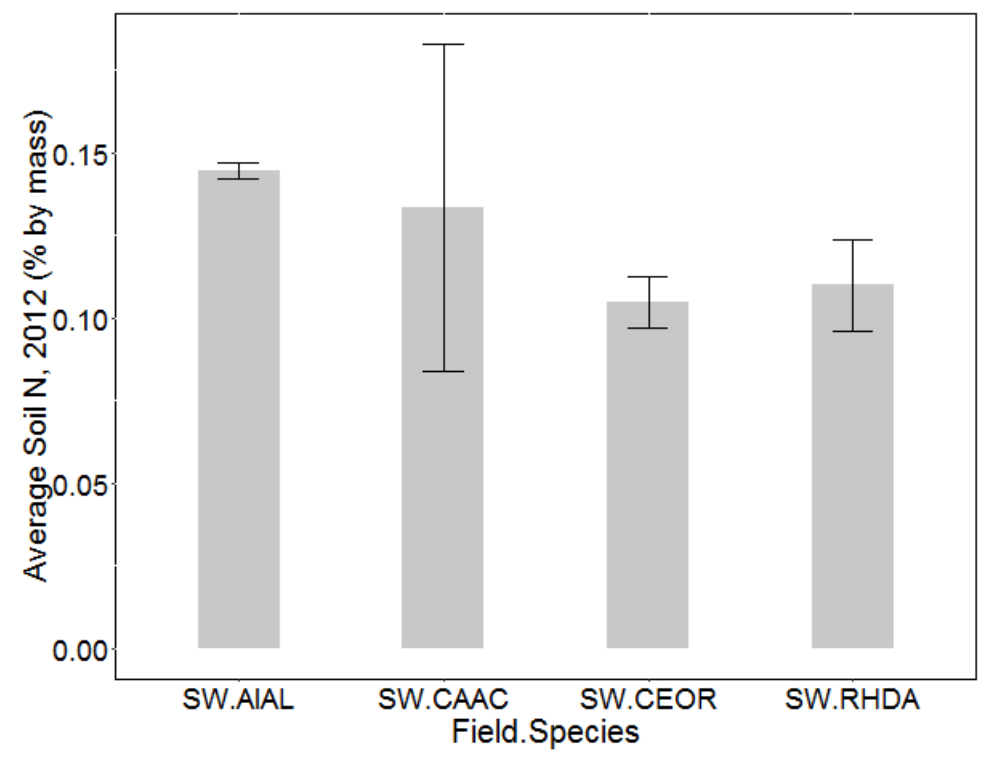

(d)

Figure 21: Average soil nitrogen (\% by mass) for the summer of 2012 by species (Ailanthus altissima (AIAL), Carduus acanthoides (CAAC), Celastrus orbiculatus (CEOR), Cirsium arvense (CIAR), Galium verum (GAVE), and Rhamnus davurica (RHDA)) for the fields a) Lake Arnold (LA), b) the northeast boundary (NEB), c) the northeast field chronosequence $(\mathrm{NE})$, and d) the southwest field chronosequence at the Blandy Experimental Farm in northcentral Virginia. No comparisons led to significant differences at $\mathrm{p}<0.05$. 


\subsubsection{Leaf Carbon and Nitrogen}

Leaf $\mathrm{C}$ and $\mathrm{N}$ field comparisons varied by year. In 2011, NEB had greater leaf $\mathrm{N}$ than LA, but similar leaf C, while in 2012, NEB had greater leaf C and leaf N than LA. SW had greater leaf $\mathrm{N}$ than $\mathrm{NE}$, but similar leaf $\mathrm{C}$ in both years. Leaf $\mathrm{C}$ and $\mathrm{N}$ were similar across stages in NE and SW except that NEL had greater leaf $\mathrm{N}$ than NEE when only $R$. davurica samples were considered in 2011. There were many similarities in leaf $\mathrm{C}$ and $\mathrm{N}$ levels across species, with several exceptions (Figures 22 and 23). R. davurica had greater leaf $\mathrm{C}$ and lower leaf $\mathrm{N}$ than $C$. acanthoides in SWE during 2011. Within SWM, A. altissima also had greater leaf C than C. acanthoides, but similar leaf N. Within NEE, C. acanthoides had greater leaf $\mathrm{N}$ than $G$. verum and $R$. davurica but similar leaf C. Within NEL, $A$. altissima had greater leaf $\mathrm{N}$ than $R$. davurica but similar leaf $\mathrm{C}$. There were several specieslevel differences in 2012. G. verum had greater leaf $\mathrm{C}$ and lower leaf $\mathrm{N}$ than C. acanthoides and C. arvense in Lake Arnold. A. altissima had greater leaf C than C. acanthoides and C. arvense but similar $\mathrm{N}$ in the northeast boundary. R. davurica had greater leaf $\mathrm{C}$ and lower leaf $\mathrm{N}$ than $C$. acanthoides in the northeast field chronosequence. G. verum and $R$. davurica had greater leaf $\mathrm{C}$ than $C$. orbiculatus, and G. verum had greater leaf $\mathrm{N}$ than C. orbiculatus also in the northeast field. In the same field, G. verum had greater leaf C than $R$. davurica but similar leaf N. A. altissima had greater leaf $\mathrm{C}$ than $C$. acanthoides, $C$. orbiculatus, and R. davurica and greater leaf $\mathrm{N}$ than $C$. orbiculatus and $R$. davurica in the

southwest field chronosequence. Also in the southwest field, C. orbiculatus had greater leaf C than C. acanthoides but similar leaf N. 


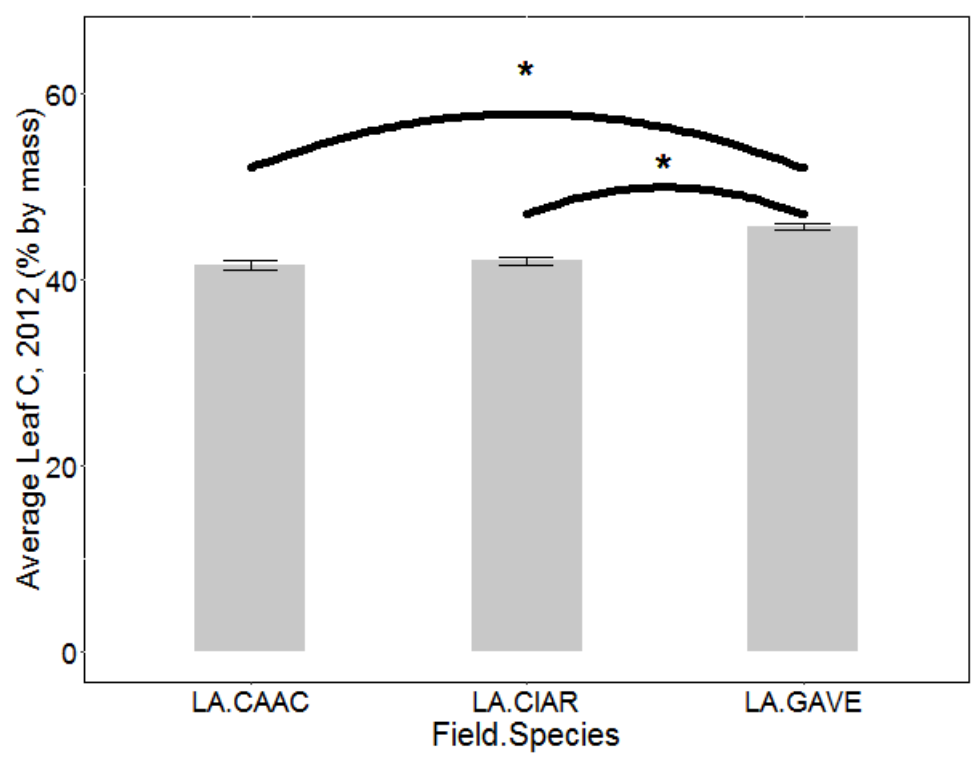

(a)

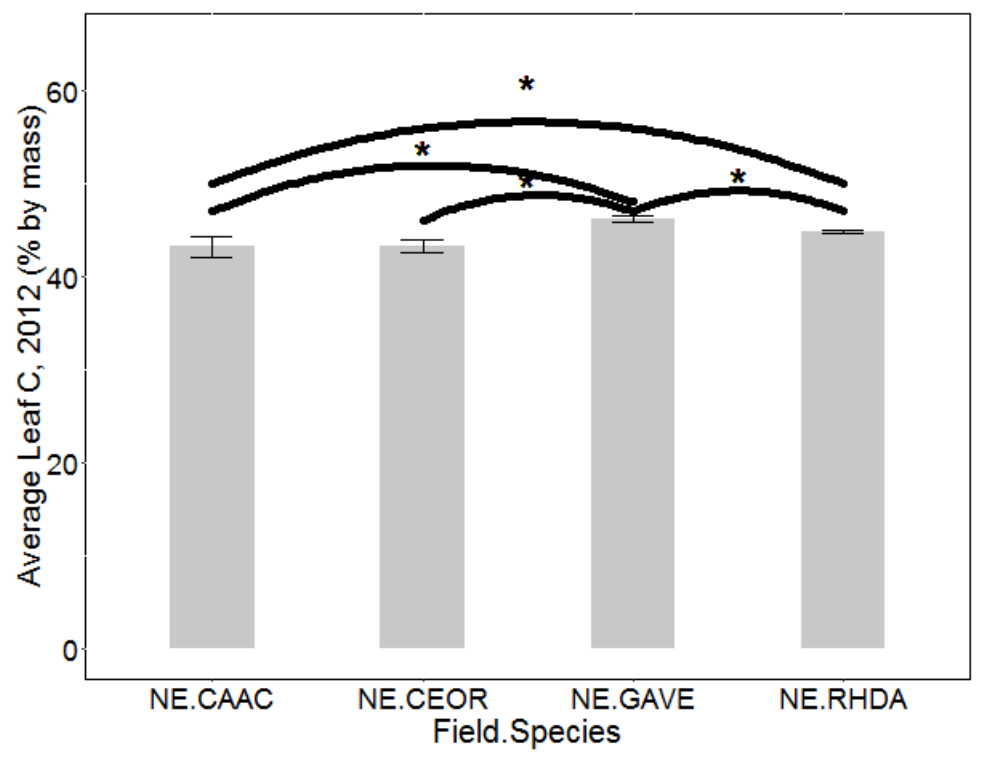

(c)

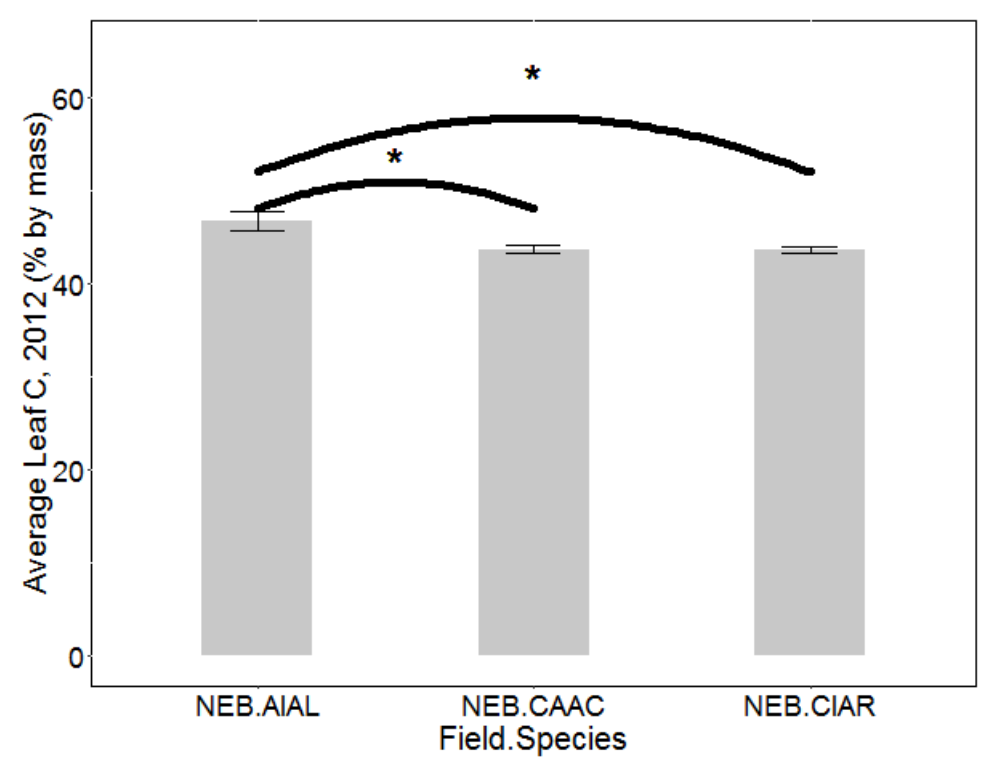

(b)

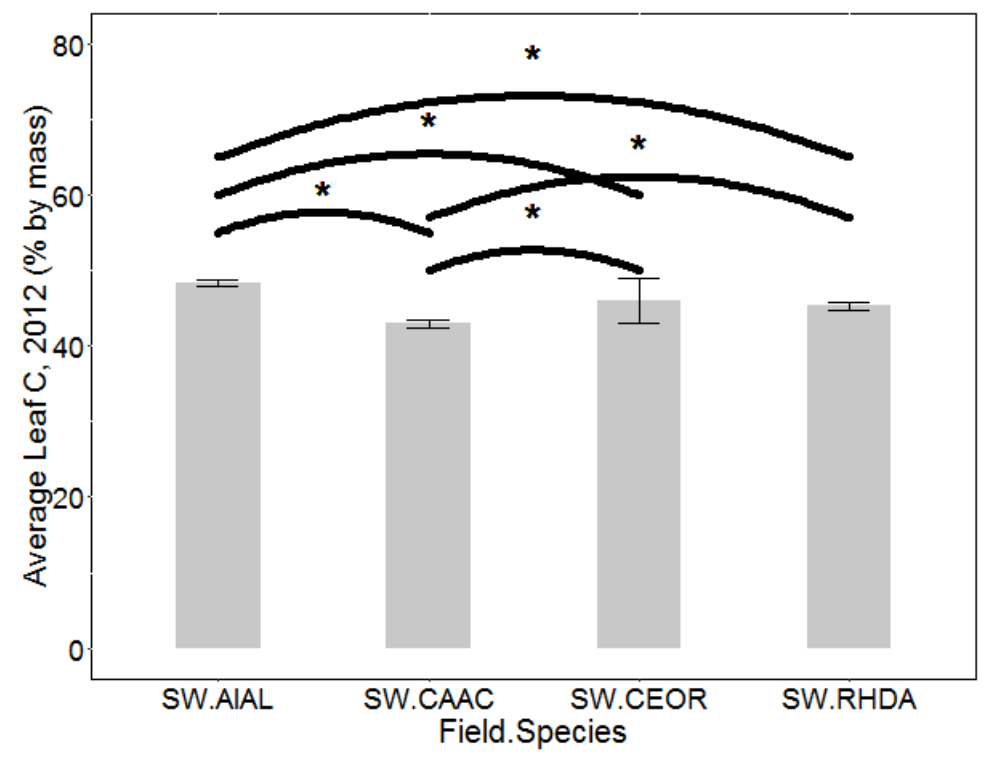

(d)

Figure 22: Average leaf carbon (\% by mass) for the summer of 2012 by species (Ailanthus altissima (AIAL), Carduus acanthoides (CAAC), Celastrus orbiculatus (CEOR), Cirsium arvense (CIAR), Galium verum (GAVE), and Rhamnus davurica (RHDA)) for the fields a) Lake Arnold (LA), b) the northeast boundary (NEB), c) the northeast field chronosequence $(\mathrm{NE})$, and d) the southwest field chronosequence at the Blandy Experimental Farm in northcentral Virginia. Asterisks represent significant differences at $\mathrm{p}<0.05$. 


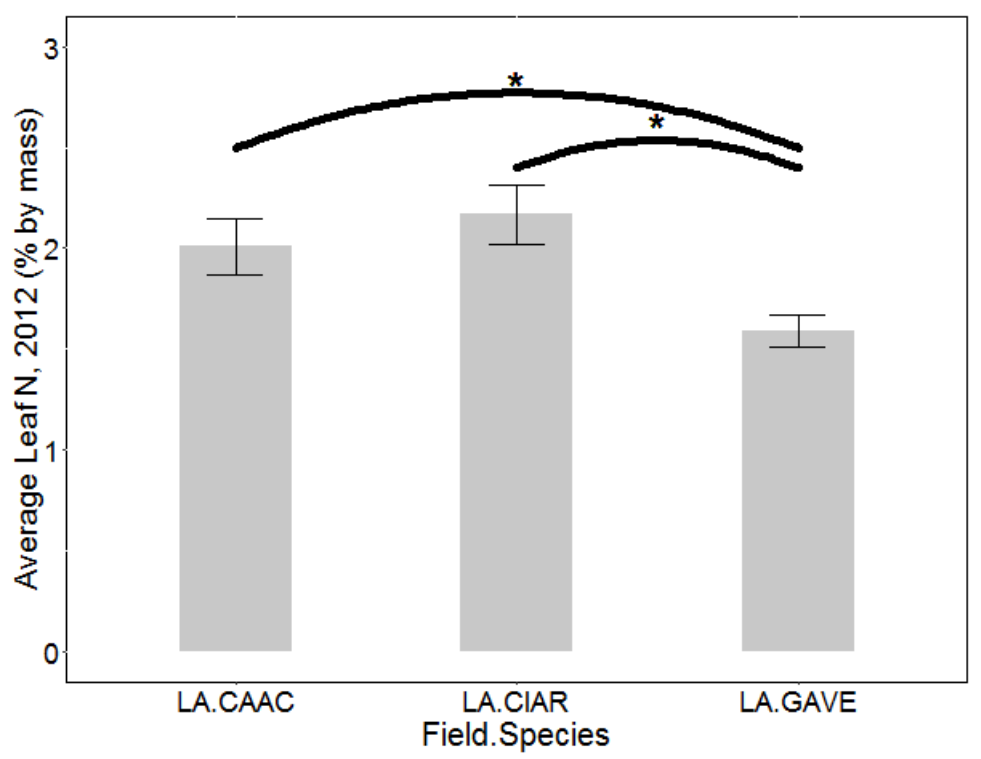

(a)

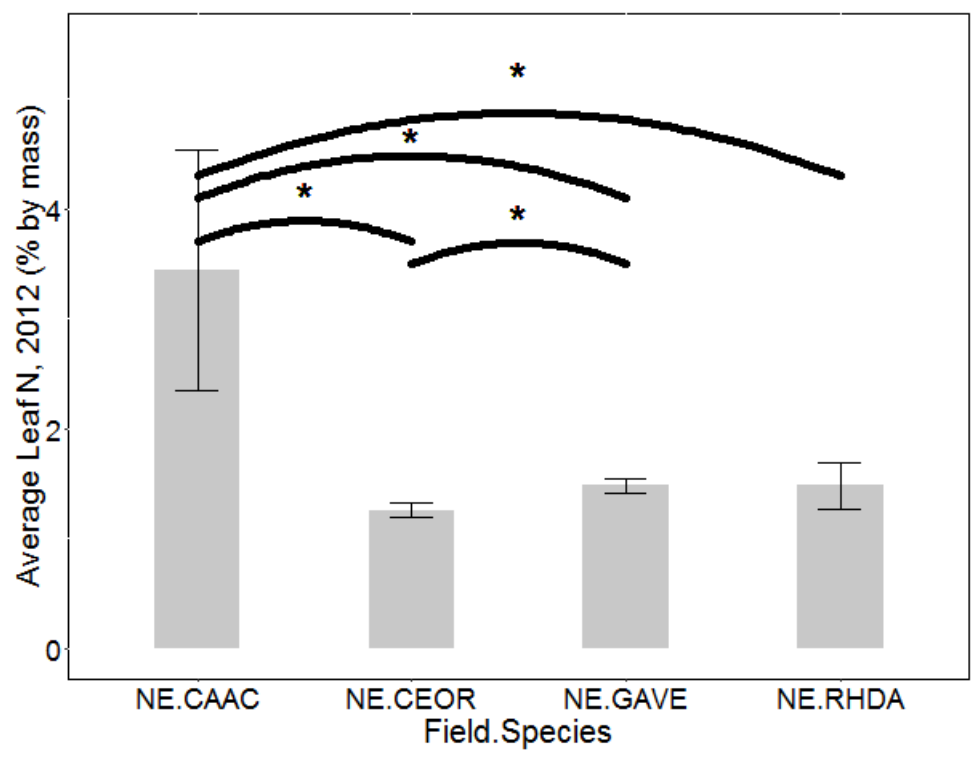

(c)

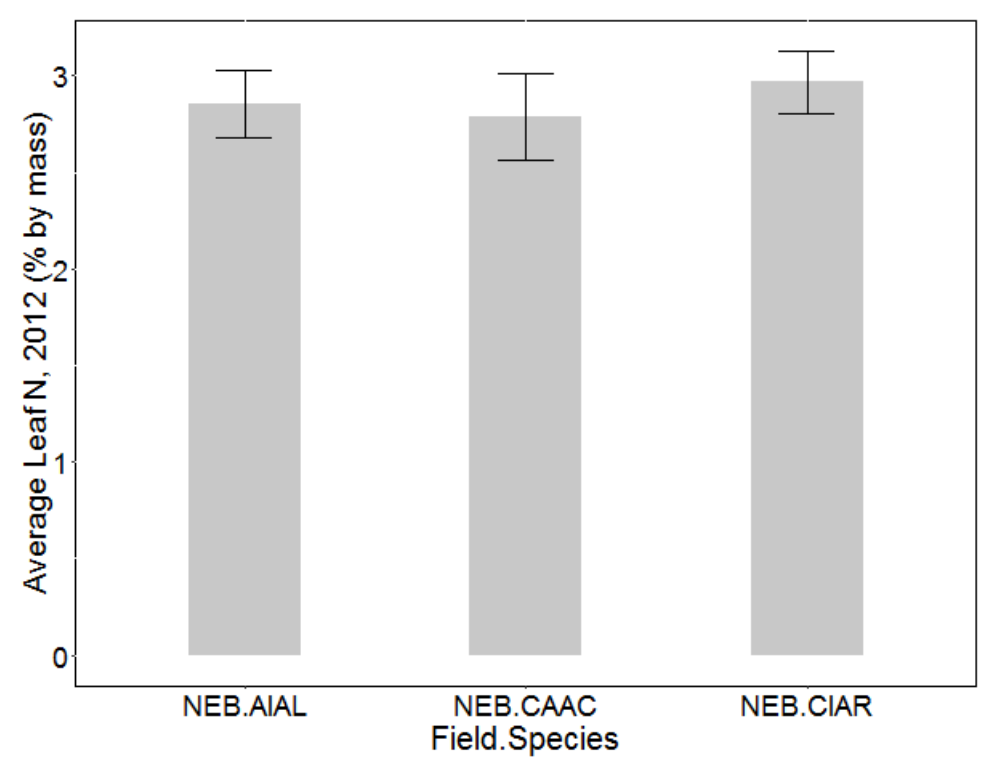

(b)

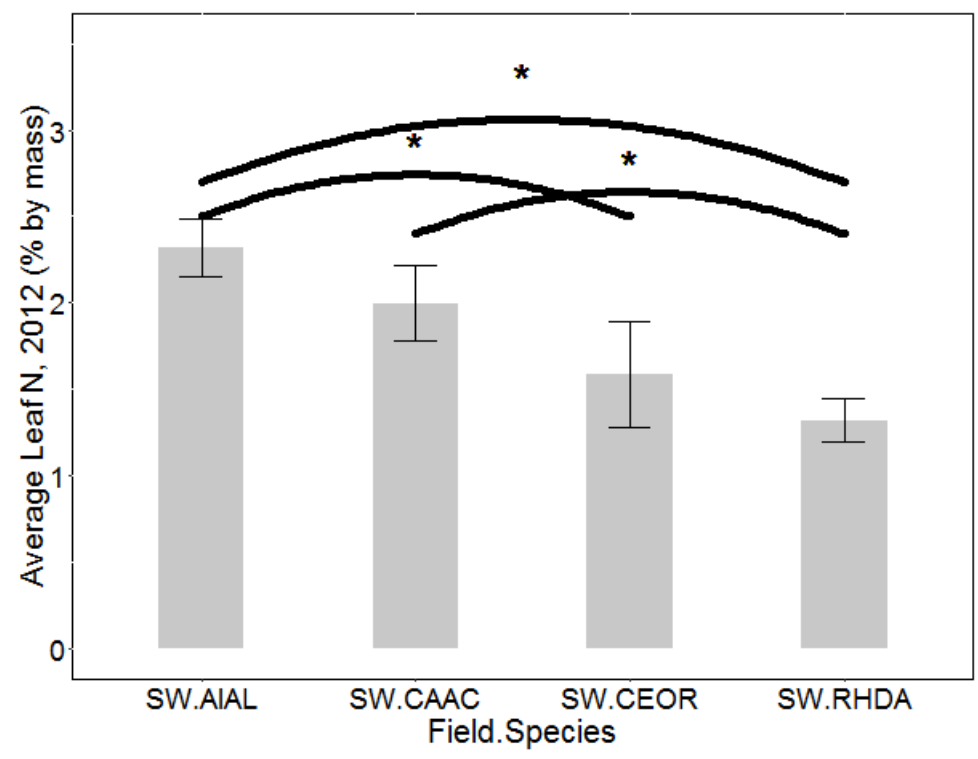

(d)

Figure 23: Average leaf nitrogen (\% by mass) for the summer of 2012 by species (Ailanthus altissima (AIAL), Carduus acanthoides (CAAC), Celastrus orbiculatus (CEOR), Cirsium arvense (CIAR), Galium verum (GAVE), and Rhamnus davurica (RHDA)) for the fields a) Lake Arnold (LA), b) the northeast boundary (NEB), c) the northeast field chronosequence $(\mathrm{NE})$, and d) the southwest field chronosequence at the Blandy Experimental Farm in northcentral Virginia. Asterisks represent significant differences at $\mathrm{p}<0.05$. 


\subsection{Discussion}

Overall, there were differences between fields and stages in terms of soil and leaf characteristics, but these differences varied by year. This may be due to differences in plot locations (transects vs community and population plots), differences in weather, and limited sample sizes. Many of the stage effects observed follow predictions of succession. There were fewer differences among species than across fields and stages for both years.

\subsubsection{Soil temperature, moisture, and $\mathrm{pH}$}

LA and NEB were not significantly different in terms of temperature in 2011, but were different in terms of moisture. The difference in moisture may be due to differences in topography, as Lake Arnold is a depression collecting water and the NEB is essentially flat. It is interesting that in 2012, LA had greater soil moisture and soil temperature, as I thought higher soil temperatures would be correlated with lower soil moisture levels. Indeed, this was observed in soil temperature and soil moisture measurements throughout the summer of 2011, where temperatures increased throughout the summer and moisture decreased. This discrepancy across fields may be because the soil temperature is more influenced by lack of shading at LA, as opposed to large amounts of shading in NEB, than by soil moisture.

It was expected that early stages of succession would have higher soil temperatures and lower soil moisture levels than later stages; this was to some extent supported. For example, SWE had higher soil temperatures than SWM, and NEM had greater soil moisture levels than NEE in 2011. In 2012, NEL had greater soil moisture than NEE, and SWM had greater soil moisture than SWE. This was also observed in the SW looking at only $R$. davurica across successional stages, as SWE had higher soil temperatures than SWM in 2011.

It is also interesting that LA had a higher soil $\mathrm{pH}$ and higher soil moisture levels than 
NEB. I thought that these would also be negatively correlated, as soils with high moisture tend to have greater production of carbonic acid from mixing of $\mathrm{CO}_{2}$ and $\mathrm{H}_{2} \mathrm{O}$. Along the same line, it was also unexpected that NE and SW differed in soil moisture but not in $\mathrm{pH}$.

The lack of a negative correlation between soil moisture and soil $\mathrm{pH}$ at the field level may be due to other factors that influence soil $\mathrm{pH}$ than soil moisture. Fields may have differed in terms of land use history and management practices. Soil fertilization has been found to decrease soil pH (Sainju et al., 2015; Tian and Niu, 2015). However, this

decrease depends on ecosystem type, amount of organic matter, temperature, precipitation, nitrogen addition rates, the forms of nitrogen added, and the duration of the management regime (Tian and Niu, 2015). Sites with high organic matter may have less soil acidification because of the higher cation exchange capacity (Tian and Niu, 2015). The addition of urea and $\mathrm{NH}_{4} \mathrm{NO}_{3}$ can lead to greater soil acidification than the addition of $\mathrm{NH}_{4}{ }^{+}$(Tian and Niu, 2015). Effects of fertilization on soil pH have lasted for up to 20 years (Tian and Niu, 2015).

The expected inverse correlation between soil moisture and soil $\mathrm{pH}$ was supported across successional stages. NEL had greater soil moisture and lower pH than NEE in 2012. A similar relationship was found between SWE and SWM. This was also supported in the NE field with 2011 comparisons of $R$. davurica across successional stages, as NEL had greater moisture levels and lower $\mathrm{pH}$ than NEE.

\subsubsection{Soil $\mathrm{C}$ and $\mathrm{N}$, Leaf $\mathrm{C}$ and $\mathrm{N}$}

Soil C and N values differed across fields; the NE had greater soil C and N than SW in both years and NEB had greater levels of both than LA in 2012. This might be due to differences in management histories. With agricultural land use, there is a depletion of soil $\mathrm{C}$ and $\mathrm{N}$ as decomposition rates are accelerated through tillage and aboveground growth is harvested. Thus, as succession proceeds with a decrease in soil disturbance and an increase in plant litter input, there should be an increase in soil $\mathrm{C}$ and $\mathrm{N}$. This was observed in this 
study, as NEL had greater amounts of both than NEM in 2011, and in 2012 NEL had greater amounts of both than NEE. This was also observed when assessing $R$. davurica across stages, as NEL had greater soil C and N than NEM, and SWL greater than SWM.

Also as succession proceeds, there is an increase in N-use efficiency in plants. However, there were no stage-level differences in leaf $\mathrm{C}$ and $\mathrm{N}$ levels. This might be because the increase in resource use efficiency is more apparent in other parts of the plant than leaves, such as the wood which has high $\mathrm{C}: \mathrm{N}$ ratios. The long time over which soil changes take place over succession might also explain why I did not observe differences in leaf nutrients with succession. As an example, Compton et al. (1998) found that C:N ratios only weakly increased over time since abandonment.

Similarly, there may have been a lack of species effects because successional changes are stronger than species level changes at Blandy. This supports Tscherko et al. (2005), who found no species-level influences on soil characteristics and soil communities during the first 43 years of succession. Yelenik and Levine (2011) also found that aboveground competition was more important in influencing the trajectory of changes in species composition in native species recovery than were plant-soil feedbacks under exotic species. Compton et al. (1998) also found that land use history had a strong influence on field characteristics after abandonment, but after 50 years since abandonment, species effects became more influential. Another reason for the lack of differences in soil characteristics across species may be that soil $\mathrm{C}$ and $\mathrm{N}$ content was measured, not the rates of change in soil $\mathrm{C}$ and $\mathrm{N}$. Rates may be more influenced by invasive species than content.

When comparing successional stages, there are several factors that may need to be considered. For example, variation in vegetation structure, species composition, plant community properties, productivity, and other ecosystem properties at similar stages of succession can be due to differences in environmental variables, precipitation regimes, soil nutrients, rates of herbivory, land-use history, seed availability, seed dispersal mode, and soil treatment 
at abandonment (Aragon and Morales, 2003; Arroyo-Mora et al., 2005; Grau et al., 1997; Otto et al., 2006; Riedel and Epstein, 2005; Tilman, 1987). Additionally, successional trajectory and outcome are influenced by life history traits, interspecific interactions, type of substrate, starting vegetation composition, and precipitation regime (Otto et al., 2006; Rebele, 1992; Walker and Chapin, 1987). Rates of herbivory can also influence rate of succession (Fraser and Grime, 1999). Thus, several factors need to be considered when observing changes through succession, and these observations must be extended to long periods of time after abandonment.

\section{Conclusion}

I examined changes in soil and vegetation characteristics in secondary successional field chronosequences, assessing differences over time, field, stage, and species. I found that temperature increased and soil moisture decreased as the summer progressed. There were field-level differences in all soil and vegetation characteristics. Soil temperature and soil moisture differed by stage, with earlier stages often being warmer and drier. Soil pH was inversely correlated with soil moisture within stages, as expected. Soil C and N increased with succession as expected; however, leaf $\mathrm{C}$ and $\mathrm{N}$ were similar across successional stages, maybe because the increase in resource use efficiency is more apparent in other parts of the plant, such as the wood. Species also did not differ often by soil and vegetation characteristics. This may be because the effects of succession or land use history are stronger than species-

level effects during the time since abandonment studied here. Hence, it may be interesting to continue studying these characteristics for longer periods of time since abandonment to detect species effects. 
Table 12: Differences in soil temperature across fields, stages, and species

\begin{tabular}{|c|c|c|c|}
\hline Level & Year & Comparison & $\mathrm{P}$-value \\
\hline$\overline{\text { Field }}$ & 2011 & $\mathrm{LA}=\mathrm{NEB}$ & $\overline{0.20}$ \\
\hline Field & 2011 & $\mathrm{NE}>\mathrm{SW}$ & 0.01 \\
\hline Field & 2012 & $\mathrm{LA}>\mathrm{NEB}$ & 0.03 \\
\hline Field & 2012 & $\mathrm{SW}=\mathrm{NE}$ & 0.60 \\
\hline Stage & 2011 & $\mathrm{NEE}=\mathrm{NEM}$ & 0.21 \\
\hline Stage & 2011 & $\mathrm{NEM}=\mathrm{NEL}$ & 0.11 \\
\hline Stage & 2011 & $\mathrm{SWE}>\mathrm{SWM}$ & 2.E-04 \\
\hline Stage & 2012 & $\mathrm{NEE}>\mathrm{NEM}$ & 0.02 \\
\hline Stage & 2012 & $\mathrm{NEE}=\mathrm{NEL}$ & 0.11 \\
\hline Stage & 2012 & $\mathrm{NEM}=\mathrm{NEL}$ & 0.76 \\
\hline Stage & 2012 & $\mathrm{SWE}=\mathrm{SWM}$ & 0.06 \\
\hline Stage & 2012 & $\mathrm{SWE}=\mathrm{SWL}$ & 0.28 \\
\hline Stage & 2012 & $\mathrm{SWM}=\mathrm{SWL}$ & 0.64 \\
\hline R. davurica & 2011 & $\mathrm{NEE}=\mathrm{NEM}$ & 0.96 \\
\hline R. davurica & 2011 & $\mathrm{NEE}=\mathrm{NEL}$ & 0.26 \\
\hline R. davurica & 2011 & $\mathrm{NEM}=\mathrm{NEL}$ & 0.44 \\
\hline R. davurica & 2011 & $\mathrm{SWE}>\mathrm{SWM}$ & 1.E-04 \\
\hline R. davurica & 2011 & SWE-SWL & . \\
\hline R. davurica & 2011 & SWM-SWL & . \\
\hline Species & 2011 & $\mathrm{NEE} \mathrm{CAAC}=\mathrm{GAVE}$ & 0.18 \\
\hline Species & 2011 & $\mathrm{NEE} \mathrm{CAAC}=\mathrm{RHDA}$ & 0.08 \\
\hline Species & 2011 & NEE GAVE $=$ RHDA & 0.97 \\
\hline Species & 2011 & NEM AIAL $=$ CAAC & 0.29 \\
\hline Species & 2011 & NEM AIAL $=$ GAVE & 0.45 \\
\hline Species & 2011 & NEM AIAL $=$ RHDA & 0.46 \\
\hline Species & 2011 & NEM CAAC $=$ GAVE & 0.90 \\
\hline Species & 2011 & $\mathrm{NEM} \mathrm{CAAC}=\mathrm{RHDA}$ & 0.85 \\
\hline Species & 2011 & NEM GAVE $=$ RHDA & 1.00 \\
\hline Species & 2011 & NEL AIAL-RHDA & . \\
\hline Species & 2011 & $\mathrm{SWE} \mathrm{CAAC}=\mathrm{RHDA}$ & 0.42 \\
\hline Species & 2011 & SWM CAAC $>$ AIAL & 0.01 \\
\hline Species & 2011 & SWM AIAL=RHDA & 0.56 \\
\hline Species & 2011 & SWM CAAC $>$ RHDA & 3.E-03 \\
\hline Species & 2012 & LA CAAC=GAVE & 0.86 \\
\hline Species & 2012 & NEB CAAC $>$ AIAL & 0.04 \\
\hline Species & 2012 & NEE GAVE $>$ CEOR & 0.04 \\
\hline Species & 2012 & NEE $\mathrm{CEOR}=\mathrm{RHDA}$ & 0.85 \\
\hline Species & 2012 & NEE GAVE $>$ RHDA & 0.04 \\
\hline Species & 2012 & $\mathrm{SWE} \mathrm{CAAC}=\mathrm{CEOR}$ & 0.98 \\
\hline Species & 2012 & $\mathrm{SWE} \mathrm{CAAC}=\mathrm{RHDA}$ & 1.00 \\
\hline Species & 2012 & $\mathrm{SWE} \mathrm{CEOR}=\mathrm{RHDA}$ & 0.99 \\
\hline
\end{tabular}


Table 13: Differences in soil moisture across fields, stages, and species

\begin{tabular}{|c|c|c|c|}
\hline Level & Year & Comparison & $\mathrm{P}$-value \\
\hline Field & 2011 & LA $>$ NEB & $<<1 . \mathrm{E}-04$ \\
\hline Field & 2011 & $\mathrm{NE}=\mathrm{SW}$ & 0.37 \\
\hline Field & 2012 & $\mathrm{LA}>\mathrm{NEB}$ & 0.04 \\
\hline Field & 2012 & $\mathrm{NE}>\mathrm{SW}$ & 4.E-03 \\
\hline Stage & 2011 & $\mathrm{NEM}>\mathrm{NEE}$ & 0.02 \\
\hline Stage & 2011 & $\mathrm{NEM}=\mathrm{NEL}$ & 0.17 \\
\hline Stage & 2011 & $\mathrm{SWM}>\mathrm{SWE}$ & 0.05 \\
\hline Stage & 2012 & $\mathrm{NEE}=\mathrm{NEM}$ & 0.34 \\
\hline Stage & 2012 & NEL $>$ NEE & 0.03 \\
\hline Stage & 2012 & $\mathrm{NEM}=\mathrm{NEL}$ & 0.06 \\
\hline Stage & 2012 & $\mathrm{SWM}>\mathrm{SWE}$ & 0.01 \\
\hline Stage & 2012 & $\mathrm{SWE}=\mathrm{SWL}$ & 0.79 \\
\hline Stage & 2012 & $\mathrm{SWM}=\mathrm{SWL}$ & 0.63 \\
\hline R. davurica & 2011 & $\mathrm{NEM}>\mathrm{NEE}$ & 0.04 \\
\hline R. davurica & 2011 & $\mathrm{NEL}>\mathrm{NEE}$ & 0.03 \\
\hline R. davurica & 2011 & $\mathrm{NEM}=\mathrm{NEL}$ & 0.96 \\
\hline R. davurica & 2011 & $\mathrm{SWE}=\mathrm{SWM}$ & 0.44 \\
\hline R. davurica & 2011 & SWE-SWL & 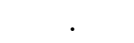 \\
\hline R. davurica & 2011 & SWM-SWL & \\
\hline Species & 2011 & NEE $\mathrm{CAAC}=\mathrm{GAVE}$ & 0.67 \\
\hline Species & 2011 & NEE CAAC $=$ RHDA & 0.55 \\
\hline Species & 2011 & NEE GAVE $=$ RHDA & 0.17 \\
\hline Species & 2011 & NEM AIAL-CAAC & \\
\hline Species & 2011 & NEM AIAL-GAVE & \\
\hline Species & 2011 & NEM AIAL-RHDA & \\
\hline Species & 2011 & NEM CAAC $=$ GAVE & 0.50 \\
\hline Species & 2011 & NEM CAAC $=$ RHDA & 0.99 \\
\hline Species & 2011 & NEM GAVE $=$ RHDA & 0.45 \\
\hline Species & 2011 & NEL AIAL > RHDA & 0.03 \\
\hline Species & 2011 & SWE $\mathrm{CAAC}=\mathrm{RHDA}$ & 0.22 \\
\hline Species & 2011 & SWM AIAL=CAAC & 0.74 \\
\hline Species & 2011 & SWM AIAL=RHDA & 0.61 \\
\hline Species & 2011 & SWM CAAC $=$ RHDA & 0.40 \\
\hline Species & 2012 & LA CAAC=CIAR & 0.41 \\
\hline Species & 2012 & LA CAAC=GAVE & 0.41 \\
\hline Species & 2012 & LA CIAR=GAVE & 0.87 \\
\hline Species & 2012 & NEB AIAL $=$ CAAC & 0.87 \\
\hline Species & 2012 & NEB AIAL=CIAR & 0.87 \\
\hline Species & 2012 & NEB CAAC $=$ CIAR & 1.00 \\
\hline Species & 2012 & NEE CAAC=CEOR & $>0.05$ \\
\hline Species & 2012 & NEE CAAC=GAVE & $>0.05$ \\
\hline Species & 2012 & NEE CAAC=RHDA & $>0.05$ \\
\hline Species & 2012 & NEE $\mathrm{CEOR}=\mathrm{GAVE}$ & $>0.05$ \\
\hline Species & 2012 & NEE CEOR=RHDA & $>0.05$ \\
\hline Species & 2012 & NEE GAVE $=$ RHDA & $>0.05$ \\
\hline Species & 2012 & SWE AIAL $=$ CAAC & 0.53 \\
\hline Species & 2012 & SWE AIAL $=$ CEOR & 0.53 \\
\hline Species & 2012 & SWE AIAL $=$ RHDA & 0.53 \\
\hline Species & 2012 & $\mathrm{SWE} \mathrm{CAAC}=\mathrm{CEOR}$ & 0.94 \\
\hline Species & 2012 & SWE CAAC=RHDA & 1.00 \\
\hline Species & 2012 & SWE CEOR=RHDA & 0.94 \\
\hline
\end{tabular}


Table 14: Differences in soil pH across fields, stages, and species

\begin{tabular}{|c|c|c|c|}
\hline Level & Year & Comparison & P-value \\
\hline Field & 2011 & LA $>$ NEB & $<1 . \mathrm{E}-04$ \\
\hline Field & 2011 & $\mathrm{SW}=\mathrm{NE}$ & 0.25 \\
\hline Field & 2012 & $\mathrm{LA}>\mathrm{NEB}$ & $<0.05$ \\
\hline Field & 2012 & $\mathrm{SW}=\mathrm{NE}$ & $>0.05$ \\
\hline Stage & 2011 & $\mathrm{NEE}=\mathrm{NEM}$ & 0.14 \\
\hline Stage & 2011 & $\mathrm{NEM}>\mathrm{NEL}$ & 0.02 \\
\hline Stage & 2011 & $\mathrm{SWE}>\mathrm{SWM}$ & $<1$.E-04 \\
\hline Stage & 2012 & $\mathrm{NEE}=\mathrm{NEM}$ & 0.99 \\
\hline Stage & 2012 & NEE $>$ NEL & 0.01 \\
\hline Stage & 2012 & $\mathrm{NEM}=\mathrm{NEL}$ & 0.15 \\
\hline Stage & 2012 & $\mathrm{SWE}=\mathrm{SWM}$ & 0.89 \\
\hline Stage & 2012 & $\mathrm{SWE}=\mathrm{SWL}$ & 0.39 \\
\hline Stage & 2012 & $\mathrm{SWM}=\mathrm{SWL}$ & 0.48 \\
\hline R. davurica & 2011 & $\mathrm{NEE}=\mathrm{NEM}$ & $>0.05$ \\
\hline R. davurica & 2011 & NEE $>$ NEL & $<0.05$ \\
\hline R. davurica & 2011 & $\mathrm{NEM}=\mathrm{NEL}$ & $>0.05$ \\
\hline R. davurica & 2011 & $\mathrm{SWE}>\mathrm{SWM}$ & 1.E-03 \\
\hline R. davurica & 2011 & SWL $>$ SWE & 8.E-03 \\
\hline R. davurica & 2011 & $\mathrm{SWL}>\mathrm{SWM}$ & $<1$.E-04 \\
\hline Species & 2011 & NEE CAAC $>$ GAVE & 7.E-03 \\
\hline Species & 2011 & NEE CAAC $=$ RHDA & 0.21 \\
\hline Species & 2011 & NEE GAVE $=$ RHDA & 0.55 \\
\hline Species & 2011 & NEM AIAL $=$ CAAC & 0.34 \\
\hline Species & 2011 & NEM AIAL=GAVE & 0.27 \\
\hline Species & 2011 & NEM AIAL $=$ RHDA & 0.20 \\
\hline Species & 2011 & NEM CAAC $=$ GAVE & 0.08 \\
\hline Species & 2011 & NEM CAAC $=$ RHDA & 0.98 \\
\hline Species & 2011 & NEM GAVE $=$ RHDA & 0.26 \\
\hline Species & 2011 & NEL AIAL=RHDA & 0.09 \\
\hline Species & 2011 & SWE $\mathrm{CAAC}=\mathrm{RHDA}$ & 0.39 \\
\hline Species & 2011 & SWM AIAL $=$ CAAC & 0.72 \\
\hline Species & 2011 & SWM AIAL $>$ RHDA & 8.E-03 \\
\hline Species & 2011 & SWM CAAC $=$ RHDA & 0.66 \\
\hline Species & 2012 & LA CAAC > CIAR & $<0.05$ \\
\hline Species & 2012 & LA GAVE $>$ CAAC & $<0.05$ \\
\hline Species & 2012 & LA GAVE $>$ CIAR & $<0.05$ \\
\hline Species & 2012 & NEB AIAL $=$ CAAC & 1.00 \\
\hline Species & 2012 & NEB AIAL=CIAR & 0.23 \\
\hline Species & 2012 & NEB CAAC $=$ CIAR & 0.09 \\
\hline Species & 2012 & NEE CAAC=CEOR & 0.14 \\
\hline Species & 2012 & NEE $\mathrm{CAAC}=\mathrm{GAVE}$ & 0.05 \\
\hline Species & 2012 & NEE CAAC=RHDA & 1.00 \\
\hline Species & 2012 & NEE $\mathrm{CEOR}=\mathrm{GAVE}$ & 0.91 \\
\hline Species & 2012 & NEE $\mathrm{CEOR}=\mathrm{RHDA}$ & 0.14 \\
\hline Species & 2012 & NEE GAVE=RHDA & 0.05 \\
\hline Species & 2012 & SWE AIAL=CAAC & 0.41 \\
\hline Species & 2012 & SWE AIAL $=$ CEOR & 1.00 \\
\hline Species & 2012 & SWE AIAL=RHDA & 0.14 \\
\hline Species & 2012 & $\mathrm{SWE} \mathrm{CAAC}=\mathrm{CEOR}$ & 0.78 \\
\hline Species & 2012 & $\mathrm{SWE}$ CAAC $=\mathrm{RHDA}$ & 1.00 \\
\hline Species & 2012 & SWE $\mathrm{CEOR}=\mathrm{RHDA}$ & 0.14 \\
\hline
\end{tabular}


Table 15: Differences in soil carbon (C) across fields, stages, and species

\begin{tabular}{|c|c|c|c|}
\hline Level & Year & Comparison & P-value \\
\hline Field & 2011 & $\mathrm{LA}=\mathrm{NEB}$ & $>0.05$ \\
\hline Field & 2011 & $\mathrm{NE}>\mathrm{SW}$ & $<0.05$ \\
\hline Field & 2012 & $\mathrm{LA}=\mathrm{NEB}$ & 0.15 \\
\hline Field & 2012 & $\mathrm{NE}>\mathrm{SW}$ & 0.02 \\
\hline Stage & 2011 & NEE $>$ NEM & $<1$.E-04 \\
\hline Stage & 2011 & NEL $>$ NEM & 5.E-04 \\
\hline Stage & 2011 & $\mathrm{SWE}=\mathrm{SWM}$ & 0.39 \\
\hline Stage & 2012 & $\mathrm{NEE}=\mathrm{NEM}$ & 0.63 \\
\hline Stage & 2012 & NEL $>$ NEE & 8.E-03 \\
\hline Stage & 2012 & NEL $>$ NEM & 6.E-04 \\
\hline Stage & 2012 & $\mathrm{SWE}=\mathrm{SWM}$ & 0.54 \\
\hline Stage & 2012 & $\mathrm{SWL}>\mathrm{SWE}$ & 1.E-03 \\
\hline Stage & 2012 & $\mathrm{SWM}=\mathrm{SWL}$ & 0.09 \\
\hline R. davurica & 2011 & $\mathrm{NEE}=\mathrm{NEM}$ & 0.36 \\
\hline R. davurica & 2011 & $\mathrm{NEE}=\mathrm{NEL}$ & 1.00 \\
\hline R. davurica & 2011 & NEL $>$ NEM & 0.02 \\
\hline R. davurica & 2011 & $\mathrm{SWE}=\mathrm{SWM}$ & 0.90 \\
\hline R. davurica & 2011 & $\mathrm{SWE}=\mathrm{SWL}$ & 0.11 \\
\hline R. davurica & 2011 & $\mathrm{SWL}>\mathrm{SWM}$ & 0.04 \\
\hline Species & 2011 & NEE CAAC $=$ GAVE & 0.25 \\
\hline Species & 2011 & NEE CAAC $=$ RHDA & 1.00 \\
\hline Species & 2011 & NEE GAVE $=$ RHDA & 1.00 \\
\hline Species & 2011 & NEM AIAL $=$ CAAC & 0.41 \\
\hline Species & 2011 & NEM AIAL $=$ GAVE & 0.31 \\
\hline Species & 2011 & NEM AIAL $=$ RHDA & 0.16 \\
\hline Species & 2011 & NEM CAAC $=$ GAVE & 0.31 \\
\hline Species & 2011 & NEM CAAC $=$ RHDA & 0.16 \\
\hline Species & 2011 & NEM GAVE $=$ RHDA & 0.07 \\
\hline Species & 2011 & SWE RHDA $>$ CAAC & 4.E-03 \\
\hline Species & 2011 & SWM AIAL $=$ RHDA & 0.08 \\
\hline Species & 2012 & LA CAAC $=$ CIAR & $>0.05$ \\
\hline Species & 2012 & LA CAAC $=$ GAVE & $>0.05$ \\
\hline Species & 2012 & LA GAVE $>$ CIAR & $<0.05$ \\
\hline Species & 2012 & NEB AIAL $=$ CAAC & 0.10 \\
\hline Species & 2012 & NEB AIAL=CIAR & 0.10 \\
\hline Species & 2012 & NEB CAAC $=$ CIAR & 1.00 \\
\hline Species & 2012 & NEE CAAC $=$ CEOR & 0.62 \\
\hline Species & 2012 & NEE CAAC $=$ GAVE & 0.93 \\
\hline Species & 2012 & NEE CAAC $=$ RHDA & 0.21 \\
\hline Species & 2012 & NEE CEOR $=$ GAVE & 0.96 \\
\hline Species & 2012 & NEE CEOR $=$ RHDA & 0.14 \\
\hline Species & 2012 & NEE GAVE $=$ RHDA & 0.05 \\
\hline Species & 2012 & SWE AIAL $=$ CAAC & 1.00 \\
\hline Species & 2012 & SWE AIAL $=$ CEOR & 0.14 \\
\hline Species & 2012 & SWE AIAL $=$ RHDA & 0.14 \\
\hline Species & 2012 & SWE CAAC $=$ CEOR & 0.60 \\
\hline Species & 2012 & SWE CAAC $=$ RHDA & 1.00 \\
\hline Species & 2012 & SWE CEOR=RHDA & 0.41 \\
\hline
\end{tabular}


Table 16: Differences in soil nitrogen (N) across fields, stages, and species

\begin{tabular}{|c|c|c|c|}
\hline Level & Year & Comparison & P-value \\
\hline Field & 2011 & $\overline{L A}=\mathrm{NEB}$ & $>0.05$ \\
\hline Field & 2011 & $\mathrm{NE}>\mathrm{SW}$ & $<0.05$ \\
\hline Field & 2012 & $\mathrm{LA}=\mathrm{NEB}$ & 0.57 \\
\hline Field & 2012 & $\mathrm{NE}>\mathrm{SW}$ & $<1$.E-04 \\
\hline Stage & 2011 & $\mathrm{NEE}>\mathrm{NEM}$ & $<1$.E-04 \\
\hline Stage & 2011 & NEL $>$ NEM & 4.E-03 \\
\hline Stage & 2011 & $\mathrm{SWE}=\mathrm{SWM}$ & 0.76 \\
\hline Stage & 2012 & $\mathrm{NEE}=\mathrm{NEM}$ & 0.64 \\
\hline Stage & 2012 & NEL $>$ NEE & 4.E-03 \\
\hline Stage & 2012 & NEL $>$ NEM & 2.E-03 \\
\hline Stage & 2012 & $\mathrm{SWE}=\mathrm{SWM}$ & 0.22 \\
\hline Stage & 2012 & $\mathrm{SWE}=\mathrm{SWL}$ & 0.32 \\
\hline Stage & 2012 & $\mathrm{SWM}=\mathrm{SWL}$ & 0.70 \\
\hline R. davurica & 2011 & $\mathrm{NEE}=\mathrm{NEM}$ & 0.36 \\
\hline R. davurica & 2011 & $\mathrm{NEE}=\mathrm{NEL}$ & 1.00 \\
\hline R. davurica & 2011 & NEL $>$ NEM & 0.04 \\
\hline R. davurica & 2011 & $\mathrm{SWE}=\mathrm{SWM}$ & $>0.05$ \\
\hline R. davurica & 2011 & $\mathrm{SWE}=\mathrm{SWL}$ & $>0.05$ \\
\hline R. davurica & 2011 & SWL $>$ SWM & $<0.05$ \\
\hline Species & 2011 & NEE CAAC $=$ GAVE & 0.07 \\
\hline Species & 2011 & NEE CAAC $=$ RHDA & 0.99 \\
\hline Species & 2011 & NEE GAVE $=$ RHDA & 0.97 \\
\hline Species & 2011 & NEM AIAL $=$ CAAC & 0.27 \\
\hline Species & 2011 & NEM AIAL $=$ RHDA & 0.09 \\
\hline Species & 2011 & NEM CAAC $=$ RHDA & 0.55 \\
\hline Species & 2011 & SWE RHDA $>$ CAAC & 5.E-03 \\
\hline Species & 2011 & SWM AIAL $=$ RHDA & 0.15 \\
\hline Species & 2012 & LA CAAC=CIAR & $>0.05$ \\
\hline Species & 2012 & $\mathrm{LA} C A A C=\mathrm{GAVE}$ & $>0.05$ \\
\hline Species & 2012 & $\mathrm{LA}$ CIAR $=\mathrm{GAVE}$ & $>0.05$ \\
\hline Species & 2012 & NEB AIAL $=$ CAAC & 0.10 \\
\hline Species & 2012 & NEB AIAL=CIAR & 0.10 \\
\hline Species & 2012 & NEB CAAC $=$ CIAR & 0.82 \\
\hline Species & 2012 & NEE CAAC $=$ CEOR & 0.21 \\
\hline Species & 2012 & NEE CAAC=GAVE & 0.93 \\
\hline Species & 2012 & NEE CAAC $=$ RHDA & 0.21 \\
\hline Species & 2012 & NEE CEOR=GAVE & 1.00 \\
\hline Species & 2012 & NEE CEOR=RHDA & 0.14 \\
\hline Species & 2012 & NEE GAVE $=$ RHDA & 0.05 \\
\hline Species & 2012 & SWE AIAL $=$ CAAC & 1.00 \\
\hline Species & 2012 & SWE AIAL $=$ CEOR & 0.14 \\
\hline Species & 2012 & SWE AIAL $=$ RHDA & 0.14 \\
\hline Species & 2012 & SWE CAAC $=$ CEOR & 0.41 \\
\hline Species & 2012 & SWE CAAC=RHDA & 0.78 \\
\hline Species & 2012 & SWE CEOR=RHDA & 0.91 \\
\hline
\end{tabular}


Table 17: Differences in leaf carbon (C) across fields, stages, and species

\begin{tabular}{|c|c|c|c|}
\hline Level & Year & Comparison & $\mathrm{P}$-value \\
\hline Field & 2011 & $\mathrm{LA}=\mathrm{NEB}$ & 0.17 \\
\hline Field & 2011 & $\mathrm{NE}=\mathrm{SW}$ & 0.79 \\
\hline Field & 2012 & $\mathrm{NEB}>\mathrm{LA}$ & $<0.05$ \\
\hline Field & 2012 & $\mathrm{SW}=\mathrm{NE}$ & $>0.05$ \\
\hline Stage & 2011 & $\mathrm{NEE}=\mathrm{NEM}$ & 0.90 \\
\hline Stage & 2011 & $\mathrm{NEM}=\mathrm{NEL}$ & 0.41 \\
\hline Stage & 2011 & $\mathrm{SWE}=\mathrm{SWM}$ & 0.16 \\
\hline R. davurica & 2011 & $\mathrm{NEE}=\mathrm{NEM}$ & 0.47 \\
\hline R. davurica & 2011 & $\mathrm{NEE}=\mathrm{NEL}$ & 0.85 \\
\hline R. davurica & 2011 & $\mathrm{NEM}=\mathrm{NEL}$ & 0.38 \\
\hline R. davurica & 2011 & $\mathrm{SWE}=\mathrm{SWM}$ & 0.08 \\
\hline R. davurica & 2011 & $\mathrm{SWE}=\mathrm{SWL}$ & 0.39 \\
\hline R. davurica & 2011 & $\mathrm{SWM}=\mathrm{SWL}$ & 0.28 \\
\hline Species & 2011 & NEE $\mathrm{CAAC}=\mathrm{GAVE}$ & $>0.05$ \\
\hline Species & 2011 & NEE $\mathrm{CAAC}=\mathrm{RHDA}$ & $>0.05$ \\
\hline Species & 2011 & NEE GAVE=RHDA & $>0.05$ \\
\hline Species & 2011 & NEM AIAL $=$ CAAC & 1.00 \\
\hline Species & 2011 & NEM AIAL=GAVE & 0.66 \\
\hline Species & 2011 & NEM AIAL $=$ RHDA & 1.00 \\
\hline Species & 2011 & NEM CAAC $=$ GAVE & 0.89 \\
\hline Species & 2011 & NEM CAAC $=$ RHDA & 0.67 \\
\hline Species & 2011 & NEM GAVE $=$ RHDA & 0.53 \\
\hline Species & 2011 & NEL AIAL=RHDA & 0.95 \\
\hline Species & 2011 & SWE RHDA >CAAC & 9.E-03 \\
\hline Species & 2011 & SWM AIAL $>$ CAAC & 0.04 \\
\hline Species & 2011 & SWM AIAL=RHDA & 0.71 \\
\hline Species & 2011 & SWM CAAC $=$ RHDA & 0.06 \\
\hline Species & 2012 & LA CIAR=CAAC & 0.38 \\
\hline Species & 2012 & LA GAVE $>$ CAAC & $<1 . \mathrm{E}-04$ \\
\hline Species & 2012 & LA GAVE>CIAR & $<1 . \mathrm{E}-04$ \\
\hline Species & 2012 & NEB AIAL $>$ CAAC & $<0.05$ \\
\hline Species & 2012 & NEB AIAL $>$ CIAR & $<0.05$ \\
\hline Species & 2012 & NEB CAAC $=$ CIAR & $>0.05$ \\
\hline Species & 2012 & NEE $\mathrm{CAAC}=\mathrm{CEOR}$ & $>0.05$ \\
\hline Species & 2012 & NEE GAVE $>$ CAAC & $<0.05$ \\
\hline Species & 2012 & NEE RHDA $>$ CAAC & $<0.05$ \\
\hline Species & 2012 & NEE GAVE $>$ CEOR & $<0.05$ \\
\hline Species & 2012 & NEE RHDA $>$ CEOR & $<0.05$ \\
\hline Species & 2012 & NEE GAVE $>$ RHDA & $<0.05$ \\
\hline Species & 2012 & SWE AIAL $>$ CAAC & 5.E-03 \\
\hline Species & 2012 & SWE AIAL $>$ CEOR & 6.E-04 \\
\hline Species & 2012 & SWE AIAL $>$ RHDA & 3.E-04 \\
\hline Species & 2012 & SWE CEOR $>$ CAAC & 0.02 \\
\hline Species & 2012 & SWE RHDA $>$ CAAC & 4.E-03 \\
\hline Species & 2012 & SWE RHDA=CEOR & 0.51 \\
\hline
\end{tabular}


Table 18: Differences in leaf nitrogen $(\mathrm{N})$ across fields, stages, and species

\begin{tabular}{|c|c|c|c|}
\hline Level & Year & Comparison & $\mathrm{P}$-value \\
\hline Field & 2011 & $\mathrm{NEB}>\mathrm{LA}$ & 5.E-03 \\
\hline Field & 2011 & $\mathrm{SW}>\mathrm{NE}$ & 2.E-03 \\
\hline Field & 2012 & $\mathrm{NEB}>\mathrm{LA}$ & $<1 . \mathrm{E}-04$ \\
\hline Field & 2012 & $\mathrm{SW}>\mathrm{NE}$ & 0.03 \\
\hline Stage & 2011 & $\mathrm{NEE}=\mathrm{NEM}$ & 0.84 \\
\hline Stage & 2011 & $\mathrm{NEM}=\mathrm{NEL}$ & 0.05 \\
\hline Stage & 2011 & $\mathrm{SWE}=\mathrm{SWM}$ & 0.16 \\
\hline R. davurica & 2011 & $\mathrm{NEE}=\mathrm{NEM}$ & $>0.05$ \\
\hline R. davurica & 2011 & NEL $>$ NEE & $<0.05$ \\
\hline R. davurica & 2011 & $\mathrm{NEM}=\mathrm{NEL}$ & $>0.05$ \\
\hline R. davurica & 2011 & $\mathrm{SWE}=\mathrm{SWM}$ & 0.44 \\
\hline R. davurica & 2011 & $\mathrm{SWE}=\mathrm{SWL}$ & 0.46 \\
\hline R. davurica & 2011 & $\mathrm{SWM}=\mathrm{SWL}$ & 0.82 \\
\hline Species & 2011 & NEE CAAC $>$ GAVE & 8.E-03 \\
\hline Species & 2011 & NEE CAAC $>$ RHDA & 2.E-03 \\
\hline Species & 2011 & NEE GAVE=RHDA & 0.96 \\
\hline Species & 2011 & NEM AIAL $=$ CAAC & 0.79 \\
\hline Species & 2011 & NEM AIAL=GAVE & 0.31 \\
\hline Species & 2011 & NEM AIAL $=$ RHDA & 1.00 \\
\hline Species & 2011 & NEM CAAC $=$ GAVE & 0.15 \\
\hline Species & 2011 & NEM CAAC $=$ RHDA & 0.67 \\
\hline Species & 2011 & NEM GAVE $=$ RHDA & 0.33 \\
\hline Species & 2011 & NEL AIAL>RHDA & 0.04 \\
\hline Species & 2011 & SWE CAAC $>$ RHDA & 0.04 \\
\hline Species & 2011 & SWM AIAL=CAAC & 0.38 \\
\hline Species & 2011 & SWM AIAL=RHDA & 0.14 \\
\hline Species & 2011 & SWM CAAC $=$ RHDA & 0.31 \\
\hline Species & 2012 & LA CAAC=CIAR & 0.15 \\
\hline Species & 2012 & LA CAAC $>$ GAVE & 5.E-04 \\
\hline Species & 2012 & LA CIAR>GAVE & 2.E-04 \\
\hline Species & 2012 & NEB AIAL $=$ CAAC & $>0.05$ \\
\hline Species & 2012 & NEB AIAL=CIAR & $>0.05$ \\
\hline Species & 2012 & NEB CIAR $=$ CAAC & $>0.05$ \\
\hline Species & 2012 & NEE CAAC $>$ CEOR & 0.05 \\
\hline Species & 2012 & NEE CAAC $>$ GAVE & 0.03 \\
\hline Species & 2012 & NEE CAAC $>$ RHDA & 0.05 \\
\hline Species & 2012 & NEE GAVE $>$ CEOR & 2.E-03 \\
\hline Species & 2012 & NEE RHDA=CEOR & 0.31 \\
\hline Species & 2012 & NEE GAVE=RHDA & 0.73 \\
\hline Species & 2012 & $\mathrm{SWE}$ AIAL $=\mathrm{CAAC}$ & 0.15 \\
\hline Species & 2012 & SWE AIAL $>$ CEOR & 5.E-03 \\
\hline Species & 2012 & SWE AIAL $>$ RHDA & 3.E-04 \\
\hline Species & 2012 & $\mathrm{SWE} \mathrm{CAAC}=\mathrm{CEOR}$ & 0.43 \\
\hline Species & 2012 & SWE CAAC $>$ RHDA & 4.E-03 \\
\hline Species & 2012 & SWE $\mathrm{CEOR}=\mathrm{RHDA}$ & 0.43 \\
\hline
\end{tabular}




\section{Chapter 6: Conclusion}

\subsection{Biodiversity and invasion}

Biodiversity affects ecosystem productivity and community stability (Gustafsson and Bostrom, 2011). Invasive species can negatively impact biodiversity by altering community and ecosystem characteristics (Kuhman et al., 2011; Mascaro and Schnitzer, 2007). Disturbances can facilitate invasion (Kuhman et al., 2011), and as agricultural fields become more prevalent in the U.S. (Wang et al., 2010), we need more efficient ways to monitor the effects of invasive species at large spatial extents. Although field measurements have been used to monitor the growth and spread of invasive species, these measurements can be costly and time-consuming. Using a combination of remote sensing and field measurements can facilitate conservation efforts (Wilfong et al., 2009). In this dissertation, I assessed the role of these species in successional plant communities using ground-level hyperspectral remote sensing.

\subsection{Distinguishing among plant communities}

In the first chapter, I found that remote sensing can be used to differentiate among plant communities. The most influential species to community discriminability are considered invasive, suggesting that these species can strongly influence species compositions and other community properties. The most influential wavelengths for discrimination are distributed throughout the spectral profile and correspond with plant physiological and struc-

tural elements. Species discrimination is better achieved using multiple narrowbands rather than using simulated broadbands. 


\subsection{Distinguishing among plant species}

After discriminability of plant communities was established, I assessed whether six exotic invasive plant species could be differentiated. I found that these species were discriminable, but their discriminability varied by species. Interestingly, the two thistle species that are similar phylogenetically and in structure were readily distinguished among each other. However, the shrubby Rhamnus davurica was difficult to distinguish from the liana Celastrus orbiculatus despite phylogenetic distance and differences in structure, due to physical overlap in the field and thus the difficulty in obtaining pure signatures for discrimination. Discriminability also differed by the spectral region examined. For example, Rhamnus davurica and Celastrus orbiculatus were least discriminable in the $550-599 \mathrm{~nm}$ and $650-699 \mathrm{~nm}$ regions, due to greater intraspecific variability of spectral data in these regions. The most important spectral regions for differentiation vary by species, based on their physiological and structural characteristics.

\subsection{Correlating species diversity and spectral diversity}

Since plant species were able to be discriminated among one another using hyperspectral remote sensing, I asked whether their effects on community properties could be assessed using remote sensing. Specifically, I examined whether spectral diversity could be used to estimate species diversity. Species diversity and spectral diversity were positively correlated, but again the strength of the correlation varied by spectral region examined and the type of noise correction technique used to transform the reflectance profiles. For example, there was a strong positive correlation between the two in the visible region when band depth was used, but not when first derivatives were used, because first derivatives exaggerate spectral noise in the visible region. The two diversities were positively correlated in the near-infrared region when first derivatives were used, but not when band depth was used, because when 
the continuum hull is anchored to the near-infrared shoulder, variability in the near-infrared plateau is removed. There were no strong correlations in the red edge regardless of the noise correction technique used. This might be due to high intraspecific variability in the red trough region.

\subsection{Assessing species effects in successional communities}

I also examined the role that species, such as these six exotic invasive species, can play in secondary successional plant communities by measuring leaf and soil characteristics. I found differences across fields, and within fields by sucessional stage, but not many differences by species. This may be because all six species affected succession in the same way. More plausibly, secondary successional dynamics may be more predominant than species effects on succession, at least during the first several decades since disturbance.

\subsection{Limitations}

\subsubsection{Vegetation discrimination}

To discriminate among species, I used support vector machines (SVM) so that information from the whole spectral profile from 350 to $1025 \mathrm{~nm}$ was considered. The SVM is especially useful for complex, noisy, and/ or small datasets (Bai et al., 2012) but also can be computationally intensive (Naidoo et al., 2012). Another draw-back to such machine learning analyses is that they can be difficult to interpret. I used Matthew's correlation coefficient and sensitivity analysis, but there are many other ways to interpret these results, including examining weighting coefficients. There are also methods other than SVMs with which information from the entire spectral profile can be consolidated into fewer components using principal components analysis (PCA), segmented PCA, discriminant analysis (DA), linear DA, segmented LDA, penalized DA, canonical analysis (CA), k-nearest neigh- 
bor analysis (KNN), random forest $(\mathrm{RF})$, artificial neural network (ANN), support vector machine (SVM), spectral angle mapper (SAM), classification and regression trees (CART), and Bayesian additive regression trees (BART), Maximum likelihood classification (MLC), wavelet analysis, constrained energy minimization (CEM) and linear regression (Agarwal et al., 2013; Bai et al., 2012; Bajwa et al., 2004; Banskota et al., 2011; Cheng et al., 2014; Cho et al., 2012; Eddy et al., 2014; Farrell and Mersereau, 2005; Goel et al., 2003; Koger et al., 2003; Lewis, 2002; Mirik et al., 2006; Naidoo et al., 2012; Nooni et al., 2014; Ranganathan and Borges, 2010; Shafri et al., 2007; Sun et al., 2014; Villa et al., 2011; Xu and Gong, 2007; Yu et al., 2014; Zhang et al., 2006). Different methods may be best suited for different purposes (Bajwa et al., 2004).

When discriminating among species, intraspecific variability needs to be taken into account. I discussed intraspecific variability in pigments, but various types of stress can also cause intraspecific variability. Remote sensing data, such as the plant stress detection index (PSDI) can also be used to detect vegetation stress (Sanches et al., 2014). However, stress detection can be complicated if different forms of stress affect spectra similarly (Sanches et al., 2014), if some forms of stress are more spectrally distinct than other forms of stress (El-Shikha et al., 2007), and if stressors are interactive (El-Shikha et al., 2007). Water stress can lead to an increase in reflectance in the red region and a decrease in reflectance in the NIR region (Genc et al., 2013); it can cause decreases in chlorophyll content, chlorophyll activity, nutrient absorption, and nutrient transportation (Genc et al., 2013). This water stress can be detected using the water deficit index (El-Shikha et al., 2007), using vegetation indices (Normalized Difference Vegetation Index, green NDVI, simple ratio, blue:NIR, green: NIR, and $(R+G) / N I R)$, and classification trees (Genc et al., 2013). Nitrogen stress can be detected using the canopy chlorophyll concentration index (CCCI) (El-Shikha et al., 2007); nutrient stress can cause a decrease in the red edge slope and a red edge shift to shorter wavelengths (Yang et al., 2010). 
During high-light stress, there is an increase in Chl fluorescence with the decrease in photosynthetic activity because fluorescence is a mode of photoprotection (Buschmann et al., 1990). Trichome presence can also aid in photoprotection and lessen the need for xanthophyll-related photoprotection (Naumann et al., 2010); therefore leaf structure needs to be taken into account when evaluating light stress responses. Disease and infestation stress can also be observed spectrally. For example, Calderon et al. (2013) found that infection by Verticillium spp. wilt increased crown temperature, decreased leaf stomatal conductance, increased PRI, and decreased chlorophyll fluorescence. There was a decrease in the chlorophyll red edge index, but no difference in greenness, red index, and blue/green ratio.

Data fusion may facilitate species identification, with combinations of spatial and spectral information (Feret and Asner, 2013; Gould, 2000; Lu et al., 2007), with combinations of spectral and structural data (Cho et al., 2012; Colgan et al., 2012; Hill and Thomson, 2005; Ko et al., 2013; Magney et al., 2014; Naidoo et al., 2012), and with the combination of multiple sensors (Alemie, 2005; Biradar et al., 2007; Gevaert and Garcia-Haro, 2015; Mezned et al., 2009; Papes et al., 2010; Thiessen, 2007). Similarly, the use of multiple images over time can also increase species discriminability (Bradley and Mustard, 2006; Dymond et al., 2002; Gao and Zhang, 2006; Gevaert and Garcia-Haro, 2015; Liang et al., 2011; Somers and Asner, 2012; Wilfong et al., 2009); however differences in image quality and in plant growing stages need to be accounted for (Zhong et al., 2014).

\subsubsection{Estimating community and ecosystem properties}

I estimated pigments using spectral data in this dissertation, which is supported by literature; it may also have been beneficial to verify results with pigment extractions. Additionally, it is beneficial to take leaf water content into account when estimating leaf pigment because leaves with higher water content have lower chlorophyll index values, maybe 
due to the greater thickness of the leaves inhibiting the detection of chlorophyll in the lower layer of the leaf (Sims and Gamon, 2002).

As mentioned earlier, there are many noise correction techniques available including continuum removal, band depth, and derivatives (Broge and Leblanc, 2001; Mitchell et al., 2012; Mutanga et al., 2004; Zhang et al., 2006), all with unique assumptions, advantages, and disadvantages. The technique used does influence results, so the choice needs to be made carefully.

I estimated species diversity in community plots using spectral diversity. However, the spectral diversity may also have been influenced by plant structural diversity within the plots. Future research may explore how to tease apart the influences of species diversity and structural diversity on spectral diversity. Additionally, examining the correlations between species diversity and spectral diversity at different spatial scales may lead to the conclusion that the correlation is dependent on spatial scales (Gaertner et al., 2009) as well as on the spectral region examined and the noise correction technique used.

Although spectral data can successfully be used to estimate ecological properties and processes, the combination of spectral data with structural, spatial, and temporal data can lead to more accurate estimations. The use of multiple sensors has also been useful for the accurate estimation of ecological properties and processes (Liang et al., 2011). Incorporating phenological information into methods decisions can also increase ability to monitor ecological properties and processes. For example, since it is difficult to study understory invasive species because of obstruction by canopy vegetation, understory invasive species may be monitored when native species do not have leaves, if invasive species differ from natives phenologically (Wilfong et al., 2009). Incorporating phenological variables into classifiers can also help increase robustness to low-quality images and image gaps (Zhong et al., 2014). 


\section{7 $\quad$ Future directions}

I have been able to use ground-level remote sensing data to distinguish among plant communities and plant species, and assess the role of invasive species in plant communities through estimating diversity. However, this study is limited in only using ground-level data, in that I could not assess their role at the ecosystem level using remote sensing without employing airborne or satellite imagery.

In addition to assessing the role of invasive species at the ecosystem level remotely, such airborne or satellite imagery may also allow the upscaling of ground-level measurements to a broader spatial extent. For example, the discriminability of plant communities and plant species was possible at the ground level with its fine spatial resolution. However, this is more challenging with airborne and satellite data with coarser spatial resolutions. Different techniques would need to be explored to unmix spectral signatures at these coarser resolutions.

When attempting to discriminate different classes spectrally from mixed pixels, there are various ways to select endmembers to define each class using spectral, spatial, or a combination of spectral and spatial information (Bai et al., 2012; Shi and Wang, 2014; Somers et al., 2011, 2012). Due to high spectral variability within classes, the use of multiple endmembers for each class may result in greater accuracy (Cho et al., 2010). For species discriminability, there are also several ways to measure the distance between endmembers, including spectral angle mapper (SAM), Euclidean minimum distance (EMD), Bhattacharyya distance, and Jeffries-Matusita distance (Keshava, 2004; Schmidt and Skidmore, 2003). These distance methods can also be used to select bands to maximize class discriminability, including the band add-on (BAO) method, parametric Bhattacharya and Jeffries-Matusita distances, and non-parametric Kruskal-Wallis, since spectral variability in tree canopy spectra is not normally distributed (Keshava, 2004; Sanchez-Azofeifa et al., 2009; Zhang et al., 2006). 
Using multiple endmembers is especially important at large spatial extents and coarse spatial resolutions, where pixels are often composed of more than one class (Xiao, Y. et al., 2014). Mixture analyses can be used to distinguish endmembers and define spectral classes and estimate class abundances in these mixed pixels (Shi and Wang, 2014). Roberts et al. (1998) found that the use of 2 or 3 endmembers in land cover classification using multiple endmember spectral mixture analysis (MESMA) was most accurate for differentiating soil, non-photosynthetic vegetation, and green vegetation; too few endmembers would result in misclassification within fractions and high RMS; too many would lead to high sensitivity to noise from the sensor, atmosphere, and spectral variability within an endmember. Another way to deal with mixed pixels is to use object-based classification instead of pixel-based calculation; object-based classification uses information from surrounding pixels to classify one pixel; it starts with one pixel and begins merging adjacent pixels and groups of pixels by similarity in terms of shape, extent, and color (Pringle et al., 2009) and is often found to be more accurate than pixel-based classification (Jiao et al., 2014; Pringle et al., 2009).

Advances in satellite remote sensing technology, such as greater spatial, temporal, and spectral resolutions, will make vegetation discrimination, and community and ecosystem property estimation, more efficient at larger spatial extents, which should help inform conservation efforts within invaded landscapes.

\section{References}

Agarwal, R., Ranjan, P., and Chipman, H. (2013). A new Bayesian ensemble of trees classifier for identifying multi-class labels in satellite images. Can. J. Remote Sens., 39(6):507-520.

Albright, T., Chen, H., Chen, L., and Guo, Q. (2010). The ecological niche and reciprocal prediction of the disjunct distribution of an invasive species: The example of Ailanthus altissima. Biol. Invasions, 12(8):2413-2427.

Aleksoff, K. (1999). Achillea millefolium. In: Fire effects information systems, [Online]. U.S. Department of Agriculture, Forest Service, Rocky Mountain Research Station, Fire Sciences Laboratory (Producer) (Archived by WebCite at http://www.webcitation.org/6b28ywlyz).

Alemie, B. (2005). Spectral unmixing of hyperspectral and multispectral images for pre- 
dictive mapping of surface soil organic matter. $\mathrm{PhD}$ thesis, International Institute for Geo-information Science and Earth Observation, Enschede, The Netherlands.

Allen, M. and Shea, K. (2006). Spatial segregation of congeneric invaders in central Pennsylvania, USA. Biol. Invasions, 8(3):509-521.

Alvarez-Anorve, M. Y., Quesada, M., Sanchez-Azofeifa, G. A., Avila-Cabadilla, L. D., and Gamon, J. A. (2012). Functional regeneration and spectral reflectance of trees during succession in a highly diverse tropical dry forest ecosystem. Am. J. Bot., 99(5):816-826.

Aragon, R. and Morales, J. (2003). Species composition and invasion in NW Argentinian secondary forests: effects of land use history, environment and landscape. J. Veg. Sci., 14(2):195-204.

Armel, G., Hall, G., Wilson, H., and Cullen, N. (2005). Mesotrione plus Atrazine mixtures for control of Canada thistle (Cirsium arvense). Weed Sci., 53(2):202-211.

Arroyo-Mora, J., Sanchez-Azofeifa, A., Kalacska, M., Rivard, B., Calvo-Alvarado, J., and Janzen, D. (2005). Secondary forest detection in a neotropical dry forest landscape using Landsat 7 ETM+ and IKONOS imagery. Biotropica, 37(4):497-507.

Asner, G. (1998). Biophysical and biochemical sources of variability in canopy reflectance. Remote Sens. Environ., 64(3):234-253.

Asner, G. and Martin, R. (2011). Canopy phylogenetic, chemical and spectral assembly in a lowland Amazonian forest. New Phytol., 189(4):999-1012.

Asner, G., Martin, R., Ford, A., Metcalfe, D., and Liddell, M. (2009). Leaf chemical and spectral diversity in Australian tropical forests. Ecol. Appl., 19(1):236-253.

Asner, G. P., Boardman, J., Field, C. B., Knapp, D. E., Kennedy-Bowdoin, T., Jones, M. O., and Martin, R. E. (2007). Carnegie airborne observatory: In-flight fusion of hyperspectral imaging and waveform light detection and ranging for three-dimensional studies of ecosystems. Journal of Applied Remote Sensing, 1(1):013536-013536.

Asner, G. P. and Martin, R. (2008). Spectral and chemical analysis of tropical forests: Scaling from leaf to canopy levels. Remote Sens. Environ., 112(10):3958-3970.

Asner, G. P. and Martin, R. E. (2009). Airborne spectranomics: mapping canopy chemical and taxonomic diversity in tropical forests. Frontiers in Ecology and the Environment, $7(5): 269-276$.

Asner, G. P., Martin, R. E., and Suhaili, A. B. (2012). Sources of canopy chemical and spectral diversity in lowland Bornean forest. Ecosystems, 15(3):504-517.

Bai, L., Lin, H., Sun, H., Zang, Z., and Mo, D. (2012). Remotely sensed percent tree cover mapping using support vector machine combined with autonomous endmember extraction. Phys. Procedia, 33:1702-1709.

Bajwa, S. G., Bajcsy, P., Groves, P., and Tian, L. F. (2004). Hyperspectral image data mining for band selection in agricultural applications. Transactions of ASAE, 47(3):895908.

Banskota, A., Wynne, R., and Kayastha, N. (2011). Improving within-genus tree species discrimination using the discrete wavelet transform applied to airborne hyperspectral data. Int. J. Remote Sens., 32(13):3551-3563. 
Barbehenn, R. and Bernays, E. (1992). Relative nutritional quality of $\mathrm{C}_{3}$ and $\mathrm{C}_{4}$ grasses for a graminivorous lepidopteran, Paratrytone melane(Hesperiidae). Oecologia, 92:97-103.

Baron, J., Barber, M., Adams, M., Agboola, J., Allen, E., Bealey, W., Bobbink, R., Bobrovsky, M.V., Bowman, W., Branquinho, C., Bustamente, M., Clark, C., Cocking, E., Cruz, C., Davidson, E., Denmead, O., Dias, T., Dise, N., Feest, A., Galloway, J., Geiser, L., Gilliam, F., Harrison, I., Khanina, L., Lu, X., Manrique, E., Hueso, R., Ometto, J., Payne, R., Scheuschner, T., Sheppard, L., Simpson, G., Singh, Y., Stevens, C., Strachan, I., Sverdrup, H., Tokuchi, N., van Dobben, H., and Woodin, S. (2014). The effects of atmospheric nitrogen deposition on terrestrial and freshwater biodiversity. In Sutton, M., Mason, K., Sheppard, L., Sverdrup, H., Haeuber, R., and Hicks, W., editors, Nitrogen Deposition, Critical Loads and Biodiversity, pages 465-480. Springer Netherlands, Dordrecht.

Battaglia, L., Keough, J., and Pritchett, D. (1995). Early secondary succession in a southeastern U.S. alluvial floodplain. J. Veg. Sci., 6(6):769-776.

Bickmore, E. (2003). Integrated weed management plan. Technical report, Las Vegas Wash Project Coordination Team, Southern Nevada Water Authority.

Bioucas-Dias, J., Plaza, A., Camps-Valls, G., Scheunders, P., Nasrabadi, N., and Chanussot, J. (2013). Hyperspectral remote sensing data analysis and future challenges. IEEE Geosci. Remote Sens. Magazine, 1(2):6-36.

Biradar, C., Thenkabail, P., Islam, M., Anputhas, M., Tharme, R., Vithanage, J., Alankara, R., and Gunasinghe, S. (2007). Establishing the best spectral bands and timing of imagery for land use- land cover (LULC) class separability using Landsat ETM+ and Terra MODIS data. Can. J. Remote Sens., 33(5):431-444.

Blackburn, G. A. (2006). Hyperspectral remote sensing of plant pigments. J. Exp. Bot., 58(4):855-867.

Bongard, C., Butler, K., and Fulthorpe, R. (2013). Investigation of fungal root colonizers of the invasive plant Vincetoxicum rossicum and co-occurring local native plants in a field and woodland area in southern Ontario. Nat. Conserv., 4:55-76.

Bottcher, K., Aurela, M., Kervinen, M., Markkanen, T., Mattila, O., Kolari, P., Metsamaki, S., Aalto, T., Arslan, A., and Pulliainen, J. (2014). MODIS time-series-derived indicators for the beginning of the growing season in boreal coniferous forest A comparison with $\mathrm{CO}<$ sub $>2<\backslash$ sub $>$ flux measurements and phenological observations in Finland. Remote Sens. Environ., 140:625-638.

Bowers, M. A. (1997). University of Virginia's Blandy Experimental Farm. Bull. Ecol. Soc. Am., pages 220-225.

Boyd, I. L., Freer-Smith, P. H., Gilligan, C. A., and Godfray, H. (2013). The consequence of tree pests and diseases for ecosystem services. Science, 342(6160):1235773-1235773.

Bradley, B. and Mustard, J. (2006). Characterizing the landscape dynamics of an invasive plant and risk of invasion using remote sensing. Ecol. Appl., 16(3):1132-1147.

Broge, N. and Leblanc, E. (2001). Comparing prediction power and stability of broadband and hyperspectral vegetation indices for estimation of green leaf area index and canopy chlorophyll density. Remote Sens. Environ., 76(2):156-172. 
Burda, S. and Oleszek, W. (2004). Allelochemicals isolated from Canada thistle shoots. Allelopathy J., 14(1):23-34.

Burkholder, A. (2010). Seasonal trends in separability of leaf reflectance spectra for Ailanthus altissima and four other tree species. Master of Arts in Geography, Eberly College of Arts and Sciences at West Virginia University, West Virginia.

Buschmann, C., Nagel, E., Rang, S., and Stober, F. (1990). Interpretation of reflectance spectra of terrestrial vegetation based on specifical plant test systems. In Geoscience and Remote Sensing Symposium, 1990. IGARSS'90.'Remote Sensing Science for the Nineties'., 10th Annual International, pages 1927-1930. IEEE.

Bush, T., Ogle, D., St. John, L., Stannard, M., and Jensen, K. (2012). Plant guide for orchardgrass (Dactylis glomerata).

Butler, S., McAlpine, C., Fensham, R., and House, A. (2014). Climate and exotic pasture area in landscape determines invasion of forest fragments by two invasive grasses. J. Appl. Ecol., 51(1):114-123.

Calderon, R., Navas-Cortes, J., Lucena, C., and Zarco-Tejada, P. (2013). High-resolution airborne hyperspectral and thermal imagery for early detection of Verticillium wilt of olive using fluorescence, temperature and narrow-band spectral indices. Remote Sens. Environ., 139:231-245.

Campbell Scientific (2010). HydroSense soil water measurement system.

Cao, K. (2000). Leaf anatomy and chlorophyll content of 12 woody species in contrasting light conditions in a Bornean heath forest. Can. J. Bot., 78:1245-1253.

Cardinale, B., Wright, J., Cadotte, M., Carroll, I., Hector, A., Srivastava, D., Loreau, M., and Weis, J. (2007). Impacts of plant diversity on biomass production increase through time because of species complementarity. P. Natl. Acad. Sci., 104(46):18123-18128.

Carlson, K., Asner, G., Hughes, R., Ostertag, R., and Martin, R. (2007). Hyperspectral remote sensing of canopy biodiversity in Hawaiian lowland rainforests. Ecosystems, 10(4):536-549.

Castro, H., Fortunel, C., and Freitas, H. (2010). Effects of land abandonment on plant litter decomposition in a Montado system: Relation to litter chemistry and community functional parameters. Plant Soil, 333(1-2):181-190.

Castro-Esau, K., Sanchez-Azofeifa, G., and Caelli, T. (2004). Discrimination of lianas and trees with leaf-level hyperspectral data. Remote Sens. Environ., 90(3):353-372.

Castro-Esau, K., Sanchez-Azofeifa, G., Rivard, B., Wright, S., and Quesada, M. (2006). Variability in leaf optical properties of Mesoamerican trees and the potential for species classification. Am. J. Bot., 93(4):517-530.

Chapin III, S., Walker, B., Hobbs, R., Hooper, D., Lawton, J., Sala, O., and Tilman, D. (1997). Biotic control over the functioning of ecosystems. Science, 277(5325):500-504.

Cheng, T., Riano, D., and Ustin, S. (2014). Detecting diurnal and seasonal variation in canopy water content of nut tree orchards from airborne imaging spectroscopy data using continuous wavelet analysis. Remote Sens. Environ., 143:39-53.

Cho, M., Mathieu, R., Asner, G., Naidoo, L., van Aardt, J., Ramoelo, A., Debba, P., Wessels, 
K., Main, R., Smit, I., and Erasmus, B. (2012). Mapping tree species composition in South African savannas using an integrated airborne spectral and LiDAR system. Remote Sens. Environ., 125:214-226.

Cho, M. A., Debba, P., Mathieu, R., Naidoo, L., van Aardt, J., and Asner, G. P. (2010). Improving discrimination of savanna tree species through a multiple-endmember spectral angle mapper approach: Canopy-level analysis. IEEE Transactions on Geoscience and Remote Sensing.

Cho, M. A. and Skidmore, A. K. (2009). Hyperspectral predictors for monitoring biomass production in Mediterranean mountain grasslands: Majella National Park, Italy. International Journal of Remote Sensing, 30(2):499-515.

Clark, R. and Roush, T. (1984). Reflectance spectroscopy: Quantitative analysis techniques for remote sensing applications. J. Geophys. Res., 89(B7):6329-6340.

Clevers, J. and Kooistra, L. (2012). Using hyperspectral remote sensing data for retrieving canopy chlorophyll and nitrogen content. IEEE J. Sel. Top. Appl. Earth Obs., 5(2):574583.

Cochrane, M. A. (2000). Using vegetation reflectance variability for species level classification of hyperspectral data. Int. J. Remote Sens., 21(10):2075-2087.

Colgan, M., Baldeck, C., Feret, J., and Asner, G. (2012). Mapping savanna tree species at ecosystem scales using support vector machine classification and BRDF correction on airborne hyperspectral and LiDAR data. Remote Sens., 4(12):3462-3480.

Compton, J., Boone, R., Motzkin, G., and Foster, D. (1998). Soil carbon and nitrogen in a pine-oak sand plain in central Massachusetts: Role of vegetation and land-use history. Oecologia, 116:536-542.

Crowley, J., Brickey, D., and Rowan, L. (1989). Airborne imaging spectrometer data of the Ruby Mountains, Montana: Mineral discrimination using relative absorption band-depth images. Remote Sens. Environ., 29(2):121-134.

Cummins, D. (2014). Field-grown cut flowers for Luisiana. Available at: www.lsuagcenter.com/.

Cunard, C. and Lee, T. (2009). Is patience a virtue? Succession, light, and the death of invasive glossy buckthorn (Frangula alnus). Biol. Invasions, 11(3):577-586.

Daughtry, C. and Walthall, C. L. (1998). Spectral discrimination of Cannabis sativa L. leaves and canopies. Remote Sens. Environ., 64(2):192-201.

DCR (2014). Virginia invasive plant species list. In: Natural Heritage Program, [online]. Virginia Department of Conservation and Recreation. Available: http://www.dcr.virginia.gov/natural_heritage/ip.shtml. (Archived by WebCite at http://www.webcitation.org/6b29g2fp9).

Deckmyn, G. and Impens, I. (1999). Seasonal responses of six Poaceae to differential levels of solar UV-B radiation. Environ. Exp. Bot., 41:177-184.

Delegido, J., Alonso, L., Gonzalez, G., and Moreno, J. (2010). Estimating chlorophyll content of crops from hyperspectral data using a normalized area over reflectance curve (NAOC). Int. J. Appl. Earth Obs. Geoinf., 12(3):165-174. 
Delvin, R. and Barker, A. (1971). Photosynthesis. Litton Educational Publishing, Inc., New York, NY.

DeMeester, J. and deB. Richter, D. (2010). Differences in wetland nitrogen cycling between the invasive grass Microstegium vimineum and a diverse plant community. Ecol. Appl., 20(3):609-619.

Denslow, J. and Hughes, R. (2004). Exotic plants as ecosystem dominants. Weed Technol., 18:1283-1287.

Dolle, M. and Schmidt, W. (2009). Impact of tree species on nutrient and light availability: Evidence from a permanent plot study of old-field succession. Plant Ecol., 203(2):273-287.

Dymond, C., Mladenoff, D., and Radeloff, V. (2002). Phenological differences in tasseled cap indices improve deciduous forest classification. Remote Sens. Environ., 80(3):460-472.

EDDMapS (2014). EDDMapS: Early detection and distribution mapping system. Available at: http://www.eddmaps.org/ (Archived by WebCite at http://www.webcitation.org/6b29r7ktl).

Eddy, P., Smith, A., Hill, B., Peddle, D., Coburn, C., and Blackshaw, R. (2014). Weed and crop discrimination using hyperspectral image data and reduced bandsets. Can. J. Remote Sens., 39(6):481-490.

Ehrenfeld, J., Kourtev, P., and Huang, W. (2001). Changes in soil functions following invasions of exotic understory plants in deciduous forests. Ecol. Appl., 11(5):1287-1300.

El-Shikha, D., Waller, P., Hunsaker, D., Clarke, T., and Barnes, E. (2007). Ground-based remote sensing for assessing water and nitrogen status of broccoli. Agr. Water Manage., $92(3): 183-193$.

Ellsworth, D. S. and Reich, P. B. (1996). Photosynthesis and leaf nitrogen in five Amazonian tree species during early secondary succession. Ecology, 77(2):581.

EnMAP (2015). Mission | enmap. Available at <http://www.enmap.org/?q=mission>.

Evans, C. and Etherington, J. (1990). The effect of soil water potential on seed germination of some British plants. New Phytol., 115(3):539-548.

Everitt, J. H., Yang, C., Sriharan, S., and Judd, F. W. (2008). Using high resolution satellite imagery to map black mangrove on the Texas Gulf Coast. J. Coastal Res., 246:1582-1586.

Farrell, M. and Mersereau, R. (2005). On the impact of PCA dimension reduction for hyperspectral detection of difficult targets. IEEE Geosci. Remote Sens. Lett., 2(2):192195.

Feldman, S. (1997). Biological control of plumeless thistle (Carduus acanthoides L.) in Argentina. Weed Sci., 45(4):534-537.

Feldpausch, T., Rondon, M., Fernandes, E., Riha, S., and Wandelli, E. (2004). Carbon and nutrient accumulation in secondary forests regenerating on pastures in central Amazonia. Ecol. Appl., 14(sp4):164-176.

Feret, J. and Asner, G. (2013). Tree species discrimination in tropical forests using airborne imaging spectroscopy. IEEE T. Geosci. Remote, 51(1):73-84.

Feret, J. and Asner, G. P. (2014). Mapping tropical forest canopy diversity using high-fidelity imaging spectroscopy. Ecol. Appl., 24(6):1289-1296. 
Feret, J.-B. and Asner, G. P. (2011). Spectroscopic classification of tropical forest species using radiative transfer modeling. Remote Sensing of Environment, 115(9):2415-2422.

Ficco, D., De Simone, V., Colecchia, S., Pecorella, I., Platani, C., Nigro, F., Finocchiaro, F., Papa, R., and De Vita, P. (2014). Genetic variability in anthocyanin composition and nutritional properties of blue, purple, and red bread (Triticum aestivum L.) and durum (Triticum turgidum L. spp. turgidum convar. durum) wheats. J. Agr. Food Chem., 62:8686-8695.

Fike, J. and Niering, W. (1999). Four decades of old field vegetation development and the role of Celastrus orbiculatus in the northeastern United States. J. Veg. Sci., 10(4):483-492.

Foody, G. and Cutler, M. (2003). Tree biodiversity in protected and logged Bornean tropical rain forests and its measurement by satellite remote sensing. J. Biogeogr., 30:1053-1066.

Fournier-Level, A., Le Cunff, L., Gomez, C., Doligez, A., Ageorges, A., Roux, C., Bertrand, Y., Souquet, J., Cheynier, V., and This, P. (2009). Quantitative genetic bases of anthocyanin variation in grape (Vitis vinifera L. ssp. sativa) berry: A Quantitative trait locus to quantitative trait nucleotide integrated study. Genetics, 183:1127-1139.

Frappier, B., Eckert, R., and Lee, T. (2003). Potential impacts of the invasive exotic shrub Rhamnus frangula L. (glossy buckthorn) on forests of southern New Hampshire. Northeast Nat., 10(3):277.

Fraser, L. and Grime, J. P. (1999). Interacting effects of herbivory and fertility on a synthesized plant community. J. Ecol., 87:514-525.

Fryer, J. (2011). Celastrus orbiculatus. In: Fire effects information system, [Online]. U.S. Department of Agriculture, Forest Service, Rocky Mountain Research Station, Fire Sciences Laboratory (Producer). http://www.fs.fed.us/database/feis/. (Archived by WebCite at http://www.webcitation.org/6b2azwsth).

Gaertner, M., Breeyen, A., Hui, C., and Richardson, D. M. (2009). Impacts of alien plant invasions on species richness in Mediterranean-type ecosystems: A meta-analysis. Prog. Phys. Geog., 33(3):319-338.

Gamon, J. and Berry, J. (2012). Facultative and constitutive pigment effects on the Photochemical Reflectance Index (PRI) in sun and shade conifer needles. Israel J. Plant Sci., 60(1):85-95.

Gamon, J., Field, C., Roberts, D., Ustin, S., and Valentini, R. (1993). Functional patterns in an annual grassland during an AVIRIS overflight. Remote Sens. Environ., 44:239-253.

Gao, Z. and Zhang, L. (2006). Multi-seasonal spectral characteristics analysis of coastal salt marsh vegetation in Shanghai, China. Estuar. Coast. Shelf S., 69(1-2):217-224.

Genc, L., Inalpulat, M., Kizil, U., Mirik, M., Smith, S., and Mendes, M. (2013). Determination of water stress with spectral reflectance on sweet corn (Zea mays L.) using classification tree (CT) analysis. Zemdirbyste, 100(1):81-90.

Gevaert, C. and Garcia-Haro, F. (2015). A comparison of STARFM and an unmixing-based algorithm for Landsat and MODIS data fusion. Remote Sens. Environ., 156:34-44.

Gitelson, A., Merzlyak, M., and Chivkunova, O. (2001). Optical properties and nondestructive estimation of anthocyanin content in plant leaves. Photochem. Photobio., 74(1):38-45. 
Gitelson, A., Merzlyak, M., and Gritz, Y. (2003). Relationships between leaf chlorophyll content and spectral reflectance and algorithms for non-destructive chlorophyll assessment in higher plant leaves. J. Plant. Physiol., 160(3):271-282.

Gitelson, A., Zur, Y., Chivkunova, O., and Merzlyak, M. (2002). Assessing carotenoid content in plant leaves with reflectance spectroscopy. Photochem. Photobiol., 75(3):272281.

Gitelson, A. A., Keydan, G., and Merzlyak, M. N. (2006). Three-band model for noninvasive estimation of chlorophyll, carotenoids, and anthocyanin contents in higher plant leaves. Geophysical Research Letters, 33.

Goel, P., Prasher, S., Patel, R., Landry, J., Bonnell, R., and Viau, A. (2003). Classification of hyperspectral data by decision trees and artificial neural networks to identify weed stress and nitrogen status of corn. Comput. Electron. Agr., 39(2):67-93.

Gomez-Aparicio, L. and Canham, C. (2008). Neighborhood models of the effects of invasive tree species on ecosystem processes. Ecol. Monogr., 78(1):69-86.

Gorham, E., Vitousek, P., and Reiners, W. (1979). The regulation of chemical budgets over the course of terrestrial ecosystem succession. Annu. Rev. Ecol. Syst., 10:53-84.

Gould, W. (2000). Remote sensing of vegetation, plant species richness, and regional biodiversity hotspots. Ecol. Appl., 10(6):1861-1870.

Grau, H. R., Arturi, M. F., Brown, A. D., and Acenolaza, P. G. (1997). Floristic and structural patterns along a chronosequence of secondary forest succession in Argentinean subtropical montane forests. Forest Ecol. Manag., 95(2):161-171.

Grekul, C. and Bork, E. (2004). Herbage yield losses in perennial pasture due to Canada thistle (Cirsium arvense). Weed Technol., 18(3):784-794.

Grime, J. (1998). Benefits of plant diversity to ecosystems: immediate, filter and founder effects. J. Ecol., 86:902-910.

Gustafsson, C. and Bostrom, C. (2011). Biodiversity influences ecosystem functioning in aquatic angiosperm communities. Oikos, 120(7):1037-1046.

Guzman, I., Hamby, S., Romero, J., Bosland, P., and O'Connell, M. (2010). Variability of carotenoid biosynthesis in orange colored Capsicum spp. Plant Sci., 179(1-2):49-59.

Haas, S., Hooten, M., Rizzo, D., and Meentemeyer, R. (2011). Forest species diversity reduces disease risk in a generalist plant pathogen invasion: Species diversity reduces disease risk. Ecol. Lett., 14(11):1108-1116.

Heckman, R. (2005). The effects of nutrient pulses and community diversity on invasive plant success in Virginia. Master of Science, Dept of Environmental Sciences, University of Virginia.

Heimpel, G., Frelich, L., Landis, D., Hopper, K., Hoelmer, K., Sezen, Z., Asplen, M., and Wu, K. (2010). European buckthorn and Asian soybean aphid as components of an extensive invasional meltdown in North America. Biol. Invasions, 12(9):2913-2931.

Hejda, M., Pysek, P., and Jarosik, V. (2009). Impact of invasive plants on the species richness, diversity and composition of invaded communities. J. Ecol., 97(3):393-403.

Heneghan, L., Fatemi, F., Umek, L., Grady, K., Fagen, K., and Workman, M. (2006). 
The invasive shrub European buckthorn (Rhamnus cathartica, L.) alters soil properties in midwestern U.S. woodlands. Appl. Soil Ecol., 32(1):142-148.

Hill, R. A. and Thomson, A. G. (2005). Mapping woodland species composition and structure using airborne spectral and LiDAR data. International Journal of Remote Sensing, 26(17):3763-3779.

Hilty, J. (2015). Wildflowers of Illinois in savannas and thickets: Coralberry (Symphoricarpos orbiculatus), honeysuckle family (Caprifoliaceae). Available at: http://www.illinoiswildflowers.info/. (Archived by WebCite at http://www.webcitation.org/6b2c4i810).

Hook, S. (2015). Welcome to HyspIRI mission study website: Hyperspectral Infrared Imager. Available at $<$ https://hyspiri.jpl.nasa.gov/ $>$.

Hooper, D. and Vitousek, P. (1998). Effects of plant composition and diversity on nutrient cycling. Ecol. Monogr., 68(1):121.

Hunter, J. (1996). Control of Canada thistle (Cirsium arvense) with glyphosate applied at the bud vs rosette stage. Weed Sci., 44(4):934-938.

Hurteau, M. (2001). Plant guide for common yarrow (Achillea millefolium).

Isbell, F., Polley, H., and Wilsey, B. (2009). Biodiversity, productivity and the temporal stability of productivity: Patterns and processes. Ecol. Lett., 12(5):443-451.

Jafari, R. and Lewis, M. (2012). Arid land characterisation with EO-1 Hyperion hyperspectral data. Int. J. Appl. Earth Obs. Geoinf., 19:298-307.

Jensen, J. (2007). Remote Sensing of the Environment: an earth resource perspective. Pearson Prentice-Hall.

Jiao, X., Kovacs, J., Shang, J., McNairn, H., Walters, D., Ma, B., and Geng, X. (2014). Object-oriented crop mapping and monitoring using multi-temporal polarimetric RADARSAT-2 data. ISPRS J. Photogramm. Remote Sens., 96:38-46.

Johnson, D. and Tieszen, L. (1976). Aboveground biomass allocation, leaf growth, and photosynthesis patterns in tundra plant forms in Arctic Alaska. Oecologia, 24(2):159-173.

Kassi N'Dja, J. and Decocq, G. (2008). Successional patterns of plant species and community diversity in a semi-deciduous tropical forest under shifting cultivation. J. Veg. Sci., 19(6):809-820.

Keshava, N. (2004). Distance metrics and band selection in hyperspectral processing with applications to material identification and spectral libraries. IEEE Transactions on Geoscience and Remote Sensing, 42(7):1552-1565.

Kim, H., Hoelmer, K., Lee, W., Kwon, Y., and Lee, S. (2010). Molecular and morphological identification of the soybean aphid and other Aphis species on the primary host Rhamnus davurica in Asia. Ann. Entomol. Soc. Am., 103(4):532-543.

Knight, K., Kurylo, J., Endress, A., Stewart, J., and Reich, P. (2007). Ecology and ecosystem impacts of common buckthorn (Rhamnus cathartica): A review. Biol. Invasions, 9(8):925937.

Ko, C., Sohn, G., and Remmel, T. (2013). Tree genera classification with geometric features from high-density airborne LiDAR. Can. J. Remote Sens., 39(sup1):S73-S85. 
Koger, C., Bruce, L., Shaw, D., and Reddy, K. (2003). Wavelet analysis of hyperspectral reflectance data for detecting pitted morningglory (Ipomoea lacunosa) in soybean (Glycine max). Remote Sens. Environ., 86(1):108-119.

Kok, L. (2001). Classical biological control of nodding and plumeless thistles. Biol. Control, $21(3): 206-213$.

Kokaly, R. and Clark, R. (1999). Spectroscopic determination of leaf biochemistry using band-depth analysis of absorption features and stepwise multiple linear regression. Remote Sens. Environ., 67(3):267-287.

Koning, R. (1994). Light reactions. Plant Physiology Information Website. http://plantphys.info/plant_physiology/lightrxn.shtml.

Kota, N., Landenberger, R., and McGraw, J. (2007). Germination and early growth of Ailanthus and tulip poplar in three levels of forest disturbance. Biol. Invasions, 9(2):197211.

Kruk, B. and Benech-Arnold, R. (2000). Evaluation of dormancy and germination responses to temperature in Carduus acanthoides and Anagallis arvensis using a screening system, and relationship with field-observed emergence patterns. Seed Sci. Res., 10(01):77-88.

Kuhman, T., Pearson, S., and Turner, M. (2011). Agricultural land-use history increases non-native plant invasion in a southern Appalachian forest a century after abandonment. Can. J. Forest Res., 41(5):920-929.

Ladwig, L. and Meiners, S. (2010). Liana host preference and implications for deciduous forest regeneration. J. Torrey Bot. Soc., 137(1):103-112.

Laidler, G., Treitz, P., and Atkinson, D. (2008). Remote sensing of Arctic vegetation: relations between the NDVI, spatial resolution and vegetation cover on Boothia Peninsula, Nunavut. Arctic, 61(1):1-13.

Landenberger, R., Kota, N., and McGraw, J. (2007). Seed dispersal of the non-native invasive tree Ailanthus altissima into contrasting environments. Plant Ecol., 192(1):55-70.

Leicht-Young, S., Silander, J., and Latimer, A. (2007). Comparative performance of invasive and native Celastrus species across environmental gradients. Oecologia, 154(2):273-282.

Leicht-Young, S. A., Latimer, A. M., and Silander, J. A. (2011). Lianas escape self-thinning: Experimental evidence of positive density dependence in temperate lianas Celastrus orbiculatus and C. scandens. Perspectives in Plant Ecology, Evolution and Systematics, 13(3):163-172.

Leicht-Young, S. A., O’Donnell, H., Latimer, A. M., and Silander, J. A. (2009). Effects of an invasive plant species, Celastrus orbiculatus, on soil composition and processes. The American Midland Naturalist, 161(2):219-231.

Lemaire, G., Francois, C., Soudani, K., Berveiller, D., Pontailler, J., Breda, N., Genet, H., Davi, H., and Dufrene, E. (2008). Calibration and validation of hyperspectral indices for the estimation of broadleaved forest leaf chlorophyll content, leaf mass per area, leaf area index and leaf canopy biomass. Remote Sens. Environ., 112(10):3846-3864.

Lengyel, S., Kobler, A., Kutnar, L., Framstad, E., Henry, P., Babij, V., Gruber, B., Schmeller, D., and Henle, K. (2008). A review and a framework for the integration of biodiversity monitoring at the habitat level. Biodiv. Conserv., 17:3341-3356. 
Letts, M., Flannagan, L., Van Gaalen, K., and Johnson, D. (2009). Interspecific differences in photosynthetic gas exchange characteristics and acclimation to soil moisture stress among shrubs of a semiarid grassland. Ecoscience, 16(1):125-137.

Lewis, M. (2002). Spectral characterization of Australian aird zone plants. Can. J. Remote Sens., 28(2):219-230.

Liang, L., Schwartz, M., and Fei, S. (2011). Validating satellite phenology through intensive ground observation and landscape scaling in a mixed seasonal forest. Remote Sens. Environ., 115(1):143-157.

Liu, N., Lin, Z., Van Devender, A., Lin, G., Peng, C., Pan, X., Chen, S., and Gu, Q. (2009). Spectral reflectance indices and pigment functions during leaf ontogenesis in six subtropical landscape plants. Plant Growth Regul., 58(1):73-84.

Lu, S., Oki, K., Shimizu, Y., and Omasa, K. (2007). Comparison between several feature extraction/classification methods for mapping complicated agricultural land use patches using airborne hyperspectral data. Int. J. Remote Sens., 28(5):963-984.

MacDougall, A. and Turkington, R. (2005). Are invasive species the drivers or passengers of change in degraded ecosystems? Ecology, 86(1):42-55.

Magney, T., Eusden, S., Eitel, J., Logan, B., Jiang, J., and Vierling, L. (2014). Assessing leaf photoprotective mechanisms using terrestrial LiDAR: Towards mapping canopy photosynthetic performance in three dimensions. New Phytol., 201(1):344-356.

Maharning, A., Mills, A., and Adl, S. (2009). Soil community changes during secondary succession to naturalized grasslands. Appl. Soil Ecol., 41(2):137-147.

Mahlein, A. (2011). Detection, identification, and quantification of fungal diseases of sugar beet leaves using imaging and non-imaging hyperspectral techniques. PhD thesis, Universitats-und Landesbibliothek Bonn.

Malyshev, A., Arfin Khan, M., Beierkuhnlein, C., Steinbauer, M., Henry, H., Jentsch, A., Dengler, J., Willner, E., and Kreyling, J. (2016). Plant responses to climatic extremes: within-species variation equals among-species variation. Glob. Change Biol., 22:449-464.

Mascaro, J. and Schnitzer, S. (2007). Rhamnus cathartica L. (common buckthorn) as an ecosystem dominant in southern Wisconsin forests. Northeast. Nat., 14(3):387-402.

Mastelic, J. and Jerkovic, I. (2002). Volatile constituents from the leaves of young and old Ailanthus altissima (Mill.) Swingle tree. Croat. Chem. Acta, 75(1):189-197.

Mayer, P. M., Tunnell, S. J., Engle, D. M., Jorgensen, E. E., and Nunn, P. (2005). Invasive grass alters litter decomposition by influencing macrodetritivores. Ecosystems, 8(2):200209.

Merzlyak, M. N., Gitelson, A. A., Chivkunova, O. B., Solovchenko, A. E., and Pogosyan, S. I. (2003). Application of reflectance spectroscopy for analysis of higher plant pigments. Russ. J. Plant Physl., 50(5):704-710.

Mezned, N., Abdeljaoued, S., and Boussema, M. (2009). Unmixing based Landsat ETM+ and ASTER image fusion for hybrid multispectral image analysis, advances in geoscience and remote sensing.

Miao, X., Gong, P., Swope, S., Pu, R., Carruthers, R., Anderson, G., Heaton, J., and 
Tracy, C. (2006). Estimation of yellow starthistle abundance through CASI-2 hyperspectral imagery using linear spectral mixture models. Remote Sens. Environ., 101(3):329-341.

Milchunas, D. and Lauenroth, W. (1995). Inertia in plant community structure: State changes after cessation of nutrient-enrichment stress. Ecol. Appl., 5(2):452-458.

Mirik, M., Steddom, K., and Michels, Jr, G. (2006). Estimating biophysical characteristics of musk thistle (Carduus nutans) with three remote sensing instruments. Rangeland Ecol. Manage., 59(1):44-54.

Mitchell, J., Glenn, N., Sankey, T., Derryberry, D., and Germino, M. (2012). Remote sensing of sagebrush canopy nitrogen. Remote Sens. Environ., 124:217-223.

Mosher, E., Silander, J., and Latimer, A. (2009). The role of land-use history in major invasions by woody plant species in the northeastern North American landscape. Biol. Invasions, 11(10):2317-2328.

Mutanga, O., Skidmore, A., and Prins, H. (2004). Predicting in situ pasture quality in the Kruger National Park, South Africa, using continuum-removed absorption features. Remote Sens. Environ., 89(3):393-408.

Naidoo, L., Cho, M., Mathieu, R., and Asner, G. (2012). Classification of savanna tree species, in the Greater Kruger National Park region, by integrating hyperspectral and LiDAR data in a Random Forest data mining environment. ISPRS J. Photogramm. Remote Sens., 69:167-179.

Narumalani, S., Mishra, D., Wilson, R., Reece, P., and Kohler, A. (2009). Detecting and mapping four invasive species along the floodplain of North Platte River, Nebraska. Weed Technol., 23:99-107.

Naumann, J., Bissett, S., Young, D., Edwards, J., and Anderson, J. (2010). Diurnal patterns of photosynthesis, chlorophyll fluorescence, and PRI to evaluate water stress in the invasive species, Elaeagnus umbellata Thunb. Trees, 24(2):237-245.

NEON (2015). NEON: National Ecological Observatory Network, field sites. Available at: http://www.neoninc.org/science-design/field-sites. (Archived by WebCite at http://www.webcitation.org/6b2axzrm0).

Nicolle, C., Simon, G., Rock, E., Amouroux, P., and Remesy, C. (2004). Genetic variability influences carotenoid, vitamin, phenolic, and mineral content in white, yellow, purple, orange, and dark-orange carrot cultivars. J. Amer. Soc. Hort. Sci., 129(4):523-529.

Niinemets, U. (2010). A review of light interception in plant stands from leaf to canopy in different plant functional types and in species with varying shade tolerance. Ecol. Res., 25:693-714.

Nooni, I., Duker, A., Van Duren, I., Addae-Wireko, L., and Osei Jnr, E. (2014). Support vector machine to map oil palm in a heterogeneous environment. Int. J. Remote Sens., 35(13):4778-4794.

Otto, R., Krusi, B., Burga, C., and Fernandez-Palacios, J. (2006). Old-field succession along a precipitation gradient in the semi-arid coastal region of Tenerife. J. Arid Environ., 65(1):156-178.

Papes, M., Tupayachi, R., Martinez, P., Peterson, A., and Powell, G. (2010). Using hyperspectral satellite imagery for regional inventories: a test with tropical emergent trees in 
the Amazon Basin. J. Veg. Sci., 21(2):342-354.

Paschke, M., McLendon, T., and Redente, E. (2000). Nitrogen availability and old-field succession in a shortgrass steppe. Ecosystems, 3(2):144-158.

Pavia, D., Lampman, G., Kriz, G., and Engel, R. (1999). Isolation of chlorophyll and carotenoid pigments from spinach. In Introduction to Organic Laboratory Techniques: A Microscale Approach. Saunders College Publishing, New York, NY, 3rd edition.

Pavlovic, N. and Leicht-Young, S. (2011). Are temperate mature forests buffered from invasive lianas? J. Torrey Bot. Soc., 138(1):85-92.

Philpot, W. (2011). Vegetation indices (VI). CEE 6150: Digital Image Processing, pages $1-15$.

Pinard, V. and Bannari, A. (2003). Spectroradiometric analysis in a hyperspectral use perspective to discriminate between forest species. In Geoscience and Remote Sensing Symposium, 2003. IGARSS'03. Proceedings. 2003 IEEE International, volume 7, pages 4301-4303. IEEE.

Pisula, N. and Meiners, S. (2010). Relative allelopathic potential of invasive plant species in a young disturbed woodland. J. Torrey Bot. Soc., 137(1):81-87.

Pooler, M., Dix, R., and Feely, J. (2002). Interspecific hybridizations between the native bittersweet, Celastrus scandens, and the introduced invasive species, C. orbiculatus. Southeast. Nat., 1(1):69-76.

Pringle, R., Syfert, M., Webb, J., and Shine, R. (2009). Quantifying historical changes in habitat availability for endangered species: Use of pixel- and object-based remote sensing. J. Appl. Ecol., 46(3):544-553.

Rahimzadeh-Bajgiran, P., Munehiro, M., and Omasa, K. (2012). Relationships between the photochemical reflectance index (PRI) and chlorophyll fluorescence parameters and plant pigment indices at different leaf growth stages. Photosynth. Res., 113(1-3):261-271.

Ranganathan, Y. and Borges, R. M. (2010). Reducing the babel in plant volatile communication: Using the forest to see the trees. Plant Biology, 12(5):735-742.

Rascher, U., Nichol, C., Small, C., and Hendricks, L. (2007). Monitoring spatio-temporal dynamics of photosynthesis with a portable hyperspectral imaging system. Photogramm. Eng. Rem. S., 73(1):45-56.

Rebele, F. (1992). Colonization and early succession on anthropogenic soils. J. Veg. Sci., $3(2): 201-208$.

Ribeiro da Luz, B. and Crowley, J. (2010). Identification of plant species by using high spatial and spectral resolution thermal infrared $(8.013 .5 \mathrm{~m})$ imagery. Remote Sens. Environ., 114(2):404-413.

Rice, M., Cloutis, E., Bell, J., Bish, D., Horgan, B., Mertzman, S., Craig, M., Renaut, R., Gautason, B., and Mountain, B. (2013). Reflectance spectra diversity of silica-rich materials: Sensitivity to environment and implications for detections on Mars. Icarus, 223(1):499-533.

Riedel, S. and Epstein, H. (2005). Edge effects on vegetation and soils in a Virginia old-field. Plant Soil, 270(1):13-22. 
Roberts, D., Gardner, M., Church, R., Ustin, S., Scheer, G., and Green, R. O. (1998). Mapping chaparral in the Santa Monica Mountains using multiple endmember spectral mixture models. Remote Sens. Environ., 65(3):267-279.

Roberts, D., Ustin, S. L., Ogunjemio, S., Greenberg, J., Dobrowski, S., Chen, J., and Hinckley, T. (2004). Spectral and structural measures of northwest forest vegetation at leaf to landscape scales. Ecosystems, 7(5):545-562.

Rocchini, D., Balkenhol, N., Carter, G., Foody, G., Gillespie, T., He, K., Kark, S., Levin, N., Lucas, K., Luoto, M., Nagendra, H., Oldeland, J., Ricotta, C., Southworth, J., and Neteler, M. (2010). Remotely sensed spectral heterogeneity as a proxy of species diversity: Recent advances and open challenges. Ecol. Inform., 5(5):318-329.

Rodewald, A., Shustack, D., and Hitchcock, L. (2010). Exotic shrubs as ephemeral ecological traps for nesting birds. Biol. Invasions, 12(1):33-39.

Rooney, T. and Rogers, D. (2011). Colonization and effects of garlic mustard (Alliaria petiolata), European buckthorn (Rhamnus cathartica), and Bell's honeysuckle (Lonicera $x$ bella) on understory plants after five decades in southern Wisconsin forests. Invasive Plant Sci. Manage., 4(3):317-325.

Rosevear, M. J., Young, A. J., and Johnson, G. N. (2001). Growth conditions are more important than species origin in determining leaf pigment content of British plant species. Funct. ecol., 15(4):474-480.

Rud, R., Shoshany, M., Alchanatis, V., and Cohen, Y. (2006). Application of spectral features' ratios for improving classification in partially calibrated hyperspectral imagery: A case study of separating Mediterranean vegetation species. J. Real-Time Image Process., $1(2): 143-152$.

Sainju, U., Allen, B., Caesar-TonThat, T., and Lenssen, A. (2015). Dryland soil chemical properties and crop yields affected by long-term tillage and cropping sequence. SpringerPlus, 4:320-333.

Sanches, I., Filho, C., and Kokaly, R. (2014). Spectroscopic remote sensing of plant stress at leaf and canopy levels using the chlorophyll 680nm absorption feature with continuum removal. ISPRS J. Photogramm. Remote Sens., 97:111-122.

Sanchez-Azofeifa, G., Castro, K., Wright, S., Gamon, J., Kalacska, M., Rivard, B., Schnitzer, S., and Feng, J. (2009). Differences in leaf traits, leaf internal structure, and spectral reflectance between two communities of lianas and trees: Implications for remote sensing in tropical environments. Remote Sens. Environ., 113(10):2076-2088.

SAS support (2012). SAS support: The NPAR1way procedure. Available at: http://support.sas.com. (Archived by WebCite at http://www.webcitation.org/6b8facfec).

Scherber, C., Mwangi, P. N., Schmitz, M., Scherer-Lorenzen, M., Bessler, H., Engels, C., Eisenhauer, N., Migunova, V. D., Scheu, S., Weisser, W. W., Schulze, E., and Schmid, B. (2010). Biodiversity and belowground interactions mediate community invasion resistance against a tall herb invader. J. Plant. Ecolo., 3(2):99-108.

Schmidt, K. and Skidmore, A. (2003). Spectral discrimination of vegetation types in a coastal wetland. Remote Sens. Environ., 85(1):92-108. 
Schmidt, K. and Whelan, C. (1999). Effects of exotic Lonicera and Rhamnus on songbird nest predation. Conserv. Biol., 13(6):1502-1506.

Schmidt, K. S. and Skidmore, A. K. (2001). Exploring spectral discrimination of grass species in African rangelands. Int. J. Remote Sens., 22(17):3421-3434.

Schmidtlein, S., Zimmermann, P., Schupferling, R., and WeiB, C. (2007). Mapping the floristic continuum: Ordination space position estimated from imaging spectroscopy. $J$. Veg. Sci., 18(1):131.

Seabloom, E., Borer, E., Buckley, Y., Cleland, E., Davies, K., Firn, J., Harpole, W., Hautier, Y., Lind, E., MacDougall, A., Orrock, J., Prober, S., Adler, P., Alberti, J., Anderson, T., Bakker, J., Biederman, L., Blumenthal, D., Brown, C., Brudvig, L., Caldeira, M., Chu, C., Crawley, M., Daleo, P., Damschen, E., D’Antonio, C., DeCrappeo, N., Dickman, C., Du, G., Fay, P., Frater, P., Gruner, D., Hagenah, N., Hector, A., Helm, A., Hillebrand, H., Hofmockel, K., Humphries, H., Iribarne, O., Jin, V., Kay, A., Kirkman, K., Klein, J., Knops, J., La Pierre, K., Ladwig, L., Lambrinos, J., Leakey, A., Li, Q., Li, W., McCulley, R., Melbourne, B., Mitchell, C., Moore, J., Morgan, J., Mortensen, B., O'Halloran, L., Partel, M., Pascual, J., Pyke, D., Risch, A., Salguero-Gomez, R., Sankaran, M., Schuetz, M., Simonsen, A., Smith, M., Stevens, C., Sullivan, L., Wardle, G., Wolkovich, E., Wragg, P., Wright, J., and Yang, L. (2013). Predicting invasion in grassland ecosystems: Is exotic dominance the real embarrassment of richness? Glob. Change Biol., 19(12):3677-3687.

Shafri, H., Suhaili, A., and Mansor, S. (2007). The performance of maximum likelihood, spectral angle mapper, neural network and decision tree classifiers in hyperspectral image analysis. J. Comput. Sci., 3(6):419.

Shi, C. and Wang, L. (2014). Incorporating spatial information in spectral unmixing: A review. Remote Sens. Environ., 149:70-87.

Simberloff, D. (2010). Invasions of plant communities- More of the same, something very different, or both? Am. Midl. Nat., 163(1):220-233.

Sims, D. and Gamon, J. (2002). Relationships between leaf pigment content and spectral reflectance across a wide range of species, leaf structures and developmental stages. Remote Sens. Environ., 81(2):337-354.

Skarpaas, O. and Shea, K. (2007). Dispersal patterns, dispersal mechanisms, and invasion wave speeds for invasive thistles. Am. Nat., 170(3):421-430.

Smith, A. and Blackshaw, R. (2003). Weed: Crop discrimination using remote sensing: A detached leaf experiment. Weed Technol., 17(4):811-820.

Somers, B. and Asner, G. (2012). Hyperspectral time series analysis of native and invasive species in Hawaiian rainforests. Remote Sens., 4(12):2510-2529.

Somers, B., Asner, G., Tits, L., and Coppin, P. (2011). Endmember variability in spectral mixture analysis: A review. Remote Sens. Environ., 115(7):1603-1616.

Somers, B., Zortea, M., Plaza, A., and Asner, G. (2012). Automated extraction of imagebased endmember bundles for improved spectral unmixing. IEEE J. Sel. Top. Appl. Earth Obs., 5(2):396-408.

St. John, L., Tilley, D., Hunt, P., and Wright, S. (2012). Plant guide for red fescue (Festuca rubra). 
Steele, B. (1955). Soil pH and base status as factors in the distribution of calcicoles. J. Ecol., 43(1):120-132.

Sullivan, J. (1992). Dactylis glomerata. In: Fire effects information system, [Online]. U.S. Department of Agriculture, Forest Service, Rocky Mountain Research Station, Fire Sciences Laboratory (Producer). Available: http://www.fs.fed.us/database/feis/. (Archived by WebCite at http://www.webcitation.org/6b2a4jbhx).

Sullivan, J., Williams, P., and Timmins, S. (2007). Secondary forest succession differs through naturalised gorse and native kanuka near Wellington and Nelson. New Zeal. J. Ecol., 31(1):22-38.

Sun, K., Geng, X., and Ji, L. (2014). A band selection approach for small target detection based on CEM. Int. J. Remote Sens., 35(13):4589-4600.

Symstad, A. and Jonas, J. (2011). Incorporating biodiversity into rangeland health: Plant species richness and diversity in Great Plains grasslands. Rangeland Ecol. Manage., 64(6):555-572.

Tenaglia, D. (2007). Solidago altissima L. Available at: http://missouriplants.com/. (Archived by WebCite at http://www.webcitation.org/6b2drwwzu).

Thenkabail, P., Gumma, M., Teluguntla, P., and Mohammed, I. (2014). Hyperspectral remote sensing of vegetation and agricultural crops. Photogramm. Eng. Rem. S.

Thenkabail, P., Mariotto, i., Gumma, M., Middleton, E., Landis, D., and Huemmrich, K. (2013). Selection of hyperspectral narrowbands (HNBs) and composition of hyperspectral twoband vegetation indices (HVIs) for biophysical characterization and discrimination of crop types using field reflectance and Hyperion/EO-1 data. IEEE J. Sel. Top. Appl. Earth Obs., 6(2):427-439.

Thiessen, B. (2007). Satellite detection of Cannabis sativa outdoor grow operations. Canadian Police Research Centre.

Tian, D. and Niu, S. (2015). A global analysis of soil acidifcation caused by nitrogen addition. Environ. Res. Lett., 10:024019.

Tiley, G. (2010). Biological flora of the British Isles: Cirsium arvense (L.) Scop.: Cirsium arvense (L.) Scop. J. Ecol., 98(4):938-983.

Tilman, D. (1985). The resource-ratio hypothesis of plant succession. Am. Nat., 125(6):827852.

Tilman, D. (1987). Secondary succession and the pattern of plant dominance along experimental nitrogen gradients. Ecological Monographs, 57(3):189.

Tilman, D. (1990). Constraints and tradeoffs: Toward a predictive theory of competition and succession. Oikos, 58(1):3.

Tree of Life Web Project (2002). Sapindales. Version 01 January 2002 (temporary). Available at: http://tolweb.org/Sapindales/21051/2002.01.01 in the Tree of Life Web Project, http://tolweb.org/. (Archived by WebCite at http://www.webcitation.org/6b2abzeg8).

Tsahar, E., Friedman, J., and Izhaki, I. (2002). Impact on fruit removal and seed predation of a secondary metabolite, Emodin, in Rhamnusalaternus fruit pulp. Oikos, 99(2):290-299.

Tscherko, D., Hammesfahr, U., Zeltner, G., Kandeler, E., and Bocker, R. (2005). Plant 
succession and rhizosphere microbial communities in a recently deglaciated alpine terrain. Basic Appl. Ecol., 6:367-383.

Turner, W., Spector, S., Gardiner, N., Fladeland, M., Sterling, E., and Steininger, M. (2003). Remote sensing for biodiversity science and conservation. Trends Ecol. Evol., 18(6):306314.

United, C. (2010). Plants of southern New Jersey: Plant profile for Solidago altissima (tall goldenrod). www.cumauriceriver.org/. (Archived by WebCite at http://www.webcitation.org/6b2cpieit).

USDA Plants Database (2015). USDA: United States Department of Agriculture, Natural Resources Conservation Services, Plants Database. Available at: http://www.plants.usda.gov/. (Archived by WebCite at http://www.webcitation.org/6b2devnck).

Ustin, S. and Gamon, J. (2010). Remote sensing of plant functional types: Tansley review. New Phytol., 186(4):795-816.

van Aardt, J. and Wynne, R. (2001). Spectral separability among six southern tree species. Photogramm. Eng. Rem. S., 67(12):1367-1375.

van den Berg, L., Tomassen, H., Roelofs, J., and Bobbink, R. (2005). Effects of nitrogen enrichment on coastal dune grassland: A mesocosm study. Environ. Pollut., 138(1):77-85.

Veres, S., Toth, V., Laposi, R., Olah, V., Lakatos, G., and Meszaros, I. (2006). Carotenoid composition and photochemical activity of four sandy grassland species. Photosynthetica, 44(2):255-261.

Vicente, J., Pinto, A., Araujo, M., Verburg, P., Lomba, A., Randin, C., Guisan, A., and Honrado, J. (2013). Using life strategies to explore the vulnerability of ecosystem services to invasion by alien plants. Ecosystems, 16(4):678-693.

Villa, A., Benediktsson, J. A., Chanussot, J., and Jutten, C. (2011). Hyperspectral image classification with independent component discriminant analysis. IEEE T. Geosci. Remote, 49(12):4865-4876.

Vitousek, P. (1990). Biological invasions and ecosystem processes: Towards an integration of population biology and ecosystem studies. Oikos, 57(1):7.

Walker, D. A., Epstein, H. E., Jia, G., Balser, A., Copass, C., Edwards, E., Gould, W., Hollingsworth, J., Knudson, J., Maier, H., Moody, A., and Raynolds, M. K. (2003). Phytomass, LAI, and NDVI in northern Alaska: Relationships to summer warmth, soil pH, plant functional types, and extrapolation to the circumpolar Arctic. J. Geophys. Res., 108(D2).

Walker, L. and Chapin, F. (1987). Interactions among processes controlling successional change. Oikos, 50(1):131.

Wang, J., Epstein, H., and Wang, L. (2010). Soil CO 2 flux and its controls during secondary succession. J. Geophys. Res., 115(G2).

Wang, J., Xu, R., and Yang, S. (2009). Estimation of plant water content by spectral absorption features centered at 1,450 nm and 1,940 nm regions. Environ. Monit. Assess., 157(1-4):459-469. 
Wang, L., Shaner, P., and Macko, S. (2007). Foliar delta ${ }^{15} \mathrm{~N}$ patterns along successional gradients at plant community and species levels. Geophys. Res. Lett., 34(16):n/a-n/a.

Weidenhamer, J. and Callaway, R. (2010). Direct and indirect effects of invasive plants on soil chemistry and ecosystem function. J. Chem. Ecol., 36(1):59-69.

Wilfong, B., Gorchov, D., and Henry, M. (2009). Detecting an invasive shrub in deciduous forest understories using remote sensing. Weed Sci., 57(5):512-520.

Wilsey, B. and Potvin, C. (2000). Biodiversity and ecosystem functioning: Importance of species evenness in an old field. Ecology, 81(4):887.

Xiao, Y., Zhao, W., Zhou, D., and Gong, H. (2014). Sensitivity analysis of vegetation reflectance to biochemical and biophysical variables at leaf, canopy, and regional scales. IEEE T. Geosci. Remote, 52(7):4014-4024.

$\mathrm{Xu}$, B. and Gong, P. (2007). Land-use/land-cover classification with multispectral and hyperspectral EO-1 data. Photogrammetric Engineering \& Remote Sensing, 73(8):955965.

Yachi, S. and Loreau, M. (1999). Biodiversity and ecosystem productivity in a fluctuating environment: The insurance hypothesis. Proceedings of the National Academy of Sciences, 96(4):1463-1468.

Yang, C., Everitt, J., and Bradford, J. (2008). Yield estimation from hyperspectral imagery using spectral angle mapper (SAM). Trans. ASABE, 51(2):729-737.

Yang, F., Li, J., Gan, X., Qian, Y., Wu, X., and Yang, Q. (2010). Assessing nutritional status of Festuca arundinacea by monitoring photosynthetic pigments from hyperspectral data. Comput. Electron. Agr., 70(1):52-59.

Yelenik, S. and Levine, J. (2011). The role of plant-soil feedbacks in driving native-species recovery. Ecology, 92(1):66-74.

Yingying, G., Wenjie, F., Xiru, X., and Yuanzhen, Z. (2011). Flower species identification and coverage estimation based on hyperspectral remote sensing data. In Geoscience and Remote Sensing Symposium (IGARSS), 2011 IEEE International, pages 1243-1246. IEEE.

Yoshida, K. and Oka, S. (2004). Invasion of Leucaena leucocephala and its effects on the native plant community in the Ogasawara (Bonin) Islands. Weed Technol., 18(sp1):13711375.

Yu, K., Lenz-Wiedemann, V., Chen, X., and Bareth, G. (2014). Estimating leaf chlorophyll of barley at different growth stages using spectral indices to reduce soil background and canopy structure effects. ISPRS J. Photogramm. Remote Sens., 97:58-77.

Yurkonis, K., Meiners, S., and Wachholder, B. (2005). Invasion impacts diversity through altered community dynamics. J. Ecol., 93(6):1053-1061.

Zhang, J., Rivard, B., Sanchez-Azofeifa, A., and Castro-Esau, K. (2006). Intra- and interclass spectral variability of tropical tree species at La Selva, Costa Rica: Implications for species identification using HYDICE imagery. Remote Sens. Environ., 105(2):129-141.

Zhang, R., Heberling, J., Haner, E., and Shea, K. (2011). Tolerance of two invasive thistles to repeated disturbance. Ecol. Res., 26(3):575-581.

Zhang, X. and Ervin, E. (2009). Physiological assessment of cool-season turfgrasses under 
Ultraviolet-B stress. HortScience, 44(6):1785-1789.

Zhao, D., Huang, L., Li, J., and Qi, J. (2007). A comparative analysis of broadband and narrowband derived vegetation indices in predicting LAI and CCD of a cotton canopy. ISPRS J. Photogramm. Remote Sens., 62(1):25-33.

Zhong, L., Gong, P., and Biging, G. (2014). Efficient corn and soybean mapping with temporal extendability: A multi-year experiment using Landsat imagery. Remote Sens. Environ., 140:1-13.

Zouhar, K. (2001). Cirsium arvense. In: Fire effects information system, [Online]. U.S. Department of Agriculture, Forest Service, Rocky Mountain Research Station, Fire Sciences Laboratory (Producer). Available: http://www.fs.fed.us/database/feis/ [2015, May 26]. (Archived by WebCite at http://www.webcitation.org/6b2amrlck).

Zouhar, K. (2011). Rhamnus cathartica, R. davurica. In: Fire effects information system, [Online]. U.S. Department of Agriculture, Forest Service, Rocky Mountain Research Station, Fire Sciences Laboratory (Producer). Available: http://www.fs.fed.us/database/feis/ [2015, May 26]. (Archived by WebCite at http://www.webcitation.org/6b2azwsth). 